\title{
Variability of wood and leaf functional traits in response to structural and environmental changes in natural and
}

transformed systems in Indonesia

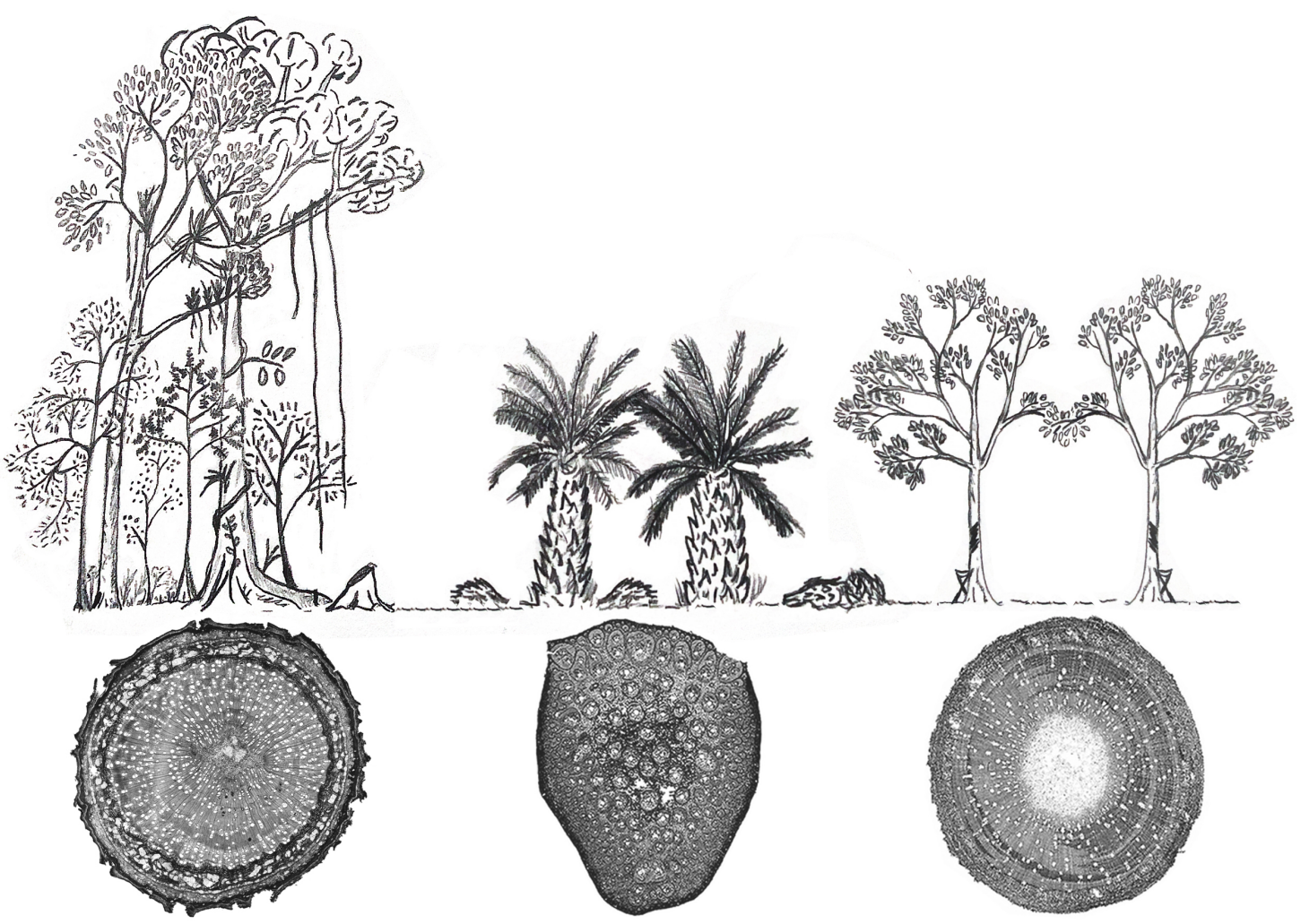

Dissertation for the award of the degree

Doctor in Philosophy

Division of mathematics and natural science at the

Georg-August-Universität Göttingen

Doctoral program Biology

Georg-August University School of Science (GAUSS)

submitted by

Pierre-André Waite

from

Bois-Guillaume, France

Göttingen, June 2020 



\section{Thesis advisory committee}

Prof. Dr. Christoph Leuschner

Institute for plant ecology and ecosystems research, Georg-August-Universität Göttingen

\section{Prof. Dr. Dirk Hölscher}

Institute for tropical silviculture and forest ecology, Georg-August-Universität Göttingen

Prof. Dr. Bernhard Schuldt

Department of botany II - Ecophysiology and vegetation ecology, Julius-Maximilians-Universität Würzburg

\section{Members of the examination board}

referee: Prof. Dr. Christoph Leuschner

Institute for plant ecology and ecosystems research, Georg-August-Universität Göttingen

Co-referee: Prof. Dr. Dirk Hölscher

Institute for tropical silviculture and forest ecology, Georg-August-Universität Göttingen

Prof. Dr. Bernhard Schuldt

Department of botany II - Ecophysiology and vegetation ecology, Julius-Maximilians-Universität Würzburg

\section{Prof. Dr. Hermann Behling}

Department of Palynology and Climate Dynamics, Georg-August-Universität Göttingen

Prof. Dr. Erwin Bergmeier

Department Vegetation and Phytodiverity Analysis, Georg-August-Universität Göttingen

Prof. Dr. Holger Kreft

Biodiversity, Macroecology \& Biogeography, Georg-August-Universität Göttingen

Day of the oral examination: 13 August 2020 



\section{Summary}

Warming climate associated with increasing drought spells are threatening plants from both natural and transformed systems of Indonesia. On one side, Indonesian natural forests are home of an incredible plant diversity but their ability to cope with drought events is still poorly known. The fate of the large trees growing in these forests is particularly concerning since they are reported particularly vulnerable to drought. On the other side, important land-use conversions have led to the cultivation of highly productive species such as rubber (Hevea brasiliensis) and oil palm (Elaeis guineensis). These usually mono-specific plantations have rapidly expanded in the extensive lowlands of Indonesia, reaching areas that may not be suitable for their growth. Thus, understanding properties involved to mitigate the negative impact of water stress is of primary importance in the context of a changing climate.

In the present thesis we investigated mechanisms associated with plant mortality during heatinduced droughts in lowland rainforests, and in oil palm and rubber plantations from the region of Jambi in the island of Sumatra, Indonesia. To achieve this, we studied interrelationships across plant height, growth, and structural and functional wood and leaf properties related to hydraulic safety and efficiency. We especially focused on the anatomy of the xylem and its resistance to drought-induced embolism, investigating changes associated with variations of plant structure in the forest and fluctuations of the local environment in the plantations.

The 7 to 10 investigated rainforest species presented a wide range of vulnerability to drought induced embolism as they had a water potential at $50 \%$ loss of hydraulic conductivity $\left(P_{50}\right)$ stretching from -1.71 to $-3.11 \mathrm{MPa}$. Their leaf turgor loss point $\left(\pi_{\text {tlp }}\right)$ was particularly high, ranging from -1.37 to $-2.09 \mathrm{MPa}$, indicating leaves with limited functions during mild droughts. Further investigations showed that tall and light-wooded trees were more vulnerable to droughtinduced embolism than short and dense-wooded trees. This was associated with vascular adjustments since vessel diameter $(D)$ and lumen-to-sapwood area ratio $(F)$ were higher both in the stem and in distant twigs of tall trees compared to trees with smaller height at maturity. Likewise, trees with a lower wood density presented larger $D$ in the stem and in the branches compared to denser-wooded trees. Beside embolism resistance, $\pi_{\text {tlp }}$ tended to be positively related to height but not to wood density. Despite a missing relationship between $P_{50}$ and annual aboveground biomass increment (ABI), fast-growing trees were more efficient, as indicated by their low sapwood-to-leaf-area ratio (Huber value), and had a high $\pi_{\text {tlp }}$, indicating a potential trade-off between growth performance and safety. Our findings contribute to show that tall and 
light-wooded trees may be more vulnerable to drought probably because of their large vessels and lumen area. We conclude that $D$ and $F$ associated with tree height are promising as easily accessible traits giving insights on plant vulnerability to drought.

In mono-specific plantations, we focused on trait plasticity in response to the environment. We found that oil palm had fronds rather vulnerable to embolism with a $P_{50}$ of $-1.86 \mathrm{MPa}$. However, diurnal courses of stomatal conductance evidence a sensitive water loss regulation which may provide a higher safety during mild drought events. Moreover, palms growing in plots with higher soil water availability (i.e. riparian sites) had on average by $0.4 \mathrm{MPa}$ higher $P_{50}$ values than genetically similar palms growing in sites with a well-drained soil. Like in the forest, $P_{50}$ of oil palm fronds was highly dependent of palm height. However, $P_{50}$ was not associated with vascular changes although $D$ decreased with height. The high plasticity of frond embolism resistance may be part of oil palm strategy to cope with heat-induced droughts.

In contrast, rubber trees were more resistant to drought than oil palms with respect of their $\pi_{\text {tlp }}$ (mean $=-2.12 \mathrm{MPa}$ ) and their $P_{50}$. Indeed, across eight plantation plots, we found that $P_{50}$ values of genetically similar rubber trees ranged from -2.14 to $-2.58 \mathrm{MPa}$, with no dependence on soil moisture unlike for oil palm. Instead, we found that embolism resistance and hydraulic safety margin $\left(\pi_{\mathrm{tlp}}-P_{50}\right)$ increased with increasing vapour pressure deficit. This was also associated with vascular changes but in this species, vessel density, and not diameter, was closely related to $P_{50}$. These results demonstrate a high degree of plasticity of traits related to hydraulic safety but only in response to changes in evaporative demand and not soil moisture.

Our results highlight the diversity of mechanisms involved by plants to mitigate water stress. The association of structural, functional and hydraulic traits allowed us to draw general species hydraulic strategies, helping to understand how increasing drought events may affect them and the systems they belong. Notably, forest dynamic would probably change if large trees were to die more from hydraulic failure, shifting the community towards short-statured stands which may harm forest function as a carbon sink. In addition, oil palm plantation sites with tall palms at the end of their life cycle may be particularly vulnerable, especially if grown on riparian sites. If these sites were to get dry, oil palms may be unable to cope even with their plastic fronds. Finally, it emerged that rubber trees are more resistant than previously described and could probably be grown in a drier habitat, although this may be at the cost of their productivity. Overall, our results give knowledge on the resistance to drought of the understudied lowland Indonesian systems and should be taken into account in future studies. 


\section{CONTENTS}

Page

Chapter 1:

$\begin{array}{ll}\text { Introduction } & 1\end{array}$

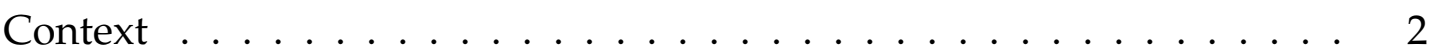

The basis of plant hydraulics . . . . . . . . . . . . . . . . . . 4

Xylem embolism resistance . . . . . . . . . . . . . . . 8

Xylem anatomy $\ldots \ldots \ldots \ldots \ldots \ldots$

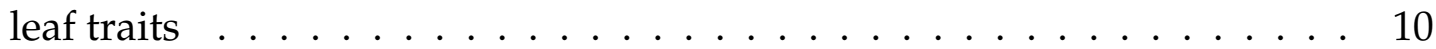

Common species strategies $\ldots \ldots \ldots$. . . . . . . . . . . . . 11

Trait variability across species: impact of tree height $\ldots$. . . . . . . . 12

Trait variability within species: adaptation and acclimation $\ldots$. . . . . 13

Project framework and study area . . . . . . . . . . . . . . . . . . 14

Objectives and hypothesis $\ldots \ldots \ldots \ldots \ldots$

\section{Chapter 2:}

Tall tropical trees are more vulnerable to drought-induced hydraulic $\begin{array}{ll}\text { failure than individuals from lower strata } & 37\end{array}$

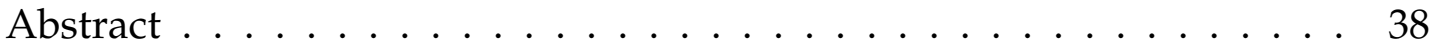

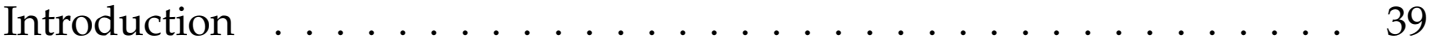

Materials and methods . . . . . . . . . . . . . . . . . . 42

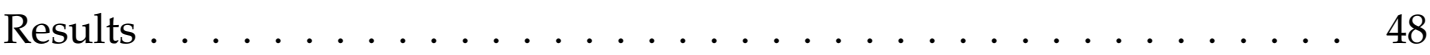

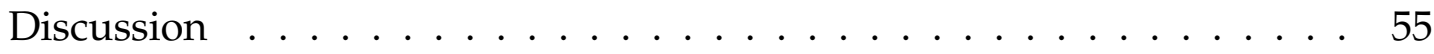

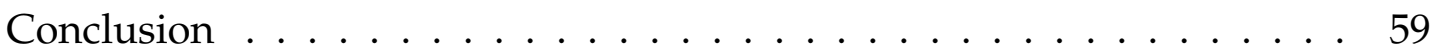

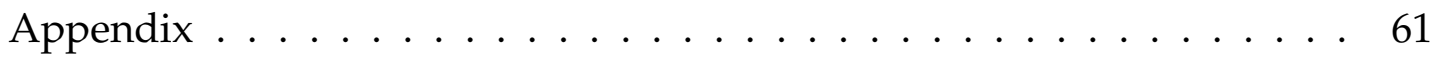




\section{Chapter 3:}

Soil moisture regime and palm height influence embolism resistance $\begin{array}{ll}\text { in oil palm } & 81\end{array}$

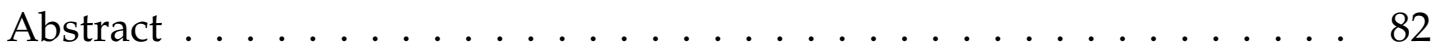

Introduction $\ldots \ldots \ldots \ldots \ldots$

Materials and methods . . . . . . . . . . . . . . . . 87

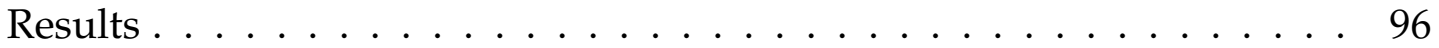

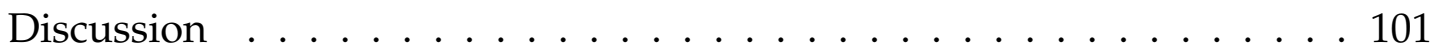

Conclusion . . . . . . . . . . . . . . . . . . 105

Appendix . . . . . . . . . . . . . . . . . 107

\section{Chapter 4:}

Plasticity of wood and leaf traits related to hydraulic efficiency and safety is linked to the evaporative demand and not soil moisture in $\begin{array}{ll}\text { rubber } & 119\end{array}$

Abstract . . . . . . . . . . . . . . . . . . . . 120

Introduction . . . . . . . . . . . . . . . . . . . 121

Materials and methods . . . . . . . . . . . . . . . . 123

Results . . . . . . . . . . . . . . . . . . . 133

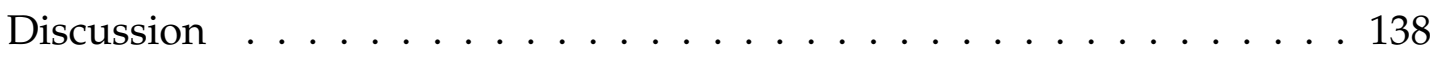

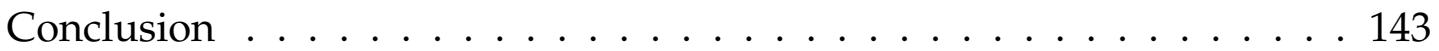

Appendix . . . . . . . . . . . . . . . . . . . 145

\section{Chapter 5:}

$\begin{array}{ll}\text { Synthesis } & 165\end{array}$

Comparison of hydraulic safety traits across species and systems . . . 166 Effects of plant height on hydraulic safety . . . . . . . . . . . . . 171

Relationships between hydraulic safety and xylem anatomy . . . . . . . . 174 Conclusion . . . . . . . . . . . . . . . . . 176 
Index of figures

Index of tables

199

Acknowledgement

201

Curiculum vitae

203 

Chapter 1

Introduction 


\section{Context}

There is currently a scientific consensus to support the hypothesis that increasing emissions of greenhouse gases are causing global climate change (IPCC 2013, Cook et al. 2016). Earth and ocean temperatures have been rising at a rate faster than any reported warming period and are predicted to continue along this path (Diffenbaugh and Field 2013, IPCC 2013, GISTEMP team 2020). Despite this consensus, the extent of the global changes is relatively unknown and cannot be summarized only as an increase in temperature. Experts also report and predict an increase in the intensity and frequency of extreme events (IPCC 2013, USGCRP 2017). In combination, the hydrological cycle is also expected to be modified, with wet regions becoming more humid and dry areas generally becoming drier (Betts et al. 2007). As a result of hydrological modifications coupled with the increase of extreme events, drought and heatwaves are projected to be more intense (Dai 2013, IPCC 2014, USGCRP 2017). Droughts can be defined in many ways but generally correspond to periods in which water is scarce in the soil, i.e. soil water content is below full capacity, due to reduced water supply or excessive evaporative demand (Lloyd-Hughes 2013, Volaire et al. 2018). In the case of heat-induced droughts, or "global-change-type droughts" (Breshears et al. 2005, Allen et al. 2015), it is often a deficit of water supply combined with unusually high temperatures leading to high evaporative demand. The consequences of increasing heat-induced drought spells for plants are still uncertain (Friend et al. 2013), even though water availability is a paramount abiotic factor determining plant growth, survivability and distribution (Aroca et al. 2012). Although the increase of $\mathrm{CO}_{2}$ in the atmosphere may help plants to cope with increasing water stress by enhancing water-use efficiency, the associated stress on their hydraulic systems increases mortality risks and some species may not be able to adapt sufficiently quickly (Aitken et al. 2008, Allen et al. 2010, 2015, Keenan et al. 2013, van der Sleen et al. 2015). The extent of global changes in specific systems is thus poorly known since species differ greatly in their ability to cope with a changing local environment (Allen et al. 2015). Therefore, with the prospect of increasing drought spells, studies targeting particular biomes and systems are urgently needed in order to evaluate the local modalities of a global process.

Despite contrasting perspectives on the resistance to drought of plant species in a changing environment, multiple reports of major tree diebacks across biomes have been documented (Fig. 1.1; Allen et al. 2015). Among these biomes, tropical systems are facing more drought periods, the impact of which is alarming as it is poorly known (Feeley et al. 2012, Fu 2015, Corlett et al. 2016). Tropical ecosystems, and particularly rainforests, are of major interest since they are 
biodiversity hotspots, i.e. biogeographic regions characterized by their wide diversity (Myers 1988). In addition to harboring the majority of Earth species, tropical rainforest represents $25 \%$ of the terrestrial carbon pool while covering only 10\% of the Earth surface (Aragão et al. 2014, Corlett et al. 2016). Higher mortality driven by exceptional and intensive drought events (i.e. additional to the natural dry season) can strongly impair the tropical forest carbon sink, leading to dramatic effects on the global climate (van der Laan-Luijkx et al. 2015). Overall, drought associated with rising temperature and atmospheric $\mathrm{CO}_{2}$ is substantially changing mortality patterns and the dynamic of tropical forests to unknown extents (McDowell et al. 2018).

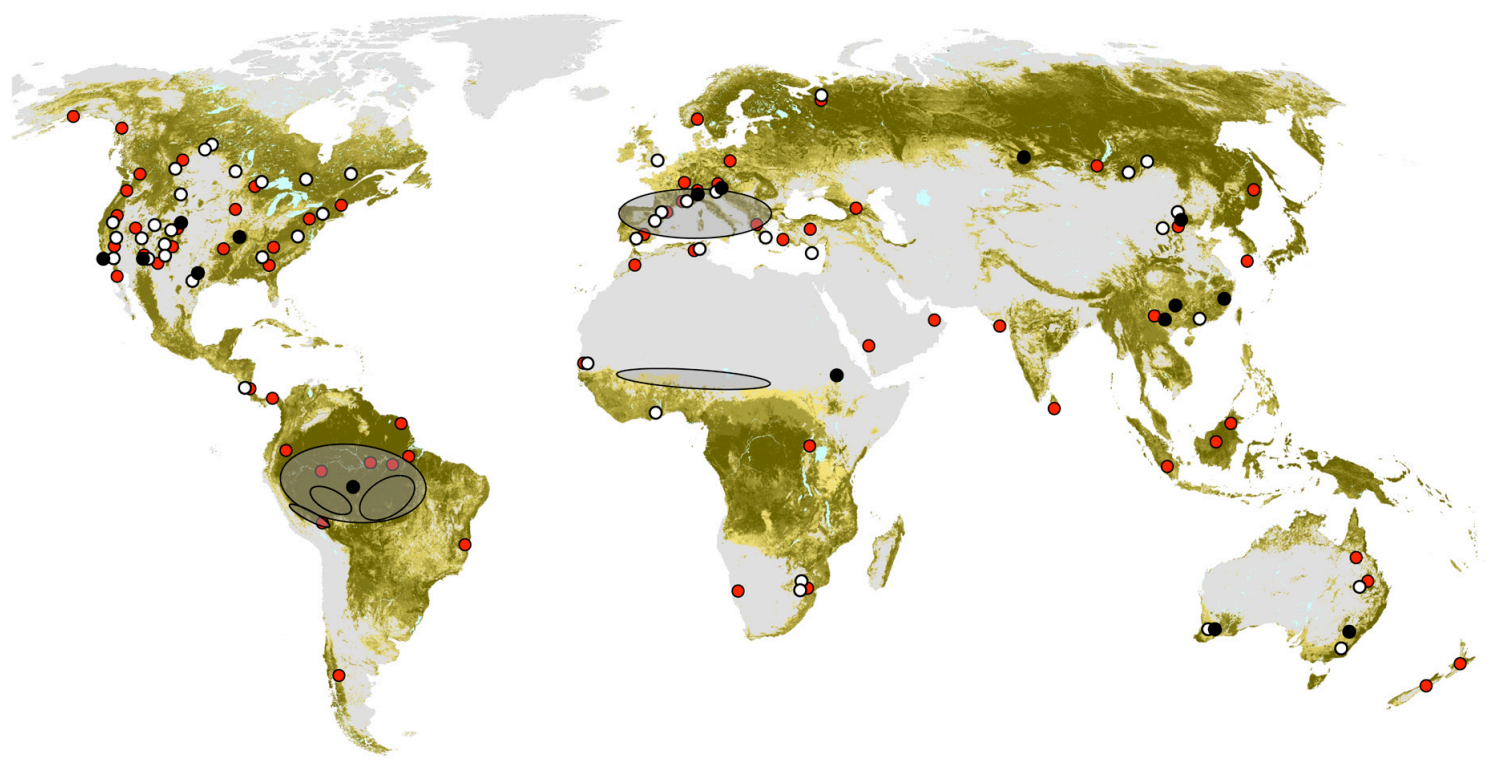

Fig. 1.1: Locations of substantial drought- and heat-induced tree mortality around the globe since 1970, documented by peer-reviewed studies. Global forest cover (dark green) and other wooded regions (light green) are based on FAO (2005). Red dots represent studies from 1970 to 2009. White dots (local studies) and shapes (studies focusing on broad areas) represent localities and measurement networks from post-2009 publications. Black dots represent post-2014 publications. A list of publications is available in Allen et al. 2010, IPCC 2014 and Allen et al. 2015. (Source: Allen et al. 2015)

Tropical forests are also threatened by rapid population expansion and associated changes in land use (Cincotta et al. 2000). Increasing demand for agricultural products across tropical regions leads to massive conversion of forest areas into cropland (Gibbs et al. 2010). Indeed, between 1980 and 2000, more than half of new farmlands was originally forested (Gibbs et al. 2010). Although the loss of a genetic biodiversity reservoir associated with the loss of ecosystem functions (e.g. climate regulation, nutrient cycling, carbon sequestration) (Laurance et al. 2012, Richardson et al. 2013, Slik et al. 2013) is enormous, cash crops offer a broad economic base for the development of a population (Achterbosch et al. 2014). Therefore, these crops should also be considered by 
studies focusing on the impact of droughts in the tropics. However, whereas the effects of heatinduced drought events on tropical forests are the subject of an increasing number of reports in recent decades (e.g. Choat et al. 2012, 2018, Eller et al. 2018, Santiago et al. 2018), very few cash crops have been studied from the standpoint of their resistance to intense drought spells.

Indonesia is a tropical country concentrating all previously described challenges. Indonesia hosts $60 \%$ of Asian tropical forest but it is, at the present time, the country with the world's highest rainforest conversion rate (Margono et al. 2014). These forests are converted mainly into cash crops (Stibig et al., 2014). The heart of this conversion is located in lowland Sumatra (Miettinen et al., 2011, Ekadinata and Vincent, 2011). In recent decades, pluri-specific farmland has been converted into mono-specific rubber (Hevea brasiliensis Müll. Arg.) and oil palm (Elaeis guineensis Jacq.) plantations (Ekadinata and Vincent, 2011). These two crop species are rapidly expanding to include regions that do not correspond to their optimal growth range (Fox et al. 2014, Pirker et al. 2016). Intensifying droughts (e.g. linked to El Niño and La Niña anomalies) could thus expose them to critical damage (Irawan, 2003). Despite this, only a small number of studies focus on the ability of $H$. brasiliensis to cope with intense water stress periods (e.g. Chen et al. 2015, Kumagai et al. 2015, Jinagool et al. 2016, Rungwattana et al. 2018). Likewise, most oil palm studies have focused largely on productivity and growth responses to water stress, with the aim of improving management practices (e.g. Maillard et al. 1974, Dufrêne and Saugier 1993, Cornaire et al. 1994, Carr 2011). Currently, these two cash crops are of a major importance for Indonesia's economy, with 34.9 million tons of palm oil and 3.6 million tons of latex produced in 2017, making Indonesia respectively the first and second worldwide producer of palm oil and latex (FAO 2017).

In a context of intensifying heat-induced drought events in Indonesia, there is a lack of knowledge on the capacity of species and systems to cope with extended water stress periods. Yet, only a limited number of studies have focused on the impact of drought on lowland Indonesian forest, let alone on cash crops such as rubber and oil palm, despite these three systems being of major importance for ecosystem functions or for Indonesia's economy and food security.

\section{The basis of plant hydraulics}

\section{Plant sap ascent mechanisms}

Terrestrial plants need water to obtain atmospheric $\mathrm{CO}_{2}$, as it reacts with $\mathrm{H}_{2} \mathrm{O}$ to form organic molecules during the photosynthesis. (Hall and Rao 1999). $\mathrm{CO}_{2}$ enters the plant through the stomates (i.e. pores at the leaf surface) but in the process a large quantity of $\mathrm{H}_{2} \mathrm{O}$ molecules evaporate 
(i.e. are transpired) into the atmosphere (McElrone et al. 2013) because the water present in saturated leaves passively moves to the drier atmosphere via osmosis (Cochard 2014). Transpiration is the principal driver of sap ascent in the plant (Nobel 1999, McElrone et al. 2013).

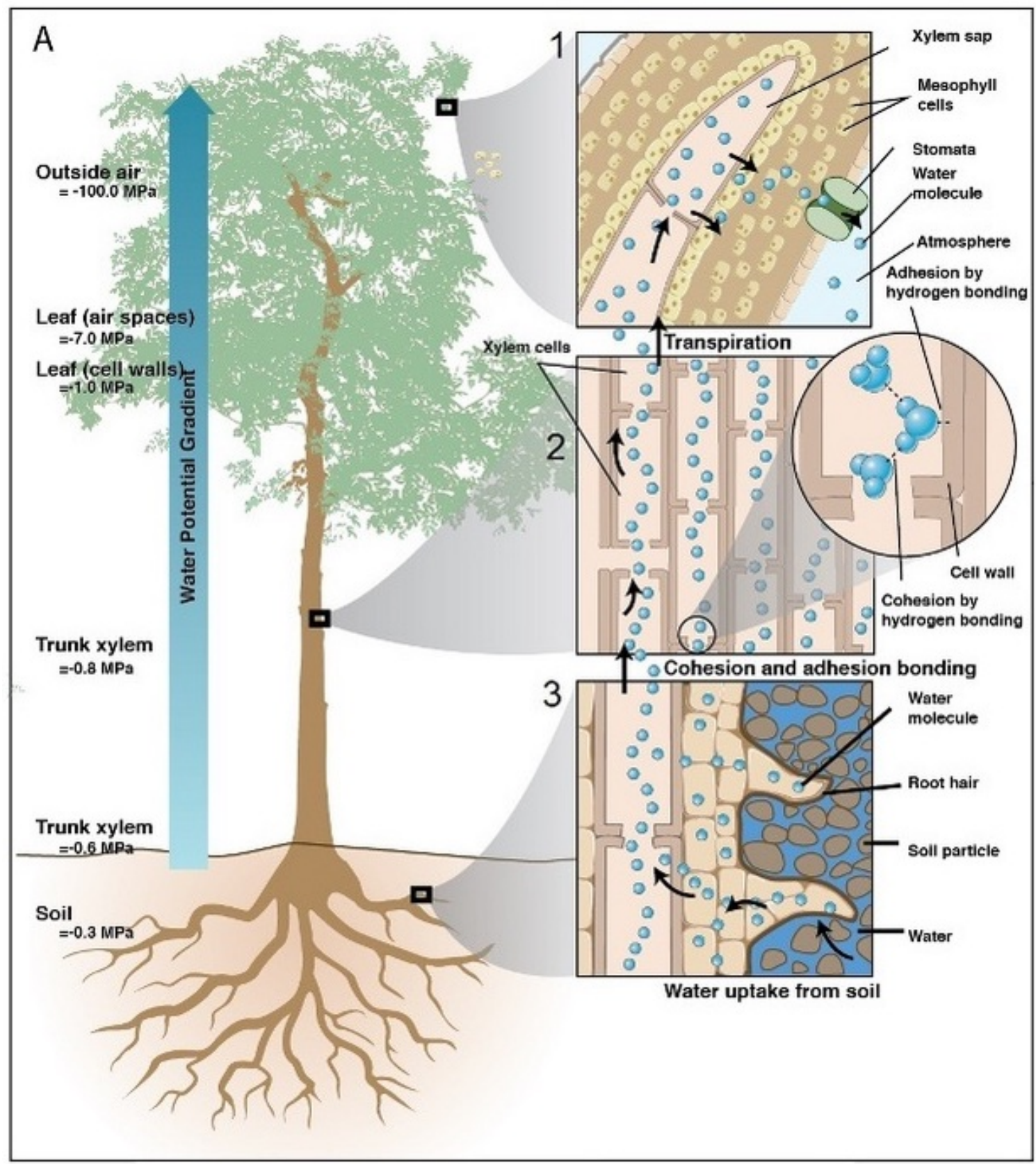

Fig. 1.2: Representation of the water transport pathways along the soil-plant-atmosphere continuum. Water moves from areas of high water potential (i.e. close to zero in the soil) to low water potential (i.e., air outside the leaves). Details of the Cohesion-Tension mechanism are illustrated with the inset panels (1) where tension is generated by the evaporation of water molecules during leaf transpiration and is transmitted (2) down the continuous, cohesive water columns through the xylem and (3) out of the roots to the soil. (Source: McElrone et al. 2013) 
Plants take up water from the soil via their roots. Firstly, laterally through the cells and cell walls (i.e. apoplastic and symplastic pathways; Steudle 2001); and secondly, vertically within a specialized tissue in vascular plants, the xylem, that extends from roots to leaf veins via stems and leaf petioles. The xylem is composed of conduits that consist of (1) tracheids, mainly comprising a single cell, and of (2) vessels consisting of a chain of dead cells (i.e. vessel members) that have partially lost their common walls (i.e. perforation plates) (Wilson and White 1986). The vessels, mostly found in angiosperms, generally have a much larger diameter and length than tracheids (Zimmermann 1983, Venturas et al. 2017). To allow water to flow, conduits are connected together with pits developed from secondary cell walls and constituted by a pit membrane (Choat et al. 2008).

Along the hydraulic path, water molecules are bonded tightly together, forming continuous water columns from soil to leaves (i.e. soil-plant-atmosphere continuum; Fig. 1.2). At its interface with the atmosphere, in the leaves, the water column forms a meniscus with high capillary forces. During transpiration, the surface tension in the meniscus pulls new molecules of water in, to replace those evaporating off into the atmosphere. The movement of water is thus passively generated by the negative pressure (i.e. tension) generated by the water evaporation. This mechanism is known as cohesion-tension theory (Dixon and Joly 1895, Pickard 1981) and explains how large quantities of water can rise over several meters against gravitational forces. The negative pressure gradient along the hydraulic path is commonly expressed as a water potential gradient $\left(\Delta \psi_{\mathrm{x}} ; \mathrm{MPa}\right)$, which is a measure of the potential energy of a liquid compared to pure water. Water potential is a negative pressure (zero being pure water). Water moves passively from higher to lower water potential in order to reach equilibrium.

\section{Major risks linked to water transport in the plants}

Tension inside the xylem can increase because of a more negative $\psi_{\text {soil }}$ (e.g. in dry or saline soils) and/or longer path length and resistance, although xylem conduits are specialized to limit friction (Venturas et al. 2017). To flow at negative pressure, the water inside the xylem conduits is in a metastable phase, i.e. the liquid phase is maintained under negative pressure as long as the water remains away from air bubbles or impurities (Pickard 1981, Haynes et al. 2014). A waterfilled xylem conduit placed in contact with air bubbles will see its pressure quickly rise to near zero MPa, rapidly leading to cavitation (Fig. 1.3; Tyree and Zimmermann 2002) and an inability to transport water. Bubbles are unlikely to form spontaneously inside the conduits since metastable liquid water can withstand pressure ranging from -25 to -30 MPa, far lower than the lowest $\psi_{\text {xylem }}$ 
observed (Briggs 1950, Mercury and Shmulovich 2014). However, during a drought air bubbles can seed inside a conduit through large pores of the bordered pit membrane (Zimmermann 1983, Crombie et al. 1985, Sperry and Tyree 1988). Water-filled conduits connected to air-filled conduits (e.g. appearing following leaf abscission, root senescence or rupture due to storms and herbivores; Venturas et al. 2017) can suck in air bubbles through their pit membranes, causing the spread of embolism (i.e. air bubbles clogging up the conduits; Fig. 1.3). Involved here is the pressure differential between the two compartments: close to zero for air-filled conduits and negative for water-filled conduits. The greater this differential (i.e. the more intense the drought), the more likely air can seed inside a conduit. There are mechanisms that can potentially stop the spread of embolism, for example the pit membrane itself is built to limit embolism spread (McElrone et al. 2013) and surfactants present in sap can prevent air bubble nucleation (Schenk et al. 2015). Nevertheless, if a long drought drives down $\psi_{\text {soil }}$ and $\psi_{\text {xylem }}$ severely, air can spread inside the conduits and cause major hydraulic failure (i.e. many conduits are embolized, limiting the plant's ability to transport water to the leaves). This can strongly impair plant growth and ultimately lead to its death (e.g. Brodribb and Cochard 2009, Vilagrosa et al. 2012).
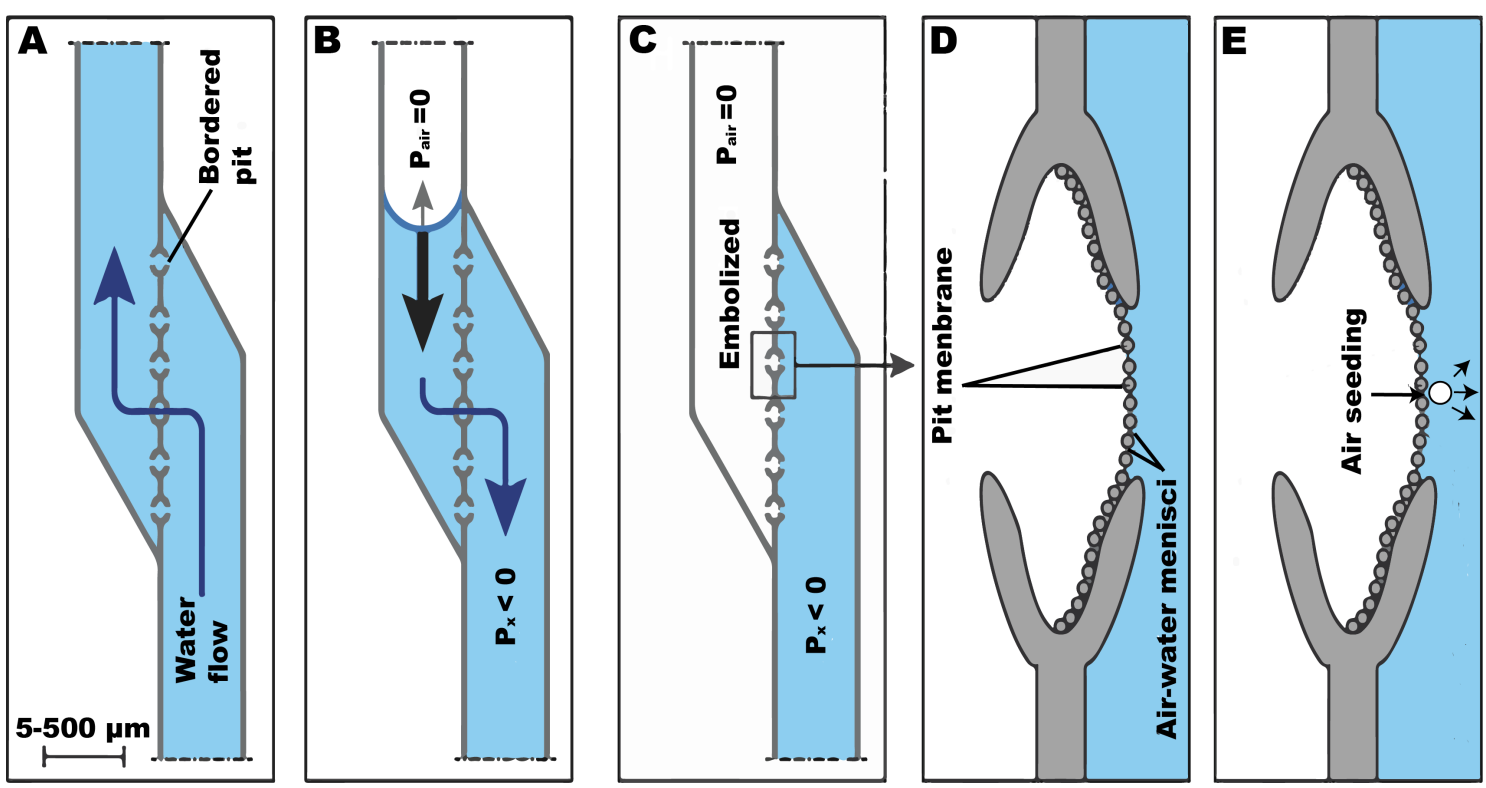

Fig. 1.3: (A) Conduits in the xylem are interconnected through pits, which offer resistance to flow but provide safety to the system. (B) If air gets into these conduits, capillary forces are not strong enough to retain the water column because conduit diameters are too large, and $(\mathrm{C})$ water recedes into the adjacent tissue and the vessel becomes embolized and non-functional for water transport. (D) Pit "membranes" of modified primary cell wall material avoid the spread of air throughout the xylem network by generating the same capillary forces as the menisci of mesophyll cell walls, but $(\mathrm{E})$ if the pressure differential between the air-filled and water-filled conduits is too large, air can seed in the water-filled conduit through stretched pit-pores or rupture of the membrane (in angiosperms). (Modified from Venturas et al. 2017: panel E was added) 


\section{Plant hydraulics in a context of multiples adaptations and study aproaches}

Plants need very large quantities of water but, as sessile organisms, they must cope with fluctuations of water availability in the soil and evaporative demand, carefully balancing their carbon intake while limiting the water transpired. This dilemma is the basis of an increasing number of studies investigating whether plants die from carbon starvation (i.e. limited carbon uptake) or from hydraulic failure. While both mechanisms undoubtedly play a role in plant dieback during heat-induced droughts, their relative importance is still unknown (McDowell et al. 2008, Rowland et al. 2015, Trifilò et al. 2017, McDowell et al. 2018). This underlines the extent to which the adaptations and mechanisms involved in mitigating the negative effects of water stress are complex, depending on plant habit, evolution and biogeography. They occur at multiple scales ranging from metabolic adjustments to morphological adaptations (Aroca et al. 2012).

Accordingly, a range of approaches are commonly used to study plant responses to drought (Volaire et al. 2018). One method proposes the study of some plant characteristics, or traits, implicitly representing a plant's long-term response to a multi-factorial environment and indicating its performance within that environment (Nock et al. 2001). Traits can be directly or indirectly linked to physiological processes, drought avoidance and resistance mechanisms in the present instance, in response to biotic and abiotic factors (Volaire et al. 2018). This ecophysiological approach of plant hydraulics using functional traits has the advantage of approximating complex processes by measuring specific properties related to species' hydraulic performance and safety.

\section{Xylem embolism resistance as a key hydraulic trait}

The ability of the xylem to limit the spread of runaway embolism is an essential functional trait for understanding how species can cope with periods of water shortage (Choat et al. 2012). For more than 50 years scientists have been developing methods of assessing xylem vulnerability to cavitation under increasing stress (Vilagrosa et al. 2012, Cochard et al. 2013). The first methods involved direct or indirect quantification of cavitation events (e.g. acoustic methods; Milburn and Johnson 1966, Crombie et al. 1985). However, with these methods it is not easy to assess the consequences of multiple cavitation events dependent on drought intensity (Vilagrosa et al. 2012). Most current techniques involve studying the evolution of water transport disruption as a function of applied water stress by building xylem vulnerability curves (VCs; Cochard et al. 2013). Commonly, the relative (e.g. percent loss of maximum conductivity) or absolute conductivity values of an organ is measured as a function of the xylem pressure expressed in MPa. There 
are however multiple ways of building VCs, and the methods and their associated artefacts and biases are still under constant discussion (Cochard et al. 2013, Rockwell et al. 2014, Jansen et al. 2015).

Despite the many ways of building VCs, common thresholds derived from the curves have been defined to allow comparisons across studies. The most common thresholds are the $P_{50}$ and $P_{88}$, i.e. water potential at $50 \%$ and $88 \%$ loss of conductivity (PLC), respectively. $P_{50}$ and $P_{88}$ have been linked to mortality and irreversible hydraulic failure in angiosperms and gymnosperms (Brodribb and Cochard 2009, Brodribb et al. 2010, Urli et al. 2013). In addition, $P_{12}$, the water potential at 12 PLC, is another common value extracted from VCs, giving an indication of the onset of embolism (Domec and Gartner 2001).

Most negative $P_{50}$ values, indicating higher cavitation resistance, are commonly found in gymnosperms and in drier biomes (Choat et al. 2012, Gleason et al. 2016). For gymnosperms, $P_{50}$ values average around -5.60 MPa (Choat et al. 2012), whereas angiosperm species growing in moist tropics have high $P_{50}$ values, with an average for tropical lowland rainforest species of $-1.76 \mathrm{MPa}$ (Choat et al. 2012). Nonetheless, there is wide variation in $P_{50}$ values across reports: for tropical rainforest only, studies report $P_{50}$ values ranging from -7.63 MPa to -0.18 MPa (Tyree et al. 1998, Ziegler et al. 2019). This underlines not only the considerable variation of this trait even within the same biome, but also the multiple difficulties and biases encountered when attempting to determine xylem resistance to drought-induced embolism (Jansen et al. 2015). There is therefore a need for reliable cavitation resistance data taking into account some of the major advances in methodology over the last decade (e.g. Wheeler et al. 2013, Torres-Ruiz et al. 2015). Furthermore, to this day there are only very few reports of $P_{50}$ values for Southeast Asian species (Tyree et al. 1998).

\section{Relationships of xylem anatomy with hydraulic efficiency and safety}

Closely related to species' hydraulic performance and safety, xylem properties are the key for the assessment of the impacts of drought on vegetation (Anderegg and Meinzer 2015). Flow conductance depends largely on conduit diameter, especially when considering vessels found in angiosperms, as is shown in the Hagen-Poiseuille equation where it is raised to the fourth power $\left(D^{4}\right.$, Calkin et al. 1986). Wide conduits are also commonly reported more prone to cavitation (Hargrave et al. 1994, Maherali et al. 2006, Awad et al. 2010, Hacke et al. 2010, Hajek et al. 2014). Variation in conduit size can thus be associated with a trade-off between, on the one hand, 
xylem hydraulic conductance, influencing transpiration, carbon fixation, and growth (Tyree 2003, Poorter et al. 2010) and, on the other, safety from drought-induced embolism, preventing major hydraulic failure (Tyree et al. 1994). However, conduit diameter is linked to embolism resistance rather indirectly because bordered pit membrane structure, and notably membrane pore size, is most likely to be directly related to embolism resistance (Li et al. 2016). Because diameter and length tend to be well correlated (Hacke et al. 2006, Liu et al. 2017, Jacobsen et al. 2019), the larger the conduit, the more bordered pits, and so the more likely air can seed inside (Wheeler et al. 2005, Christman et al. 2009, Pittermann et al. 2010, Lens et al. 2011).

A denser tissue matrix in which vessels are embedded also influences xylem safety, by reducing the risk of vessel implosion (Hacke et al. 2001). By extension, wood density (i.e. secondary vascular tissue generally found in angiosperm dicots and gymnosperms) is also often closely associated with hydraulic traits (e.g. embolism resistance) and plant mortality (Chave et al. 2009, Kraft et al. 2010, Bucci et al. 2013, Anderegg et al. 2016, Christoffersen et al. 2016). However, in angiosperms, wood density does not directly affect water transport and is mostly driven by fiber density rather than vessel lumen (Ziemińska et al. 2013). Wood density and vessel diameter can be decoupled, as for example in tropical tree species in the moist tropics (Schuldt et al. 2013, Ziemińska et al. 2013). Despite indirect relationships with water transport, wood density is a good indicator of stress resistance that is related to growth performance (Rosner et al. 2017). In association with other functional and hydraulic traits, wood density provides substantial information on the ability of species to buffer the impact of water stress (Anderegg and Meinzer 2015), especially through its relationship with hydraulic capacitance (i.e. the wood's capacity to store water in order to buffer periods of high evaporative demand) (Scholz et al. 2008, McCulloh et al. 2014).

\section{Relationships of leaf traits with hydraulic efficiency and drought resistance}

As the organs at the interface with the atmosphere, leaves have evolved multiple properties to mitigate evaporative demand (Sack et al. 2015). The ability of a plant to close its stomates in the event of high evaporative demand is essential for its survival (Mitchell et al. 2013). Stomatal closure is of primary importance for preventing the onset of embolism in the xylem but also reduce carbon intake. Thus, among other traits, measuring stomatal conductance during highly evaporative periods indicates whether plant stomatal control is prioritizing carbon intake over prevention of embolism formation, and how the balance changes over time. Because of its close 
relation with stomatal closure, the water potential at which leaves lose their turgor (i.e. the wilting point) is also of particular interest (Brodribb et al. 2003). The leaf turgor loss point can capture leaf stomatal behavior in response to evaporative stress, therefore constituting a good predictor of species resistance to drought (Bartlett et al. 2012, Zhu et al. 2018). Nonetheless, long droughts associated with high temperature ultimately lead to complete stomatal closure, and even tightly closed stomata can leak water if evaporative demand is too high (e.g. through cuticular conductance; Duursma et al. 2019).

Overall, leaf response to drought is coordinated to prevent major hydraulic failure. Stomatal closure, leaf turgor loss point or even leaf shedding (i.e. opportunist or seasonal leaf drop to limit transpiration) should take place at a milder water potential than that responsible for major hydraulic failure (i.e. $P_{50}$ ) (Nolf et al., 2015, Martin-StPaul et al., 2017, Ziegler et al., 2019). To capture the delay between leaf response and xylem hydraulic failure, hydraulic safety margins are usually determined (Alder et al. 1996, Meinzer et al. 2009). Such safety margins are calculated with $P_{50}$ or $P_{88}$ deducted from the water potential experienced by sun-exposed leaves at midday (or from the leaf turgor loss point) (e.g. Meinzer et al. 2009, Choat et al. 2012, Barros et al. 2019). For tropical rainforest, hydraulic safety margins are reported to be rather narrow ( $<1 \mathrm{MPa}$; Choat et al. 2012), although reports vary widely on this (e.g. safety margin around $2 \mathrm{MPa}$ in Ziegler et al. 2019).

\section{Association of hydraulic and functional traits: common species strategies}

Species with a stringent stomatal control in response to evaporative demand typically present a xylem that is less resistant to embolism (Tardieu and Davies 1993, Tardieu and Simonneau 1998). They are isohydric species and represent one extremity of a continuum of water-use strategy (i.e. association of traits linked to growth habit and performance) (Klein 2014, Martínez-Vilalta et al. 2014, Martínez-Vilalta and Garcia-Former 2017, Hochberg et al. 2018). Isohydric species tend to close their stomates on mild atmospheric demand in order to maintain a high leaf and xylem water potential decoupled from soil and atmospheric water potential, preventing water loss and spread of embolism in the xylem. At the other end of the continuum, anisohydric species are able to keep their stomata open at more negative atmospheric water potentials, prioritizing carbon uptake. Consequently, anisohydric species tend to have a xylem that is resistant to embolism. The iso-anisohydry continuum can also be described as a dehydration-avoidant to -tolerant continuum (Volaire et al. 2018). Species that avoid dehydration typically minimize water loss (i.e. 
isohydry) but also maximize water uptake, while drought-tolerant species present adaptations for tolerance of dehydration (Volaire et al. 2018).

In the case of tropical tree species, leaf phenology is central to understanding the modalities of species' water-use strategy. Tropical deciduous trees tend to be more drought-avoiders since they maximize water and carbon uptake during the rainy season while completely avoiding the drought season by shedding their leaves at the cost of carbon uptake. On the other hand, evergreen tropical trees tend to be more drought-resistant since they must cope with the limiting season while continuing to grow (Tardieu and Simonneau 1998). It is also possible to link plant water-use strategy with other aspects of growth habit and performance. For example, fastgrowing pioneer species tend to have large vessels and light wood (Enquist et al. 1999, King et al. 2005, Poorter et al. 2010), which can potentially lead to low xylem resistance to drought-induced cavitation and high hydraulic conductance (Bucci et al. 2004, Santiago et al. 2004, Maherali et al. 2006, Awad et al. 2010, Pratt et al. 2007).

\section{Trait variability across species: impact of tree height}

Tall trees are often described as being subject to a higher mortality risk than smaller trees (Mueller et al. 2005, Nepstad et al. 2007, Prior and Bowman 2014, Bennett et al. 2015, Rowland et al. 2015). As trees grow in height, the advantage of increased direct sunlight exposure is balanced by multiple constraints (Prendin et al. 2018). Notably, higher carbon maintenance costs (Meinzer et al. 2011), higher resistance due to a longer hydraulic path (Ryan and Yoder 1997, Mencuccini 2002), higher gravitational tension (Koch et al. 2004) and higher evaporative demand (McDowell and Allen 2015).

To mitigate the negative effects of path resistance, taller trees have larger vessel diameters (Zach et al. 2010, Schuldt et al. 2013, Olson et al. 2014, 2018, Liu et al. 2019, Toft et al. 2019) than these of shorter trees. This allows trees to directly increase sapwood-specific hydraulic efficiency (Couvreur et al. 2018, Liu et al. 2019). Models also show that branch xylem resistance can increase to compensate for the negative effect of height (Couvreur et al. 2018). Accordingly, some studies have observed an increase in branch embolism resistance with height in some of the tallest trees (e.g. Burgess et al. 2006, Ambrose et al. 2009). However, most recent studies show that larger trees tend instead to have less negative branch $P_{50}$ (Rowland et al. 2015, Olson et al. 2018, Liu et al. 2019). 
At the leaf level, increasing hydraulic constraints with height result in lower cell turgor and higher leaf mass per area (Marshall and Monserud 2003, Woodruff et al. 2004, Meinzer et al. 2008). The ratio leaf area:sapwood area also seems to decrease with height in temperate angiosperm trees but to increase in tropical trees (McDowell et al. 2002, Calvo-Alvarado et al. 2008). Higher constraints on tree-top leaves might also be offset by leaf turgor loss avoidance (Bartlett et al. 2012, Skelton et al. 2015, Brum et al. 2019) resulting in a more negative leaf wilting point in taller trees.

Overall, it appears that the mechanisms leading to higher drought-induced mortality in large trees are still relatively unclear. There is therefore an increasing need for investigation to relate plant hydraulics to height, taking into account plant vascular architecture, especially in tropical forests.

\section{Trait variability within species: adaptation and acclimation}

Changes in plant structure associated with increasing abiotic stresses can lead to trait modification. This shows the ability of plants to cope with environmental changes by adjusting their morphology and physiology within a population through greater intra-specific genetic variability and phenotypic plasticity (Aitken et al. 2008). Despite its overarching importance, little is known regarding the variability of hydraulic traits at the intra-specific level since the focus of most research is inter-specific (Anderegg and Meinzer 2015).

Variation of xylem traits seems to be subject to little genetic influence (e.g. Carlquist 2001, Christensen-Dalsgaard et al. 2008) and to largely depend on environmental changes (Hajek et al. 2016, Venturas et al. 2017). Indeed, drought generally leads to vascular adjustments such as vessels with smaller diameters but higher in densities (Beikircher and Mayr 2009, Arx et al. 2012, Bryukhanova and Fonti 2013, Lübbe et al. 2017). Likewise, vulnerability to embolism tends to depend on environmental factors (e.g. mean annual precipitation, soil water availability, light exposition) as it has been demonstrated in Fagus sylvatica (Cochard et al. 1999, Schuldt et al. 2016) and Acer grandidantatum (Alder et al. 1996). However, only a few species have been investigated in this regard and their response may vary (Choat et al. 2018). Several studies on pine populations have indeed showed only little or no plasticity of $P_{50}$ in response to climatic gradients (Stout and Sala 2003, Martínez-Vilalta et al. 2004, 2009, Aspinwall et al. 2011, López et al. 2013, 2016). Similarly, although angiosperms tend to be more plastic than gymnosperms (Aranda et al. 2015), low or no plasticity of embolism resistance in response to water availability was observed in Quercus spp (Martin StPaul et al. 2012, Lobo et al. 2018, Rosas et al. 2019). 
Partly because of their limited life span, leaves have characteristics that are generally more variable than the xylem. For example, the leaf $P_{50}$ of Columbia calophylla changes according to population origin and climate region (Blackman et al. 2017). Likewise, in the event of water scarcity, plants can also alter for example their specific leaf area (Wright et al. 2002, Arx et al. 2012) and cell membrane permeability (Javot and Maurel 2002).

In general, leaf and xylem plasticity contribute to increased plant hydraulic safety. However, most of the studies mentioned focus largely on temperate trees, with tropical species yet to be investigated.

\section{Project framework and study area}

To investigate tropical tree species and system coping mechanisms in response to increasing drought spells, the present study was carried out as part of the "ecological and socioeconomic functions of lowland rainforest transformation systems" project (EFForTS project, http: //www. uni-goettingen.de/crc990). The aim of this interdisciplinary project is to study the environmental and socioeconomic dimensions associated with the current forest conversion to agricultural systems in Jambi province in Sumatra, which is among the provinces with the highest forest conversion rate in Indonesia (Miettinen et al. 2011, Drescher et al. 2016). This DFG-funded project stems from cooperation between the University of Göttingen and three Indonesian universities (Tadulako University of Palu on Sulawesi; Bogor Agricultural University on Java, and University of Jambi on Sumatra).

Jambi Province is located in central Sumatra and covers an area of approximately 50,000 km2 (Drescher et al. 2016). The province ranges from the Barisan Mountains in the West to broad lowlands in the east. The lowlands have a tropical humid climate and two peak rainy seasons in March and December (Drescher et al. 2016). The traditional dry season covers the period from July to August but may extend to May and September. Annual average temperature is around $26.7^{\circ} \mathrm{C}$ while mean annual precipitation is approximately $2235 \mathrm{~mm} \mathrm{y}^{-1}$ (Drescher et al. 2016).

In Jambi province, lowland natural dipterocarp-dominated rainforests (Laumonier 1997) have been largely converted into cash crops of oil palm (Elaeis guineensis) and rubber (Hevea brasiliensis). However, there are still substantial areas of lowland rainforest in the province. The EFForTS project has therefore established rainforest plots in Bukit Duabelas national park and in Harapan Rainforest, and rubber and oil palm plantation plots located around the forest sites (Fig. 1.4). Although the forests are not completely free of human impacts, they are nevertheless close to 
their natural state.

The present study focuses on forest and transformation systems plots located inside and near the Harapan Rainforest. In the Harapan landscape, we focused on eight plots, each 50 x 50 m, of oil palm, rubber and forest (24 plots) that were previously established within the EFForTS study sites (Fig. 1.4). For each of the three systems, four plots were defined as well-drained and four others were defined as riparian. Riparian sites are flooded at least once a year and the soil profile presents hydromorphic features (mottles), a sign of alternating aerobic and anaerobic conditions.

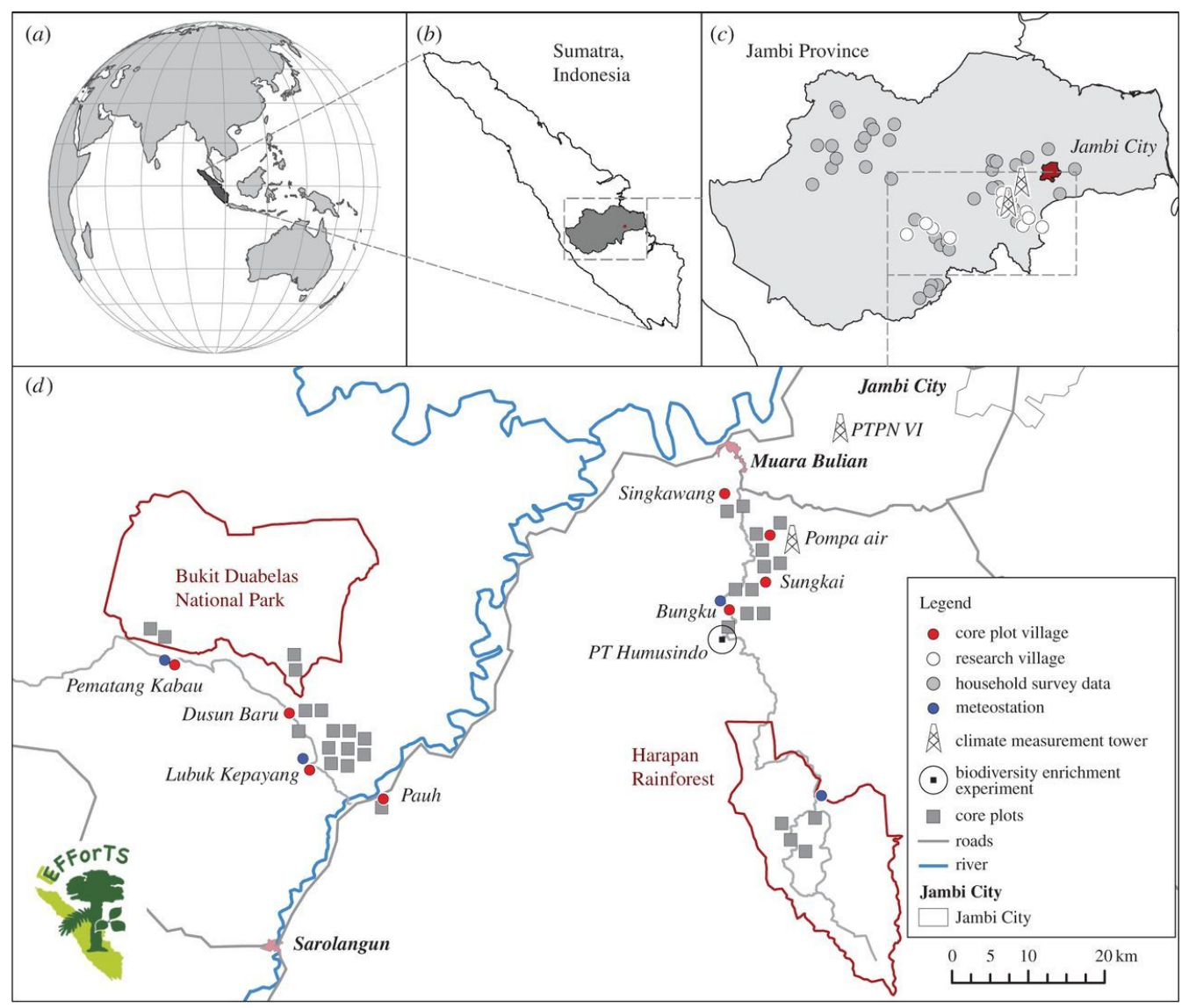

Fig. 1.4: Location of EFForTS study sites in $(a, b)$ Sumatra and $(c, d)$ Jambi Province. (d) Plot design is located in two landscapes near Bukit Duabelas National Park and Harapan Rainforest. (Source: Drescher et al. 2016)

\section{Objectives and hypothesis}

From 2016 to 2018 we collected data in the three main systems of Jambi's lowland area: forest area along with oil palm and rubber plantations growing on riparian and well-drained soils. To study the mechanisms associated with tree mortality during exceptional droughts, we sampled and measured variables linked to growth performance and to leaf, stem and branch hydraulic 
transport. For the three systems, we focused on aspects of the response to drought that are inherent to the type of system and organism. In the forest we focused on the response to drought of several species, since this is a pluri-specific system. Likewise, in the oil palm and rubber plantations we focused on intra-specific variability and diversity of hydraulic traits in response to water availability since these are mono-specific systems. Trait variability as a principal mechanism of drought survival is central to the present study as it is the ground base for understanding the resistance to drought of whole systems.

Our main aim was:

1. To expand knowledge of species' and systems' strategies to resist heat-induced drought spells in insufficiently studied Southeast Asian lowland tropical systems.

Secondary objectives included:

1. In all systems, to investigate the role of easily accessible wood anatomy traits as key variables for assessing species' drought resistance.

2. In all systems, to investigate the inter- and intra-specific diversity of xylem embolism resistance associated with other functional traits in order to assess the capacity of species and systems to cope with heat-induced drought spells.

3. In pluri-specific systems such as lowland forest, to investigate the influence of tree structure on hydraulic and functional traits given that tall trees are often considered more vulnerable to drought.

4. In mono-specific systems such as oil palm and rubber plantations, to investigate the plasticity of hydraulic traits in response to changing soil moisture regimes and evaporative demand.

In order to achieve these objectives, the following group of variables and traits were investigated during the study:

1. Stem diameter was measured for most trees and tree radial growth across plots was monitored for three years in all systems except oil palm plantations.

2. Stem wood density and wood anatomy-related traits such as vessel density and diameter were determined for most trees across plots. 
3. Xylem anatomy and conductivity related traits, as well as vulnerability to cavitation, were determined in tree branches and palm fronds.

4. Leaf turgor loss point and specific leaf area were determined in forest and rubber trees, and leaf conductance at midday was measured on oil palms.

The general hypotheses of the present dissertation were :

1. There is greater inter-specific diversity in hydraulic safety traits in the forest areas in comparison to the intra-specific diversity present at the plantation sites

2. As a result of phenotypic plasticity, oil palms and rubber trees growing in well-drained sites present adjustments of their hydraulic safety and efficiency in comparison to equally sized palms and trees growing at riparian sites.

3. Oil palm, as a monocot with a deterministic hydraulic architecture, presents greater frond hydraulic trait plasticity in response to water availability than the branches of rubber trees.

4. In comparison to smaller trees and palms, tall trees and palms have wider vessel diameters in their stems and/or in their distal twigs and fronds.

5. The xylem of tall trees and palms is most vulnerable to drought-induced hydraulic failure due to the commonly observed (indirect) relationship between vessel diameter and embolism resistance.

6. Variability of xylem embolism resistance is generally associated with vascular adjustments such as modifications of vessels diameter and/or density. 


\section{References}

Achterbosch, T., van Berkum, S., Meijerink, G., Asbreuk, H., And OudendaG, D. 2014. Cash crops and food security : contributions to income, livelihood risk and agricultural innovation. LEI report. LEI Wageningen UR.

Aitken, S. N., Yeaman, S., Holliday, J. A., WANG, T., And Curtis-McLane, S. 2008. Adaptation, migration or extirpation: climate change outcomes for tree populations. Evolutionary applications 1:95-111.

Alder, N. N., Sperry, J. S., AND Pockman, W. T. 1996. Root and stem xylem embolism, stomatal conductance, and leaf turgor in acer grandidentatum populations along a soil moisture gradient. Oecologia 105:293-301.

Allen, C. D., Breshears, D. D., AND McDowell, N. G. 2015. On underestimation of global vulnerability to tree mortality and forest die-off from hotter drought in the anthropocene. Ecosphere 6:1-55.

Allen, C. D., Macalady, A. K., Chenchouni, H., Bachelet, D., McDowell, N. G., VenNetier, M., Kitzberger, T., Rigling, A., Breshears, D. D., HogG, E. H., GonZalez, P., Fensham, R., Zhang, Z., Castro, J., Demidova, N., Lim, J.-H., Allard, G., Running, S. W., SEmerci, A., AND СовB, N. 2010. A global overview of drought and heat-induced tree mortality reveals emerging climate change risks for forests. Forest Ecology and Management 259:660-684.

Ambrose, A. R., Sillett, S. C., And Dawson, T. E. 2009. Effects of tree height on branch hydraulics, leaf structure and gas exchange in california redwoods. Plant, cell $\mathcal{E}$ environment 32:743-757.

Anderegg, W. R. L., Klein, T., Bartlett, M. K., SAck, L., Pellegrini, A. F. A., Choat, B., AND JANSEN, S. 2016. Meta-analysis reveals that hydraulic traits explain cross-species patterns of drought-induced tree mortality across the globe. Proceedings of the National Academy of Sciences of the United States of America 113:5024-5029.

ANDeregG, W. R. L. AND Meinzer, F. C. 2015. Wood anatomy and plant hydraulics in a changing climate, pp. 235-253. In U. G. Hacke (ed.), Functional and Ecological Xylem Anatomy. Springer International Publishing, Cham.

Aragão, L. E. O. C., Poulter, B., Barlow, J. B., Anderson, L. O., Malhi, Y., SaAtchi, S., Phillips, O. L., AND GlOOR, E. 2014. Environmental change and the carbon balance of 
amazonian forests. Biological reviews of the Cambridge Philosophical Society 89:913-931.

Aranda, I., Cano, F. J., Gascó, A., Cochard, H., Nardini, A., Mancha, J. A., López, R., AND SÁNCHEZ-GÓMEZ, D. 2015. Variation in photosynthetic performance and hydraulic architecture across european beech (fagus sylvatica 1.) populations supports the case for local adaptation to water stress. Tree physiology 35:34-46.

AROCA, R. 2012. Plant Responses to Drought Stress: From Morphological to Molecular Features. Springer, Berlin and Heidelberg.

Aspinwall, M. J., King, J. S., Domec, J.-C., McKeand, S. E., And IsiK, F. 2011. Genetic effects on transpiration, canopy conductance, stomatal sensitivity to vapour pressure deficit, and cavitation resistance in loblolly pine. Ecohydrology 4:168-182.

Awad, H., Barigah, T., Badel, E., Cochard, H., And Herbette, S. 2010. Poplar vulnerability to xylem cavitation acclimates to drier soil conditions. Physiologia plantarum 139:280-288.

Barros, F. D. V., Bittencourt, P. R. L., Brum, M., Restrepo-Coupe, N., Pereira, L., Teodoro, G. S., Saleska, S. R., Borma, L. S., Christoffersen, B. O., Penha, D., Alves, L. F., Lima, A. J. N., Carneiro, V. M. C., Gentine, P., Lee, J.-E., Aragão, L. E. O. C., Ivanov, V., Leal, L. S. M., Araujo, A. C., And Oliveira, R. S. 2019. Hydraulic traits explain differential responses of amazonian forests to the 2015 el niño-induced drought. The New phytologist 223:1253-1266.

BARTLETT, M. K., SCOFFONI, C., AND SACK, L. 2012a. The determinants of leaf turgor loss point and prediction of drought tolerance of species and biomes: a global meta-analysis. Ecology letters 15:393-405.

BEIKIRCHER, B. AND MAYR, S. 2009. Intraspecific differences in drought tolerance and acclimation in hydraulics of ligustrum vulgare and viburnum lantana. Tree physiology 29:765-775.

Bennett, A. C., McDowell, N. G., Allen, C. D., And Anderson-Teixeira, K. J. 2015. Larger trees suffer most during drought in forests worldwide. Nature plants 1:15139.

Betts, R. A., Boucher, O., Collins, M., Cox, P. M., Falloon, P. D., Gedney, N., HemMing, D. L., Huntingford, C., Jones, C. D., Sexton, D. M. H., And WebB, M. J. 2007. Projected increase in continental runoff due to plant responses to increasing carbon dioxide. Nature 448:1037-1041.

Blackman, C. J., Aspinwall, M. J., Tissue, D. T., And Rymer, P. D. 2017. Genetic adaptation and phenotypic plasticity contribute to greater leaf hydraulic tolerance in response to drought in warmer climates. Tree physiology 37:583-592. 
Breshears, D. D., Cobb, N. S., Rich, P. M., Price, K. P., Allen, C. D., Balice, R. G., Romme, W. H., Kastens, J. H., Floyd, M. L., Belnap, J., Anderson, J. J., Myers, O. B., AND MEYER, C. W. 2005. Regional vegetation die-off in response to global-change-type drought. Proceedings of the National academy of Sciences of the United States of America 102:15144.

BRIGGS, L. J. 1950. Limiting negative pressure of water. Journal of Applied Physics 21:721-722.

Brodribb, T. J., Bowman, David J. M. S., Nichols, S., Delzon, S., ANd Burlett, R. 2010. Xylem function and growth rate interact to determine recovery rates after exposure to extreme water deficit. New Phytologist 188:533-542.

BRODRIBB, T. J. AND COCHARD, H. 2009. Hydraulic failure defines the recovery and point of death in water-stressed conifers. Plant physiology 149:575-584.

Brodribb, T. J., Holbrook, N. M., Edwards, E. J., And Gutiérrez, M. V. 2003. Relations between stomatal closure, leaf turgor and xylem vulnerability in eight tropical dry forest trees. Plant, Cell and Environment 26:443-450.

Brum, M., Vadeboncoeur, M. A., Ivanov, V., Asbjornsen, H., Saleska, S., Alves, L. F., Penha, D., Dias, J. D., Aragẽo, L. E. O. C., Barros, F., Bittencourt, P., Pereira, L., AND OLIVEIRA, R. S. 2019. Hydrological niche segregation defines forest structure and drought tolerance strategies in a seasonal amazon forest. Journal of Ecology 107:318-333.

BRYUKHANOVA, M. AND FONTI, P. 2013. Xylem plasticity allows rapid hydraulic adjustment to annual climatic variability. Trees 27:485-496.

Bucci, S. J., Goldstein, G., Meinzer, F. C., Scholz, F. G., Franco, A. C., And BustaMANTE, M. 2004. Functional convergence in hydraulic architecture and water relations of tropical savanna trees: from leaf to whole plant. Tree physiology 24:891-899.

Bucci, S. J., Scholz, F. G., Peschiutta, M. L., Arias, N. S., Meinzer, F. C., And GoldSTEIN, G. 2013. The stem xylem of patagonian shrubs operates far from the point of catastrophic dysfunction and is additionally protected from drought-induced embolism by leaves and roots. Plant, cell E environment 36:2163-2174.

Burgess, Stephen, O., Pittermann, J., And Dawson, T. E. 2006. Hydraulic efficiency and safety of branch xylem increases with height in sequoia sempervirens (d. don) crowns. Plant, Cell and Environment 29:229-239.

CAlkin, H. W., Gibson, A. C., AND Nobel, P. S. 1986. Biophysical model of xylem conductance in tracheids of the fern pteris vittata. Journal of Experimental Botany 37:1054-1064. 
Calvo-Alvarado, J.-C., McDowell, N. G., And Waring, R. H. 2008. Allometric relationships predicting foliar biomass and leaf area:sapwood area ratio from tree height in five costa rican rain forest species. Tree Physiology 28:1601-1608.

CARlquist, S. 2001. Comparative Wood Anatomy: Systematic, Ecological, and Evolutionary Aspects of Dicotyledon Wood. Springer Series in Wood Science. Springer Berlin Heidelberg.

CARR, M. K. 2011. The water relations and irrigation requirements of oil palm (elaeis guineensis): A review. Experimental Agriculture 47:629-652.

Chave, J., Coomes, D., Jansen, S., Lewis, S. L., Swenson, N. G., and Zanne, A. E. 2009. Towards a worldwide wood economics spectrum. Ecology letters 12:351-366.

CHEN, J.-W. AND CAO, K.-F. 2015. A possible link between hydraulic properties and leaf habits in hevea brasiliensis. Functional Plant Biology 42:718.

Chot, B., Brodribb, T. J., Brodersen, C. R., Duursma, R. A., López, R., And Medlyn, B. E. 2018. Triggers of tree mortality under drought. Nature 558:531-539.

Choat, B., СobB, A. R., AND JAnsen, S. 2008. Structure and function of bordered pits: new discoveries and impacts on whole-plant hydraulic function. New Phytologist 177:608-626.

Choat, B., Jansen, S., Brodribb, T. J., Cochard, H., Delzon, S., Bhaskar, R., Bucci, S. J., Feild, T. S., Gleason, S. M., Hacke, U. G., Jacobsen, A. L., Lens, F., Maherali, H., Martínez-Vilalta, J., Mayr, S., Mencuccini, M., Mitchell, P. J., Nardini, A., Pittermann, J., Pratt, R. B., Sperry, J. S., Westoby, M., Wright, I. J., And Zanne, A. E. 2012. Global convergence in the vulnerability of forests to drought. Nature 491:752-755.

Christensen-DalsgaArd, K. K., Ennos, A. R., And Fournier, M. 2008. Are radial changes in vascular anatomy mechanically induced or an ageing process? evidence from observations on buttressed tree root systems. Trees - Structure and Function 22:543-550.

Christman, M. A., Sperry, J. S., AND Adler, F. R. 2009. Testing the 'rare pit' hypothesis for xylem cavitation resistance in three species of acer. The New phytologist 182:664-674.

Christoffersen, B. O., Gloor, M., FAuset, S., Fyllas, N. M., Galbraith, D. R., BaKer, T. R., Rowland, L., Fisher, R. A., Binks, O. J., Sevanto, S. A., XU, C., JANSEn, S., ChOAT, B., Mencuccini, M., McDowell, N. G., AND Meir, P. 2016. Linking hydraulic traits to tropical forest function in a size-structured and trait-driven model (tfs v.1-hydro). Geoscientific Model Development Discussions pp. 1-60.

CincotTA, R., WiSNEWSKI, J., AND ENGELMAN, R. 2000. Human populations in the biodiversity hotspots. Nature 404:990-992. 
COCHARD, H. 2014. The basics of plant hydraulics. Journal of Plant Hydraulics 1:e0001.

Cochard, H., Badel, E., Herbette, S., Delzon, S., Choat, B., and Jansen, S. 2013. Methods for measuring plant vulnerability to cavitation: a critical review. Journal of experimental botany 64:4779-4791.

Cochard, H., Lemoine, D., AND DReYer, E. 1999. The effects of acclimation to sunlight on the xylem vulnerability to embolism in fagus sylvatica 1. Plant, cell \& environment 22:101-108.

Cook, J., Oreskes, N., Doran, P. T., ANDeregG, W. R. L., Verheggen, B., Maibach, E. W., Carlton, J. S., Lewandowsky, S., Skuce, A. G., Green, S. A., Nuccitelli, D., Jacobs, P., Richardson, M., Winkler, B., Painting, R., And Rice, K. 2016. Consensus on consensus: a synthesis of consensus estimates on human-caused global warming. Environmental Research Letters 11:048002.

CORLETT, R. T. 2016. The impacts of droughts in tropical forests. Trends in plant science 21:584-593.

Cornaire, B., DANiel, C., ZuILY-Fodil, Y., AND LAMADE, E. 1994. Oil palm performance under water stress. background to the problem, first results and research approaches. Oléagineux, 49:1-12.

Couvreur, V., Ledder, G., Manzoni, S., Way, D. A., Muller, E. B., And Russo, S. E. 2018.

Water transport through tall trees: A vertically explicit, analytical model of xylem hydraulic conductance in stems. Plant, cell E environment 41:1821-1839.

Crombie, D. S., Hipkins, M. F., AND Milburn, J. A. 1985. Gas penetration of pit membranes in the xylem of Rhododendron as the cause of acoustically detectable sap cavitation. Functional Plant Biology 12:445-453.

DAI, A. 2013. Increasing drought under global warming in observations and models. Nature Climate Change 3:52-58.

Diffenbaugh, N. S. AND Field, C. B. 2013. Changes in ecologically critical terrestrial climate conditions. Science (New York, N.Y.) 341:486.

DiXON, H. H. AND JOLY, J. 1895. On the ascent of sap. Philosophical transactions of the Royal Society of London. Series B, Biological sciences 186:563-576.

DomeC, J.-C. AND GARTNER, B. L. 2001. Cavitation and water storage capacity in bole xylem segments of mature and young douglas-fir trees. Trees 15:204-214.

Drescher, J., Rembold, K., Allen, K., Beckschäfer, P., Buchori, D., Clough, Y., Faust, H., Fauzi, A. M., Gunawan, D., Hertel, D., Irawan, B., Jaya, I. N. S., Klarner, B., Kleinn, C., KnOhl, A., Kotowska, M. M., Krashevska, V., Krishna, V., Leuschner, 
C., Lorenz, W., Meijide, A., Melati, D., Nomura, M., Pérez-Cruzado, C., Qaim, M., Siregar, I. Z., Steinebach, S., TJOA, A., TscharntKe, T., Wick, B., Wiegand, K., Kreft, H., AND SCHEU, S. 2016. Ecological and socio-economic functions across tropical land use systems after rainforest conversion. Philosophical transactions of the Royal Society of London. Series B, Biological sciences 371 .

DUfRÊNE, E. AND SAUGIER, B. 1993. Gas exchange of oil palm in relation to light, vapour pressure deficit, temperature and leaf age. Functional Ecology 7:97-104.

Duursma, R. A., Blackman, C. J., Lopéz, R., Martin-StPaul, N. K., Cochard, H., And MEDLYN, B. E. 2019. On the minimum leaf conductance: its role in models of plant water use, and ecological and environmental controls. The New phytologist 221:693-705.

EKADINATA, A. AND VinCENT, G. 2011. Rubber agroforests in a changing landscape: Analysis of land use/cover trajectories in bungo district, indonesia. Forests, Trees and Livelihoods 20:3-14.

Eller, C. B., De Barros, F. D. V., Bittencourt, P. R., Rowland, L., Mencuccini, M., And OliveIRA, R. S. 2018. Xylem hydraulic safety and construction costs determine tropical tree growth. Plant, cell \& environment 41:548-562.

ENQUist, B., BROWN, J., AND WeSt, G. B. 1998. Allometric scaling of plant energetics and population density. Nature 395:163-165.

FAO 2017. Un food and agricultural oganisation statistic database.

Feeley, K. J., ReHM, E. M., AND MachovinA, B. 2012. perspective: The responses of tropical forest species to global climate change: acclimate, adapt, migrate, or go extinct? Frontiers of Biogeography 4.

Fox, J. M., CAstella, J.-C., Ziegler, A. D., AND Westley, S. B. 2014. Rubber plantations expand in mountainous southeast asia: What are the consequences for the environment? Analysis from the East-West Center 114:1-8.

Friend, A. D., Lucht, W., Rademacher, T. T., Keribin, R., Betts, R., Cadule, P., Ciais, P., Clark, D. B., Dankers, R., Falloon, P. D., Ito, A., Kahana, R., Kleidon, A., Lomas, M. R., Nishina, K., Ostberg, S., Pavlick, R., Peylin, P., Schaphoff, S., Vuichard, N., WARsZaWSKI, L., Wiltshire, A., AND WoodWARD, F. I. 2014. Carbon residence time dominates uncertainty in terrestrial vegetation responses to future climate and atmospheric $\mathrm{CO}_{2}$. Proceedings of the National Academy of Sciences 111:3280.

FU, R. 2015. Global warming-accelerated drying in the tropics. Proceedings of the National Academy of Sciences of the United States of America 112:3593-3594. 
Gibbs, H. K., Ruesch, A. S., Achard, F., Clayton, M. K., Holmgren, P., Ramankutty, N., AND FOLEY, J. A. 2010. Tropical forests were the primary sources of new agricultural land in the 1980s and 1990s. Proceedings of the National Academy of Sciences of the United States of America 107:16732-16737.

GISTEMP TEAM 2020. Giss surface temperature analysis (gistemp), version 4.

Gleason, S. M., Westoby, M., Jansen, S., Choat, B., Hacke, U. G., Pratt, R. B., Bhaskar, R., Brodribb, T. J., Bucci, S. J., CAO, K.-F., COChard, H., Delzon, S., DOMEC, J.-C., FAN, Z.-X., Feild, T. S., Jacobsen, A. L., Johnson, D. M., Lens, F., MAherali, H., MartínezVilalta, J., Mayr, S., McCulloh, K. A., Mencuccini, M., Mitchell, P. J., Morris, H., NArdini, A., Pittermann, J., Plavcová, L., Schreiber, S. G., Sperry, J. S., Wright, I. J., AND ZANNE, A. E. 2016. Weak tradeoff between xylem safety and xylem-specific hydraulic efficiency across the world's woody plant species. The New phytologist 209:123-136.

Hacke, U. G., Plavcová, L., Almeida-Rodriguez, A., King-Jones, S., Zhou, W., And COOKE, J. E. K. 2010. Influence of nitrogen fertilization on xylem traits and aquaporin expression in stems of hybrid poplar. Tree physiology 30:1016-1025.

HACKe, U. G. AND Sperry, J. S. 2001. Functional and ecological xylem anatomy. Perspectives in Plant Ecology, Evolution and Systematics 4:97-115.

Hacke, U. G., Sperry, J. S., Wheeler, J. K., ANd CAStro, L. 2006. Scaling of angiosperm xylem structure with safety and efficiency. Tree Physiology 26:689-701.

HajeK, P., KurjaK, D., von WÜHlisch, G., Delzon, S., AND Schuldt, B. 2016. Intraspecific variation in wood anatomical, hydraulic, and foliar traits in ten european beech provenances differing in growth yield. Frontiers in Plant Science 7:791.

Hajek, P., Leuschner, C., Hertel, D., Delzon, S., And Schuldt, B. 2014. Trade-offs between xylem hydraulic properties, wood anatomy and yield in populus. Tree physiology 34:744756.

Hall, D. O. And RaO, K. K. 1999. Photosynthesis. Cambridge University Press, 6th edition edition.

Hargrave, K., R., Kolb, T. E., Ewers, B. E., And Davis, S. D. 1994. Conduit diameter and drought-induced embolism in salvia mellifera greene (labiatae). New Phytologist 126:695-705.

HAYNES, W. M. 2014. CRC handbook of chemistry and physics. 2014. CRC press.

Hochberg, U., Rockwell, F. E., Holbrook, N. M., And Cochard, H. 2018. Iso/anisohydry: A plant-environment interaction rather than a simple hydraulic trait. Trends 
in plant science 23:112-120.

IPCC 2013. Climate change 2013: The physical science basis Working Group I contribution to the Fifth assessment report of the Intergovernmental Panel on Climate Change. Cambridge University Press, New York.

IPCC 2014. Climate change 2014: Impacts, adaptation, and vulnerability Working Group II contribution to the fifth assessment report of the Intergovernmental Panel on Climate Change. Cambridge University Press, New York NY.

IRAWAN, B. Multilevel impact assessment and coping strategies against el nino: Case of food crops in indonesia: Multilevel impact assessment and coping strategies against el nino: Case of food crops in indonesia.

Jacobsen, A. L., Brandon Pratt, R., Venturas, M. D., Hacke, U. G., And Lens, F. 2019. Large volume vessels are vulnerable to water-stress-induced embolism in stems of poplar. IAWA Journal 40:4-S4.

JANSEn, S., Schuldt, B., AND CHOAT, B. 2015. Current controversies and challenges in applying plant hydraulic techniques: International workshop on plant hydraulic techniques, ulm university, germany, september 2014. The New phytologist 205:961-964.

JAVOt, H. AND MAUREL, C. 2002. The role of aquaporins in root water uptake. Annals of Botany 90:301-313.

Jinagool, W., RatTAnawong, R., SANGsing, K., BARigaH, T. S., GAY, F., Cochard, H., Kasemsap, P., AND Herbette, S. 2016. Clonal variability for vulnerability to cavitation and other drought-related traits hevea brasiliensis müll. arg. Journal of Plant Hydraulics 2:1-12.

Keenan, T. F., Hollinger, D. Y., Bohrer, G., Dragoni, D., Munger, J. W., Schmid, H. P., AND RICHARDSON, A. D. 2013. Increase in forest water-use efficiency as atmospheric carbon dioxide concentrations rise. Nature 499:324-327.

King, D. A., Davies, S. J., Supardi, M. N. N., AND TAN, S. 2005. Tree growth is related to light interception and wood density in two mixed dipterocarp forests of malaysia. Functional Ecology 19:445-453.

KLEIN, T. 2014. The variability of stomatal sensitivity to leaf water potential across tree species indicates a continuum between isohydric and anisohydric behaviours. Functional Ecology 28:1313-1320.

Koch, G. W., Sillett, S. C., Jennings, G. M., And Davis, S. D. 2004. The limits to tree height. Nature 428:851-854. 
Kraft, N. J. B., Metz, M. R., Condit, R. S., And Chave, J. 2010. The relationship between wood density and mortality in a global tropical forest data set. The New phytologist 188:11241136.

Kumagai, T., Mudd, R. G., Giambelluca, T. W., Kobayashi, N., Miyazawa, Y., Lim, T. K., Liu, W., Huang, M., Fox, J. M., Ziegler, A. D., Yin, S., MaK, S. V., And Kasemsap, P. 2015. How do rubber ( hevea brasiliensis ) plantations behave under seasonal water stress in northeastern thailand and central cambodia? Agricultural and Forest Meteorology 213:10-22.

Laumonier, Y. The Vegetation and Physiography of Sumatra. Kluwer Academic Publishers, Dorderecht, The Netherlands.

Laurance, W. F., Useche, D. C., Rendeiro, J., Kalka, M., Bradshaw, C. J. A., Sloan, S. P., Laurance, S. G., Campbell, M., Abernethy, K., Alvarez, P., And et al. 2012. Averting biodiversity collapse in tropical forest protected areas. Nature 489:290-294.

Lens, F., Sperry, J. S., Christman, M. A., Choat, B., Rabaey, D., And Jansen, S. 2011. Testing hypotheses that link wood anatomy to cavitation resistance and hydraulic conductivity in the genus acer. The New phytologist 190:709-723.

Li, S., Klepsch, M., Jansen, S., Schmitt, M., Lens, F., KARimi, Z., Schuldt, B., Espino, S., AND SCHENK, H. J. 2016. Intervessel pit membrane thickness as a key determinant of embolism resistance in angiosperm xylem. IAWA Journal 37:152-171.

Liu, H., Gleason, S. M., HaO, G., Hua, L., He, P., Goldstein, G., and Ye, Q. 2019. Hydraulic traits are coordinated with maximum plant height at the global scale. Science Advances 5:eaav1332.

LiU, M., PAN, R., AND TyReE, M. T. 2018. Intra-specific relationship between vessel length and vessel diameter of four species with long-to-short species-average vessel lengths: further validation of the computation algorithm. Trees 32:51-60.

Lloyd-Hughes, B. 2014. The impracticality of a universal drought definition. Theoretical and Applied Climatology 117:607-611.

Lobo, A., Torres-Ruiz, J. M., Burlett, R., Lemaire, C., PArise, C., Francioni, C., Truffaut, L., TomášKovÁ, I., Hansen, J. K., KJÆR, E. D., Kremer, A., And Delzon, S. 2018. Assessing inter- and intraspecific variability of xylem vulnerability to embolism in oaks. Forest Ecology and Management 424:53-61.

LÓPez, R., CANO, F. J., ChOAT, B., COCHARD, H., AND GIL, L. 2016. Plasticity in vulnerability to cavitation of pinus canariensis occurs only at the driest end of an aridity gradient. Frontiers 
in plant science 7:1-10.

López, R., lópez de Heredia, U., Collada, C., CANO, F. J., Emerson, B. C., Cochard, H., AND GIL, L. 2013. Vulnerability to cavitation, hydraulic efficiency, growth and survival in an insular pine (pinus canariensis). Annals of botany 111:1167-1179.

LÜBBE, T., SCHULDT, B., AND LEUSCHNER, C. 2017. Acclimation of leaf water status and stem hydraulics to drought and tree neighbourhood: alternative strategies among the saplings of five temperate deciduous tree species. Tree physiology 37:456-468.

Maherali, H., Moura, C. E., Caldeira, M. C., Willson, C. J., And Jackson, R. B. 2006. Functional coordination between leaf gas exchange and vulnerability to xylem cavitation in temperate forest trees. Plant, cell E environment 29:571-583.

Maillard, G., DAniel, C., And OCHS, R. 1974. Analyse des effets de la sécheresse sur le palmier a huile. Oléagineux 8:397-404.

Margono, B. A., Potapov, P. V., Turubanova, S., Stolle, F., and Hansen, M. C. 2014. Primary forest cover loss in indonesia over 2000-2012. Nature Climate Change 4:730-735.

Marshall, J. D. And Monserud, R. A. 2003. Foliage height influences specific leaf area of three conifer species. Canadian Journal of Forest Research 33:164-170.

Martin-StPaul, N. K., Delzon, S., And Cochard, H. 2017. Plants resistance to drought relies on early stomata closure.

Martin-StPaul, N. K., Limousin, J.-M., Rodríguez-Calcerrada, J., Ruffault, J., RaMBAL, S., LetTS, M. G., AND Misson, L. 2012. Photosynthetic sensitivity to drought varies among populations of quercus ilex along a rainfall gradient. Functional Plant Biology 39:25.

Martínez-Vilalta, J., Cochard, H., Mencuccini, M., Sterck, F., Herrero, A., KorhoNen, J. F. J., Llorens, P., NikinmaA, E., Nolè, A., Poyatos, R., Ripullone, F., SassKlaAssen, U., AND ZWEIFEL, R. 2009. Hydraulic adjustment of scots pine across europe. The New phytologist 184:353-364.

MartíneZ-Vilalta, J. AND GARCIA-FornER, N. 2017. Water potential regulation, stomatal behaviour and hydraulic transport under drought: deconstructing the iso/anisohydric concept. Plant, cell E environment 40:962-976.

Martínez-Vilalta, J., Poyatos, R., Aguadé, D., Retana, J., And Mencuccini, M. 2014. A new look at water transport regulation in plants. The New phytologist 204:105-115.

MartíneZ-VilaltA, J., SAlA, A., AND Piñol, J. 2004. The hydraulic architecture of pinaceae a review. Plant Ecology 171:3-13. 
McCulloh, K. A., Johnson, D. M., Meinzer, F. C., And Woodruff, D. R. 2014. The dynamic pipeline: hydraulic capacitance and xylem hydraulic safety in four tall conifer species. Plant, cell \& environment 37:1171-1183.

McDowell, N., Barnard, H., Bond, B., Hinckley, T., Hubbard, R., Ishit, H., Köstner, B., Magnani, F., Marshall, J., Meinzer, F., Phillips, N., Ryan, M., And Whitehead, D. 2002. The relationship between tree height and leaf area: sapwood area ratio. Oecologia 132:12-20.

McDowell, N. G. AND Allen, C. D. 2015. Darcy's law predicts widespread forest mortality under climate warming. Nature Climate Change 5:669-672.

McDowell, N. G., Allen, C. D., Anderson-Teixeira, K., Brando, P., Brienen, R. J. W., Chambers, J. Q., Christoffersen, B. O., Davies, S., Doughty, C., Duque, A., EspiritoSAnto, F., Fisher, R. A., Fontes, C. G., Galbraith, D. R., Goodsman, D., Grossiord, C., Hartmann, H., Holm, J., Johnson, D. J., Kassim, A. R., Keller, M., Koven, C., Kueppers, L., Kumagai, T., Malhi, Y., McMahon, S. M., Mencuccini, M., Meir, P., Moorcroft, P. R., Muller-Landau, H. C., Phillips, O. L., Powell, T. L., Sierra, C. A., SPERrY, J. S., WARREN, J., XU, C., AND XU, X. 2018. Drivers and mechanisms of tree mortality in moist tropical forests. The New phytologist 219:851-869.

McDowell, N. G., Pockman, W. T., Allen, C. D., Breshears, D. D., Cobb, N., Kolb, T., Plaut, J., Sperry, J. S., West, A., Williams, D. G., And Yepez, E. A. 2008. Mechanisms of plant survival and mortality during drought: why do some plants survive while others succumb to drought? The New phytologist 178:719-739.

McElrone, A., Choat, B., Gambetta, G., AND Brodersen, C. 2013. Water uptake and transport in vascular plants. Nat. Educ. Knowl. 4.

Meinzer, F. C., Campanello, P. I., DomeC, J.-C., Gatti, M. G., Goldstein, G., Villalobos-Vega, R., AND WoOdRufF, D. R. 2008. Constraints on physiological function associated with branch architecture and wood density in tropical forest trees. Tree Physiology 28:1609-1617.

Meinzer, F. C., Johnson, D. M., Lachenbruch, B., McCulloh, K. A., AND WoodrufF, D. R. 2009. Xylem hydraulic safety margins in woody plants: coordination of stomatal control of xylem tension with hydraulic capacitance. Functional Ecology 23:922-930.

Meinzer, F. C., Lachenbruch, B., And Dawson, T. E. 2011. Size- and Age-Related Changes in Tree Structure and Function. Tree Physiology. Springer Netherlands, Dordrecht. 
Mencuccini, M. 2002. Hydraulic constraints in the functional scaling of trees. Tree Physiology 22:553-565.

MerCuRY, L. AND SHMUlOViCH, K. I. 2014. Experimental superheating and cavitation of water and solutions at spinodal-like negative pressures. In L. Mercury, N. Tas, and M. Zilberbrand (eds.), Transport and Reactivity of Solutions in Confined Hydrosystems, pp. 159-171, Dordrecht. Springer Netherlands.

Miettinen, J., ShI, C., AND LiEW, S. C. 2011. Deforestation rates in insular southeast asia between 2000 and 2010. Global Change Biology 17:2261-2270.

Milburn, J. A. AND Johnson, R. P. 1966. The conduction of sap. Planta 69:43-52.

Mitchell, P. J., O'Grady, A. P., Tissue, D. T., White, D. A., Ottenschlaeger, M. L., And PINKARD, E. A. 2013. Drought response strategies define the relative contributions of hydraulic dysfunction and carbohydrate depletion during tree mortality. The New phytologist 197:862-872.

Mueller, R. C., Scudder, C. M., Porter, M. E., Talbot Trotter, R., Gehring, C. A., And Whitham, T. G. 2005. Differential tree mortality in response to severe drought: evidence for long-term vegetation shifts. Journal of Ecology 93:1085-1093.

MYERS, N. 1988. Threatened biotas: hot spots in tropical forests. Environmentalist 8:187-208.

Nepstad, D. C., Tohver, I. M., Ray, D., Moutinho, P., And Cardinot, G. 2007. Mortality of large trees and lianas following experimental drought in an amazon forest. Ecology 88:22592269.

NoBeL, P. S. 1999. Physicochemical \& environmental plant physiology. Academic press.

Nock, C. A., Vogt, R. J., AND Beisner, B. E. 2001. Functional traits, pp. 1-8. In J. W. \&. S. Ltd (ed.), eLS, volume 111. John Wiley \& Sons, Ltd, Chichester, UK.

Nolf, M., Creek, D., Duursma, R., Holtum, J., Mayr, S., and Choat, B. 2015. Stem and leaf hydraulic properties are finely coordinated in three tropical rain forest tree species. Plant, cell \& environment 38:2652-2661.

Olson, M. E., Anfodillo, T., Rosell, J. A., Petit, G., Crivellaro, A., Isnard, S., LeónGómez, C., Alvarado-CÁrdenas, L. O., And Castorena, M. 2014. Universal hydraulics of the flowering plants: vessel diameter scales with stem length across angiosperm lineages, habits and climates. Ecology letters 17:988-997.

Olson, M. E., Soriano, D., Rosell, J. A., Anfodillo, T., Donoghue, M. J., Edwards, E. J., León-Gómez, C., Dawson, T. E., Camarero Martínez, J. J., Castorena, M., Echeverría, A., Espinosa, C. I., Fajardo, A., Gazol, A., Isnard, S., Lima, R. S., Marcati, 
C. R., AND MÉNDEZ-AlOnZO, R. 2018. Plant height and hydraulic vulnerability to drought and cold. Proceedings of the National Academy of Sciences of the United States of America 115:75517556.

PICKARD, W. F. 1981. The ascent of sap in plants. Progress in Biophysics and Molecular biology 37:181-229.

Pirker, J., Mosnier, A., Kraxner, F., Havlík, P., And Obersteiner, M. 2016. What are the limits to oil palm expansion? Global Environmental Change 40:73-81.

Pittermann, J., Choat, B., Jansen, S., Stuart, S. A., LynN, L., And Dawson, T. E. 2010. The relationships between xylem safety and hydraulic efficiency in the cupressaceae: the evolution of pit membrane form and function. Plant physiology 153:1919-1931.

Poorter, L., McDonald, I., Alarcón, A., Fichtler, E., Licona, J.-C., Peña-Claros, M., SterCK, F., VillegAs, Z., AND SASS-KLAASSEN, U. 2010. The importance of wood traits and hydraulic conductance for the performance and life history strategies of 42 rainforest tree species. New Phytologist 185:481-492.

Pratt, R. B., Jacobsen, A. L., Ewers, F. W., AND Davis, S. D. 2007. Relationships among xylem transport, biomechanics and storage in stems and roots of nine rhamnaceae species of the california chaparral. The New phytologist 174:787-798.

Prendin, A. L., Mayr, S., Beikircher, B., von Arx, G., And Petit, G. 2018. Xylem anatomical adjustments prioritize hydraulic efficiency over safety as norway spruce trees grow taller. Tree physiology 38:1088-1097.

PRIOR, L. D. AND BOWMAN, D. M. J. S. 2014. Big eucalypts grow more slowly in a warm climate: evidence of an interaction between tree size and temperature. Global change biology 20:2793-2799.

Richardson, A. D., Keenan, T. F., Migliavacca, M., Ryu, Y., Sonnentag, O., and ToOmeY, M. 2013. Climate change, phenology, and phenological control of vegetation feedbacks to the climate system. Agricultural and Forest Meteorology 169:156-173.

RocKWell, F. E., WHEeler, J. K., AND HOLBROOK, N. M. 2014. Cavitation and its discontents: opportunities for resolving current controversies. Plant physiology 164:1649-1660.

Rosas, T., Mencuccini, M., Barba, J., Cochard, H., Saura-Mas, S., and MartínezVILALTA, J. 2019. Adjustments and coordination of hydraulic, leaf and stem traits along a water availability gradient. The New phytologist 223:632-646. 
ROSNER, S. 2017. Wood density as a proxy for vulnerability to cavitation: Size matters. Journal of Plant Hydraulics 4:001.

Rowland, L., Da Costa, A. C. L., Galbraith, D. R., Oliveira, R. S., Binks, O. J., Oliveira, A. A. R., Pullen, A. M., Doughty, C., Metcalfe, D., Vasconcelos, S. S., Ferreira, L. V., Malhi, Y., Grace, J., Mencuccini, M., And Meir, P. 2015. Death from drought in tropical forests is triggered by hydraulics not carbon starvation. Nature 528:119-122.

Rungwattana, K., Kasemsap, P., Phumichai, T., Kanpanon, N., Rattanawong, R., And HIETZ, P. 2018. Trait evolution in tropical rubber ( hevea brasiliensis ) trees is related to dry season intensity. Functional Ecology 32:2638-2651.

RYAN, M. G. AND YODER, B. J. 1997. Hydraulic limits to tree height and tree growth: What keeps trees from growing beyond a certain height? BioScience 47:235-242.

Sack, L., Scoffoni, C., Johnson, D. M., Buckley, T. N., And Brodribb, T. J. 2015. The anatomical determinants of leaf hydraulic function, pp. 255-271. In U. Hacke (ed.), Functional and Ecological Xylem Anatomy. Springer International Publishing, Cham.

Santiago, L. S., de Guzman, M. E., Baraloto, C., Vogenberg, J. E., Brodie, M., Hérault, B., Fortunel, C., AND BONAL, D. 2018. Coordination and trade-offs among hydraulic safety, efficiency and drought avoidance traits in amazonian rainforest canopy tree species. The New phytologist 218:1015-1024.

Santiago, L. S., Goldstein, G., Meinzer, F. C., Fisher, J. B., Machado, K., Woodruff, D., AND JONES, T. 2004. Leaf photosynthetic traits scale with hydraulic conductivity and wood density in panamanian forest canopy trees. Oecologia 140:543-550.

SCHENK, H. J., STEPPE, K., AND JANSEN, S. 2015. Nanobubbles: a new paradigm for air-seeding in xylem. Trends in plant science 20:199-205.

Scholz, F. G., Bucci, S. J., Goldstein, G., Moreira, M. Z., Meinzer, F. C., Domec, J.C., Villalobos-Vega, R., Franco, A. C., And Miralles-Wilhelm, F. 2008. Biophysical and life-history determinants of hydraulic lift in neotropical savanna trees. Functional Ecology 22:773-786.

Schuldt, B., Knutzen, F., Delzon, S., Jansen, S., Müller-Haubold, H., Burlett, R., Clough, Y., AND LeusChner, C. 2016. How adaptable is the hydraulic system of european beech in the face of climate change-related precipitation reduction? The New phytologist 210:443458. 
Schuldt, B., Leuschner, C., Brock, N., And Horna, V. 2013. Changes in wood density, wood anatomy and hydraulic properties of the xylem along the root-to-shoot flow path in tropical rainforest trees. Tree physiology 33:161-174.

SKELTON, R. P., WeSt, A. G., AND DAWSON, T. E. 2015. Predicting plant vulnerability to drought in biodiverse regions using functional traits. Proceedings of the National Academy of Sciences of the United States of America 112:5744-5749.

Slik, J. W. F., Paoli, G., McGuire, K., Amaral, I., Barroso, J., Bastian, M., Blanc, L., Bongers, F., Boundja, P., Clark, C., Collins, M., Dauby, G., Ding, Y., Doucet, J.-L., Eler, E., Ferreira, L., Forshed, O., Fredriksson, G., Gillet, J.-F., Harris, D., Leal, M., Laumonier, Y., Malhi, Y., Mansor, A., Martin, E., Miyamoto, K., AraujoMurakami, A., Nagamasu, H., Nilus, R., Nurtjahya, E., Oliveira, Á., Onrizal, O., Parada-Gutierrez, A., Permana, A., Poorter, L., Poulsen, J., Ramirez-Angulo, H., Reitsma, J., Rovero, F., Rozak, A., Sheil, D., Silva-Espejo, J., Silveira, M., Spironelo, W., ter Steege, H., Stevart, T., Navarro-Aguilar, G. E., Sunderland, T., Suzuki, E., TAng, J., Theilade, I., VAn der Heijden, G., van Valkenburg, J., VAn Do, T., Vilanova, E., Vos, V., Wich, S., WÖll, H., YonedA, T., ZANG, R., ZHANG, M.-G., AND ZWEIfEL, N. 2013. Large trees drive forest aboveground biomass variation in moist lowland forests across the tropics. Global Ecology and Biogeography 22:1261-1271.

SPERRY, J. S. AND TYREE, M. T. 1988. Mechanism of water stress-induced xylem embolism. Plant Physiology 88:581.

STEUdLE, E. 2001. The cohesion-tension mechanism and the acquisition of water by plant roots. Annual Review of Plant Physiology and Plant Molecular Biology 52:847-875.

Stibig, H.-J., ACHARD, F., CARBOnI, S., RAŠI, R., AND Miettinen, J. 2014. Change in tropical forest cover of southeast asia from 1990 to 2010. Biogeosciences 11:247-258.

Stout, D. L. AND SALA, A. 2003. Xylem vulnerability to cavitation in pseudotsuga menziesii and pinus ponderosa from contrasting habitats. Tree physiology 23:43-50.

TARDIEU, F. AND DAvieS, W. J. 1993. Integration of hydraulic and chemical signalling in the control of stomatal conductance and water status of droughted plants. Plant, cell \& environment 16:341-349.

TARDieU, F. AND SimONnEAU, T. 1998. Variability among species of stomatal control under fluctuating soil water status and evaporative demand: modelling isohydric and anisohydric behaviours. Journal of experimental botany 49:419-432. 
TOFT, B. D., AlAM, M. M., AND TOPP, B. L. 2019. Anatomical structure associated with vegetative growth variation in macadamia. Plant and Soil 444:343-350.

Torres-Ruiz, J. M., Jansen, S., ChoAt, B., McElrone, A. J., Cochard, H., Brodribb, T. J., Badel, E., Burlett, R., Bouche, P. S., Brodersen, C. R., Li, S., Morris, H., ANd Delzon, S. 2015. Direct x-ray microtomography observation confirms the induction of embolism upon xylem cutting under tension. Plant physiology 167:40-43.

Trifilò, P., Casolo, V., Raimondo, F., Petrussa, E., Boscutti, F., Lo Gullo, M. A., And NARDINI, A. 2017. Effects of prolonged drought on stem non-structural carbohydrates content and post-drought hydraulic recovery in laurus nobilis l.: The possible link between carbon starvation and hydraulic failure. Plant physiology and biochemistry : PPB 120:232-241.

TYREE AND T, M. 2003. Hydraulic limits on tree performance: transpiration, carbon gain and growth of trees. Trees 17:95-100.

TYReE, M. T., Cochard, H., AND DAVIS, S. D. 1994. Biophysical perspectives of xylem evolution: is there a tradeoff of hydraulic efficiency for vulnerability to dysfunction? IAWA Journal 15:335-360.

Tyree, M. T., PatiÑo, S., AND Becker, P. 1998. Vulnerability to drought-induced embolism of bornean heath and dipterocarp trees. Tree Physiology 18:583-588.

Tyree, M. T. And ZimmermanN, M. H. 2002. Xylem Structure and the Ascent of Sap. Springer Series in Wood Science. Springer Berlin Heidelberg, Berlin, Heidelberg, second edition edition.

Urli, M., Porté, A. J., Cochard, H., Guengant, Y., Burlett, R., And Delzon, S. 2013. Xylem embolism threshold for catastrophic hydraulic failure in angiosperm trees. Tree physiology 33:672-683.

VAn Der LaAn-Luijkx, I. T., VAn Der Velde, I. R., Krol, M. C., Gatti, L. V., Domingues, L. G., Correia, C. S. C., Miller, J. B., Gloor, M., van Leeuwen, T. T., Kaiser, J. W., Wiedinmyer, C., Basu, S., Clerbaux, C., AND Peters, W. 2015. Response of the amazon carbon balance to the 2010 drought derived with carbontracker south america. Global Biogeochemical Cycles 29:1092-1108.

VAn Der Sleen, P., Groenendijk, P., Vlam, M., Anten, N. P. R., Boom, A., Bongers, F., Pons, T. L., Terburg, G., AND Zuidema, P. A. 2015. No growth stimulation of tropical trees by 150 years of co2 fertilization but water-use efficiency increased. Nature Geoscience 8:24-28.

Venturas, M. D., Sperry, J. S., And Hacke, U. G. 2017. Plant xylem hydraulics: What we understand, current research, and future challenges. Journal of integrative plant biology 59:356- 
389.

Vilagrosa, A., Chirino, E., Peguero-Pina, J. J., Barigah, T., Cochard, H., And Pelegrín, E. 2012. Plant responses to drought stress, pp. 63-109. In R. Aroca (ed.), Plant Responses to Drought Stress. Springer, Berlin and Heidelberg.

VOLAIRE, F. 2018. A unified framework of plant adaptive strategies to drought: Crossing scales and disciplines. Global change biology 24:2929-2938.

VON ARX, G., ARCHER, S. R., AND HUGHES, M. K. 2012. Long-term functional plasticity in plant hydraulic architecture in response to supplemental moisture. Annals of botany 109:1091-1100.

Wheeler, J. K., Huggett, B. A., Tofte, A. N., Rockwell, F. E., AND Holbrook, N. M. 2013. Cutting xylem under tension or supersaturated with gas can generate plc and the appearance of rapid recovery from embolism. Plant, cell \& environment 36:1938-1949.

Wheeler, J. K., Sperry, J. S., HACKe, U. G., AND HoAnG, N. 2005. Inter-vessel pitting and cavitation in woody rosaceae and other vesselled plants: a basis for a safety versus efficiency trade-off in xylem transport. Plant, cell \& environment 28:800-812.

WiLson, K. AND White, D. J. 1986. The anatomy of wood. Stobart Davies Ltd.

Woodruff, D. R., Bond, B. J., AND MeINZER, F. C. 2004. Does turgor limit growth in tall trees? Plant, cell \& environment 27:229-236.

Wright, I. J., WeStoby, M., AND Reich, P. B. 2002. Convergence towards higher leaf mass per area in dry and nutrient-poor habitats has different consequences for leaf life span. Journal of Ecology 90:534-543.

Wuebbles, D. J., Fahey, D. W., Hibbard, K. A., Dokken, D. J., Stewart, B. C., And MayCOCK, T. K. Climate science special report.

Zach, A., Schuldt, B., Brix, S., Horna, V., Culmsee, H., And Leuschner, C. 2010. Vessel diameter and xylem hydraulic conductivity increase with tree height in tropical rainforest trees in sulawesi, indonesia. Flora - Morphology, Distribution, Functional Ecology of Plants 205:506-512.

Zhu, S.-D., Chen, Y.-J., Ye, Q., He, P.-C., LiU, H., LI, R.-H., FU, P.-L., JiAnG, G.-F., AND CAO, K.-F. 2018. Leaf turgor loss point is correlated with drought tolerance and leaf carbon economics traits. Tree physiology 38:658-663.

Ziegler, C., Coste, S., Stahl, C., Delzon, S., Levionnois, S., Cazal, J., Cochard, H., Esquivel-Muelbert, A., Goret, J.-Y., Heuret, P., Jaouen, G., Santiago, L. S., And BONAL, D. 2019. Large hydraulic safety margins protect neotropical canopy rainforest tree species against hydraulic failure during drought. Annals of Forest Science 76:1285. 
ZiemińsKa, K., Butler, D. W., Gleason, S. M., Wright, I. J., And Westoby, M. 2013. Fibre wall and lumen fractions drive wood density variation across 24 australian angiosperms. $A o B$ PLANTS 5:25.

ZimmermanN, M. H. 1983. Xylem Structure and the Ascent of Sap. Springer Berlin Heidelberg, Berlin, Heidelberg. 



\section{Chapter 2}

Tall tropical trees are more vulnerable to drought-induced hydraulic failure than individuals from lower strata

Pierre-André WAITE, Christoph LEUSCHNER, Kira ZEMBOLD, Triadiati TRIADIATI, Asmadi SAAD, Bernhard SCHULDT 


\begin{abstract}
Heat-induced droughts are among the major causes of tree diebacks in the tropics, raising concerns for large trees. However, effects of tree structure and growth on xylem anatomy and hydraulic safety are not well understood. Here, we investigated the mutual interrelationships between tree height $(H)$, aboveground biomass increment (ABI), and ten structural and functional wood and leaf properties related to hydraulic safety and efficiency in 7-10 tropical tree species from lowland rainforests in Sumatra, Indonesia. The main objective was to determine the link between tree structure and drought resistance through easily accessible anatomy traits. Across trees, vessel diameter $(D)$ scaled with height both in stem $\left(r^{2}=0.50\right)$ and distal branch xylem $\left(r^{2}\right.$ $=0.15)$. Tall trees had a higher water potential at $50 \%$ loss of conductivity, $P_{50}\left(r^{2}=0.45\right)$. Lightwooded trees had wider vessels $\left(r^{2}=0.28\right)$ and higher $P_{50}\left(r^{2}=0.42\right)$ than dense-wooded trees. No relationship between $\mathrm{ABI}$ and $P_{50}$ was found but fast-growing trees had a higher leaf turgor loss point $\left(\pi_{\mathrm{tlp}}\right)$ compared to slow growing trees $\left(r^{2}=0.14\right)$. We confirm that tall and light-wooded trees are more vulnerable to drought-induced embolism but not fast-growing trees. Overall, $D$ associated to lumen-to-sapwood area ratio emerged as the most important anatomical traits related to drought-induced embolism, supporting the idea that embolism resistance is linked to the number of pits per vessels.
\end{abstract}

keywords: embolism resistance, hydraulic efficiency, Indonesia, leaf turgor loss point, trade-offs, tropical forest, vulnerability curves, wood anatomy. 


\section{Introduction}

Heat-induced drought periods are among the major causes of massive tree diebacks in multiple biomes (Allen et al. 2010, 2015, Choat et al. 2018). Moist tropics are especially vulnerable (IPCC 2014) and understanding drivers of tree mortality is currently one of the major challenges in plant ecology (Corlett et al. 2016). Studies show that large trees, like light-wooded and fastgrowing trees, are associated with high mortality (e.g. Wright et al. 2010, Bennett et al. 2015, Rowland et al. 2015, Anderegg et al. 2016). The anticipated increase in frequency and severity of El Niño-related drought spells in the tropics (IPCC 2014) have raised concerns for large trees given their importance for ecosystems function and services (Lindenmayer and Laurance, 2017).

Tree structure greatly affect water transport patterns (e.g. Koch et al. 2004, Anderegg and Meinzer 2015, Brienen et al. 2017, Eller et al. 2018) and therefore wood anatomy. Taller trees have larger vessel diameter in stem (Olson et al. 2014, 2018, Toft et al. 2019) but also in distal twigs (Zach et al. 2010, Schuldt et al. 2013, Liu et al. 2019) despite the commonly observed vessel widening from the apex towards the stem base (McCulloh et al. 2003, Anfodillo et al. 2006). Larger vessel diameter allows trees to directly increase sapwood-specific hydraulic efficiency (Couvreur et al. 2018, Liu et al. 2019) to mitigate negative effects of a higher path resistance. Vessel diameter is therefore directly linked to hydraulic efficiency through the law of Hagen-Poiseuille (Calkin et al. 1986) and, in numerous studies, is shown to be negatively related to drought-induced embolism formation (e.g. Hargrave et al. 1994, Hacke et al. 2010). This is the ground base for a theoretical trade-off between hydraulic efficiency and safety (Tyree et al. 1994). However, embolism formation is rather directly linked to pit membrane structure (Li et al. 2016) and only indirectly to vessel diameter (e.g. rare pit hypothesis; Christman et al. 2009, Lens et al. 2011), partially decoupling safety from efficiency.

Because tall trees tend to have wide vessels, they should be indirectly more prone to droughtinduced embolism. However, models show that branch xylem resistance may be increased to compensate negative effect of height (Couvreur et al. 2018). Accordingly, some studies observed an increase of branch embolism resistance with height in some of the tallest trees, e.g. in different Sequoia sempervirens and Sequoiadendron giganteum trees (Ambrose et al. 2009) and in branches sampled along a stem height gradient (Burgess et al. 2006). Other studies showed that larger trees tend to have a less negative water potential at $50 \%$ loss of hydraulic conductivity $\left(P_{50}\right.$; Rowland et al. 2015, Olson et al. 2018, Liu et al. 2019). Nevertheless, studies jointly investigating the interrelationships between tree height, vessel diameter at the stem base and additionally in distal 
twigs as well as embolism resistance in mature tropical trees are virtually lacking. However, Olson et al. $(2014,2018)$ support the idea that tall trees have large vessels both at stem base and distal twigs while being more vulnerable.

Wood density (WD) is also a good predictor of tree mortality (Chave et al. 2009, Kraft et al. 2010, Anderegg et al. 2016) as it provides information on general resistances to stresses. WD of angiosperms is related to plant vulnerability to drought with, e.g., dense-wooded species generally more resistant to drought-induced embolism formation (e.g. Bucci et al. 2013, Christoffersen et al. 2016, Eller et al. 2018). However, in angiosperms, WD does not directly affect water transport and is mostly driven by density of fibers rather than vessels lumen (Zieminska et al. 2013). Studies are often showing an absence of relationship between WD and vessel diameter for tropical tree species from the moist tropics (Schuldt et al. 2013, Zieminska et al. 2013) although such relation is observed in the seasonally dry tropics (e.g. Hoeber et al. 2014).

In addition to tree structure, tree growth rate is also often linked to mortality (e.g. Davies 2001, Wright et al. 2010), although the relationship is probably mediated by tree height and WD, one of the main drivers of growth rate variance (Wright et al. 2010). While a growing number of studies have related tree growth to vulnerability to drought in temperate species, a limited number of them focus on tropical trees (e.g. Fichot et al. 2010, Sterck et al. 2012, Eller et al. 2018, Schumann et al. 2019). One of the only recent examples is Eller et al. (2018) showing that fast growing tropical tree species tend to be more vulnerable to drought-induced hydraulic failure.

As trees grow in height, other (i.e. not directly related to xylem) traits associated with drought resistance might change, e.g. leaf mass to leaf area ratio (Woodruff et al. 2004, Meinzer et al. 2008) and leaf area to sapwood area ratio (Mcdowell et al. 2002, Calvo-Alvarado et al. 2008). Effects of height on leaf turgor loss point are also relatively unknown although it is a good predictor of plant vulnerability to drought (Bartlett et al. 2012a). Leaf turgor loss point is indeed interrelated with embolism resistance (e.g. Brodribb et al. 2003) since there is a relationship between the onset of embolism formation and stomatal closure, which depend of leaf turgor (Rodriguez-Dominguez et al. 2016).

Here, we investigated the mutual interrelationships between tree height, aboveground biomass increment, and ten structural and functional wood and leaf properties related to hydraulic safety and efficiency (see Table 2.1) in 7-10 tropical tree species from lowland rainforests in Sumatra, Indonesia. A main motivation was to test whether easily accessible stem wood traits in combination with tree height are suited to predict embolism resistance of sun-exposed upper canopy 
branches. We hypothesized that (i) the wood of tall trees is composed of large xylem vessels not only at the stem base but also in distal twigs compared to trees with smaller height at maturity, (ii) the branch xylem of tall trees is most vulnerable to drought-induced hydraulic failure due to the commonly observed relationship between vessel diameter and embolism resistance, (iii) wood density is unrelated to embolism resistance due to a weak or a missing relationship with vessel traits, but (iv) aboveground biomass increment as integrative measure of tree size and wood density is negatively related to branch embolism resistance.

Table 2.1: List of studied variables with abbreviations, units and definitions.

\begin{tabular}{|c|c|c|}
\hline Abbreviation & Unit & Definition \\
\hline \multicolumn{3}{|c|}{ Stand structural parameters } \\
\hline$H$ & $\mathrm{~m}$ & Tree height \\
\hline WD & $\mathrm{g} \mathrm{cm}^{-3}$ & Stem wood density \\
\hline \multicolumn{3}{|c|}{ Growth parameter } \\
\hline ABI & $\mathrm{kg} \mathrm{yr}^{-1}$ & Above ground biomass increment \\
\hline \multicolumn{3}{|c|}{ Hydraulic traits } \\
\hline$P_{50}$ & $\mathrm{MPa}$ & Xylem pressure at $50 \%$ loss of hydraulic conductance \\
\hline HSM & $\mathrm{MPa}$ & Hydraulic safety margin calculated as $\pi_{\text {tlp }}-P_{50}$ \\
\hline $\begin{array}{l}K_{\mathrm{p} \mathrm{stem}} \\
K_{\mathrm{p} \text { branch }}\end{array}$ & $\mathrm{kg} \mathrm{m}^{-1} \mathrm{MPa}^{-1} \mathrm{~s}^{-1}$ & Potential hydraulic conductivity \\
\hline \multicolumn{3}{|c|}{ Anatomical traits } \\
\hline $\begin{array}{l}D_{\text {stem }} \\
D_{\text {branch }}\end{array}$ & $\mathrm{m}$ & Vessel diameter \\
\hline $\begin{array}{l}\mathrm{VD}_{\text {stem }} \\
\text { VD }_{\text {branch }}\end{array}$ & $\mathrm{n} \mathrm{mm} \mathrm{m}^{-2}$ & Vessel density \\
\hline $\begin{array}{l}F_{\text {stem }} \\
F_{\text {branch }}\end{array}$ & $\%$ & Lumen-to-sapwood-area ratio \\
\hline \multicolumn{3}{|l|}{ Leaf traits } \\
\hline$\pi_{\mathrm{tlp}}$ & Mpa & Leaf turgor loss point \\
\hline SLA & $\mathrm{m}^{2} \mathrm{~kg}^{-1}$ & Specific leaf area \\
\hline $\mathrm{HV}$ & $\mathrm{m}^{2} \mathrm{~m}^{-2}$ & $\begin{array}{l}\text { Huber value; ratio between the branch sapwood area and supported } \\
\text { leaf area }\end{array}$ \\
\hline
\end{tabular}




\section{Materials and methods}

\section{Study location, design and plot characteristics}

We carried out the study in four $50 \times 50 \mathrm{~m}$ plots of a lowland rainforest, Harapan Rainforest, located in the province of Jambi, Sumatra (Indonesia; Drescher et al. 2016). Plots have elevations from 58 to $77 \mathrm{~m}$ a.s.l and have a dominant clay Acrisol soil (Allen et al. 2016). The site has a moist equatorial climate with a mean annual precipitation of $2,235 \mathrm{~mm}$, a mean annual temperature of $26.7^{\circ} \mathrm{C}$ (Drescher et al. 2016) and a dry season between May and September. All four plots are located in close proximity to each other (maximum distance: $3 \mathrm{~km}$ ) and, as of 2016, had 500 -692 stems with diameter at breast height $(\mathrm{DBH})>10 \mathrm{~cm}$ per hectare, trees with a mean DBH of $20-23 \mathrm{~cm}$ and a mean height of $18-21 \mathrm{~m}$ (Table A2.1). We measured and calculated tree structure, radial growth, xylem and leaf traits in 3-5 mature individuals for 7 (xylem embolism resistance) to 10 (all other traits) of the most abundant evergreen tree species at site ( $n=49$ trees, Table 2.2). We selected trees based on species abundance and availability in all four plots. Additionally, we dismissed species with only few healthy individuals or with an unreachable canopy. Species list is: Aporosa nervosa (Hook. F.), phyllanthaceae; Gymnacranthera bancana (Mic.), myristicaceae; Gynotroches axillaris (Blume), rhizophoraceae; Koompassia malaccensis (Benth.), Fabaceae; Neoscortechinia kingii (Pax and K. Hoffm.), Euphobiaceae; Porterandia anisophylla (Jack ex Roxb.), rubiaceae ; Pternandra caerulescens (Jack), melastomataceae; Santiria apiculata (Benn.), burseraceae; Shorea ovalis (Blume) and Shorea parvifolia (Dyer), dipterocarpaceae (Table 2.2)

\section{Sampling of plant material}

From March to September 2017, we sampled wood cores of c. $7 \mathrm{~cm}$ length in all 49 trees with an increment corer (Haglöf, Långsele, Sweden) at a stem height of $1.3 \mathrm{~m}$ for trees without buttresses or above buttresses $(2-4 \mathrm{~m})$ in K. malaccensis and in some individuals of S. apiculata and A. nervosa. In site, we stored the cores in humidified tubes and saved them for determination of wood density and stem anatomy. From October 2017 to March 2018, we collected 11-13 leafy branches per tree from uppermost sun-exposed canopy with a Big Shot throw-line launcher (SherrillTree Inc., Greensboro, NC, USA). Branches were used (1) to determine maximum vessel length (MVL) of each tree $(n=2-3$ branches per tree; Table A2.2) by injecting air with a syringe at low pressure $(0.10 \mathrm{MPa})$ into the cut and open xylem cross-section of the proximal branch end. The distal end was submerged in water and cut successively until bubbles, i.e. air from the syringe, became visible. We assumed that the remaining length of the branch roughly equalled MVL. (2) for xylem 
embolism resistance measurements $(n=5-6$ branches per tree, used also for branch anatomy analysis). In the field, we re-cut the branches proximal end under water to avoid artefacts from cutting under tension (Wheeler et al. 2013, Torres-Ruiz et al. 2015) and applied 1.7-fold species MVL to determine the branch section for conductance measurement. Labelled branches were then transferred into humidified black plastic bags with their proximal end in water-filled tubes. (3) for determination of leaf morphology (dry mass and area) and turgor loss point ( $n=4$ branches). All leaves distal to the four branch segments were collected and immediately stored in humidified bags for subsequent analyses. After harvest, all branch and leaf samples were transported to the University of Jambi (UNJA; transportation time of 2-3 h) and stored at $4^{\circ} \mathrm{C}$ until they were possessed.

\section{Stand height, wood density and biomass increment}

Tree height $(H)$ was measured with a Vertex III height meter in 2013 (Haglöf, Långsele, Sweden). Radial tree diameter growth was monitored every 3-6 months (with the exception of year 2015 where no monitoring was done) with dendrometer tapes (UMS, München, Germany) placed at 1.3 - $4.3 \mathrm{~m}$ stem height either from April 2013 or from September 2016 until June 2019 depending of the tree. We calculated annual diameter increment with the slope of regression line of diameter against time. We determined annual aboveground increment (ABI) with the generalized allometric model of Chave et al. (2014) and R package "BIOMASS" (Réjou-Méchain et al. 2017). We determined stem wood density $\left(\mathrm{WD}, \mathrm{g} \mathrm{cm}^{-3}\right)$, i.e. oven-dry mass over wet volume, for the 49 trees after removing the bark from the cores. We calculated the fresh volume of each core from the means of two length and ten diameter measurements with a digital calliper. Subsequently, we oven-dried the cores at $105^{\circ} \mathrm{C}$ for $72 \mathrm{~h}$. 


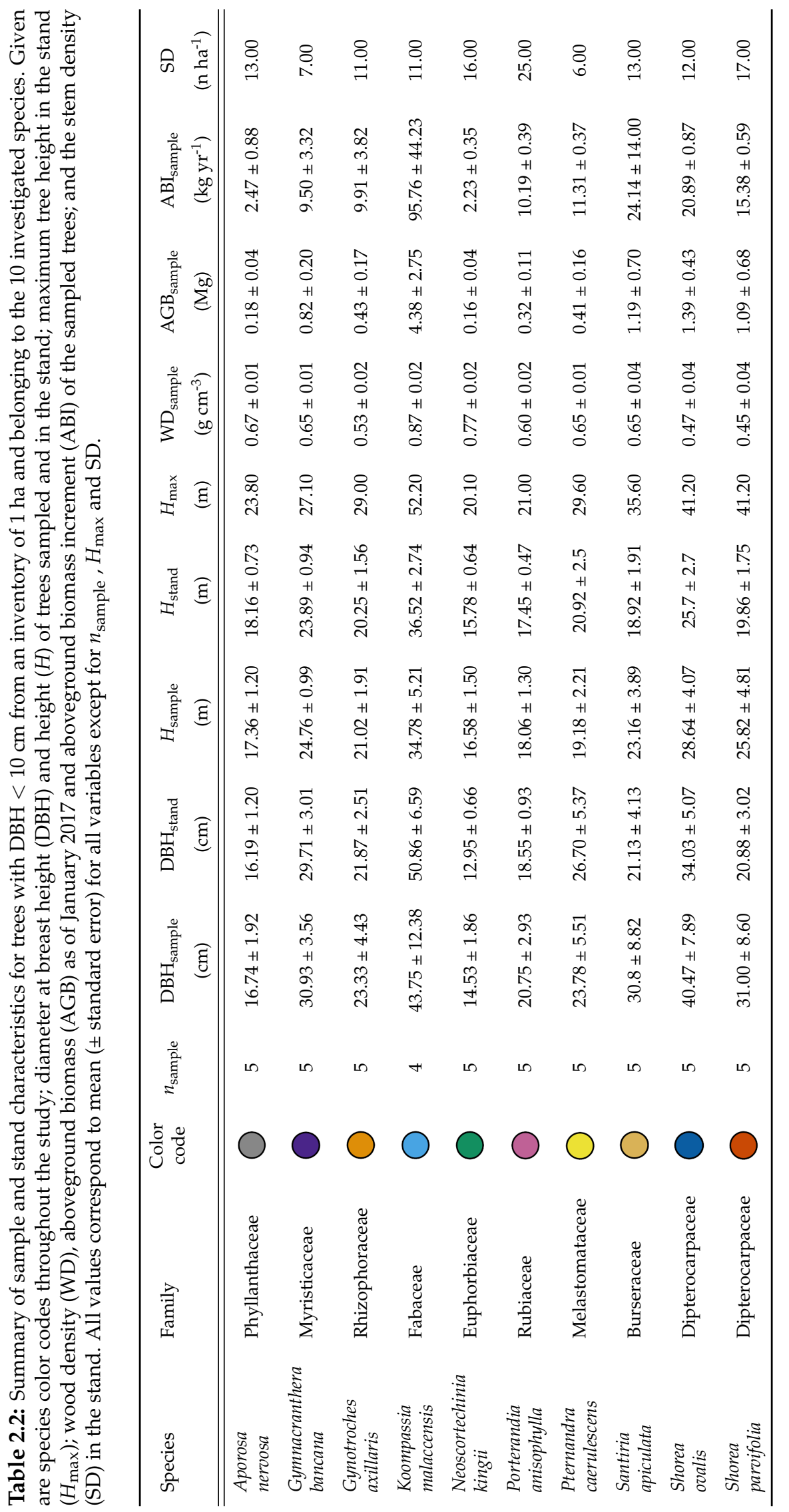




\section{Wood anatomy and potential conductivity}

Branch $(n=44)$ and stem $(n=48)$ transversal sections were cut with a sliding microtome (G.S.L.1; Schenkung Dapples, Zurich, Switzerland). The sections were dyed with Alcian blue and safranin, embedded in Euparal (Carl Roth, Karlsruhe, Germany) and digitalized at $\times 100$ magnification using a stereomicroscope equipped with a digital camera (SteREOV20; Carl Zeiss MicroImaging $\mathrm{GmbH}$, Göttingen, Germany). Image processing was done with Adobe Photoshop CC (Adobe Systems Inc., San Jose, CA, USA) and ImageJ using the particle analysis function. For every stem and branch sections, we calculated vessel density (VD; $\mathrm{n} \mathrm{mm}^{-2}$ ), lumen-to-sapwood area ratio $(F ; \%)$ and vessel diameter $(D ; \mu \mathrm{m})$ from major and minor vessel radii according to the equation of Lewis and Boose (1995). Potential conductivities $\left(K_{\mathrm{p}} ; \mathrm{kg} \mathrm{m}^{-1} \mathrm{MPa}^{-1} \mathrm{~s}^{-1}\right)$ in stem base and distal branches were calculated according to the Hagen-Poiseuille equation as:

$$
K_{p}=\left(\left(\left(\pi * \sum D^{4}\right) / 128 \eta\right) * \rho\right) /\left(A_{x y l e m}\right)
$$

where $A_{\text {xylem }}$ is the investigated xylem area $(\mathrm{m}), \eta$ is the viscosity $\left(1.00210^{-9} \mathrm{MPa} \mathrm{s}^{-1}\right)$ and $\rho$ the density of water $\left(998.2 \mathrm{~kg} \mathrm{~m}^{-3}\right)$, both at $20^{\circ} \mathrm{C}$.

\section{Leaf-based traits}

All leaves distal to the sampled branch segments ( $n=2$ per tree) were scanned to determine single and cumulative leaf areas (WinFolia 2005; Régent Instruments, Quebec, Canada). Per branch segment, five to 129 leaves were scanned, yielding 83 to 492 leaves per species (2,933 in total). Subsequently, we oven-dried the leaves at $70^{\circ} \mathrm{C}$ for $48 \mathrm{~h}$ and calculated specific leaf area $\left(\mathrm{SLA} ; \mathrm{m}^{2} \mathrm{~kg}^{-1}\right)$ as the ratio between cumulative leaf area and leaf dry mass per tree. We also calculated the Huber value as the ratio of proximal branch sapwood area and total distal leaf area ( $A_{\text {xylem }}: A_{\text {leaf }} ; 10^{-4} \mathrm{~m}^{2} \mathrm{~m}^{-2}$ ). On four leaves belonging to two distinct sampled twigs per tree, a vapour pressure osmometer (VAPRO 5600, Wescor, Logan, US) was used to measure leaf osmotic potential $\left(\pi_{\mathrm{osm}} ; \mathrm{MPa}\right)$, from which the turgor loss point $\left(\pi_{\mathrm{tlp}} ; \mathrm{MPa}\right)$ was determined (Bartlett et al. 2012b). We used fully hydrated leaves from branches covered with an opaque plastic bag, re-cut underwater and stored at $4^{\circ} \mathrm{C}$ with their proximal end remaining submerged until measurement completion. Minutes before the measurements, we stored two leaves per branch segment in humidified, air-blown and refrigerated plastic bags to avoid dehydration. For each leaf, one 8-mmdiameter disc was stamped out avoiding minor veins. Following the method described in Bartlett et al. (2012b), we wrapped each disc in an aluminium foil and submerged it into liquid nitrogen 
$\left(\mathrm{LN}_{2}\right)$ for 2 minutes. After the $\mathrm{LN}_{2}$ treatment, the disc was punctured with sharp pliers in order to facilitate evaporation and placed it in the osmometer chamber within $30 \mathrm{sec}$. The apparatus subsequently measured $\pi_{\mathrm{osm}}$ until the equilibrium was reached, i.e. two following values differ by less than ¡0.01 MPa. Subsequently, we calculated leaf $\pi_{\text {tlp }}$ according to Bartlett et al. (2012b) as:

$$
\pi_{t l p}=0.832 * \pi_{o s m}-0.631
$$

\section{Xylem embolism resistance}

We used the bench dehydration method (Sperry and Tyree 1988, Jansen et al. 2015) to establish xylem vulnerability curve for species and to (1) determine water potential at $50 \%$ loss of conductivity $\left(P_{50}\right)$ and (2) calculate the hydraulic safety margin (HSM) with the difference between $\pi_{\text {tlp }}$ and $P_{50}$ (Martin-StPaul et al. 2017, Berry et al. 2019) for each tree. Before starting branch drying, all branches ( $n=5-6$ per tree) were allowed to recover full turgor for at least one night and stored at $4^{\circ} \mathrm{C}$ with their proximal end submerged in water (storage duration of 1-3 days). Subsequently, each branch was exposed to a unique drying period ranging from 1 to $24 \mathrm{~h}$. Once the drying procedure was completed, two leaves distal to the segment for conductance measurement (c. $5 \mathrm{~mm}$ length, located at 1.7 MVL from proximal branch end) were used to determine the water potential with a pressure chamber (PMS Instruments, Corvallis, OR, USA). The leaves were covered with aluminium foils and placed in a black, moistened plastic bag for $1 \mathrm{~h}$. Subsequently, branches were recut several times under water to release the tension, and segments for conductance measurement carefully collected with a sharp razorblade (avoiding parenchyma shrinking) and connected to a xyl'em plus embolism meter apparatus (Bronkhorst, Montigny-lès-Cormeilles, France). We used a solution of deionized water to which $10 \mathrm{mM} \mathrm{KCl}$ and $1 \mathrm{mM} \mathrm{CaCl}_{2}$ in order to simulate the ion concentration of natural xylem sap. We degassed the solution for at least $6 \mathrm{~h}$ using a vacuum pump that created a vacuum of $10 \mathrm{kPa}$ (ME1 diaphragm pump; Vacuubrand GMBH + CO KG, Wertheim, Germany). The initial conductance value $\left(K_{\mathrm{i}}\right)$ that is obtained before flushing reflects the state of the xylem with emboli generated through the dehydration treatment. Emboli were then eliminated by flushing the segment with pressurized solution (c. $0.20 \mathrm{MPa}$ ) for $5 \mathrm{~min}$, and conductance was measured again to obtain $K_{1}$. We repeated the flushing and conductance measurement cycle until conductance reached a plateau $\left(K_{\max }\right)$ and remained fairly constant. 
Vulnerability curves per species were generated by plotting the leaflet water potential against the corresponding percent loss of conductivity $\left(\mathrm{PLC}_{\mathrm{i}}\right)$ according to equation (2.3):

$$
\mathrm{PLC}_{\mathbf{i}}=100 *\left(\left(1-K_{\mathrm{i}}\right) / K_{\max }\right)
$$

\section{Statistical analysis}

Statistical analyses were conducted with R version 3.6.0 (R Core Team 2019). All investigated variables are summarized in Table 2.1. Species-level vulnerability curves were described with the cumulative function of the Weibull distribution (Ogle et al. 2009) and first fit with the package "fitplc" (Duursma and Choat 2017) in order to extract $P_{50}$ and slope at $P_{50}\left(S_{50}\right)$ at species level (Fig. A2.1, Table A2.2). We could not fit all species with a reliable sigmoidal vulnerability curve and therefore three species from the initial 10 were dismissed for this trait. Subsequently, we determined tree-level $P_{50}$ with a Weibull distribution and fit it to the data with a non-linear model (M1 in Table A2.3). Individuals belonging from species already dismissed were not included. Moreover, for some trees, models did not converge, yielding a total of 28 tree-level $P_{50}$ in seven species. In addition, as our first aim is to study effects of embolism resistance on tree height, wood density and tree annual growth, we tested the effects of those 3 characteristics against $P_{50}$ and $S_{50}$ in 3 additional models (M2 to M4 in Table A2.3) using R package "nlme" (Pinheiro et al. 2018) to account for species and tree effects in parameter estimates. We used a nested study design and investigated 5 branch $i$ per tree $j$ and 3-5 trees per species $k$. we built equation (2.4) still based on the Weibull distribution (Ogle et al. 2009):

$$
\left.P L C_{i j k}=100 *\left(0.5^{\left(\frac{\psi_{i j k}}{P_{50 j k}}\right)}\right)^{\left(\frac{-P_{50 j k} * \text { slope }_{j k}}{50 * \ln (0.5)}\right)}\right)
$$

We also performed a multivariate non-linear regression to determine which anatomical traits $(F, V D$ or $D)$ in association with tree height best predicted the tree-level $P_{50}$ (Table A2.7). We additionally performed a Pearson's correlation table using the package "corrmorant" (https: //github.com/r-link/corrmorant/). This correlation matrix allows to visualize the density curve of each traits (diagonal panels in Fig. 2.1) as well as the sense (lower triangle) and strength (Pearson's $r$ in the upper triangle) of each relationship. For this matrix, we log-transformed some traits to reach normal distribution (Fig. 2.1). For display purpose and better understanding of the relationships, we used the tree-level $P_{50}$ predictions from each embolism resistance model (M1 to 
M4; Table A2.3) to build appropriate linear mixed effect models (e.g. $P_{50} \sim$ tree height; $R$ package "Ime4"; Bates et al. 2015) taking into account trees nested in species as random effects. In some cases, we applied weights to reach a better distribution of the residuals (details in Table A2.5) and Akaike information criterion (AIC). From these models we established the goodness-of-fit with a conditional pseudo- $r^{2}$ using package "g2lmm" and a standardized generalized variance approach (Jaeger et al. 2016). We also calculated the marginal pseudo-r2 using the approach of Nakagawa and Schielzeth (2013). In addition to the models including $P_{50}$, we used a similar linear mixed effect models' approach with determination of pseudo- $r^{2}$ to investigate (1) dependence of investigated traits with stem and branch vascular anatomy (Table A2.4); (2) effects of $H$, WD and ABI on

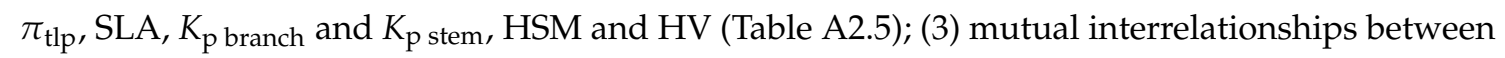
tree structure and growth traits (Table A2.5); (4) mutual interrelationships across functional traits (Table A2.6).

\section{Results}

\section{Embolism resistance of paleotropical tree species from Sumatra}

Vulnerability curves of seven lowland rainforest species (Fig. A2.1) showed a large range of xylem resistance to cavitation. Notably, the xylem pressure at $50 \%$ of loss of hydraulic conductance $\left(P_{50}\right)$ ranged from -1.79 (S. ovalis) to $-3.11 \mathrm{MPa}(N$. kingii) across species $(n=7$; Table A2.2) with a mean \pm SE $P_{50}$ of $\left.-2.32 \pm 0.57\right)$ MPa. In addition, the slope at $50 \%$ loss of conductivity, indicating the spreading rate of runaway embolism, also showed a large variability across species, ranging from $26.03 \%$ (P. caerulescens) to $66.36 \%$ (K. malaccensis; Table A2.2). At the tree level, $P_{50}$ $(n=28)$ ranged from -1.17 MPa in S. parvifolia to -3.37 MPa in N. kingii.

\section{Relations of tree height and wood density with stem and branch wood anatomy}

Across trees, stem and branch vessel diameter ( $D_{\text {stem }}$ and $D_{\text {branch }}$, respectively) were closely related $(r=0.58, P<0.001$; Fig. 2.1$)$ and were both positively associated with tree height $(H$; $r=0.61, P<0.001$ and $r=0.30, P=0.045$, respectively; Fig. 2.1). This was confirmed by our linear models accounting for species and trees as random effects (Fig. 2.2a, b, c; Table 2.3). The wood of tall trees also showed lower vessel densities in their stems at breast height $\left(\operatorname{VD}_{\text {stem }} r=\right.$ $-0.50, P<0.001)$ but not in branches from the uppermost sun-exposed canopy $\left(\mathrm{VD}_{\mathrm{branch}} ; r=-0.16\right.$, $P=0.29$; Fig. 2.1). According to the Pearson's table, these changes only slightly affected lumento-sapwood-area ratio (F; Fig. 2.1). However, when accounting for species identity and trees as random effects we found that tall trees had more lumen in the stem $\left(F_{\text {stem }} ; r^{2}=0.22, P=0.02\right.$; Table 
2.3) and in the branch $\left(F_{\text {branch }} ; r^{2}=0.12, P=0.09\right.$; Table 2.3$)$, although at a marginal significance.

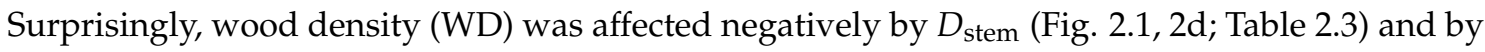
$F_{\text {stem }}$ (Fig. 2.1; Table 2.3), although for the latter at a marginal significance when accounting for species and trees (Table 2.3).

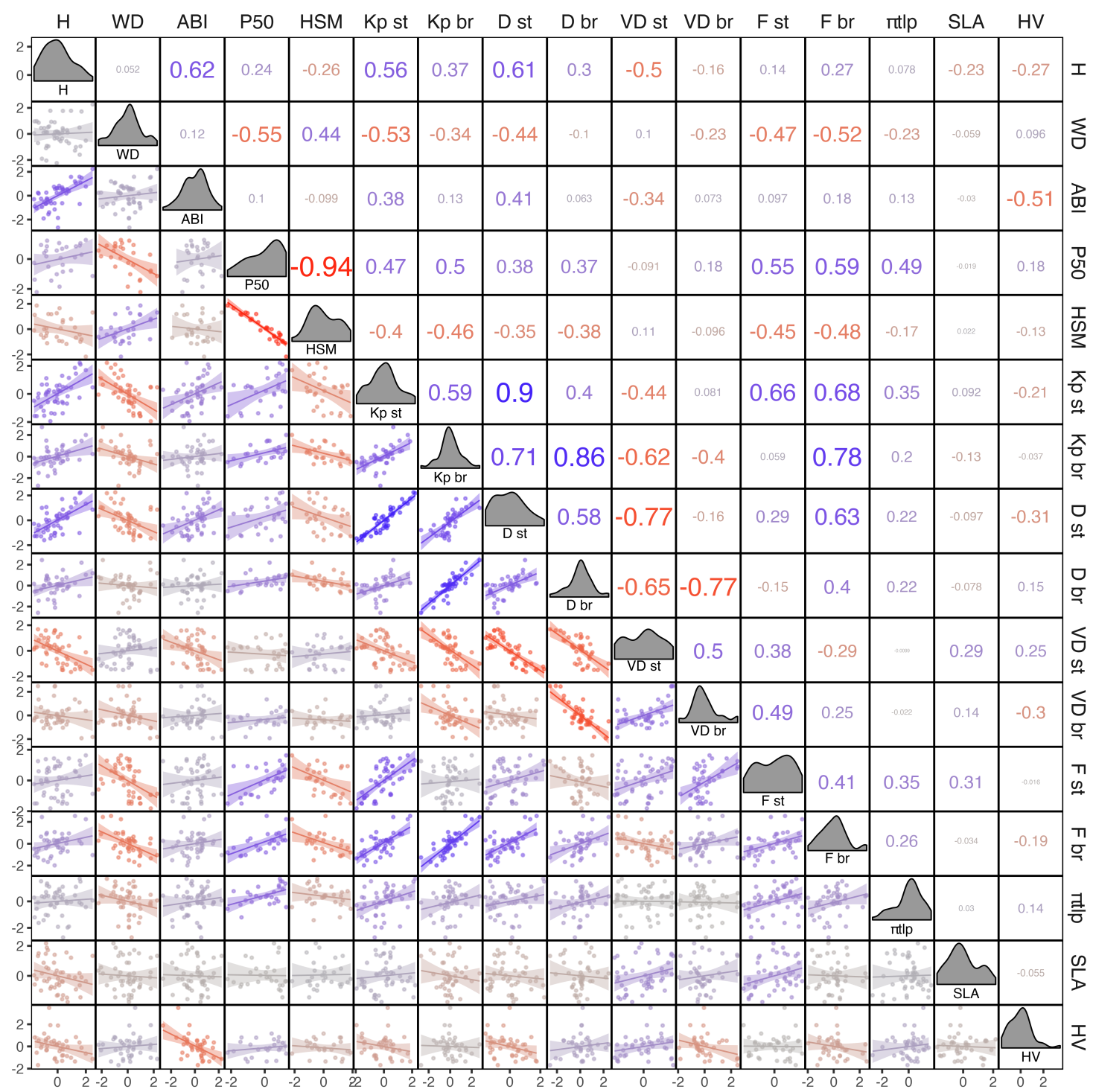

Fig. 2.1: Pearson's correlation matrix of key functional traits. Tree height $(H)$, aboveground biomass increment (ABI), stem and branch potential hydraulic conductivity $\left(K_{\mathrm{p} \text { stem }}\right.$ and $\left.K_{\mathrm{p} \text { branch }}\right)$, stem vessel diameter $\left(D_{\text {stem }}\right)$, stem and branch vessel density $\left(\mathrm{VD}_{\text {stem }}\right.$ and $\left.V D_{\text {branch }}\right)$, stem and branch lumen-to-sapwood-area ratio $\left(F_{\text {stem }}\right.$ and $\left.F_{\text {branch }}\right)$, specific leaf area (SLA) and Huber value (HV) were logarithm transformed to achieve a normal distribution. Upper triangle indicates correlation strength. Lower triangle shows repartition of data points and linear interrelationships, data have been scaled by standard deviation and centred around zero. Colors indicate coefficient of correlation gradient from -1 (blue) to 1 (red). Diagonal line shows density curves of each variables. Abbreviations and definitions are available in Table 2.1. 
Table 2.3: Relationships summary of structural and growth variables with key functional traits. Given are marginal pseudo $r^{2}$ (mar. $r^{2}$ ), conditional pseudo $r^{2}$ ) (cond. $r^{2}$ ) and the effect $P$ value from linear mixed effect models (Table A2.5). Relationships with $P<0.05$ are given in bold, marginal relationships with $P<0.10$ are given in bold and italic. For abbreviations and units see Table 1.

\begin{tabular}{|c|c|c|c|c|c|c|c|c|c|}
\hline \multirow{2}{*}{ Variable } & \multicolumn{3}{|c|}{$H$} & \multicolumn{3}{|c|}{ WD } & \multicolumn{3}{|c|}{$\mathrm{ABI}$} \\
\hline & $\begin{array}{c}\text { mar. } \\
r^{2}\end{array}$ & $\begin{array}{c}\text { cond. } \\
r^{2}\end{array}$ & $P$ & $\begin{array}{c}\text { mar. } \\
r^{2}\end{array}$ & $\begin{array}{c}\text { cond. } \\
r^{2}\end{array}$ & $P$ & $\begin{array}{c}\text { mar. } \\
r^{2}\end{array}$ & $\begin{array}{c}\text { cond. } \\
r^{2}\end{array}$ & $P$ \\
\hline$H$ & - & - & - & 0.07 & 0.12 & 0.16 & 0.48 & 0.60 & $<0.001$ \\
\hline WD & 0.07 & 0.10 & 0.06 & - & - & - & 0.01 & 0.07 & 0.11 \\
\hline $\mathrm{ABI}$ & 0.39 & 0.50 & $<0.001$ & 0.05 & 0.09 & 0.22 & - & - & - \\
\hline$P_{50}$ & 0.15 & 0.45 & 0.002 & 0.27 & 0.42 & 0.02 & 0.04 & 0.13 & 0.15 \\
\hline HSM & 0.06 & 0.12 & 0.20 & 0.15 & 0.25 & 0.06 & 0.01 & 0.01 & 0.70 \\
\hline$K_{\mathrm{p} \text { stem }}$ & 0.13 & 0.28 & 0.001 & 0.13 & 0.30 & 0.04 & 0.03 & 0.08 & 0.09 \\
\hline$K_{\mathrm{p} \text { branch }}$ & 0.05 & 0.11 & 0.08 & 0.11 & 0.23 & 0.07 & 0 & 0 & 0.77 \\
\hline$D_{\text {stem }}$ & 0.38 & 0.49 & $<0.001$ & 0.07 & 0.28 & 0.04 & 0.17 & 0.25 & 0.01 \\
\hline$D_{\text {branch }}$ & 0.11 & 0.16 & 0.05 & 0.06 & 0.25 & 0.04 & 0 & 0 & 0.98 \\
\hline $\mathrm{VD}_{\text {stem }}$ & 0.25 & 0.34 & $<0.001$ & 0.03 & 0.14 & 0.16 & 0.13 & 0.2 & 0.03 \\
\hline $\mathrm{VD}_{\text {branch }}$ & 0.01 & 0.02 & 0.55 & 0.02 & 0.08 & 0.35 & 0.03 & 0.05 & 0.34 \\
\hline$F_{\text {stem }}$ & 0.12 & 0.22 & 0.02 & 0.01 & 0.08 & 0.06 & 0 & 0 & 0.73 \\
\hline$F_{\text {branch }}$ & 0.08 & 0.12 & 0.09 & 0.06 & 0.21 & 0.03 & 0.03 & 0.04 & 0.32 \\
\hline$\pi_{\mathrm{tlp}}$ & 0.04 & 0.10 & 0.06 & 0.03 & 0.01 & 0.53 & 0.06 & 0.13 & 0.04 \\
\hline SLA & 0.11 & 0.22 & 0.01 & 0.02 & 0.04 & 0.46 & 0.1 & 0.23 & 0.003 \\
\hline $\mathrm{HV}$ & 0.02 & 0.03 & 0.35 & 0.02 & 0.04 & 0.42 & 0.22 & 0.30 & 0.003 \\
\hline
\end{tabular}

\section{Mutual inter-relationships between structural and functional wood and leaf traits}

We observed a close linear dependency of the water potential at $50 \%$ loss of hydraulic conductivity $\left(P_{50}\right)$ on both $H$ and $\mathrm{WD}\left(r^{2}=0.45, P=0.002\right.$ and $r^{2}=0.42, P=0.02$, respectively; Fig. 2.3a, b; Table 2.3). However, $H$ and WD were only poorly correlated across the 10 investigated tree species (Fig. 2.1), which was confirmed by our mixed-effect models (Table 2.3). Likewise, $P_{50}$ and leaf turgor loss point $\left(\pi_{\text {tlp }}\right)$ were both linearly related $\left(r=0.49, P=0.007\right.$; Fig. 2.1 and $r^{2}=0.30, P=$ 0.04; Fig. 2.5) but $\pi_{\text {tlp }}$ was only poorly related to $H$ (Fig. 2.3d; Table 2.3) and was not related to WD (Fig 2.3e; Table 2.3). Because of its high dependence to $P_{50}\left(r^{2}=0.93, P<0.001\right.$; Table A2.6), hydraulic safety margin (HSM) tended to be higher in dense-wooded trees $\left(r^{2}=0.25, P=0.06\right.$; Table 2.3) but not in tall trees (Table 2.3). Tall and light-wooded trees also showed higher potential conductivity in their stems $\left(k_{\mathrm{p} \text { stem }} r^{2}=0.27, P=0.001\right.$ and $r^{2}=0.30, P=0.04$, respectively; Table 
2.3) but only marginally in their branches $\left(k_{\mathrm{p} \text { branch }} r^{2}=0.11, P=0.08\right.$ and $r^{2}=0.23, P=0.07$, respectively; Table 2.3). In addition, tall trees had lower specific leaf area (SLA; $r^{2}=0.22, P=0.01$; Table 2.3) but not light-wooded trees (Table 2.3). $H$ and WD were not related to leaf-to-sapwood-area ratio (HV; Table 2.3).
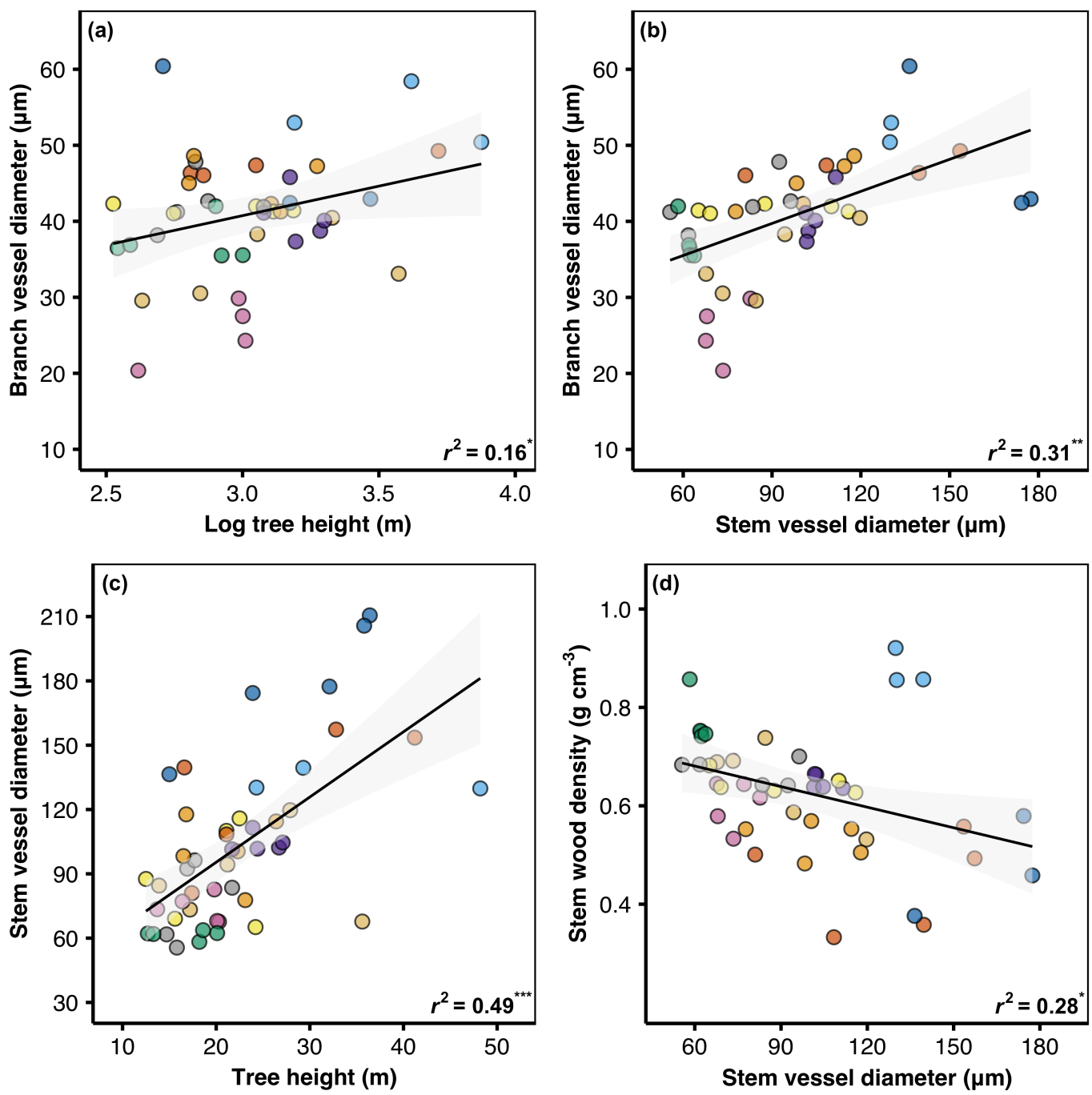

Fig. 2.2: Relationships of the average $(a, b)$ branch and (c) stem vessel diameter and (d) stem wood density with $(a, c)$ tree height, and average $(b, d)$ stem vessel diameter. Points represent trees and colors, species (color codes available in Table 2.2). Displayed as black lines are predictions from linear mixed models (LME; Table A2.4) with bootstrap confidence intervals in light grey. Conditional pseudo $r^{2}$ and level of significance of LME are indicated with ${ }^{*}$ as $P<0.05,{ }^{* *}$ as $P<$ 0.01 and $^{* * *}$ as $P<0.001$.

\section{Influence of the xylem vascular architecture on xylem safety}

According to the Pearson's correlation table and our linear mixed effect models, $D$ and $F$ emerged as major hydraulic traits linked to drought resistance (Fig. 2.1). $P_{50}$ was related to $D_{\text {stem }}$ 
and $D_{\text {branch }}\left(r^{2}=0.62, P<0.001\right.$ and $r^{2}=0.51, P=0.007$, respectively; Fig. 2.4a, b) and to $F_{\text {stem }}$ and $F_{\text {branch }}\left(r^{2}=0.56, P<0.001\right.$ and $r^{2}=0.33, P=0.009$, respectively; Fig. 2.4c, d). When accounting for height as a fixed effect, the relationships between $P_{50}$ and $D_{\text {stem }}, F_{\text {stem }}$ and $F_{\text {branch }}$ became nonsignificant indicating that $H$ was the main driver of $P_{50}$ variation $\left(D_{\text {stem }}: P=0.60, F_{\text {stem }}: P=0.85\right.$, $F_{\text {branch }}: P=0.17$; Table A2.7). However, $P_{50}$ remained significantly related to $D_{\text {branch }}$ even when including $H\left(D_{\text {branch }}: P=0.04\right.$; Table A2.7).
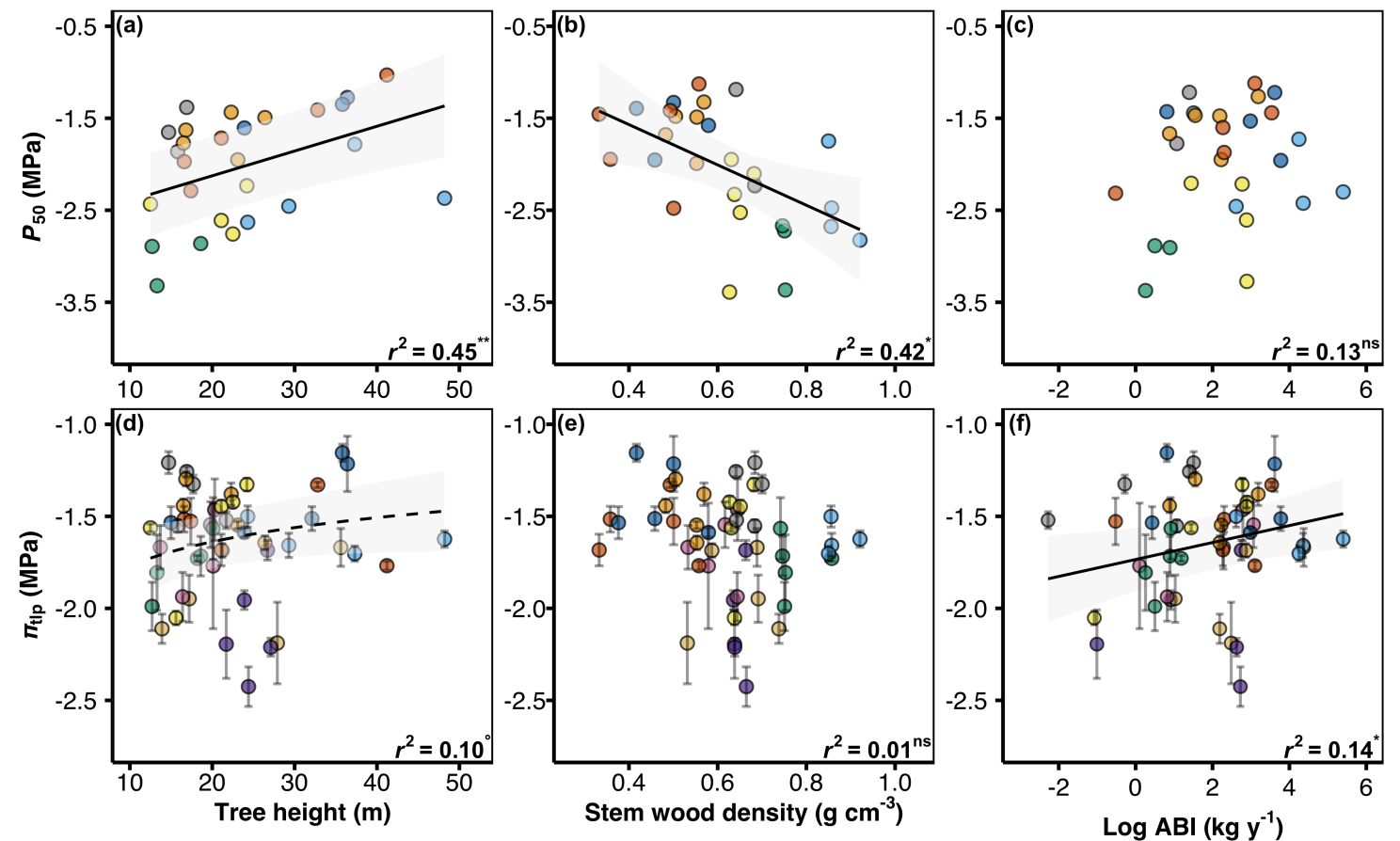

Fig. 2.3: Relationships of $(a, b, c)$ tree-level water potential at $50 \%$ loss of conductivity $\left(P_{50}\right)$ and $(d, e, f)$ leaf turgor loss point $\left(\pi_{\text {tlp }}\right)$ with $(a, d)$ tree height, $(b, e)$ stem wood density and $(c, f)$ logarithm of aboveground biomass increment. Points represent trees and colors, species (color codes available in Table 2.2). Error bars in (d, e, f) represent standard errors based on two measurements of $\pi_{50}$ per tree. Displayed as black lines are predictions from linear mixed models (LME; Table A2.5) with bootstrap confidence intervals in light grey. Conditional pseudo $r^{2}$ and level of significance of LME are indicated with ns as $P>0.10,{ }^{\circ}$ as $P<0.10,^{*}$ as $P<0.05$ and ${ }^{* *}$ as $P<$ 0.01 .

\section{Determinants of aboveground biomass increment and effects on functional wood and leaf traits}

Although aboveground biomass increment $(\mathrm{ABI})$ was related to $D_{\text {stem }}$ and $\mathrm{VD}_{\text {stem }}(r=0.41$, $P=0.004$ and $r=-0.34, P=0.02$, respectively; Fig. 2.1), which was confirmed by our linear models (Table 2.3), a major driver seems to be tree height itself $\left(r^{2}=0.60, P<0.001\right.$; Table 2.3). However, ABI was not related to $P_{50}$ (Fig. 2.3c; Table 2.3) nor HSM (Table 2.3), but affected $\pi_{\text {tlp }}\left(r^{2}=0.13, P=\right.$ 0.04 Fig. 2.3f; Table 2.3). This relationship with $\pi_{\text {tlp }}$ was probably mediated by leaf traits changes such as SLA with ABI $\left(r^{2}=0.23, P=0.003\right.$; Table 2.3) since $\pi_{\text {tlp }}$ was influenced by SLA $\left(r^{2}=0.19\right.$, 
$P=0.02$; Table A2.6) when accounted for species and tree effects. We also found that ABI was related to $k_{\mathrm{p} \text { stem }}\left(r^{2}=0.08, P=0.09\right.$; Table 2.3$)$ at a marginal significance but not to $k_{\mathrm{p} \text { branch }}$ (Table 2.3). We also found a close negative relationship between ABI and $\mathrm{HV}\left(r^{2}=0.30, P=0.003\right.$; Table 2.3).
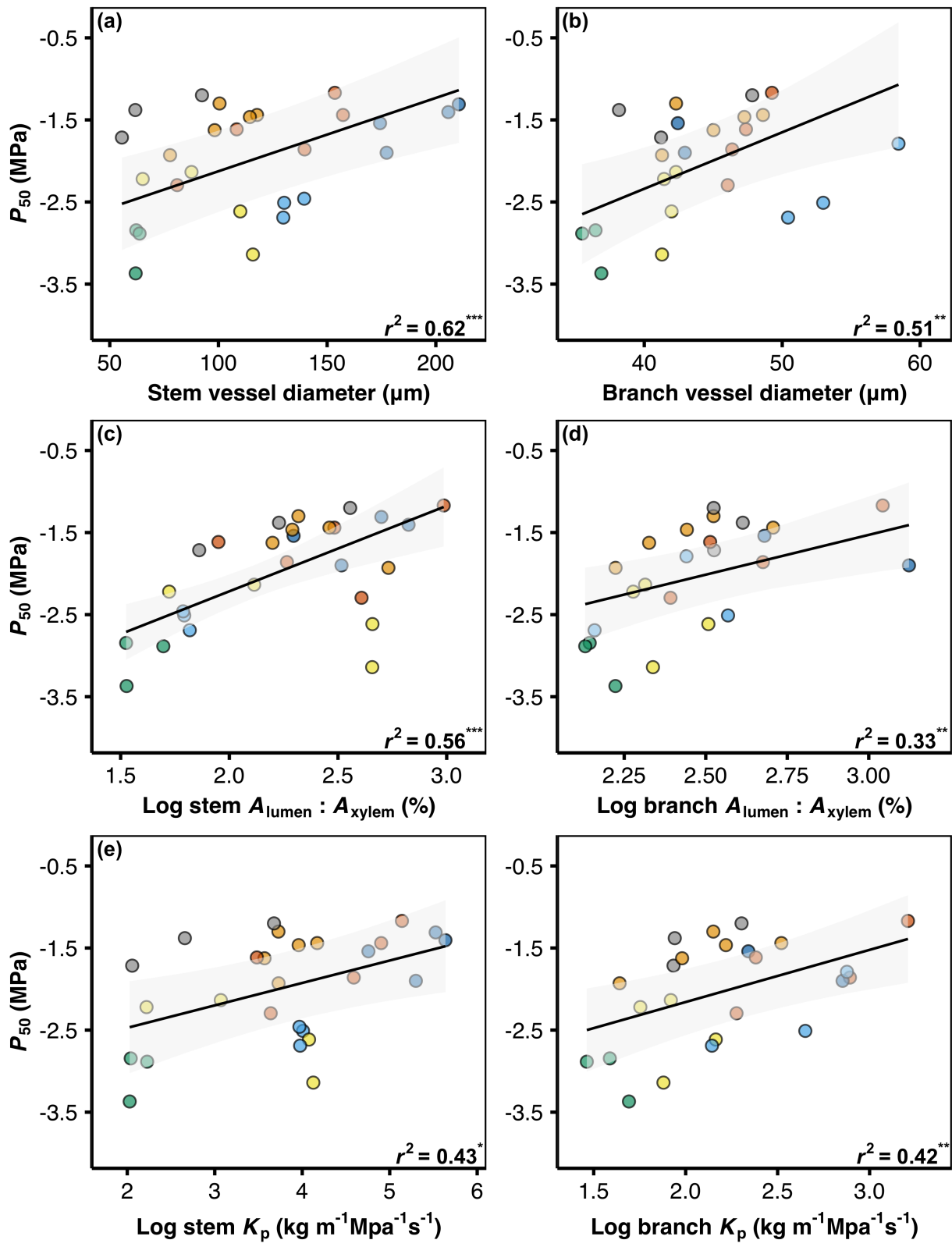

Fig. 2.4: Dependence of tree-level water potential at $50 \%$ loss of conductivity $\left(P_{50}\right)$ with average (a) stem and (b) branch vessel diameter, (c) stem and (d) branch logarithm of lumen-to-sapwood area ratio $\left(F ; A_{\text {lumen }}: A_{\text {sapwood }}\right)$, and (e) stem and (f) branch logarithm of potential hydraulic conductivity $\left(K_{\mathrm{p}}\right)$. Points represent trees and colors, species (color code available in Table 2.2). Displayed as black lines are predictions from linear mixed models (LME; Table A2.4) with bootstrap confidence intervals in light grey. Conditional pseudo $r^{2}$ and level of significance of LME are indicated with ${ }^{*}$ as $P<0.05,{ }^{* *}$ as $P<0.01$ and ${ }^{* * *}$ as $P<0.001$. 


\section{Relationships between potential hydraulic conductivity and wood and leaf traits}

we found a link between hydraulic efficiency and safety since both $k_{\mathrm{p} \text { stem }}$ and $k_{\mathrm{p} \text { branch }}$ where closely related to $P_{50}\left(r^{2}=0.43, P=0.01\right.$ and $r^{2}=0.42, P=0.006$, respectively; Fig. 2.4e, f, Table A2.6). In addition, $\pi_{\text {tlp }}$ was slightly influenced by $k_{\mathrm{p} \text { stem }}\left(r^{2}=0.14, P=0.09\right.$, Fig. 2.1$)$ but not by $k_{\mathrm{p} \text { branch }}$ (Fig. 2.1). Interestingly, $k_{\mathrm{p} \text { stem }}$ and $k_{\mathrm{p} \text { branch }}$ were both correlated to HSM $(r=-0.46, P<$ 0.05 and $r=-0.40, P<0.05$, respectively; Fig. 2.1) but not when accounting for species and tree effects (Table A2.6). $k_{\mathrm{p}}$ stem and $k_{\mathrm{p} \text { branch }}$ were not related to SLA nor to HV (Fig. 2.1; Table A2.6).

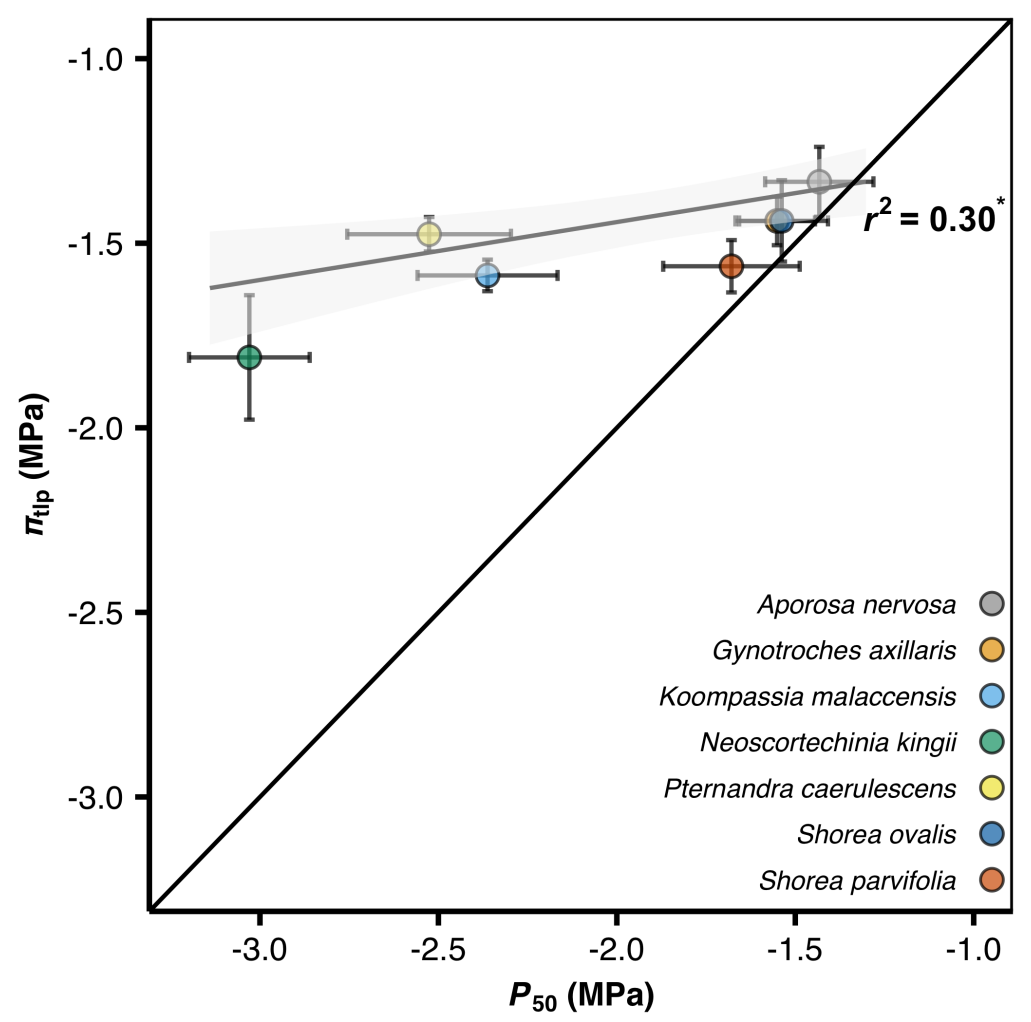

Fig. 2.5: Relationships of tree-level water potential at $50 \%$ loss of conductivity $\left(P_{50}\right)$ on leaf turgor loss point $\left(\pi_{\mathrm{tlp}}\right)$. Points and colours stand for species average. Error bars indicate standard error of $P_{50}$ and $\pi_{\text {tlp }}$, both predicted and measured at tree-level. Displayed as black lines are plot 1:1 line and predictions of linear mixed effect models (LME; Table A2.6) with bootstrap confidence intervals in light grey. Conditional pseudo $r^{2}$ and level of significance of LME are indicated next to the regression lines with * as $P<0.05$. 


\section{Discussion}

\section{Interspecific variability in xylem safety among South-Asian tropical rainforest tree species}

We measured species $P_{50}$ ranging from -1.71 to $-3.11 \mathrm{MPa}$ with a mean of $-2.32( \pm 0.57) \mathrm{MPa}$. This is lower than the average for tropical rainforest species (-1.76 MPa) but similar to that for tropical dry forest (-2.40 MPa; Choat et al. 2012). Our results are also similar to several previous reports, for example Barros et al. (2019: mean Brazilian low seasonality tropical rainforest $P_{50}=$ $-2.34 \mathrm{MPa}$ ); Oliveira et al. (2018: $P_{50}$ of valley species from Brazilian rainforest $=-2.33 \mathrm{MPa}$ ) and other studies (e.g. Santiago et al. 2018, Zhang et al. 2019). However, our reported values fall into the higher range of $P_{50}$ values of a recent study that investigated 25 Amazonian rainforest species ( $P_{50}$ ranging from -1.86 to $7.63 \mathrm{MPa}$ and averaging -3.93 MPa; Ziegler et al. 2019). This substantial variability across the different reports can be explained by species phylogeny as well as by differences in habitat and the seasonality of water availability. Another source of variability is the methodology employed to measure embolism resistance (Jansen et al. 2015). In our study, we are confident that our $P_{50}$ values for South Asian tropical rainforest species are robust given our use of the bench dehydration method, which is not considered prone to artefacts if applied correctly (e.g. avoiding induction of artificial embolism, Torres-Ruiz et al. 2015).

\section{The relationship of tree structure to vascular architecture}

All trees and species had larger vessels in their stem than in their branches, which is consistent with the almost universal pattern of basipetal vessel widening from the twigs to the stem (McCulloh et al. 2003, Anfodillo et al. 2006). This pattern allows the plant to compensate for the higher resistance associated with longer hydraulic path length and decreases the risk of xylem dysfunction (Ryan and Yoder 1997, West et al. 1999, Anfodillo et al. 2006, Sperry et al. 2012). We found that vessel widening was more important in tall trees, resulting in a well-known pattern of larger vessels in the stems of tall trees compared with shorter-statured trees (Fig. 2.1, 2a; Olson et al. 2014, Rosell et al. 2017). Most important here is that because vessel diameter consistently scaled along the hydraulic path of the investigated trees, tall trees also had wider vessels in their distal twigs. While large stem vessels in tall trees are commonly observed, few studies have confirmed a similar relationship with the vessel diameter of distal twigs (e.g. Zach et al. 2010, Olson et al. 2014, 2018). Consideration of the scaling of twig vessel diameter $\left(D_{\text {branch }}\right)$ with height $(H)$ in assessing vulnerability to drought is highly important but is often overlooked by studies investigating the matter (Olson et al. 2018). Our results confirm that regardless of basipetal vessel 
widening, $D_{\text {branch }}$ also increases with $H$ which may result in higher hydraulic efficiency but also in higher risk of hydraulic failure. This risk is reinforced by the fact that, even with lower vessel densities, tall trees in our study presented higher lumen-to-sapwood-area ratios in their stems $\left(F_{\text {stem }}\right)$ and, to a lesser extent, in their branches $\left(F_{\text {branch }}\right)$.

Despite being weakly related to height, wood density (WD) was influenced negatively by $D_{\text {stem }}$ and slightly by $F_{\text {stem. }}$. This partly refutes our fourth hypothesis since WD is generally decoupled from vessel diameter in tropics (Schuldt et al. 2013, Ziemińska et al. 2013). Such dependence of wood density on vascular properties is usually found in trees growing in seasonally dry tropical forests (Roque and Filho 2007, McCulloh et al. 2012).

\section{Effects of tree structure on hydraulic safety}

We found that $P_{50}$, increased significantly with $H$, i.e. the branch xylem of tall tropical trees was more vulnerable to drought-induced hydraulic failure than that of smaller trees. Our results are in line with a growing body of studies, which have also observed a significant relationship between tree height and embolism resistance, both within and across species (Rowland et al. 2015, Olson et al. 2018, Liu et al. 2019). However, although the number of studies analysing vertical trends in embolism resistance is limited, contradictory results exist. Because a longer hydraulic path is associated with higher tension inside the xylem (e.g. due to higher resistance, gravitational forces and evaporative demand; Koch et al. 2004, McDowell and Allen 2015), it has been conjectured that hydraulic safety traits would follow a similar vertical gradient to ensure the integrity of the hydraulic system (Burgess et al. 2006). Increasing safety with height has been demonstrated in giant sequoia (Sequoiadendron giganteum) and coast redwood (Sequoia sempervirens) (Burgess et al. 2006, Ambrose et al. 2009) as well as in the branches of Douglas fir (Pseudotsuga menziesii) and ponderosa pine (Pinus ponderosa) (Domec et al. 2008, 2009). This would be an adaptive response directed at decreasing the risk of embolism due to high xylem tension but would also decrease the efficiency of water transport. On the other hand, because a longer hydraulic path increases flow resistance, it seems that plants may also compensate for the loss of hydraulic conductivity with vertical trends in traits that improve hydraulic efficiency (e.g. the common vessel widening pattern) rather than hydraulic safety (Prendin et al. 2018). Although trade-offs between hydraulic efficiency and safety traits are generally weak, height-related constraints may strengthen the conflict between maximizing water supply to tree-top leaves and limiting the spread of runaway embolism (Domec et al. 2009).

In addition, $P_{50}$ and, as a result, hydraulic vulnerability (-HSM), was negatively and strongly 
driven by wood density. Such a relationship has already been observed in several studies (e.g. Hacke et al. 2010, Bucci et al. 2013, Christoffersen et al. 2016, Eller et al. 2018), although WD is mainly decoupled from hydraulic process in trees (Ziemińska et al. 2013, 2015, Schuldt et al. 2013 Lachenbruch and McCulloh 2014, Kotowska et al. 2015, Rosner 2017).

In contrast to $P_{50}$, the leaf turgor loss point $\left(\pi_{\text {tlp }}\right)$ was not related to WD and only weakly related to $H$ when accounting for leaf size variation in the model. We initially supposed that since the hydraulic constraints in tall trees result in low cell turgor and large leaf mass per area (LMA; e.g. Woodruff et al. 2004, Meinzer et al. 2008), the leaves of tall trees would lose their turgor at a lower water potential than those of smaller trees. It appears however that this trait is poorly adjusted by tall trees, which even tend to have sun-exposed leaves that are more vulnerable to drought. This seems to confirm that tall trees may be less able to tolerate prolonged drought exposure since plants with high $\pi_{\text {tlp }}$ tend to decrease stomatal conductance, photosynthetic gas exchange and growth rate at lower soil water potential (Sack et al. 2003, Otieno et al. 2006, Baltzer et al. 2008, Mitchell et al. 2008, Blackman et al. 2010, Barlett et al. 2012a).

\section{Effects of vascular anatomy on xylem safety and the link with tree structure}

In the investigated trees, $P_{50}$ was closely related to $D$ and $F$ in both stem and branch. However, in the stem these relationships were occurring through height-driven vascular adjustments. $H$ was indeed the main driver of $P_{50}$ differences in multi-variate models accounting for stem anatomy and $H$. These confounding relationships with height explain why branch $P_{50}$ was more closely related to stem anatomy than to branch anatomy. Indeed, although $D_{\text {branch }}$ was related

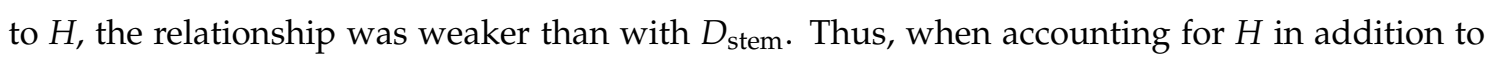
$D_{\text {branch }}$ in a multi-variate model, $D_{\text {branch }}$ and not $H$, was the main trait influencing $P_{50}$.

In general, we propose that the relationships of $H$ and WD with hydraulic safety $\left(P_{50}, \mathrm{HSM}\right)$ and efficiency $\left(K_{\mathrm{p}}\right)$ exist mainly through co-occurring changes of xylem anatomy. At the stem level, increasing $H$ strongly affects $D_{\text {stem }}$. This increase $F_{\text {stem }}$ despite lower vessel densities $\left(\mathrm{VD}_{\text {stem }}\right)$ and thus (indirectly) negatively affects branch embolism resistance and positively (directly) hydraulic efficiency. $D_{\text {branch }}$ also affects xylem safety but probably not principally through $H$ effects and may depend more on other factors such as species identity. Decoupled from $H$, increasing stem WD, associated with a probable increase in branch WD (i.e. WD does not vary greatly between different organs in tropical trees; Schuldt et al. 2013), leads to a decrease in stem and branch $D$ and $F$, which also decreases embolism resistance and increases efficiency.

The relationship between $D$ and drought-induced embolism resistance is indirect since air- 
seeding in a vessel and the ensuing cavitation depend mainly on the structure of the inter-vessel pit membrane (Li et al. 2016). According to the 'rare pit' (Wheeler et al. 2005, Pittermann et al. 2010) or 'pit area' (Hacke et al. 2006) hypothesis, the higher the number of pits per vessel, the more likely air will seed inside. Larger vessels have more inter-vessel connections (i.e. vessel diameter tends to scale along with length; e.g. Hacke et al. 2006; Liu et al. 2018; Jacobsen et al. 2019) and therefore can be indirectly more prone to cavitation. The fact that in our study not only $D$ but also $F$ were closely related to embolism resistance tends to support the view that embolism resistance is largely influenced by the number and total area of inter-vessel pits. Although we cannot exclude a species identity effect, the present relationships of $D$ and $F$ with hydraulic and structural traits in rainforest trees are highly promising for a better understanding of tree vulnerability to drought in the humid tropics.

\section{Effects of aboveground biomass increment on hydraulic safety}

The best predictor of tree aboveground biomass increment (ABI) was not WD but $H$. Consequently, we found similar but weaker or even absent relationships between ABI and xylem traits in comparison to those with $H$. A major difference was that fast-growing trees were not more vulnerable to drought-induced embolism than slow-growing trees. In general, significant relationships were mainly concentrated at the stem level. $D_{\text {branch }}$ and $K_{\mathrm{p} \text { branch }}$ were not higher in fast growing trees, probably as a consequence of basipetal vessel widening and weaker relationships between those traits and $H$. A similar conclusion can be reached for specific leaf area (SLA) which decreases with $\mathrm{ABI}$, probably because fast-growing trees are generally tall. In addition, we did not find that fast-growing species had a lower safety margin than slower growing trees, unlike in Eller et al. (2018). Nonetheless, our findings still partially confirm those of Eller et al. (2018) since we found that fast growing trees had a less negative turgor loss point, indicating a probable decrease in leaf function during prolonged drought events (Bartlett et al. 2012a). This was associated with a lower Huber value, i.e. sapwood-to-leaf-area ratio, which points to more efficient water transport. These results therefore fit within a previously described continuum ranging from hydraulic safety - i.e. a higher survival rate - to growth efficiency (Wright et al. 2010, Eller et al. 2018).

\section{Mutual interrelationships between hydraulic traits}

We found that $\pi_{\text {tlp }}$ varied positively with $P_{50}$ (e.g. Christoffersen et al. 2016) and in most trees occurred at higher water potentials than those leading to major hydraulic failure. This shows hydraulic coordination (e.g. Nolf et al. 2015, Ziegler et al. 2019) in the investigated trees and 
tends to validate our measurements of both embolism resistance and turgor loss point since $\pi_{\text {tlp }}$ is generally well related to stomatal closure (Brodribb et al. 2003, Bartlett et al. 2016). Stomatal closure and $\pi_{\mathrm{tlp}}$ should precede the spread of runaway emboli in branch and stem (Nolf et al. 2015, Martin-StPaul et al. 2017), although $\pi_{\text {tlp }}$ and $P_{50}$ are not necessarily interrelated linearly (Mencuccini et al. 2015, Martin-StPaul et al. 2017, Ziegler et al. 2019). In the present study, the interdependence of $\pi_{\mathrm{tlp}}$ and $P_{50}$ may indicate that stomatal closure occurs at water potential maximising carbon intake in accordance with individual resistance to drought-induced emboli, which can lead to lower safety margins for some trees.

We additionally found that $P_{50}$ decreased significantly with increasing $K_{\mathrm{p} \text { branch }}$ and $K_{\mathrm{p} \text { stem. }}$. This result tends to confirm a trade-off between hydraulic safety and efficiency, although such a trade-off may be weak (Gleason et al. 2016). However, because the studied species had long vessels, we did not measure empirical hydraulic conductivity (i.e. to avoid open vessels; Cochard et al. 2010, Torres-Ruiz et al. 2014), which may yield different results.

\section{Conclusion}

In this study on mature angiosperm tropical rainforest trees, we found that (1) vessel diameter scaled with height both in the stem wood at breast height and in branches from the uppermost sun-exposed canopy, while (2) the branch xylem of tall trees was most vulnerable to droughtinduced embolism formation. (3) Light-wooded trees were not the tallest, but they had wider vessels and more lumen area than dense-wooded trees, leading to (4) higher vulnerability to embolism. (5) Fast growing trees were generally the tallest, but they were not more vulnerable to embolism. They were however more efficient, as is indicated by a lower Huber value, while having leaves that lose their turgor at higher water potential compared to slow growing trees. (6) Because $D$ and $F$ were well related to embolism resistance, it seems striking to us that these easily accessible wood traits can give reliable insights into the degree of vulnerability to heat-induced drought periods of forest trees growing in the wet tropics. Because stem vascular changes and embolism resistance were driven mainly by tree height, size also emerged as one of the main drivers of variability in embolism resistance. Mechanistically, however, it is the associated vascular changes that make tall trees more prone to hydraulic failure. Additionally, branch vessel diameter was related to embolism resistance independently of tree height and therefore seems to constitute a reliable wood trait to approximate plant vulnerability to drought without tree height. To conclude, in addition to providing knowledge on the drought vulnerability of Southeast Asian rainforest trees, 
our results are promising for integrating stem vessel diameter and lumen-to-sapwood area ratio associated with tree height or branch vessel diameter alone as major traits connected to hydraulic safety. Overall, these wood anatomy characteristics constitute the basis for reliable assessment of the resistance to drought of rainforest trees.

\section{Acknowledgments}

This study is part of the Collaborative Research Centre CRC990 - EFForTS (Ecological and Socioeconomic Functions of Tropical Lowland Rainforest Transformation Systems) conducted by the University of Göttingen, Germany, Bogor Agricultural University, the University of Jambi and Tadulako University of Palu, Indonesia. We thank the University of Jambi and all our counterparts for providing space to conduct laboratory work, the staff in the offices of Jambi and Bogor universities for their logistic and administrative help, PT Restorasi Ekosystem Indonesia (PT REKI) for allowing us to sample in the Hutan Harapan, Syahbarudin and Kairul Anwar for their assistance during field sampling and laboratory measurements, Vira Addriyati Achmad and Pratiwi Hamson for their anatomical slides, Roman M. Link for his help regarding statistical questions. 


\section{Appendix}

Table A2.1: Coordinates and elevations ( $\mathrm{m}$ above sea level), and stem diameter at breath height $(\mathrm{DBH})$, height $(H)$ and stem density $(\mathrm{SD})$ of trees in each plots. Given are mean $\pm \mathrm{SE}$ of $\mathrm{DBH}$ and $H$ of trees with $\mathrm{DBH}>10 \mathrm{~cm}$

\begin{tabular}{|c|c|c|c|c|c|c|}
\hline Plot & Coordinates S & Coordinates E & $\begin{array}{l}\text { Elevation } \\
\text { (m a.s.l) }\end{array}$ & $\begin{array}{l}\text { DBH } \\
(\mathrm{cm})\end{array}$ & $\begin{array}{l}H \\
(\mathrm{~m})\end{array}$ & $\begin{array}{c}\mathrm{SD} \\
\left(\mathrm{n} \mathrm{ha}^{-1}\right)\end{array}$ \\
\hline HF1 & & Е $103^{\circ} 36^{\prime} 20.0^{\prime \prime}$ & 76.00 & $22.00 \pm 1.06$ & $19.70 \pm 0.56$ & 500.00 \\
\hline HF2 & $\mathrm{S} 02^{\circ} 16^{\prime}$ & E 10 & 75.00 & 33 & 18.40 & 692.00 \\
\hline HF3 & $\mathrm{S} 02^{\circ} 17^{\prime} 83$ & E $103^{\circ}$ & 58 & $22.70=$ & $21.10 \pm 0.58$ & 588.00 \\
\hline HF4 & S $02^{\circ} 18^{\prime} 75.6^{\prime \prime}$ & E $103^{\circ} 34^{\prime} 26.1^{\prime \prime}$ & 77.00 & $22.80 \pm 1.11$ & $21.00 \pm 0.58$ & 572.00 \\
\hline
\end{tabular}




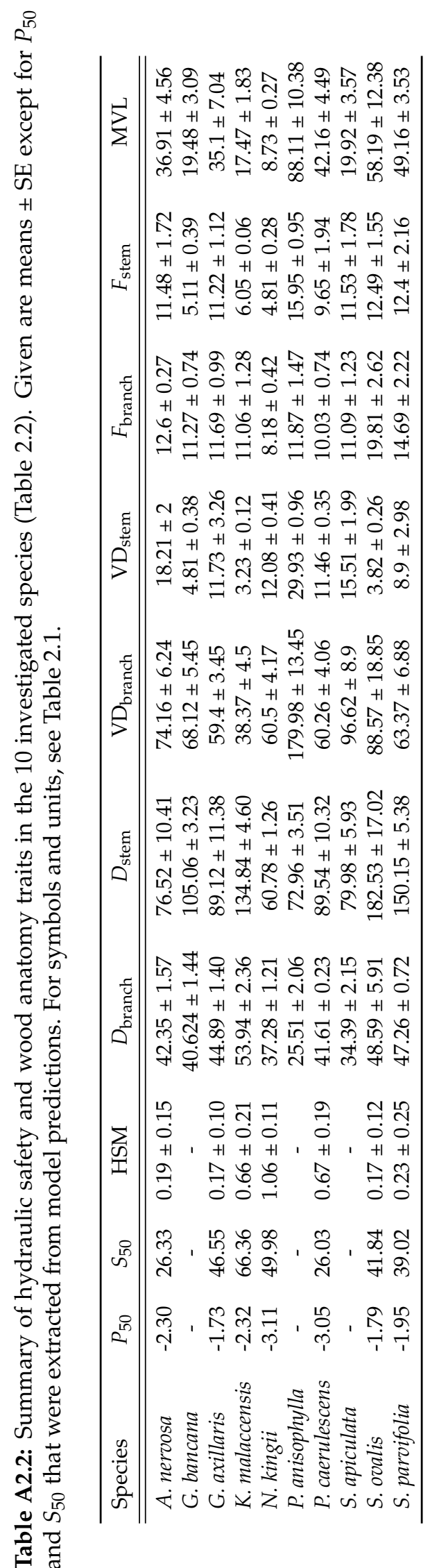


Table A2.2 (continued): Summary of hydraulic conductivity and leaf traits in the 10 investigated species (Table 2.2). Given are means \pm SE . For symbols and units, see Table 2.1.

\begin{tabular}{lccccc}
\hline Species & $K_{\mathrm{p} \text { branch }}$ & $K_{\mathrm{p} \text { stem }}$ & $\pi_{\text {tlp }}$ & SLA & HV \\
\hline \hline A. nervosa & $7.70 \pm 0.58$ & $26.45 \pm 9.04$ & $-1.34 \pm 0.06$ & $7.77 \pm 0.32$ & $4.93 \mathrm{e}-4 \pm 1.85 \mathrm{e}-4$ \\
G. bancana & $8.13 \pm 1.29$ & $18.82 \pm 0.65$ & $-2.00 \pm 0.10$ & $5.68 \pm 0.14$ & $1.46 \mathrm{e}-4 \pm 1.59 \mathrm{e}-5$ \\
G. axillaris & $8.52 \pm 1.20$ & $41.62 \pm 0.03$ & $-1.44 \pm 0.07$ & $12.43 \pm 1.77$ & $2.24 \mathrm{e}-4 \pm 2.09 \mathrm{e}-5$ \\
K. malaccensis & $13.48 \pm 2.69$ & $53.99 \pm 1.10$ & $-1.59 \pm 0.04$ & $10.81 \pm 1.11$ & $1.58 \mathrm{e}-4 \pm 2.57 \mathrm{e}-5$ \\
N. kingii & $4.71 \pm 0.38$ & $6.89 \pm 0.75$ & $-1.80 \pm 0.09$ & $7.28 \pm 0.25$ & $2.92 \mathrm{e}-4 \pm 6.51 \mathrm{e}-5$ \\
P. anisophylla & $4.03 \pm 1.15$ & $47.65 \pm 25.13$ & $-1.91 \pm 0.15$ & $11.98 \pm 0.83$ & $1.65 \mathrm{e}-4 \pm 3.79 \mathrm{e}-5$ \\
P. caerulescens & $6.53 \pm 0.64$ & $37.20 \pm 11.45$ & $-1.60 \pm 0.13$ & $8.59 \pm 0.71$ & $1.43 \mathrm{e}-4 \pm 2.29 \mathrm{e}-5$ \\
S. apiculata & $5.57 \pm 1.33$ & $28.65 \pm 4.05$ & $-2.11 \pm 0.14$ & $10.38 \pm 1.6$ & $2.40 \mathrm{e}-4 \pm 1.30 \mathrm{e}-5$ \\
S. ovalis & $22.08 \pm 8.46$ & $198.92 \pm 47.91$ & $-1.49 \pm 0.10$ & $7.70 \pm 0.58$ & $1.40 \mathrm{e}-4 \pm 3.92 \mathrm{e}-5$ \\
S. parvifolia & $15.84 \pm 3.49$ & $134.57 \pm 20.87$ & $-1.56 \pm 0.07$ & $8.92 \pm 0.7$ & $2.26 \mathrm{e}-4 \pm 3.35 \mathrm{e}-5$ \\
\hline
\end{tabular}


Table A2.3: Results of hierarchical mixed effects models to predict tree-level $P_{50}$ (M1) and to test the influence of plant height (H; M2), wood density (WD; M3) and aboveground biomass increment (ABI; M4) on $P_{50}$ and the slope at $P_{50}$. Given are PLC values (numbers in parentheses give SE of the estimates) for the fixed effects and standard deviation (SD) for random effects. Asterisks indicate the level of significance: ${ }^{\circ} P<0.10$; ${ }^{*} P<0.05$; ${ }^{* *} P<0.01$; ${ }^{* * *} P<0.001$. For symbols and units, see Table 2.1.

\begin{tabular}{|c|c|c|c|c|c|}
\hline \multicolumn{3}{|l|}{ M1: slope $+P_{50} \sim 1$} & \multicolumn{3}{|l|}{ M2: slope $+P_{50} \sim H$} \\
\hline Parameters & \multicolumn{2}{|c|}{ Coefficients } & Parameters & \multicolumn{2}{|l|}{ Coefficients } \\
\hline \multirow{4}{*}{ slope } & \multirow{4}{*}{ intercept } & PLC (SE) & \multirow{4}{*}{ slope } & \multirow[b]{2}{*}{ intercept } & PLC (SE) \\
\hline & & $32.45(3.83)^{* * *}$ & & & $\begin{array}{l}20.90 \\
(1170)\end{array}$ \\
\hline & & 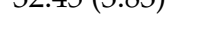 & & & 0.45 \\
\hline & & \multirow{3}{*}{$-2.04(0.22)^{* * *}$} & & & $(0.50)$ \\
\hline \multirow{2}{*}{$P_{50}$} & \multirow{2}{*}{ intercept } & & \multirow{2}{*}{$P_{50}$} & intercept & $-2.65(0.39)^{* * * *}$ \\
\hline & & & & $H$ & $\begin{array}{l}0.03 \\
(0.01)^{*}\end{array}$ \\
\hline \multicolumn{3}{|c|}{ Random effects : trees nested in species } & \multicolumn{2}{|c|}{ Random effects : trees nested in species } & \\
\hline \multicolumn{2}{|c|}{ SD residuals } & 19.53 & \multirow{2}{*}{\multicolumn{2}{|c|}{ SD residuals }} & 19.64 \\
\hline \multicolumn{2}{|l|}{ Number of species } & 7 & & & 7 \\
\hline \multicolumn{2}{|l|}{ SD species (slope) } & $1.24 \mathrm{E}-03$ & \multicolumn{2}{|l|}{ SD species (slope) } & 6.49 \\
\hline \multicolumn{2}{|l|}{ SD species $\left(P_{50}\right)$} & 0.50 & \multicolumn{2}{|l|}{ SD species $\left(P_{50}\right)$} & 0.47 \\
\hline \multicolumn{2}{|l|}{ Number of tree } & 33 & \multicolumn{2}{|l|}{ Number of tree } & 33 \\
\hline \multicolumn{2}{|l|}{ SD tree (slope) } & $1.95 \mathrm{E}-09$ & \multicolumn{2}{|l|}{ SD tree (slope) } & 0.15 \\
\hline \multicolumn{2}{|l|}{ SD tree $\left(P_{50}\right)$} & 0.46 & \multicolumn{2}{|l|}{ SD tree $\left(P_{50}\right)$} & 0.36 \\
\hline \multicolumn{3}{|c|}{ Observations } & Observations & & 165 \\
\hline M3: slope $+P_{50} \sim h$ & & & M4: slope $+P_{50} \sim \mathrm{A}$ & & \\
\hline Parameters & Coefficient & & Parameters & Coefficients & \\
\hline & & PLC (SE) & & & PLC (SE) \\
\hline slope & intercept & $\begin{array}{l}3.15 \\
(15.41)\end{array}$ & slope & intercept & $\begin{array}{l}27.50 \\
(4.65)^{* * *}\end{array}$ \\
\hline & WD & $\begin{array}{l}53.37 \\
(27.81)^{\circ}\end{array}$ & & ABI & $\begin{array}{l}393.54 \\
(278.90)^{\circ}\end{array}$ \\
\hline$P_{50}$ & intercept & $\begin{array}{l}-0.60 \\
(0.54)\end{array}$ & $P_{50}$ & intercept & $\begin{array}{l}-2.05 \\
(0.51)^{* * * *}\end{array}$ \\
\hline & WD & $\begin{array}{l}-2.38 \\
(0.86)^{* *}\end{array}$ & & ABI & $\begin{array}{l}0.51 \\
(3.38)\end{array}$ \\
\hline Random effects : tr & es nested in & ecies & Random effects : tr & es nested in species & \\
\hline SD residuals & & 18.97 & SD residuals & & 19.22 \\
\hline Number of species & & 7 & Number of species & & 7 \\
\hline SD species (slope) & & $2.79 \mathrm{E}-03$ & SD species (slope) & & $1.30 \mathrm{E}-01$ \\
\hline SD species $\left(P_{50}\right)$ & & $6.56 \mathrm{E}-05$ & SD species $\left(P_{50}\right)$ & & 0.50 \\
\hline Number of tree & & 33 & Number of tree & & 33 \\
\hline SD tree (slope) & & $1.69 \mathrm{E}-09$ & SD tree (slope) & & $5.31 \mathrm{E}-03$ \\
\hline SD tree $\left(P_{50}\right)$ & & 0.58 & SD tree $\left(P_{50}\right)$ & & 0.46 \\
\hline Observations & & 165 & Observations & & 165 \\
\hline
\end{tabular}


Table A2.4: Results of linear mixed-effects models on the relationships between vascular architecture and structural and functional traits. All models accounted for trees nested in species as random effects. Given are model used, coefficient values $( \pm \mathrm{SE}), P$ values, weight function if used, degrees of freedom $(\mathrm{DF})$, standard deviation (SD) of tree, species and residuals, number of observations $(n)$, the sense of the relationship (+ or -), marginal $r^{2}\left(\right.$ Mar. $\left.r^{2}\right)$ and the conditional $r^{2}$ (Cond. $r^{2}$ ). For symbols and units, see Table 2.1.

\begin{tabular}{|c|c|c|c|c|c|c|c|c|c|c|c|}
\hline Model & Values & $P$ & Weight & DF & $\begin{array}{l}\text { SD } \\
\text { tree }\end{array}$ & $\begin{array}{c}\text { SD } \\
\text { species }\end{array}$ & $\begin{array}{c}\text { SD } \\
\text { species }\end{array}$ & $n$ & $\begin{array}{l}\text { slope } \\
\text { sense }\end{array}$ & $\underset{r^{2}}{\text { Mar. }}$ & $\begin{array}{c}\text { Cond. } \\
r^{2}\end{array}$ \\
\hline \multicolumn{12}{|c|}{ traits dependence to stem vessel diameter } \\
\hline$D_{\text {branch }} \sim D_{\text {stem }}$ & $\begin{array}{l}\text { Intercept }=32.258(3.661) \\
D_{\text {stem }}=0.091(0.0323)\end{array}$ & $\begin{array}{l}0.000 \\
0.009\end{array}$ & $\begin{array}{c}\text { Exponential } \\
\text { variance on } D_{\text {stem }}\end{array}$ & 32 & 0.005 & 5.957 & 0.034 & 43 & + & 0.132 & 0.314 \\
\hline$H \sim D_{\text {stem }}$ & $\begin{array}{l}\text { Intercept }=9.390(2.580) \\
D_{\text {stem }}=0.127(0.024)\end{array}$ & $\begin{array}{l}0.000 \\
0.000\end{array}$ & - & 37 & 0.001 & 6.170 & 0.050 & 48 & + & 0.380 & 0.488 \\
\hline $\mathrm{WD} \sim D_{\text {stem }}$ & $\begin{array}{l}\text { Intercept }=0.733(0.0587) \\
D_{\text {stem }}=-0.001(0.000)\end{array}$ & $\begin{array}{l}0.000 \\
0.043\end{array}$ & $\begin{array}{l}\text { Exponential } \\
\text { variance }\end{array}$ & 37 & 0.037 & 0.118 & 12.353 & 48 & - & 0.067 & 0.279 \\
\hline $\log \mathrm{ABI} \sim D_{\text {stem }}$ & $\begin{array}{l}\text { Intercept }=-6.790(0.702) \\
D_{\text {stem }}=0.017(0.006)\end{array}$ & $\begin{array}{l}0.000 \\
0.011\end{array}$ & - & 37 & 1.262 & 0.530 & 0.467 & 48 & + & 0.169 & 0.245 \\
\hline$P_{50} \sim D_{\text {stem }}$ & $\begin{array}{l}\text { Intercept }=-3.019(0.359) \\
D_{\text {stem }}=0.009(0.002)\end{array}$ & $\begin{array}{l}0.000 \\
0.000\end{array}$ & $\begin{array}{l}\text { Power } \\
\text { variance }\end{array}$ & 19 & $1.87 \mathrm{E}-05$ & 0.622 & 0.090 & 27 & + & 0.242 & 0.624 \\
\hline$\pi_{\text {tlp }} \sim D_{\text {stem }}$ & $\begin{array}{l}\text { Intercept }=-1.846(0.154) \\
D_{\text {stem }}=0.002(0.001)\end{array}$ & $\begin{array}{l}0.000 \\
0.143\end{array}$ & - & 37 & $1.84 \mathrm{E}-01$ & 0.204 & 0.08 & 48 & + & 0.70 & 0.13 \\
\hline \multicolumn{12}{|c|}{ traits dependence to branch vessel diameter } \\
\hline$H \sim D_{\text {branch }}$ & $\begin{array}{l}\text { Intercept }=9.407(6.07) \\
D_{\text {branch }}=0.307(0.148)\end{array}$ & $\begin{array}{l}0.131 \\
0.046\end{array}$ & $\begin{array}{c}\text { Fixed } \\
\text { variance on } D_{\text {branch }}\end{array}$ & 33 & $6.97 \mathrm{E}-04$ & 2.696 & 1.026 & 44 & + & 0.106 & 0.155 \\
\hline $\mathrm{WD} \sim D_{\text {branch }}$ & $\begin{array}{l}\text { Intercept }=0.826(0.100) \\
D_{\text {branch }}=-0.005(0.002)\end{array}$ & $\begin{array}{l}0.000 \\
0.036\end{array}$ & - & 33 & 0.048 & 0.135 & 0.026 & 44 & - & 0.062 & 0.245 \\
\hline Log $\mathrm{ABI} \sim D_{\text {branch }}$ & $\begin{array}{l}\text { Intercept }=-5.073(1.493) \\
D_{\text {branch }}=0.001(0.035)\end{array}$ & $\begin{array}{l}0.002 \\
0.978\end{array}$ & - & 33 & 1.306 & 0.758 & 0.507 & 44 & + & 0.000 & 0.000 \\
\hline$P_{50} \sim D_{\text {branch }}$ & $\begin{array}{l}\text { Intercept }=-5.092(1.013) \\
D_{\text {branch }}=0.069(0.022)\end{array}$ & $\begin{array}{l}0.002 \\
0.007\end{array}$ & $\begin{array}{c}\text { Exponential } \\
\text { variance on } D_{\text {branch }}\end{array}$ & 16 & 0.07 & 0.569 & 1.307 & 24 & + & 0.243 & 0.509 \\
\hline$\pi_{\text {tlp }} \sim D_{\text {branch }}$ & $\begin{array}{l}\text { Intercept }=1.849(0.265) \\
D_{\text {branch }}=-0.005(0.006)\end{array}$ & $\begin{array}{l}0.002 \\
0.461 \\
\end{array}$ & - & 33 & $1.78 \mathrm{E}-01$ & 0.197 & 0.078 & 44 & - & 0.017 & 0.035 \\
\hline \multicolumn{12}{|c|}{ traits dependence to stem lumen-to-sapwood-area ratio } \\
\hline$H \sim F_{\text {stem }}$ & $\begin{array}{l}\text { Intercept }=15.804(3.421) \\
F_{\text {stem }}=0.127(0.024)\end{array}$ & $\begin{array}{l}0.000 \\
0.017\end{array}$ & - & 37 & 5.641 & 5.651 & 2.412 & 48 & + & 0.120 & 0.218 \\
\hline $\mathrm{WD} \sim \log F_{\text {stem }}$ & $\begin{array}{l}\text { Intercept }=0.704(0.052) \\
F_{\text {stem }}=-0.032(0.016)\end{array}$ & $\begin{array}{l}0.000 \\
0.060\end{array}$ & $\begin{array}{l}\text { Species identity } \\
\text { variance }\end{array}$ & 37 & 0.012 & 0.117 & 0.020 & 48 & - & 0.013 & 0.082 \\
\hline $\log \mathrm{ABI} \sim F_{\text {stem }}$ & $\begin{array}{l}\text { Intercept }=-5.213(0.644) \\
F_{\text {stem }}=0.019(0.056)\end{array}$ & $\begin{array}{l}0.000 \\
0.730\end{array}$ & - & 37 & 1.315 & 0.720 & 0.507 & 48 & + & 0.005 & 0.003 \\
\hline$P_{50} \sim \log F_{\text {stem }}$ & $\begin{array}{l}\text { Intercept }=-3.581(0.267) \\
F_{\text {stem }}=0.720(0.095)\end{array}$ & $\begin{array}{l}0.000 \\
0.000\end{array}$ & $\begin{array}{l}\text { Species identity } \\
\text { variance }\end{array}$ & 19 & 0.049 & 0.408 & 0.009 & 27 & + & 0.215 & 0.564 \\
\hline$\pi_{\text {tlp }} \sim F_{\text {stem }}$ & $\begin{array}{l}\text { Intercept }=-1.701(0.118) \\
F_{\text {stem }}=0.006(0.009)\end{array}$ & $\begin{array}{l}0.000 \\
0.530\end{array}$ & - & 37 & 0.189 & 0.204 & 0.082 & 48 & + & 0.008 & 0.018 \\
\hline \multicolumn{12}{|c|}{ traits dependence to branch lumen-to-sapwood-area ratio } \\
\hline$H \sim F_{\text {branch }}$ & $\begin{array}{l}\text { Intercept }=14.729(4.579) \\
F_{\text {branch }}=0.621(0.351)\end{array}$ & $\begin{array}{l}0.003 \\
0.086\end{array}$ & $\Gamma$ & 33 & 5.872 & 4.458 & 2.386 & 44 & + & 0.073 & 0.119 \\
\hline $\mathrm{WD} \sim F_{\text {branch }}$ & $\begin{array}{l}\text { Intercept }=0.744(0.0572) \\
F_{\text {branch }}=-0.009(0.004)\end{array}$ & $\begin{array}{l}0.000 \\
0.030\end{array}$ & $\begin{array}{l}\text { Exponential } \\
\text { variance }\end{array}$ & 33 & 0.039 & 0.108 & 13.572 & 44 & - & 0.057 & 0.208 \\
\hline $\log \mathrm{ABI} \sim F_{\text {branch }}$ & $\begin{array}{l}\text { Intercept }=-5.918(0.923) \\
F_{\text {branch }}=0.073(0.072)\end{array}$ & $\begin{array}{l}0.002 \\
0.317\end{array}$ & - & 33 & 1.298 & 0.723 & 0.500 & 44 & + & 0.026 & 0.041 \\
\hline$P_{50} \sim F_{\text {branch }}$ & $\begin{array}{l}\text { Intercept }=-4.439(0.853) \\
F_{\text {branch }}=0.970(0.328)\end{array}$ & $\begin{array}{l}0.002 \\
0.009\end{array}$ & $\begin{array}{l}\text { Power } \\
\text { variance }\end{array}$ & 16 & 7.35E-05 & 0.421 & 0.152 & 24 & + & 0.164 & 0.331 \\
\hline$\pi_{\text {tlp }} \sim D_{\text {branch }}$ & $\begin{array}{l}\text { Intercept }=-1.818(0.155) \\
D_{\text {branch }}=-0.013(0.011)\end{array}$ & $\begin{array}{l}0.000 \\
0.262 \\
\end{array}$ & - & 33 & 0.176 & 0.194 & 0.078 & 44 & - & 0.028 & 0.055 \\
\hline \multicolumn{12}{|c|}{ traits dependence to stem vessel density } \\
\hline $\log H \sim \log \mathrm{VD}_{\text {stem }}$ & $\begin{array}{l}\text { Intercept }=3.565(0.136) \\
\mathrm{VD}_{\text {stem }}=-0.22(0.057)\end{array}$ & 0.003 & - & 33 & $2.79 \mathrm{E}-08$ & $8.46 \mathrm{E}-06$ & $1.23 \mathrm{E}-03$ & 48 & - & 0.246 & 0.337 \\
\hline $\mathrm{WD} \sim \mathrm{VD}_{\text {stem }}$ & $\begin{array}{l}\text { Intercept }=0.593(0.050) \\
\text { VD }_{\text {stem }}=0.003(0.002)\end{array}$ & $\begin{array}{l}0.000 \\
0.158\end{array}$ & - & 33 & 0.049 & 0.132 & 0.027 & 48 & + & 0.030 & 0.143 \\
\hline $\log \mathrm{ABI} \sim \log \mathrm{VD}_{\text {stem }}$ & $\begin{array}{l}\text { Intercept }=-3.196(0.855) \\
\text { VD }_{\text {stem }}=-0.809(0.359)\end{array}$ & $\begin{array}{l}0.001 \\
0.030 \\
\end{array}$ & - & 37 & 1.270 & 0.598 & 0.479 & 48 & - & 0.131 & 0.196 \\
\hline \multicolumn{12}{|c|}{ traits dependence to branch vessel density } \\
\hline $\log H \sim \log \mathrm{VD}_{\text {branch }}$ & $\begin{array}{l}\text { Intercept }=3.413(0.609) \\
\text { VD }_{\text {branch }}=-0.086(0.142)\end{array}$ & $\begin{array}{l}0.003 \\
0.548\end{array}$ & - & 33 & 0.259 & 0.152 & 0.101 & 44 & - & 0.012 & 0.019 \\
\hline $\mathrm{WD} \sim \mathrm{VD}_{\text {branch }}$ & $\begin{array}{l}\text { Intercept }=0.588(0.06) \\
\mathrm{VD}_{\text {stem }}=0.001(0.001)\end{array}$ & $\begin{array}{l}0.000 \\
0.352\end{array}$ & - & 33 & 0.051 & 0.136 & 0.028 & 44 & + & 0.018 & 0.077 \\
\hline $\log \mathrm{ABI} \sim \log \mathrm{VD}_{\text {branch }}$ & $\begin{array}{l}\text { Intercept }=-8.045(3.166) \\
V^{\text {branch }}=0.707(0.736)\end{array}$ & $\begin{array}{l}0.016 \\
0.343\end{array}$ & - & 33 & 1.263 & 0.876 & 0.505 & 44 & + & 0.030 & 0.049 \\
\hline
\end{tabular}


Table A2.5: Results of linear mixed-effects models on the mutual interrelationships between tree structure, growth and wood and leaf functional traits. All models accounted for trees nested in species as random effects. Given are model used, coefficient values $( \pm \mathrm{SE}), P$ values, weight function if used, degrees of freedom (DF), standard deviation (SD) of tree, species and residuals, number of observations $(n)$, the sense of the relationship (+ or -$)$, marginal $r^{2}($ Mar. $r^{2}$ ) and the conditional $r^{2}$ (Cond. $r^{2}$ ). For symbols and units, see Table 2.1.

\begin{tabular}{|c|c|c|c|c|c|c|c|c|c|c|c|}
\hline Model & Values & $P$ & Weight & DF & $\begin{array}{l}\mathrm{SD} \\
\text { tree }\end{array}$ & $\begin{array}{c}\text { SD } \\
\text { species }\end{array}$ & $\begin{array}{c}\text { SD } \\
\text { species }\end{array}$ & $n$ & $\begin{array}{l}\text { slope } \\
\text { sense }\end{array}$ & $\underset{r^{2}}{\operatorname{Mar}}$ & $\underset{r^{2}}{\text { Cond. }}$ \\
\hline \multicolumn{12}{|c|}{ mutual interrelationships between tree structure and growth } \\
\hline $\mathrm{WD} \sim H$ & $\begin{array}{l}\text { Intercept }=0.571(0.05) \\
H=0.003(0.001)\end{array}$ & $\begin{array}{l}0.000 \\
0.055\end{array}$ & - & 38 & 0.048 & 0.127 & 0.027 & 49 & + & 0.022 & 0.121 \\
\hline $\log \mathrm{ABI} \sim H$ & $\begin{array}{l}\text { Intercept }=-7.779(0.539) \\
H=0.122(0.022)\end{array}$ & $\begin{array}{l}0.000 \\
0.000\end{array}$ & - & 38 & 1.173 & 0.169 & 0.317 & 49 & + & 0.388 & 0.498 \\
\hline$H \sim W D$ & $\begin{array}{l}\text { Intercept }=12.101(7.814) \\
W D=17.126(12.033)\end{array}$ & $\begin{array}{c}0.000 \\
0.16\end{array}$ & - & 38 & 5.950 & 2.505 & 5.407 & 49 & + & 0.066 & 0.121 \\
\hline $\log \mathrm{ABI} \sim \mathrm{WD}$ & $\begin{array}{l}\text { Intercept }=-6.752(1.461) \\
W D=2.821(2.260)\end{array}$ & $\begin{array}{l}0.000 \\
0.220\end{array}$ & - & 38 & 1.247 & 0.888 & 0.503 & 49 & + & 0.049 & 0.085 \\
\hline$H \sim \mathrm{ABI}$ & $\begin{array}{l}\text { Intercept }=19.759(1.151) \\
\mathrm{ABI}=157.464(24.345)\end{array}$ & $\begin{array}{l}0.000 \\
0.000\end{array}$ & - & 38 & 4.889 & 2.333 & 1.849 & 49 & + & 0.481 & 0.602 \\
\hline $\mathrm{WD} \sim \mathrm{ABI}$ & $\begin{array}{l}\text { Intercept }=0.682(0.051) \\
\mathrm{ABI}=0.010(0.006)\end{array}$ & $\begin{array}{l}0.000 \\
0.113\end{array}$ & - & 38 & 0.049 & 0.125 & 0.0268 & 49 & + & 0.014 & 0.065 \\
\hline \multicolumn{12}{|c|}{ Dependence of hydraulic traits to tree structure and growth } \\
\hline$P_{50} \sim H$ & $\begin{array}{l}\text { Intercept }=-2.664(0.275) \\
H=0.027(0.007)\end{array}$ & $\begin{array}{l}0.131 \\
0.002\end{array}$ & - & 19 & 0.221 & 0.542 & 0.121 & 27 & + & 0.152 & 0.448 \\
\hline $\mathrm{HSM} \sim H$ & $\begin{array}{l}\text { Intercept }=0.741(0.258) \\
H=-0.013(0.009)\end{array}$ & $\begin{array}{l}0.009 \\
0.200\end{array}$ & - & 21 & 0.343 & 0.282 & 0.141 & 28 & - & 0.06 & 0.12 \\
\hline $\log K_{\text {p stem }} \sim \mathrm{H}$ & $\begin{array}{l}\text { Intercept }=2.599(0.351) \\
H=0.042(0.012)\end{array}$ & $\begin{array}{l}0.002 \\
0.001\end{array}$ & - & 37 & 0.47 & 0.653 & 0.218 & 48 & + & 0.131 & 0.278 \\
\hline$K_{\mathrm{p} \text { branch }} \sim \log H$ & $\begin{array}{l}\text { Intercept }=0.711(0.773) \\
\log H=0.436(0.244)\end{array}$ & $\begin{array}{l}0.365 \\
0.083\end{array}$ & $\begin{array}{l}\text { Power variance } \\
\text { on height }\end{array}$ & 33 & 0.374 & 0.445 & 0.166 & 44 & + & 0.053 & 0.105 \\
\hline$\pi_{t l p} \sim \log H$ & $\begin{array}{l}\text { Intercept }=-2.206(0.314) \\
\log H=0.190(0.010)\end{array}$ & $\begin{array}{l}0.000 \\
0.065\end{array}$ & $\begin{array}{l}\text { Power variance } \\
\text { on leaf size }\end{array}$ & 38 & 4.66E-06 & 0.211 & 0.068 & 49 & + & 0.043 & 0.10 \\
\hline $\mathrm{SLA} \sim \log H$ & $\begin{array}{l}\text { Intercept }=18.572(3.34) \\
\log H=-3.06(1.06)\end{array}$ & $\begin{array}{l}0.000 \\
0.006\end{array}$ & - & 38 & 1.741 & 0.784 & $2.16 \mathrm{E}+00$ & 49 & - & 0.107 & 0.222 \\
\hline $\mathrm{HV} \sim H$ & $\begin{array}{l}\text { Intercept }=3.07 \mathrm{e}-04(9.05 \mathrm{e}-05) \\
H=-3.48 \mathrm{e}-06(3.69 \mathrm{e}-06)\end{array}$ & $\begin{array}{l}0.002 \\
0.354\end{array}$ & - & 31 & $1.54 \mathrm{E}-04$ & 7.12E-05 & 5.73E-05 & 42 & - & 0.02 & 0.03 \\
\hline$P_{50} \sim \mathrm{WD}$ & $\begin{array}{l}\text { Intercept }=-0.693(0.532) \\
W D=-2.191(0.830)\end{array}$ & $\begin{array}{l}0.207 \\
\mathbf{0 . 0 1 5}\end{array}$ & - & 21 & 0.445 & 0.248 & 0.171 & 29 & - & 0.272 & 0.422 \\
\hline $\mathrm{HSM} \sim \mathrm{WD}$ & $\begin{array}{l}\text { Intercept }=-0.305(0.391) \\
W D=1.197(0.613)\end{array}$ & $\begin{array}{l}0.444 \\
0.064\end{array}$ & - & 21 & 0.373 & 0.150 & 0.134 & 28 & + & 0.152 & 0.252 \\
\hline $\log K_{\mathrm{p} \text { stem }} \sim \mathrm{WD}$ & $\begin{array}{l}\text { Intercept }=5.322(0.867) \\
W D=-2.793(1.293)\end{array}$ & $\begin{array}{l}0.000 \\
\mathbf{0 . 0 3 7}\end{array}$ & $\begin{array}{l}\text { Power variance } \\
\text { on WD }\end{array}$ & 37 & 5.64E-05 & 0.700 & 0.306 & 48 & - & 0.133 & 0.30 \\
\hline$K_{\mathrm{p} \text { branch }} \sim \mathrm{WD}$ & $\begin{array}{l}\text { Intercept }=3.130(0.629) \\
W D=-1.723(0.936)\end{array}$ & $\begin{array}{l}0.000 \\
0.075\end{array}$ & $\begin{array}{l}\text { Power variance } \\
\text { on WD }\end{array}$ & 33 & 0.155 & 0.483 & 0.171 & 44 & - & 0.106 & 0.232 \\
\hline$\pi_{t l p} \sim W D$ & $\begin{array}{l}\text { Intercept }=-1.481(0.269) \\
W D=-0.259(0.412)\end{array}$ & $\begin{array}{l}0.000 \\
0.534\end{array}$ & - & 38 & 0.186 & 0.209 & 0.08 & 49 & - & 0.013 & 0.029 \\
\hline $\mathrm{SLA} \sim \mathrm{WD}$ & $\begin{array}{l}\text { Intercept }=11.101(2.823) \\
W D=-3.202(4.304)\end{array}$ & $\begin{array}{l}0.000 \\
0.460\end{array}$ & - & 31 & 1.875 & 2.027 & 0.822 & 42 & - & 0.022 & 0.042 \\
\hline $\mathrm{HV} \sim \mathrm{WD}$ & $\begin{array}{l}\text { Intercept }=9.17 \mathrm{e}-04(1.69 \mathrm{e}-04) \\
W D=-2.14 \mathrm{e}-04(2.60 \mathrm{e}-04)\end{array}$ & $\begin{array}{l}0.591 \\
0.416\end{array}$ & - & 31 & $1.50 \mathrm{E}-04$ & 8.74E-05 & 5.81E-05 & 42 & - & 0.024 & 0.037 \\
\hline$P_{50} \sim \log \mathrm{ABI}$ & $\begin{array}{l}\text { Intercept }=-1.535(0.393) \\
\log \mathrm{ABI}=0.102(0.068)\end{array}$ & $\begin{array}{l}0.001 \\
0.153\end{array}$ & - & 20 & 0.318 & 0.576 & 0.159 & 28 & + & 0.041 & 0.132 \\
\hline $\mathrm{HSM} \sim \log \mathrm{ABI}$ & $\begin{array}{l}\text { Intercept }=0.335(0.304) \\
\log \mathrm{ABI}=-0.022(0.058)\end{array}$ & $\begin{array}{l}0.283 \\
0.697\end{array}$ & - & 21 & 0.355 & 0.280 & 0.145 & 29 & - & 0.005 & 0.011 \\
\hline $\log K_{\text {p stem }} \sim \log \mathrm{ABI}$ & $\begin{array}{l}\text { Intercept }=4.092(0.400) \\
\log A B I=0.109(0.063)\end{array}$ & $\begin{array}{l}0.000 \\
0.093\end{array}$ & - & 37 & 0.507 & 0.731 & 2.37E-01 & 48 & + & 0.033 & 0.081 \\
\hline$K_{\mathrm{p} \text { branch }} \sim \log \mathrm{ABI}$ & $\begin{array}{l}\text { Intercept }=8.693(3.324) \\
\log \mathrm{ABI}=-0.163(0.561)\end{array}$ & $\begin{array}{l}0.013 \\
0.772\end{array}$ & - & 33 & 4.354 & 5.14 & 1.932 & 44 & - & 0.001 & 0.003 \\
\hline$\pi_{\text {tlp }} \sim \log \mathrm{ABI}$ & $\begin{array}{l}\text { Intercept }=-1.412(0.131) \\
\mathrm{ABI}=0.047(0.021)\end{array}$ & $\begin{array}{l}0.000 \\
0.036\end{array}$ & - & 38 & 0.173 & 0.224 & 0.079 & 49 & + & 0.058 & 0.131 \\
\hline SLA $\sim \log \mathrm{ABI}$ & $\begin{array}{l}\text { Intercept }=5.769(1.328) \\
\log \mathrm{ABI}=-0.661(0.207)\end{array}$ & $\begin{array}{l}0.000 \\
0.003\end{array}$ & $\begin{array}{c}\text { Exponential } \\
\text { variance on } \mathrm{ABI}\end{array}$ & 38 & 8.63E-04 & 2.383 & 1.704 & 49 & - & 0.102 & 0.234 \\
\hline $\log \mathrm{HV} \sim \log \mathrm{ABI}$ & $\begin{array}{l}\text { Intercept }=-9.296(0.250) \\
\log A B I=-0.158(0.049)\end{array}$ & $\begin{array}{l}0.000 \\
0.003\end{array}$ & - & 31 & 0.384 & 0.188 & 0.144 & 42 & - & 0.218 & 0.299 \\
\hline
\end{tabular}


Table A2.6: Results of linear mixed-effects models on the mutual interrelationships across wood and leaf functional traits. All models accounted for trees nested in species as random effects. Given are model used, coefficient values $( \pm \mathrm{SE}), P$ values, weight function if used, degrees of freedom (DF), standard deviation (SD) of tree, species and residuals, number of observations $(n)$, the sense of the relationship (+ or -), marginal $r^{2}\left(\right.$ Mar. $\left.r^{2}\right)$ and the conditional $r^{2}$ (Cond. $\left.r^{2}\right)$. For symbols and units, see Table 2.1 .

\begin{tabular}{|c|c|c|c|c|c|c|c|c|c|c|c|}
\hline Model & Values & $P$ & Weight & DF & $\begin{array}{l}\text { SD } \\
\text { tree }\end{array}$ & $\begin{array}{c}\text { SD } \\
\text { species }\end{array}$ & $\begin{array}{c}\text { SD } \\
\text { species }\end{array}$ & $n$ & $\begin{array}{l}\text { slope } \\
\text { sense }\end{array}$ & $\underset{r^{2}}{\text { Mar. }}$ & $\begin{array}{c}\text { Cond. } \\
r^{2}\end{array}$ \\
\hline \multicolumn{12}{|c|}{ Mutual interrelationships across functional wood and leaf traits } \\
\hline $\mathrm{HSM} \sim P_{50}$ & $\begin{array}{l}\text { Intercept }=-0.904(0.102) \\
P_{50}=-0.682(0.50)\end{array}$ & $\begin{array}{l}0.000 \\
0.000\end{array}$ & - & 20 & 0.163 & $6.06 \mathrm{E}-07$ & 2.73E-04 & 28 & - & 0.874 & 0.926 \\
\hline$\pi_{\text {tlp }} \sim P_{50}$ & $\begin{array}{l}\text { Intercept }=-1.245(0.133) \\
P_{50}=0.136(0.062)\end{array}$ & $\begin{array}{l}0.000 \\
0.042\end{array}$ & - & 20 & 0.145 & 0.057 & 0.087 & 28 & + & 0.182 & 0.30 \\
\hline$P_{50} \sim \log K_{\mathrm{p} \mathrm{stem}}$ & $\begin{array}{l}\text { Intercept }=-3.019(0.437) \\
\log K_{\mathrm{p} \text { stem }}=0.273(0.010)\end{array}$ & $\begin{array}{l}0.000 \\
0.013\end{array}$ & $\begin{array}{c}\text { Power } \\
\text { variance }\end{array}$ & 19 & 3.74E-05 & 0.533 & 0.130 & 27 & + & 0.172 & 0.429 \\
\hline $\mathrm{HSM} \sim \log K_{\mathrm{p} \text { stem }}$ & $\begin{array}{l}\text { Intercept }=0.917(0.357) \\
\log K_{\mathrm{p} \text { stem }}=-0.122(0.09)\end{array}$ & $\begin{array}{l}0.018 \\
0.194\end{array}$ & - & 19 & 0.337 & 0.137 & 0.262 & 27 & - & 0.081 & 0.153 \\
\hline$\pi_{\text {tlp }} \sim K_{\mathrm{p} \mathrm{stem}}$ & $\begin{array}{l}\text { Intercept }=-1.710(0.78) \\
K_{\mathrm{p} \text { stem }}=0.001(0.001)\end{array}$ & $\begin{array}{l}0.000 \\
0.086\end{array}$ & - & 37 & 0.185 & 0.191 & 0.080 & 48 & + & 0.072 & 0.138 \\
\hline SLA $\sim \log K_{\mathrm{p} \text { stem }}$ & $\begin{array}{l}\text { Intercept }=10.392(1.945) \\
\log K_{\mathrm{p} \mathrm{stem}}=-0.334(0.506)\end{array}$ & $\begin{array}{l}0.000 \\
0.513\end{array}$ & - & 37 & 1.902 & 2.176 & 0.840 & 48 & - & 0.011 & 0.024 \\
\hline $\log \mathrm{HV} \sim \log K_{\mathrm{p} \text { stem }}$ & $\begin{array}{l}\text { Intercept }=-8.230(0.394) \\
\log K_{\mathrm{p} \text { stem }}=-0.091(0.108)\end{array}$ & $\begin{array}{l}0.000 \\
0.408\end{array}$ & - & 30 & 0.409 & 0.280 & 0.163 & 41 & - & 0.022 & 0.036 \\
\hline$P_{50} \sim \log K_{\mathrm{p} \text { branch }}$ & $\begin{array}{l}\text { Intercept }=-3.430(0.494) \\
\log K_{\mathrm{p} \text { branch }}=0.636(0.199)\end{array}$ & $\begin{array}{l}0.000 \\
0.006\end{array}$ & $\begin{array}{c}\text { Power } \\
\text { variance }\end{array}$ & 16 & 3.74E-06 & 0.147 & 0.475 & 24 & + & 0.199 & 0.417 \\
\hline $\mathrm{HSM} \sim K_{\mathrm{p} \text { branch }}$ & $\begin{array}{l}\text { Intercept }=0.923(0.214) \\
K_{\mathrm{p} \text { branch }}=-0.047(0.018)\end{array}$ & $\begin{array}{l}0.039 \\
0.020\end{array}$ & - & 17 & 0.342 & 0.227 & 0.134 & 25 & - & 0.232 & 0.354 \\
\hline$\pi_{\mathrm{tlp}} \sim \log K_{\mathrm{p} \text { branch }}$ & $\begin{array}{l}\text { Intercept }=-1.812(0.158) \\
\log K_{\mathrm{p} \text { branch }}=0.075(0.069)\end{array}$ & $\begin{array}{l}0.000 \\
0.286\end{array}$ & - & 33 & 0.176 & 0.196 & 0.078 & 44 & + & 0.026 & 0.053 \\
\hline $\log$ SLA $\sim \log K_{\mathrm{p} \text { branch }}$ & $\begin{array}{l}\text { Intercept }=2.390(0.167) \\
\log K_{p \text { branch }}=-0.103(0.073)\end{array}$ & $\begin{array}{l}0.000 \\
0.168\end{array}$ & - & 33 & 0.185 & 0.082 & 0.211 & 44 & - & 0.043 & 0.086 \\
\hline $\log \mathrm{HV} \sim \log K_{\mathrm{p} \text { branch }}$ & $\begin{array}{l}\text { Intercept }=-8.601(0.339) \\
\log K_{\mathrm{p} \text { branch }}=0.02(0.154)\end{array}$ & $\begin{array}{l}0.000 \\
0.892\end{array}$ & - & 28 & 0.399 & 0.314 & 0.162 & 39 & + & 0.001 & 0.001 \\
\hline $\log \mathrm{SLA} \sim \pi_{\mathrm{tlp}}$ & $\begin{array}{l}\text { Intercept }=1.617(0.252) \\
\pi_{\mathrm{tlp}}=-0.337(0.144)\end{array}$ & $\begin{array}{l}0.000 \\
0.025\end{array}$ & - & 38 & 0.176 & 0.258 & 0.082 & 49 & - & 0.08 & 0.196 \\
\hline $\log \mathrm{HV} \sim \pi_{\text {tlp }}$ & $\begin{array}{l}\text { Intercept }=-8.486(0.579) \\
\pi_{\text {tlp }}=0.036(0.348)\end{array}$ & $\begin{array}{l}0.000 \\
0.917\end{array}$ & - & 31 & 0.404 & 0.295 & 0.163 & 42 & + & 0 & 0.001 \\
\hline $\mathrm{HSM} \sim \log \mathrm{SLA}$ & $\begin{array}{l}\text { Intercept }=-0.017(0.746) \\
\log \mathrm{SLA}=0.197(0.338)\end{array}$ & $\begin{array}{l}0.982 \\
0.567\end{array}$ & - & 21 & 0.350 & 0.297 & 0.145 & 28 & + & 0.011 & 0.024 \\
\hline$\pi_{\mathrm{tlp}} \sim \log \mathrm{SLA}$ & $\begin{array}{l}\text { Intercept }=-0.965(0.299) \\
\log \mathrm{SLA}=-0.313(0.132)\end{array}$ & $\begin{array}{l}0.003 \\
0.023\end{array}$ & - & 38 & 0.168 & 0.252 & 0.079 & 49 & - & 0.08 & 0.194 \\
\hline Log HV log SLA & $\begin{array}{l}\text { Intercept }=-8.528(0.674) \\
\log \mathrm{SLA}=-0.008(0.307)\end{array}$ & $\begin{array}{l}0.000 \\
0.979\end{array}$ & - & 31 & 0.403 & 0.298 & 0.163 & 42 & - & 0 & 0 \\
\hline $\mathrm{HSM} \sim \log \mathrm{HV}$ & $\begin{array}{l}\text { Intercept }=-0.297(2.172) \\
\log H V=-0.023(0.251)\end{array}$ & $\begin{array}{l}0.893 \\
0.928\end{array}$ & - & 17 & 0.345 & 0.330 & 0.147 & 25 & - & 0 & 0.001 \\
\hline
\end{tabular}


Table A2.7: Results of hierarchical mixed effects models to test the influence of stem and branch vessel diameter $\left(D_{\text {stem }}\right.$ and $\left.D_{\text {branch }} ; \mathrm{M} 1, \mathrm{M} 4\right)$, stem and branch vessel density (VD stem and $\mathrm{VD}_{\text {branch }}$; $\left.2, \mathrm{M} 5\right)$, and stem and branch lumento-sapwood area ratio $\left(F_{\text {stem }}\right.$ and $\left.F_{\text {branch }} ; \mathrm{M} 3, \mathrm{M} 6\right)$ on $P_{50}$ and the slope at $P_{50}$. Given are PLC values (numbers in parentheses give SE of the estimates) for the fixed effects and standard deviation (SD) for the random effects. Asterisks indicate the level of significance: ${ }^{\circ} P<0.10$; ${ }^{*} P<0.05$; ${ }^{* *} P<0.01$; ${ }^{* * *} P<0.001$. For symbols and units, see Table 2.1 .

\begin{tabular}{|c|c|c|c|c|c|c|c|c|}
\hline \multicolumn{9}{|c|}{ Dependence of $P_{50}$ and its slope to stem vascular anatomy accounting for height } \\
\hline \multicolumn{3}{|c|}{ M1: slope $+P_{50} \sim D_{\text {stem }}+H$} & \multicolumn{2}{|c|}{ M2: slope $+P_{50} \sim \mathrm{VD}_{\text {stem }}+H$} & & \multicolumn{3}{|c|}{ M3: slope $+P_{50} \sim F_{\text {stem }}+H$} \\
\hline \multirow[t]{2}{*}{ Parameters } & \multirow[t]{2}{*}{ Coefficients } & & Parameters & \multicolumn{2}{|c|}{ Coefficients } & Parameters & \multicolumn{2}{|c|}{ Coefficients } \\
\hline & & PLC (SE) & & & PLC (SE) & & & PLC (SE) \\
\hline slope & $\begin{array}{l}\text { intercept } \\
D_{\text {stem }} \\
H \\
\text { intercept }\end{array}$ & $\begin{array}{l}16.88(9.61)^{\circ} \\
-0.11(0.10) \\
0.67(0.57) \\
-3.83(0.43)^{* * *}\end{array}$ & slope & $\begin{array}{l}\text { intercept } \\
\mathrm{VD}_{\text {stem }} \\
H \\
\text { intercept }\end{array}$ & $\begin{array}{l}42.23(15.27)^{* *} \\
-0.99(0.52) \\
-0.30(0.44) \\
-2.37(0.58)^{* * *}\end{array}$ & slope & $\begin{array}{l}\text { intercept } \\
F_{\text {stem }} \\
H \\
\text { intercept }\end{array}$ & $\begin{array}{l}27.17(11.19)^{*} \\
-1.10(0.75) \\
0.39(0.40) \\
-2.82(0.45)^{* * *}\end{array}$ \\
\hline$P_{50}$ & $\begin{array}{l}D_{\text {stem }} \\
H\end{array}$ & $\begin{array}{l}0.003(0.005) \\
0.05(0.03)^{\circ}\end{array}$ & $P_{50}$ & $\begin{array}{l}\mathrm{VD}_{\text {stem }} \\
H\end{array}$ & $\begin{array}{l}-0.03(0.04) \\
0.03(0.01)^{\circ}\end{array}$ & $P_{50}$ & $\begin{array}{l}F_{\text {stem }} \\
H\end{array}$ & $\begin{array}{l}-0.01(0.04) \\
0.04(0.02)^{\circ}\end{array}$ \\
\hline \multicolumn{3}{|c|}{ Random effects : trees nested in species } & \multicolumn{3}{|c|}{ Random effects : trees nested in species } & \multicolumn{3}{|c|}{ Random effects : trees nested in species } \\
\hline SD residuals & & 22.96 & SD residuals & & 20.64 & SD residuals & & 20.75 \\
\hline Number of species & & & Number of species & & 7 & Number of species & & 7 \\
\hline SD species (slope) & & 7.88E-04 & SD species (slope) & & 6.07E-04 & SD species (slope) & & $1.44 \mathrm{E}-03$ \\
\hline SD species $\left(P_{50}\right)$ & & $3.66 \mathrm{E}-05$ & SD species $\left(P_{50}\right)$ & & 0.60 & SD species $\left(P_{50}\right)$ & & 0.55 \\
\hline Number of tree & & 22 & Number of tree & & 22 & Number of tree & & 22 \\
\hline SD tree (slope) & & $5.63 \mathrm{E}-06$ & SD tree (slope) & & $6.96 \mathrm{E}-08$ & SD tree (slope) & & $4.72 \mathrm{E}-07$ \\
\hline SD tree $\left(P_{50}\right)$ & & 3.54E-08 & SD tree $\left(P_{50}\right)$ & & $1.82 \mathrm{E}-08$ & SD tree $\left(P_{50}\right)$ & & $1.26 \mathrm{E}-07$ \\
\hline Observations & & 112 & Observations & & 112 & Observations & & 112 \\
\hline \multicolumn{9}{|c|}{ Dependence of $P_{50}$ and its slope to branch vascular anatomy accounting for height } \\
\hline \multicolumn{3}{|c|}{ M4: slope $+P_{50} \sim D_{\text {branch }}+H$} & \multicolumn{3}{|c|}{ M5: slope $+P_{50} \sim \mathrm{VD}_{\text {branch }}+H$} & \multicolumn{3}{|c|}{ M6: slope $+P_{50} \sim F_{\text {branch }}+H$} \\
\hline \multirow[t]{2}{*}{ Parameters } & \multicolumn{2}{|l|}{ Coefficients } & Parameters & Coefficien & & Parameters & \multicolumn{2}{|c|}{ Coefficients } \\
\hline & & PLC (SE) & & & PLC (SE) & & & PLC (SE) \\
\hline slope & $\begin{array}{l}\text { intercept } \\
D_{\text {branch }} \\
H \\
\text { intercept }\end{array}$ & $\begin{array}{l}-105.14(49.25)^{*} \\
3.54(1.19) \\
-0.37(0.79) \\
-4.57(1.09)^{* * *}\end{array}$ & slope & $\begin{array}{l}\text { intercept } \\
\text { VD }_{\text {branch }} \\
H \\
\text { intercept }\end{array}$ & $\begin{array}{l}32.33(13.77)^{*} \\
-0.17(0.17) \\
0.30(0.45) \\
-2.65(0.51)^{* * *}\end{array}$ & slope & $\begin{array}{l}\text { intercept } \\
F_{\text {branch }} \\
H \\
\text { intercept }\end{array}$ & $\begin{array}{l}28.09(14.72)^{\circ} \\
-1.30(1.00) \\
1.11(0.66) \\
-3.14(0.59)^{* * * *}\end{array}$ \\
\hline$P_{50}$ & $\begin{array}{l}D_{\text {branch }} \\
H\end{array}$ & $\begin{array}{l}0.05(0.03)^{*} \\
0.001(0.019)\end{array}$ & $P_{50}$ & $\begin{array}{l}\text { VD } \\
H\end{array}$ & $\begin{array}{l}0.004(0.007) \\
0.02(0.01)\end{array}$ & $P_{50}$ & $\begin{array}{l}F_{\text {branch }} \\
H\end{array}$ & $\begin{array}{l}0.06(0.04) \\
0.01(0.02)\end{array}$ \\
\hline \multicolumn{3}{|c|}{ Random effects : trees nested in species } & \multicolumn{3}{|c|}{ Random effects : trees nested in species } & \multicolumn{3}{|c|}{ Random effects : trees nested in species } \\
\hline SD residuals & & 16.65 & SD residuals & & 20.51 & SD residuals & & 17.48 \\
\hline Number of species & & 7 & Number of species & & 7 & Number of species & & 7 \\
\hline SD species (slope) & & $9.73 \mathrm{E}-03$ & SD species (slope) & & $5.22 \mathrm{E}-04$ & SD species (slope) & & $9.73 \mathrm{E}-03$ \\
\hline SD species $\left(P_{50}\right)$ & & 0.35 & SD species $\left(P_{50}\right)$ & & 0.43 & SD species $\left(P_{50}\right)$ & & 0.35 \\
\hline Number of tree & & 29 & Number of tree & & 29 & Number of tree & & 29 \\
\hline SD tree (slope) & & $1.20 \mathrm{E}-06$ & SD tree (slope) & & $3.99 \mathrm{E}-09$ & SD tree (slope) & & $1.20 \mathrm{E}-06$ \\
\hline SD tree $\left(P_{50}\right)$ & & 0.55 & SD tree $\left(P_{50}\right)$ & & $1.79 \mathrm{E}-05$ & SD tree $\left(P_{50}\right)$ & & 0.55 \\
\hline Observations & & 145 & Observations & & 145 & Observations & & 145 \\
\hline
\end{tabular}



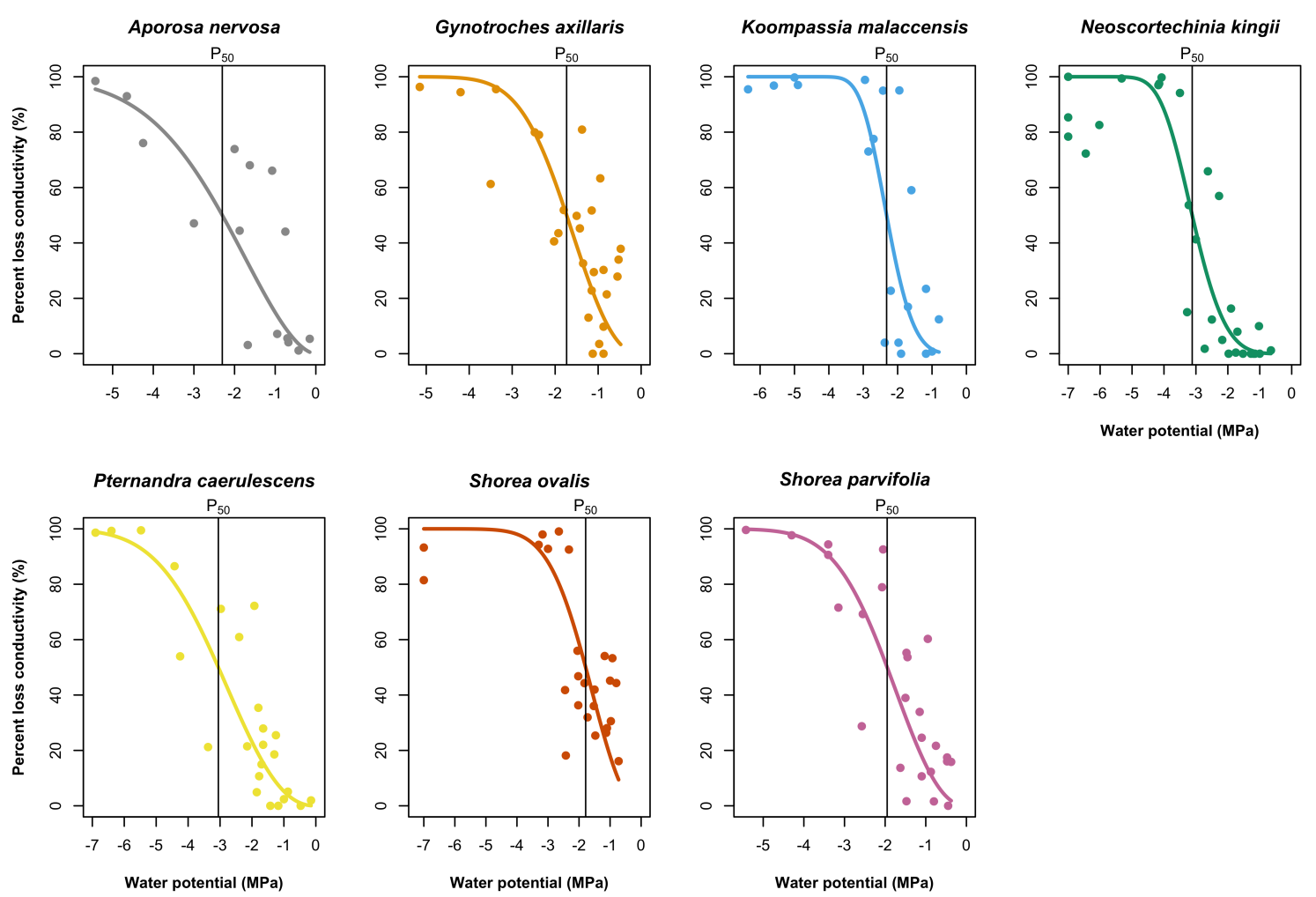

Fig. A2.1: Vulnerability curves of seven lowland tropical forest species fit with a Weibull model. The water potential at $50 \%$ loss of conductivity $\left(P_{50}\right)$ is indicated by the vertical bar 


\section{References}

Allen, C. D., Breshears, D. D., AND McDowell, N. G. 2015. On underestimation of global vulnerability to tree mortality and forest die-off from hotter drought in the anthropocene. Ecosphere 6:1-55.

Allen, C. D., Macalady, A. K., Chenchouni, H., Bachelet, D., McDowell, N. G., VenNetier, M., Kitzberger, T., Rigling, A., Breshears, D. D., Hogg, E. H., GonZalez, P., Fensham, R., Zhang, Z., Castro, J., Demidova, N., Lim, J.-H., Allard, G., Running, S. W., SEmerci, A., AND СовB, N. 2010. A global overview of drought and heat-induced tree mortality reveals emerging climate change risks for forests. Forest Ecology and Management 259:660-684.

Allen, K., Corre, M. D., Kurniawan, S., Utami, S. R., And Veldkamp, E. 2016. Spatial variability surpasses land-use change effects on soil biochemical properties of converted lowland landscapes in sumatra, indonesia. Geoderma 284:42-50.

Ambrose, A. R., Sillett, S. C., AND Dawson, T. E. 2009. Effects of tree height on branch hydraulics, leaf structure and gas exchange in california redwoods. Plant, cell $\mathcal{E}$ environment 32:743-757.

Anderegg, W. R. L., Klein, T., Bartlett, M. K., Sack, L., Pellegrini, A. F. A., Choat, B., AND JANSEN, S. 2016. Meta-analysis reveals that hydraulic traits explain cross-species patterns of drought-induced tree mortality across the globe. Proceedings of the National Academy of Sciences of the United States of America 113:5024-5029.

ANDeregG, W. R. L. AND Meinzer, F. C. 2015. Wood anatomy and plant hydraulics in a changing climate, pp. 235-253. In U. G. Hacke (ed.), Functional and Ecological Xylem Anatomy. Springer International Publishing, Cham.

Anfodillo, T., Carraro, V., CARrer, M., Fior, C., AND Rossi, S. 2006. Convergent tapering of xylem conduits in different woody species. The New phytologist 169:279-290.

Baltzer, J. L., Davies, S. J., BunyavejChewin, S., AND Noor, N. S. M. 2008. The role of desiccation tolerance in determining tree species distributions along the malay-thai peninsula. Functional Ecology 22:221-231.

Barros, F. D. V., Bittencourt, P. R. L., Brum, M., Restrepo-Coupe, N., Pereira, L., Teodoro, G. S., SAleska, S. R., Borma, L. S., Christoffersen, B. O., Penha, D., Alves, L. F., Lima, A. J. N., Carneiro, V. M. C., Gentine, P., Lee, J.-E., Aragão, L. E. O. C., 
Ivanov, V., Leal, L. S. M., Araujo, A. C., And Oliveira, R. S. 2019. Hydraulic traits explain differential responses of amazonian forests to the $2015 \mathrm{el}$ niño-induced drought. The New phytologist 223:1253-1266.

Bartlett, M. K., Klein, T., Jansen, S., Choat, B., AND SaCK, L. 2016. The correlations and sequence of plant stomatal, hydraulic, and wilting responses to drought. Proceedings of the National Academy of Sciences of the United States of America 113:13098-13103.

Bartlett, M. K., Scoffoni, C., Ardy, R., Zhang, Y., Sun, S., CaO, K.-F., And SACK, L. 2012b. Rapid determination of comparative drought tolerance traits: using an osmometer to predict turgor loss point. Methods in Ecology and Evolution 3:880-888.

BARTLETT, M. K., SCOFFONI, C., AND SACK, L. 2012a. The determinants of leaf turgor loss point and prediction of drought tolerance of species and biomes: a global meta-analysis. Ecology letters 15:393-405.

BATES, D., MÄCHLER, M., BOLKeR, B., AND WALKer, S. 2015. Fitting linear mixed-effects models using lme4. Journal of Statistical Software 67.

Bennett, A. C., McDowell, N. G., Allen, C. D., And Anderson-Teixeira, K. J. 2015. Larger trees suffer most during drought in forests worldwide. Nature plants 1:15139.

Berry, Z. C., Espejel, X., Williams-Linera, G., And Asbjornsen, H. 2019. Linking coordinated hydraulic traits to drought and recovery responses in a tropical montane cloud forest. American journal of botany .

Blackman, C. J., BRODRIBb, T. J., AND JORDAN, G. J. 2010. Leaf hydraulic vulnerability is related to conduit dimensions and drought resistance across a diverse range of woody angiosperms. The New phytologist 188:1113-1123.

Brienen, R. J. W., Gloor, E., Clerici, S., Newton, R., Arppe, L., Boom, A., Bottrell, S., Callaghan, M., Heaton, T., Helama, S., Helle, G., Leng, M. J., Mielikäinen, K., OINONEN, M., AND TIMONEN, M. 2017. Tree height strongly affects estimates of water-use efficiency responses to climate and co2 using isotopes. Nature communications 8:288.

BrodribB, T. J., Holbrook, N. M., EdwARds, E. J., AND GutiérReZ, M. V. 2003. Relations between stomatal closure, leaf turgor and xylem vulnerability in eight tropical dry forest trees. Plant, Cell and Environment 26:443-450.

Bucci, S. J., Scholz, F. G., Peschiutta, M. L., Arias, N. S., Meinzer, F. C., And GoldSTEIN, G. 2013. The stem xylem of patagonian shrubs operates far from the point of catas- 
trophic dysfunction and is additionally protected from drought-induced embolism by leaves and roots. Plant, cell E environment 36:2163-2174.

Burgess, Stephen, O., Pittermann, J., And Dawson, T. E. 2006. Hydraulic efficiency and safety of branch xylem increases with height in sequoia sempervirens (d. don) crowns. Plant, Cell and Environment 29:229-239.

CALKIN, H. W., GibSON, A. C., AND NOBEL, P. S. 1986. Biophysical model of xylem conductance in tracheids of the fern pteris vittata. Journal of Experimental Botany 37:1054-1064.

Calvo-Alvarado, J.-C., McDowell, N. G., AND Waring, R. H. 2008. Allometric relationships predicting foliar biomass and leaf area:sapwood area ratio from tree height in five costa rican rain forest species. Tree Physiology 28:1601-1608.

Chave, J., Coomes, D., Jansen, S., Lewis, S. L., Swenson, N. G., And Zanne, A. E. 2009. Towards a worldwide wood economics spectrum. Ecology letters 12:351-366.

Chave, J., Réjou-Méchain, M., Búrquez, A., Chidumayo, E., Colgan, M. S., Delitti, W. B. C., Duque, A., Eid, T., Fearnside, P. M., Goodman, R. C., Henry, M., MartínezYrízar, A., Mugasha, W. A., Muller-Landau, H. C., Mencuccini, M., Nelson, B. W., Ngomanda, A., Nogueira, E. M., Ortiz-Malavassi, E., Pélissier, R., Ploton, P., Ryan, C. M., SAldarRiaga, J. G., AND VieILledent, G. 2014. Improved allometric models to estimate the aboveground biomass of tropical trees. Global change biology 20:3177-3190.

Chota, B., Brodribb, T. J., Brodersen, C. R., Duursma, R. A., López, R., And Medlyn, B. E. 2018. Triggers of tree mortality under drought. Nature 558:531-539.

Choat, B., Jansen, S., Brodribb, T. J., Cochard, H., Delzon, S., Bhaskar, R., Bucci, S. J., Feild, T. S., Gleason, S. M., Hacke, U. G., Jacobsen, A. L., Lens, F., Maherali, H., Martínez-Vilalta, J., Mayr, S., Mencuccini, M., Mitchell, P. J., Nardini, A., Pittermann, J., Pratt, R. B., Sperry, J. S., Westoby, M., Wright, I. J., ANd Zanne, A. E. 2012. Global convergence in the vulnerability of forests to drought. Nature 491:752-755.

Christman, M. A., Sperry, J. S., AND Adler, F. R. 2009. Testing the 'rare pit' hypothesis for xylem cavitation resistance in three species of acer. The New phytologist 182:664-674.

Christoffersen, B. O., Gloor, M., FAuset, S., Fyllas, N. M., GAlbraith, D. R., BAKer, T. R., Rowland, L., Fisher, R. A., BinKs, O. J., SEvanto, S. A., Xu, C., JAnsen, S., ChOAT, B., Mencuccini, M., McDowell, N. G., AND Meir, P. 2016. Linking hydraulic traits to tropical forest function in a size-structured and trait-driven model (tfs v.1-hydro). Geoscientific Model Development Discussions pp. 1-60. 
Cochard, H., Herbette, S., Barigah, T. S., Badel, E., EnNajeh, M., And Vilagrosa, A. 2010. Does sample length influence the shape of xylem embolism vulnerability curves? a test with the cavitron spinning technique. Plant, cell E environment 33:1543-1552.

CORLETT, R. T. 2016. The impacts of droughts in tropical forests. Trends in plant science 21:584-593. Couvreur, V., Ledder, G., Manzoni, S., WAy, D. A., Muller, E. B., And Russo, S. E. 2018. Water transport through tall trees: A vertically explicit, analytical model of xylem hydraulic conductance in stems. Plant, cell \& environment 41:1821-1839.

DAVIES, S. J. 2001. Tree mortality and growth in 11 sympatric macaranga species in borneo. Ecology 82:920-932.

Domec, J.-C., Lachenbruch, B., Meinzer, F. C., Woodruff, D. R., Warren, J. M., And MCCUlLOH, K. A. 2008. Maximum height in a conifer is associated with conflicting requirements for xylem design. Proceedings of the National Academy of Sciences of the United States of America 105:12069-12074.

Domec, J.-C., Warren, J. M., Meinzer, F. C., And Lachenbruch, B. 2009. Safety factors for xylem failure by implosion and air-seeding within roots, trunks and branches of young and old conifer trees. IAWA Journal 30:101-120.

Drescher, J., Rembold, K., Allen, K., BeckschäFer, P., Buchori, D., Clough, Y., FAust, H., Fauzi, A. M., Gunawan, D., Hertel, D., Irawan, B., Jaya, I. N. S., Klarner, B., Kleinn, C., KnOHL, A., Kotowska, M. M., KrashevsKa, V., Krishna, V., Leuschner, C., Lorenz, W., Meijide, A., Melati, D., Nomura, M., Pérez-Cruzado, C., Qaim, M., Siregar, I. Z., Steinebach, S., TJOA, A., Tscharntke, T., Wick, B., Wiegand, K., Kreft, H., AND SCHEU, S. 2016. Ecological and socio-economic functions across tropical land use systems after rainforest conversion. Philosophical transactions of the Royal Society of London. Series B, Biological sciences 371 .

DuURSMA, R. AND CHOAT, B. 2017. fitplc - an r package to fit hydraulic vulnerability curves. Journal of Plant Hydraulics 4:e002.

Eller, C. B., De Barros, F. D. V., Bittencourt, P. R., Rowland, L., Mencuccini, M., And Oliveira, R. S. 2018. Xylem hydraulic safety and construction costs determine tropical tree growth. Plant, cell \& environment 41:548-562.

Fichot, R., Barigah, T. S., Chamaillard, S., Le Thiec, D., Laurans, F., Cochard, H., AND BRIGNOLAS, F. 2010. Common trade-offs between xylem resistance to cavitation and other 
physiological traits do not hold among unrelated populus deltoides $\mathrm{x}$ populus nigra hybrids. Plant, cell E environment 33:1553-1568.

Gleason, S. M., Westoby, M., Jansen, S., Choat, B., Hacke, U. G., Pratt, R. B., Bhaskar, R., Brodribb, T. J., Bucci, S. J., CAO, K.-F., Cochard, H., Delzon, S., DOMEC, J.-C., FAN, Z.-X., Feild, T. S., Jacobsen, A. L., Johnson, D. M., Lens, F., MAherali, H., MartíneZVilalta, J., Mayr, S., McCulloh, K. A., Mencuccini, M., Mitchell, P. J., Morris, H., Nardini, A., Pittermann, J., Plavcová, L., Schreiber, S. G., Sperry, J. S., Wright, I. J., AND ZANNE, A. E. 2016. Weak tradeoff between xylem safety and xylem-specific hydraulic efficiency across the world's woody plant species. The New phytologist 209:123-136.

Hacke, U. G., Plavcová, L., Almeida-Rodriguez, A., King-Jones, S., Zhou, W., And COOKE, J. E. K. 2010. Influence of nitrogen fertilization on xylem traits and aquaporin expression in stems of hybrid poplar. Tree physiology 30:1016-1025.

Hacke, U. G., Sperry, J. S., Wheeler, J. K., And Castro, L. 2006. Scaling of angiosperm xylem structure with safety and efficiency. Tree Physiology 26:689-701.

Hargrave, K., R., Kolb, T. E., Ewers, B. E., And Davis, S. D. 1994. Conduit diameter and drought-induced embolism in salvia mellifera greene (labiatae). New Phytologist 126:695-705.

Hoeber, S., Leuschner, C., KöHler, L., Arias-Aguilar, D., And Schuldt, B. 2014. The importance of hydraulic conductivity and wood density to growth performance in eight tree species from a tropical semi-dry climate. Forest Ecology and Management 330:126-136.

IPCC 2014. Climate change 2014: Impacts, adaptation, and vulnerability Working Group II contribution to the fifth assessment report of the Intergovernmental Panel on Climate Change. Cambridge University Press, New York NY.

Jacobsen, A. L., Brandon Pratt, R., Venturas, M. D., Hacke, U. G., and Lens, F. 2019. Large volume vessels are vulnerable to water-stress-induced embolism in stems of poplar. IAWA Journal 40:4-S4.

Jaeger, B., Edwards, L., DAs, K., AND Sen, P. 2016. An r 2 statistic for fixed effects in the generalized linear mixed model. Journal of Applied Statistics pp. 1-20.

JANSEN, S., SChUldT, B., AND CHOAT, B. 2015. Current controversies and challenges in applying plant hydraulic techniques: International workshop on plant hydraulic techniques, ulm university, germany, september 2014. The New phytologist 205:961-964.

Koch, G. W., Sillett, S. C., Jennings, G. M., AND DAVIS, S. D. 2004. The limits to tree height. Nature 428:851-854. 
Kotowska, M. M., Hertel, D., Rajab, Y. A., Barus, H., and Schuldt, B. 2015. Patterns in hydraulic architecture from roots to branches in six tropical tree species from cacao agroforestry and their relation to wood density and stem growth. Frontiers in plant science 6:191.

Kraft, N. J. B., Metz, M. R., Condit, R. S., And Chave, J. 2010. The relationship between wood density and mortality in a global tropical forest data set. The New phytologist 188:11241136.

LaChenbruch, B. AND MCCUlLOH, K. A. 2014. Traits, properties, and performance: how woody plants combine hydraulic and mechanical functions in a cell, tissue, or whole plant. The New phytologist 204:747-764.

Lens, F., Sperry, J. S., Christman, M. A., Choat, B., Rabaey, D., And Jansen, S. 2011. Testing hypotheses that link wood anatomy to cavitation resistance and hydraulic conductivity in the genus acer. The New phytologist 190:709-723.

Lewis, A. M. AND Boose, E. R. 1995. Estimating volume flow rates through xylem conduits. American journal of botany 82:1112-1116.

Li, S., Lens, F., Espino, S., KARIMI, Z., KlePsCh, M., Schenk, H. J., SchmitT, M., Schuldt, B., AND JANSEN, S. 2016. Intervessel pit membrane thickness as a key determinant of embolism resistance in angiosperm xylem. IAWA Journal 37:152-171.

Lindenmayer, D. B. AND LAURANCE, W. F. 2017. The ecology, distribution, conservation and management of large old trees. Biological reviews of the Cambridge Philosophical Society 92:14341458.

Liu, H., Gleason, S. M., HaO, G., Hua, L., He, P., Goldstein, G., And Ye, Q. 2019. Hydraulic traits are coordinated with maximum plant height at the global scale. Science Advances 5:eaav1332.

LiU, M., PAN, R., AND TYREE, M. T. 2018. Intra-specific relationship between vessel length and vessel diameter of four species with long-to-short species-average vessel lengths: further validation of the computation algorithm. Trees 32:51-60.

Martin-StPaul, N., Delzon, S., AND Cochard, H. 2017. Plant resistance to drought depends on timely stomatal closure. Ecology letters 20:1437-1447.

McCulloh, K. A., Johnson, D. M., Meinzer, F. C., Voelker, S. L., LAChenbruch, B., AND DOMEC, J.-C. 2012. Hydraulic architecture of two species differing in wood density: opposing strategies in co-occurring tropical pioneer trees. Plant, cell \& environment 35:116-125. 
McCulloh, K. A., Sperry, J. S., AND Adler, F. R. 2003. Water transport in plants obeys murray's law. Nature 421:939-942.

McDowell, N., Barnard, H., Bond, B., Hinckley, T., Hubbard, R., Ishit, H., Köstner, B., Magnani, F., Marshall, J., Meinzer, F., Phillips, N., Ryan, M., and Whitehead, D. 2002. The relationship between tree height and leaf area: sapwood area ratio. Oecologia 132:12-20.

McDowell, N. G. AND ALLen, C. D. 2015. Darcy's law predicts widespread forest mortality under climate warming. Nature Climate Change 5:669-672.

Meinzer, F. C., Bond, B. J., AND Karanian, Jennifer, A. 2008. Biophysical constraints on leaf expansion in a tall conifer. Tree Physiology 28:197-206.

Mencuccini, M., Minunno, F., Salmon, Y., Martínez-Vilalta, J., And Hölttä, T. 2015. Coordination of physiological traits involved in drought-induced mortality of woody plants. The New phytologist 208:396-409.

Mitchell, P. J., VeneKlaAs, E. J., LAmbers, H., AND BuRGeSs, S. S. O. 2008. Leaf water relations during summer water deficit: differential responses in turgor maintenance and variation in leaf structure among different plant communities in south-western australia. Plant, cell $\mathcal{E}$ environment 31:1791-1802.

NAKAGAWA, S. AND Schielzeth, H. 2013. A general and simple method for obtaining $\mathrm{r} 2$ from generalized linear mixed-effects models. Methods in Ecology and Evolution 4:133-142.

Nolf, M., Creek, D., Duursma, R., Holtum, J., Mayr, S., And Choat, B. 2015. Stem and leaf hydraulic properties are finely coordinated in three tropical rain forest tree species. Plant, cell E environment 38:2652-2661.

OGLE, K., BARBER, J. J., Willson, C., AND THOMPSON, B. 2009. Hierarchical statistical modeling of xylem vulnerability to cavitation. The New phytologist 182:541-554.

Oliveira, R. S., Costa, F. R. C., van BaAlen, E., De Jonge, A., Bittencourt, P. R., Almanza, Y., Barros, F. D. V., Cordoba, E. C., Fagundes, M. V., Garcia, S., Guimaraes, Z. T. M., Hertel, M., Schietti, J., Rodrigues-SouzA, J., AND PoOrter, L. 2018. Embolism resistance drives the distribution of amazonian rainforest tree species along hydro-topographic gradients. The New phytologist .

Olson, M. E., Anfodillo, T., Rosell, J. A., Petit, G., Crivellaro, A., Isnard, S., LeónGómez, C., Alvarado-CÁRdenas, L. O., And CAstorena, M. 2014. Universal hydraulics 
of the flowering plants: vessel diameter scales with stem length across angiosperm lineages, habits and climates. Ecology letters 17:988-997.

Olson, M. E., Soriano, D., Rosell, J. A., Anfodillo, T., Donoghue, M. J., Edwards, E. J., León-Gómez, C., Dawson, T. E., Camarero Martínez, J. J., Castorena, M., Echeverría, A., Espinosa, C. I., Fajardo, A., Gazol, A., IsNard, S., Lima, R. S., MarCati, C. R., AND MÉNDEZ-Alonzo, R. 2018. Plant height and hydraulic vulnerability to drought and cold. Proceedings of the National Academy of Sciences of the United States of America 115:75517556.

Otieno, D. O., Kurz-Besson, C., Liu, J., Schmidt, M. W. T., DO, R. V.-L., David, T. S., Siegwolf, R., Pereira, J. S., And Tenhunen, J. D. 2006. Seasonal variations in soil and plant water status in a quercus suber 1 . stand: Roots as determinants of tree productivity and survival in the mediterranean-type ecosystem. Plant and Soil 283:119-135.

Pinheiro, J., Bates, D., DebRoy, S., SARKar, D., AND R Core Team 2018. nlme: Linear and nonlinear mixed effects models.

Pittermann, J., Choat, B., Jansen, S., Stuart, S. A., Lynn, L., And Dawson, T. E. 2010. The relationships between xylem safety and hydraulic efficiency in the cupressaceae: the evolution of pit membrane form and function. Plant physiology 153:1919-1931.

Prendin, A. L., Mayr, S., Beikircher, B., von ArX, G., And Petit, G. 2018. Xylem anatomical adjustments prioritize hydraulic efficiency over safety as norway spruce trees grow taller. Tree physiology 38:1088-1097.

R CORE TEAM 2019. R: A language and environment for statistical computing.

RéJou-Méchain, M., TAnguy, A., Piponiot, C., Chave, J., AND Hérault, B. 2017. biomass $:$ an $\mathrm{r}$ package for estimating above-ground biomass and its uncertainty in tropical forests. Methods in Ecology and Evolution 8:1163-1167.

Rodriguez-Dominguez, C. M., Buckley, T. N., Egea, G., de Cires, A., HernandezSantana, V., Martorell, S., AND Diaz-Espejo, A. 2016. Most stomatal closure in woody species under moderate drought can be explained by stomatal responses to leaf turgor. Plant, cell \& environment 39:2014-2026.

RoQue, R. AND FILHO, M. 2007. Relationships between anatomical features and intra-ring wood density profiles in gmelina arborea applying x-ray densitometry. Cerne 13.

Rosell, J. A., Olson, M. E., AND ANFOdillo, T. 2017. Scaling of xylem vessel diameter with plant size: Causes, predictions, and outstanding questions. Current Forestry Reports 3:46-59. 
ROSNER, S. 2017. Wood density as a proxy for vulnerability to cavitation: Size matters. Journal of Plant Hydraulics 4:001.

Rowland, L., Da Costa, A. C. L., Galbraith, D. R., Oliveira, R. S., Binks, O. J., Oliveira, A. A. R., Pullen, A. M., Doughty, C., Metcalfe, D., Vasconcelos, S. S., Ferreira, L. V., Malhi, Y., Grace, J., Mencuccini, M., and Meir, P. 2015. Death from drought in tropical forests is triggered by hydraulics not carbon starvation. Nature 528:119-122.

RYAN, M. G. AND YODER, B. J. 1997. Hydraulic limits to tree height and tree growth: What keeps trees from growing beyond a certain height? BioScience 47:235-242.

SaCK, L., Cowan, P. D., Jaikumar, N., And Holbrook, N. M. 2003. The 'hydrology' of leaves: co-ordination of structure and function in temperate woody species. Plant, Cell and Environment 26:1343-1356.

Santiago, L. S., de Guzman, M. E., Baraloto, C., Vogenberg, J. E., Brodie, M., HÉrault, B., Fortunel, C., AND BONAL, D. 2018. Coordination and trade-offs among hydraulic safety, efficiency and drought avoidance traits in amazonian rainforest canopy tree species. The New phytologist 218:1015-1024.

Schuldt, B., Leuschner, C., Brock, N., And Horna, V. 2013. Changes in wood density, wood anatomy and hydraulic properties of the xylem along the root-to-shoot flow path in tropical rainforest trees. Tree physiology 33:161-174.

Schumann, K., Leuschner, C., AND SChuldt, B. 2019. Xylem hydraulic safety and efficiency in relation to leaf and wood traits in three temperate acer species differing in habitat preferences. Trees 33:1475-1490.

Sperry, J. S., Smith, D. D., van Savage, M., Enquist, B. J., McCulloh, K. A., Reich, P. B., Bentley, L. P., AND vON Allmen, E. I. 2012. A species-level model for metabolic scaling in trees i. exploring boundaries to scaling space within and across species. Functional Ecology 26:1054-1065.

SPERRY, J. S. AND TYREE, M. T. 1988. Mechanism of water stress-induced xylem embolism. Plant physiology 88:581-587.

Sterck, F. J., Martínez-Vilalta, J., Mencuccini, M., Cochard, H., Gerrits, P., Zweifel, R., Herrero, A., Korhonen, J. F., Llorens, P., NikinmaA, E., Nolè, A., Poyatos, R., Ripullone, F., AND SASS-KLAASSEN, U. 2012. Understanding trait interactions and their impacts on growth in scots pine branches across europe. Functional Ecology 26:541-549. 
TOFT, B. D., AlAM, M. M., AND TOPP, B. L. 2019. Anatomical structure associated with vegetative growth variation in macadamia. Plant and Soil 444:343-350.

Torres-Ruiz, J. M., Cochard, H., MAyr, S., Beikircher, B., DiAZ-Espejo, A., RodriguezDomingueZ, C. M., BADEL, E., AND FernÁNDEZ, J. E. 2014. Vulnerability to cavitation in olea europaea current-year shoots: further evidence of an open-vessel artifact associated with centrifuge and air-injection techniques. Physiologia plantarum 152:465-474.

Torres-Ruiz, J. M., Jansen, S., ChoAt, B., McElrone, A. J., Cochard, H., Brodribb, T. J., Badel, E., Burlett, R., Bouche, P. S., Brodersen, C. R., Li, S., Morris, H., And Delzon, S. 2015. Direct x-ray microtomography observation confirms the induction of embolism upon xylem cutting under tension. Plant physiology 167:40-43.

Tyree, M. T., Cochard, H., AND Davis, S. D. 1994. Biophysical perspectives of xylem evolution: is there a tradeoff of hydraulic efficiency for vulnerability to dysfunction? IAWA Journal 15:335-360.

West, G., BROWN, J., AND ENQUist, B. 1999. A general model for the structure and allometry of plant vascular systems. Nature 400:664-667.

Wheeler, J. K., Huggett, B. A., Tofte, A. N., Rockwell, F. E., And Holbrook, N. M. 2013. Cutting xylem under tension or supersaturated with gas can generate plc and the appearance of rapid recovery from embolism. Plant, cell \& environment 36:1938-1949.

Wheeler, J. K., Sperry, J. S., HACKe, U. G., AND HoAnG, N. 2005. Inter-vessel pitting and cavitation in woody rosaceae and other vesselled plants: a basis for a safety versus efficiency trade-off in xylem transport. Plant, cell \& environment 28:800-812.

WoodrufF, D. R., BOND, B. J., AND MEINZER, F. C. 2004. Does turgor limit growth in tall trees? Plant, cell E environment 27:229-236.

Wright, S. J., Kitajima, K., Kraft, N. J. B., Reich, P. B., Wright, I. J., Bunker, D. E., Condit, R., Dalling, J. W., Davies, S. J., Díaz, S., Engelbrecht, B. M. J., Harms, K. E., Hubbell, S. P., Marks, C. O., Ruiz-Jaen, M. C., Salvador, C. M., And Zanne, A. E. 2010. Functional traits and the growth-mortality trade-off in tropical trees. Ecology 91:3664-3674.

Zach, A., Schuldt, B., Brix, S., Horna, V., Culmsee, H., And Leuschner, C. 2010. Vessel diameter and xylem hydraulic conductivity increase with tree height in tropical rainforest trees in sulawesi, indonesia. Flora - Morphology, Distribution, Functional Ecology of Plants 205:506-512.

Zhang, L., Chen, Y., MA, K., Bongers, F., AND STERCK, F. J. 2019. Fully exposed canopy tree and liana branches in a tropical forest differ in mechanical traits but are similar in hydraulic 
traits. Tree physiology 39:1713-1724.

Ziegler, C., Coste, S., Stahl, C., Delzon, S., Levionnois, S., Cazal, J., Cochard, H., Esquivel-Muelbert, A., Goret, J.-Y., Heuret, P., Jaouen, G., Santiago, L. S., And BONAL, D. 2019. Large hydraulic safety margins protect neotropical canopy rainforest tree species against hydraulic failure during drought. Annals of Forest Science 76:1285.

ZiemińsKa, K., Butler, D. W., Gleason, S. M., Wright, I. J., And Westoby, M. 2013. Fibre wall and lumen fractions drive wood density variation across 24 australian angiosperms. $A o B$ PLANTS 5:25.

ZiEMIŃSKA, K., WESTOBY, M., AND WRIGHT, I. J. 2015. Broad anatomical variation within a narrow wood density range-a study of twig wood across 69 australian angiosperms. PloS one 10:e0124892. 


\section{Chapter 3}

Soil moisture regime and palm height influence embolism resistance in oil palm

Pierre-André WAITE, Bernhard SCHULDT, Roman M LINK, Natalie BREIDENBACH, Triadiati TRIADIATI, Nina HENNINGS, Asmadi SAAD, Christoph LEUSCHNER 


\begin{abstract}
With the prospect of climate change and more frequent El Niño-related dry spells, the drought tolerance of oil palm (Elaeis guineensis Jacq.), one of the most important tropical crop species, is of major concern. We studied the influence of soil water availability and palm height on the plasticity of xylem anatomy of oil palm fronds and their embolism resistance at well-drained and seasonally flooded riparian sites in lowland Sumatra, Indonesia. We found overall mean $P_{12}$ and $P_{50}$ values, i.e., the xylem pressures at $12 \%$ or $50 \%$ loss of hydraulic conductance, of -1.05 and $-1.86 \mathrm{MPa}$, respectively, indicating a rather vulnerable frond xylem of oil palm. This matches diurnal courses of stomatal conductance, which in combination with the observed low xylem safety evidence a sensitive water loss regulation. While the xylem anatomical traits vessel diameter $\left(D_{\mathrm{h}}\right)$, vessel density and potential hydraulic conductivity $\left(K_{\mathrm{p}}\right)$ were not different between the sites, palms in the moister riparian plots had on average by $0.4 \mathrm{MPa}$ higher $P_{50}$ values than plants in the well-drained plots. This could largely be attributed to differences in palm height between systems. As a consequence, palms of equal height had $1.3 \mathrm{MPa}$ less negative $P_{50}$ values in the moister riparian plots than in the well-drained plots. While palm height was positively related to $P_{50}, D_{\mathrm{h}}$ and $K_{\mathrm{p}}$ decreased with height. The high plasticity in embolism resistance may be an element of the drought response strategy of oil palm, which, as a monocot, has a relatively deterministic hydraulic architecture. We conclude that oil palm fronds develop a vulnerable water transport system, which may expose the palms to increasing drought stress in a warmer and drier climate. However, the risk of hydraulic failure may be reduced by considerable plasticity in the hydraulic system and the environmental control of embolism resistance, and a presumably large stem capacitance.
\end{abstract}

keywords: drought tolerance, Elaeis guineensis, hydraulic plasticity, phenotypic plasticity, riparian area, vulnerability curve, wood anatomy. 


\section{Introduction}

Heat-induced drought events are some of the major causes of massive damages and diebacks in plants (McDowell et al. 2008) in both natural and transformed systems (Allen et al. 2010, 2015). Among the latter, oil palm (Elaeis guineensis Jacq.) plantations belong to the most productive ecosystems worldwide, being second only to fertilized Eucalyptus plantations (Dufrêne and Saugier 1993). In 2017, oil palm was cultivated on 21 million hectares mostly in south-east Asia and Africa, with a total palm oil production of ca 63 million tons (FAOSTAT 2017). The largest cultivation areas are located in Indonesia and Malaysia with a moist equatorial climate, where droughts occur only irregularly, mostly in the context of El Niño events. However, climate warming scenarios predict an increasing frequency and severity of El Niño-related drought episodes for south-east Asia toward the end of the century (IPCC 2013). This could expose oil palm to critical water deficits even in the humid to perhumid climate of the Indonesian archipelago, the heart of the oil palm production area, where 32 million tons of palm oil were produced in 2016 (Statistics Indonesia 2016).

Oil palm is native to Western Africa with a seasonally dry climate (Dufrêne and Saugier 1993), where water deficits can last for several months (Corley and Tinker 2016). This suggests that the species should have developed drought adaptations. Yet, the specific anatomy and architecture of palms render most species of the Arecaceae family dependent on humid climates or on the availability of groundwater in more arid climates. In fact, water availability was found in continental-scale studies to be the most important predictor of palm species richness (Bjorholm et al. 2005). Palms, as arboreal monocots with a relatively simple architecture, produce a single orthotropic main axis without secondary radial growth and ramification. The pinnate leaves (fronds) of oil palm can reach a length of several meters (Aholoukpè et al. 2013). An adult, 8- to 10-year old oil palm produces two fronds per month (Nouy et al.. 1999, Adam et al. 2011) and a large number of fruit bunches, which is the basis for its high economic value. With the prospect of further expansion of oil palm plantations and the threat of more frequent and severe droughts in a warming climate, a better understanding of the species' drought tolerance strategy and related morphological and physiological traits is urgently needed.

During drought, liquid water is transported under increasingly negative xylem pressures, which may result in embolism formation caused by air seeding and subsequent rupturing of the water column causing water transport failure (Sperry and Tyree 1988, Rowland et al. 2015, Choat et al. 2018). Xylem water potentials at which emboli are formed vary considerably among species 
and with xylem properties. In order to evaluate the xylem resistance against drought-induced hydraulic failure, xylem vulnerability curves (VCs) are commonly built. These curves plot the percent loss of hydraulic conductivity against the water potential of the xylem. The slope of the VC as well as their extracted parameters, such as the xylem water potentials at $12 \%, 50 \%$ or $88 \%$ loss of hydraulic conductance $\left(P_{12}, P_{50}\right.$ or $P_{88}$, respectively), are commonly used to assess and compare xylem safety across and among species. In the past, physiological studies on oil palm focused mainly on photosynthesis, growth and fruit production as well as growth responses to water deficits, which have formed the basis of management recommendations (Rees 1961, Maillard et al. 1974, Smith 1989, Dufrêne and Saugier 1993, Cornaire et al. 1994, Nouy et al. 1999, Kallarackal et al. 2004, Cheng Xu et al. 2011, Carr 2011). It was found that extended droughts can strongly reduce oil palm fruit production not only in the current year but also in the subsequent 1 or 2 years (Cornaire et al. 1994, Nouy et al. 1999), partly due to inflorescence abortion under water deficit.

The species seems to sensitively regulate stomatal conductance in response to decreasing soil moisture and increasing atmospheric saturation deficits (Smith 1989, Dufrêne and Saugier 1993). This may indicate that the species has developed an isohydric strategy, in which canopy water loss is regulated sensitively to avoid large drops in xylem water potential (Hardanto et al. 2017). In isohydric species, leaf water potential is maintained more or less constant irrespective of variation in atmospheric demand and predawn soil water potential (Hochberg et al. 2018), and the xylem is typically more vulnerable to embolism (Tardieu and Simonneau 1998). However, not much is known about the xylem anatomy and hydraulic architecture of oil palm so far, information that is needed to characterize the species' position in the isohydric-anisohydric continuum of water loss regulation strategies (Klein 2014). Given the outstanding importance of oil palm as a tropical arboreal crop, our understanding of the species' drought tolerance strategy is fairly limited, especially with respect to hydraulic functioning. As a monocot, oil palm lacks secondary growth in the stem and thus cannot respond to long-term soil moisture depletion through the production of new wood with additional hydraulic conductance (Zimmermann and Tomlinson 1972, Tomlinson and Huggett 2012). The palm stem hydraulic system is organized in axial vascular bundles composed of phloem, metaxylem and protoxylem vessels. The frond hydraulic system (Fig. 3.1) develops from the protoxylem, which decouples from the axial metaxylem (Zimmermann 1973). Both axial and frond hydraulic systems are therefore largely separated, only connected by narrow protoxylem vessels in the petiole; new metaxylem is developed only in the frond rachis (Zimmermann and Sperry 1983; Fig. 3.1). The stem hydraulic system cannot acclimatize to altered envi- 
ronmental conditions in the lifespan of the palm as is possible in angiosperm and gymnosperm trees with secondary radial growth. Palms, therefore, must develop other mechanisms for ensuring sufficient water transport to their foliage and to protect the stem xylem against runaway embolism, which may threaten the integrity and functionality of their active fronds (Renninger and Phillips 2016).

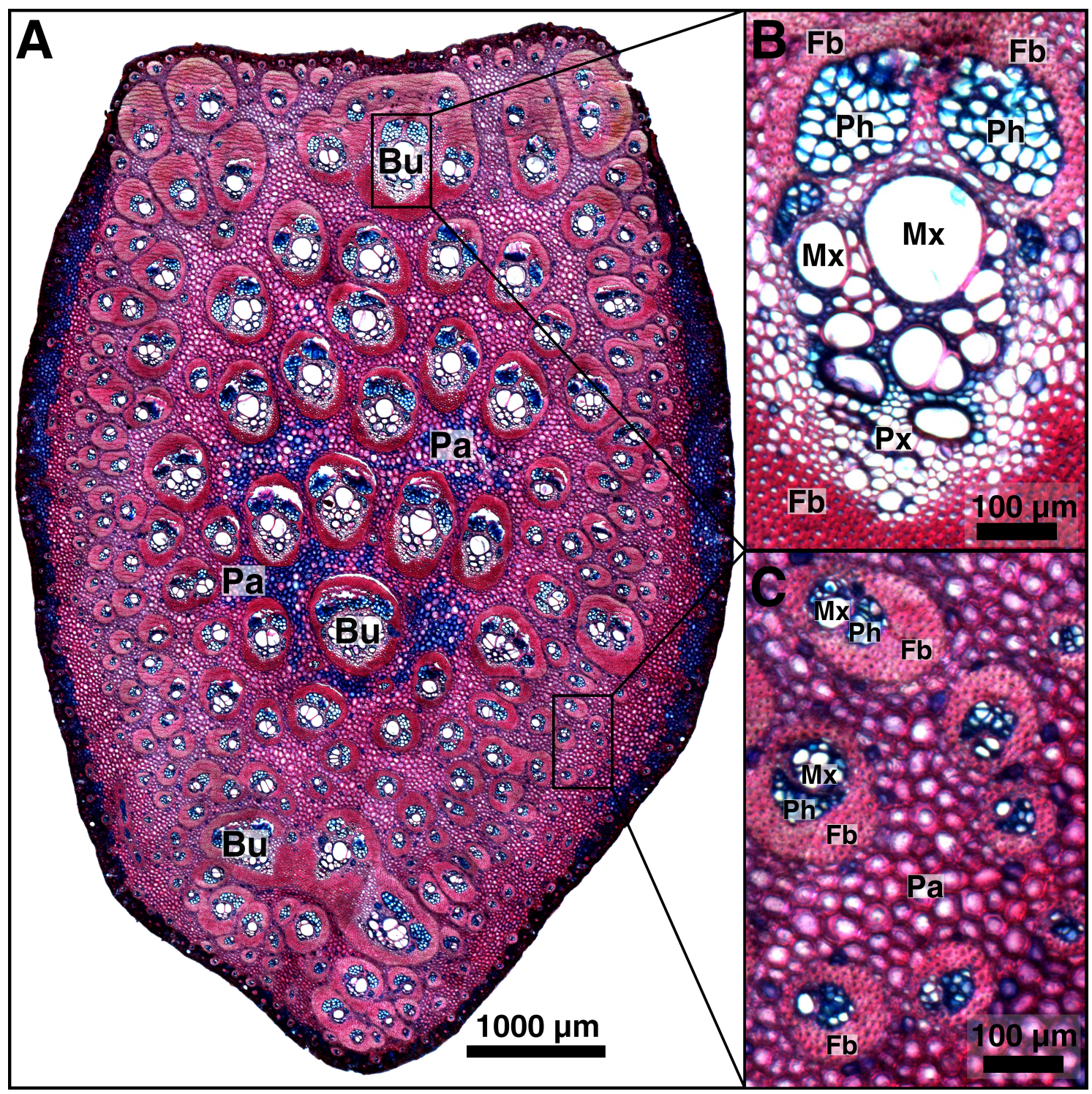

Fig. 3.1: Example of (A) a cross-section of the rachis of an oil palm frond sampled in riparian plot Ri3 with focus on (B) a vascular bundle and (C) several peripheral vascular bundles. Bu, vascular bundle; Fb, fibers; Mx, metaxylem vessels; $\mathrm{Pa}$, parenchyma cells; $\mathrm{Ph}$, phloem cells; Px, protoxylem vessels. Picture scale bars are (A) $1000 \mathrm{~m}$ and (B) and (C) $100 \mathrm{~m}$. 
As new vessels cannot be produced in the stem, monocots likely have a limited acclimation potential to water deficits that develop during the lifespan of the plant. One option to cope with the disadvantages of a relatively deterministic stem hydraulic system is to increase the morphological and physiological variability within the population through higher intraspecific genetic diversity and/or phenotypic plasticity (Aitken et al. 2008). Higher plasticity may also be achieved within the same plant when new leaves are produced. Most studies showed that the genetic influence on the embolism resistance of plants is relatively small (Hajek et al. 2016, Venturas et al. 2017). Even though species may differ in their response, vulnerability to embolism seems to be largely under environmental control at least in angiosperms, as was demonstrated for example in Fagus sylvatica (Schuldt et al. 2016). Yet, only a few species have been studied for the intraspecific plasticity of embolism resistance, and palms are greatly understudied (Choat et al. 2018). Most studies on pine populations across climatic gradients have revealed only low or no plasticity with respect to $P_{50}$ (Martínez-Vilalta and Piñol 2002, Stout and Sala 2003, Martínez-Vilalta et al. 2004, 2009, Lamy et al. 2014). This suggests that this parameter tends to be canalized in pines (Choat et al. 2018) or that the selective pressure for intraspecific variability was limited, i.e., the environment has changed only little in the past. Angiosperm trees, in contrast, seem to develop larger plasticity in $P_{50}$ (Aranda et al. 2015, Schuldt et al. 2016), even though different species largely vary in this respect (Jinagool et al. 2016, Lobo et al. 2018). It is an interesting question whether palms partly compensate for their rather deterministic stem hydraulic architecture by developing a higher phenotypic plasticity in the frond hydraulic system than gymnosperm and some angiosperm trees do in their branches.

This study on the drought tolerance of oil palm focuses on the species' vulnerability to xylem embolism and its dependence on stand structural and environmental factors, aiming at an improved understanding of the drought tolerance strategy of oil palm. From VCs established with the bench dehydration method,we determine $P_{12}, P_{50}$ and $P_{88}$ values for oil palm fronds from well-drained and periodically flooded riparian palm plantations in eastern Sumatra, Indonesia. We relate embolism resistance to xylem anatomical properties and stomatal regulation patterns. Starting from the assumption that oil palm pursues an isohydric strategy of water loss regulation, we aim to confirm that oil palm stomata are regulated sensitively to low air humidity in order to avoid diurnal leaf water deficits and to provide evidence that oil palm has a frond xylem relatively vulnerable to cavitation in comparison with tropical and extra-tropical angiosperm trees. We hypothesized that (i) frond embolism resistance of equally sized palms is higher at well-drained sites than at riparian sites with higher water availability, (ii) this difference is reflected in larger vessel 
diameters and/or vessel densities and higher potential hydraulic conductivity of riparian palms compared with palms on well-drained sites, and (iii) the differences are the result of phenotypic plasticity rather than genetic differentiation.

Table 3.1: Stand structural characteristics and soil properties of the six studied oil palm plantation plots at the well-drained or riparian sites in Jambi, Sumatra, Indonesia. Given are palm age ( $A$, in years), palm density (PD, palms per hectare), the percent of sand and clay in the top 50 $\mathrm{cm}$ of the soil, the average weight of harvested fruit bunches in 2017 (mean \pm SE) yield per plot from February to December 2017; Mg), means $( \pm \mathrm{SE})$ of palm height $(H$, stem height to the apical meristem in $\mathrm{m}$ ) and the number of plants and fronds investigated per plot.

\begin{tabular}{lccccccccc}
\hline Plantation type & Plot & $\boldsymbol{A}$ & PD & $\%$ sand & $\%$ clay & Yield & $\boldsymbol{H}$ & $\boldsymbol{n}_{\text {palm }}$ & $\boldsymbol{n}_{\text {sample }}$ \\
\hline \hline Well-drained & & & & 50.2 & 29.5 & 10.25 & $7.55 \pm 0.08$ & 16 & 48 \\
\hline & WD1 & 20 & 35 & - & - & 3.59 & $7.84 \pm 0.14$ & 6 & 18 \\
& WD2 & 16 & 35 & 55.8 & 30.3 & 3.85 & $7.30 \pm 0.11$ & 6 & 18 \\
& WD3 & 16 & 32 & 44.7 & 28.7 & 2.81 & $7.49 \pm 0.07$ & 4 & 12 \\
\hline Riparian & & & & 15.9 & 40.7 & 9.09 & $6.37 \pm 0.07$ & 18 & 54 \\
\hline \multirow{6}{*}{ Ri1 } & 13 & 43 & 10.0 & 50.7 & 1.93 & $5.95 \pm 0.07$ & 6 & 18 \\
& Ri2 & 17 & 29 & 15.5 & 41.5 & 3.30 & $6.67 \pm 0.10$ & 6 & 18 \\
& Ri3 & 19 & 34 & 22.2 & 30.0 & 3.86 & $6.50 \pm 0.12$ & 6 & 18 \\
\hline
\end{tabular}

\section{Materials and methods}

\section{Study sites and stand characteristics}

The study was conducted in the province of Jambi in the lowlands of eastern Sumatra, Indonesia, in smallholder oil palm plantations that replace the native lowland rainforest on large areas. The region has a moist equatorial climate with $2235 \mathrm{~mm}$ of annual precipitation and a mean annual temperature of $26.7^{\circ} \mathrm{C}$. The study is part of the collaborative research centre 990 - EFForTS, which investigates ecological and socioeconomic functions of tropical lowland rainforest transformation systems (see Drescher et al. 2016 for more details on the study region). We investigated oil palm plantations on both well-drained sites and periodically flooded riparian sites in the surroundings of the villages Bungku, Sungkai and Sungai Bahar; plot coordinates and elevation are given in Table A3.1 available in the Appendix. Six $50 \mathrm{~m} \times 50 \mathrm{~m}$ plots in homogeneous plantations were selected for study, three at well-drained sites and another three at riparian sites (plot codes are given in Table 3.1). All plots are spread across the landscape with a maximum distance of 10 $\mathrm{km}$ between each other. Well-drained and riparian plots were intermingled in the study region and not confined to separate areas. Palms were on average 13-20 years old, had a mean stem 
height of $6.0-7.8 \mathrm{~m}$ and were planted at densities of 116-172 stems per hectare (Table 3.1). The palms in the well-drained plots were on average $1.2 \mathrm{~m}$ taller than the plants in the riparian plots (means: $7.55 \mathrm{~m}$ vs $6.37 \mathrm{~m}$ ). Palm height was determined with a telescopic measuring rod from the stem base to the apical meristem, i.e., the insertion point of the fronds. Yield data were collected on all plots by the owners every 2 weeks from February 2017 onwards (Table 3.1).

In contrast to the well-drained plots, riparian plots are flooded at least once a year, which led to hydromorphic features (mottles) in the soil profiles, a sign of alternating aerobic and anaerobic conditions. Texture analyses were done with the pipette method according to Köhn (DIN ISO 11277:2002-08) at two of the studied well-drained sites for the 0-200 cm depth interval (Allen et al. 2016). Similar soil texture analyses were conducted on the riparian plots for the $0-50 \mathrm{~cm}$ depth interval. Soil samples were collected outside the plot in an area reserved for destructive sampling. For the sake of comparability between riparian and well-drained sites, we only considered soil texture data from the $0-50 \mathrm{~cm}$ depth interval. Soil texture was classified as sandy loam at the welldrained sites and loam at the riparian sites (see Table 3.1 for averaged data and Table A3.2 for the different depth intervals). In the well-drained soils, the sand fraction accounted for $50 \%$ (average of the sites WD2 and WD3), whereas silt and clay contributed with $20 \%$ and $30 \%$, respectively. In the riparian soils, the sand fraction was much smaller (average of three sites, 16\%), whereas the silt and clay fractions occupied $43 \%$ and $41 \%$, respectively. Thus, the riparian sites were not only characterized by high water tables and seasonal flooding, but also by a more fine-grained soil substrate, which causes considerable differences in soil hydraulic properties between the two site categories.

Climate stations were installed in the plot centre in all six plots and operated for nearly 1 year. Each station was equipped with a Trime-Pico 32 sensor (IMKO, Ettlingen, Germany) placed at 0.3 $\mathrm{m}$ depth in the soil to monitor soil moisture content (SM; vol. \%) and a thermohygrometer (Galltec Mela, Bondorf, Germany) placed at $2 \mathrm{~m}$ height to record air temperature $\left(T_{\mathrm{a}} ;{ }^{\circ} \mathrm{C}\right)$ and relative air humidity (RH; \%). Both sensors measured once every hour, and data were recorded with a UIT LogTrans 16-GPRS data logger (UIT, Dresden, Germany; see Meijide et al. 2018 for details of the climate stations). The climatic variables are listed in Table 3.2. According to these data, welldrained and riparian plots differ in the monthly averages of soil moisture, which varied by $~ 30$ vol. $\%$ in the topsoil of the well-drained plots and $\sim 40$ vol. $\%$ in the riparian plots (Fig. 3.2A). Considerable differences existed between the three plots per site. Air humidity in the stands was very high throughout the year with monthly averages of daytime vapor pressure deficit (VPD) 
generally varying between 0.4 and $0.8 \mathrm{kPa}$ (covering rainless and rainy days; Fig. 3.2B). Vapor pressure deficit was somewhat higher in the riparian plots (see Fig. A3.1A in the Appendix for averaged daily VPD courses), likely as a consequence of the lower plantation height in these plots, which allows for a more intense air mass exchange in the stands. However, when only the driest days are considered, VPD was higher at noon in the well-drained plots (Fig. A3.1B).

Table 3.2: List of studied variables with abbreviations, units and definitions.

\begin{tabular}{|c|c|c|}
\hline Abbreviation & Unit & Definition \\
\hline \multicolumn{3}{|c|}{ Environmental characteristics } \\
\hline SM & vol. \% & Soil moisture at $0.3 \mathrm{~m}$ depth \\
\hline RH & vol. \% & Air relative humidity at $2 \mathrm{~m}$ height \\
\hline$T_{\mathrm{a}}$ & ${ }^{\circ} \mathrm{C}$ & Air temperature at $2 \mathrm{~m}$ height \\
\hline VPD & $\mathrm{kPa}$ & Vapor Pressure Deficit \\
\hline Solar radiation & $\mathrm{W} \mathrm{m} \mathrm{m}^{-2}$ & $\begin{array}{l}\text { Solar radiation flux density intercepted at } 3 \mathrm{~m} \\
\text { height }\end{array}$ \\
\hline \multicolumn{3}{|l|}{ Plot parameters } \\
\hline PD & $\mathrm{n} \mathrm{ha} \mathrm{a}^{-1}$ & Palm density per hectare \\
\hline A & year & Palm age \\
\hline Yield & $\mathrm{Mg}$ & $\begin{array}{l}\text { Monthly harvested fruit bunches weight from } \\
\text { February to December } 2017\end{array}$ \\
\hline$\%$ sand & $\%$ & Percentage of sand in the first $50 \mathrm{~cm}$ of the soil \\
\hline$\%$ clay & $\%$ & Percentage of clay in the first $50 \mathrm{~cm}$ of the soil \\
\hline \multicolumn{3}{|c|}{ Palm structural parameters } \\
\hline$H$ & $\mathrm{~m}$ & Palm height \\
\hline \multicolumn{3}{|l|}{ Hydraulic traits } \\
\hline MVL & $\mathrm{m}$ & Maximum vessel length \\
\hline$g_{\mathrm{s}}$ & $\mathrm{mmol} \mathrm{m} \mathrm{m}^{-2} \mathrm{~s}^{-1}$ & Stomatal conductance \\
\hline$K_{\mathrm{p}}$ & $\mathrm{kg} \mathrm{m}^{-1} \mathrm{MPa}^{-1} \mathrm{~s}^{-1}$ & Potential conductivity \\
\hline$P_{12}$ & $\mathrm{MPa}$ & $\begin{array}{l}\text { Xylem pressure at } 12 \% \text { loss of hydraulic conduc- } \\
\text { tance }\end{array}$ \\
\hline$P_{50}$ & $\mathrm{MPa}$ & $\begin{array}{l}\text { Xylem pressure at } 50 \% \text { loss of hydraulic conduc- } \\
\text { tance }\end{array}$ \\
\hline$P_{88}$ & $\mathrm{MPa}$ & $\begin{array}{l}\text { Xylem pressure at } 88 \% \text { loss of hydraulic conduc- } \\
\text { tance }\end{array}$ \\
\hline \multicolumn{3}{|r|}{ 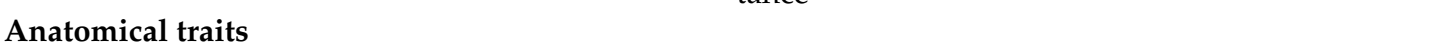 } \\
\hline$D$ & $\mathrm{~m}$ & Vessel diameter \\
\hline$D_{\mathrm{h}}$ & $\mathrm{m}$ & Hydraulically-weighted vessel diameter \\
\hline VD & $\mathrm{n} \mathrm{mm} \mathrm{m}^{-2}$ & Vessel density \\
\hline
\end{tabular}



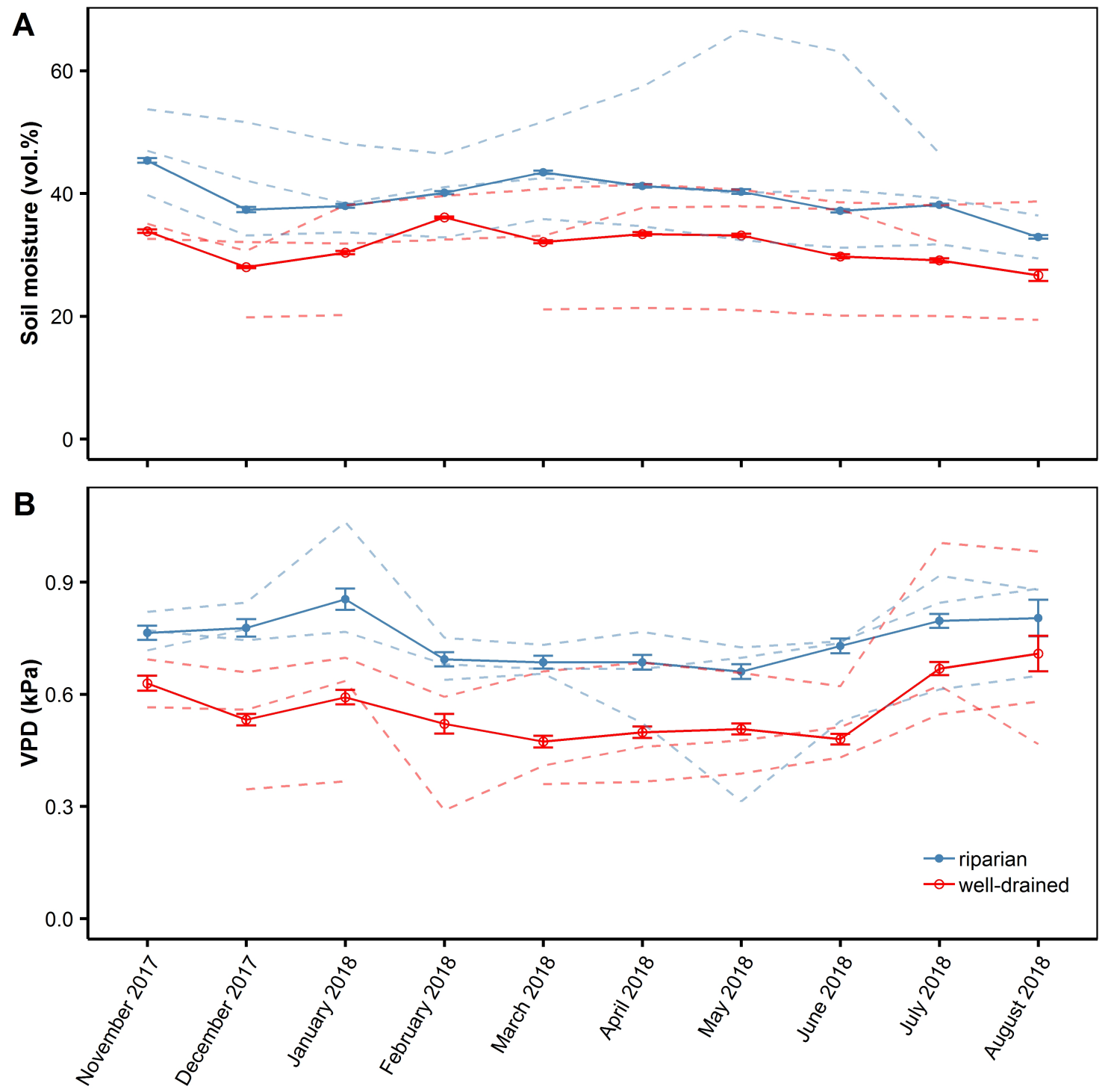

Fig. 3.2: Seasonal course of volumetric soil moisture (daily averages; A) and atmospheric VPD (daily averages; B) in the period from November 2017 to August 2018 on the six studied plots at the riparian and well-drained sites in Jambi province, Sumatra, Indonesia. Thick lines are the averages of riparian (blue lines; filled circles) and well-drained (red lines; open circles) sites; dashed lines stand for the individual plots.

\section{DNA sample collection and DNA extraction}

According to information given by the plot owners, all studied palms belong to the Marihat type from the Marihat Research Station (now Indonesian Oil Palm Research Institute). The plants are not complete genetic clones, as oil palm is generally propagated via seedlings. We performed genetic analyses to determine the genetic distance of the palms within each plot and between the well-drained and riparian sites. Leaf material of each investigated individual was collected in February 2019 and dried on silica gel prior to DNA extraction in Germany. DNA extraction from 
$\sim 1 \mathrm{~cm}^{2}$ dried leaf material was carried out using the DNeasy Plant Kit according to the manufacturer's protocol (Qiagen, Hilden, Germany). Amplified Fragment Length Polymorphism (AFLP) analysis was conducted following the protocol of Vos et al. (1995) with minor modifications. The enzyme combination EcoRI/MseI, the pre-selective E01/M03 (selective nucleotide: A and G) and selective E35/M63 (selective nucleotide: ACA and GAA) primer combinations (Keygene N.V. nomenclature) were used with the Polymerase Chain Reaction (PCR) protocols described in Breidenbach et al. (2018). Fragment visualization and determination was carried out using the software GeneMapper 4.1. (Applied Biosystems, Waltham, MA, USA). Previously validated, unambiguous and reproducible 80 fragments, within the size range of 75-400 bp and minimum fragment intensity of 100 relative fluorescence units (Breidenbach et al. 2018), were converted into a binary presence-absence matrix for each individual.

\section{Xylem vulnerability curves}

We used an adapted version of the bench dehydration method (Sperry et al. 1988, Cochard et al. 2013) to establish xylem VCs for oil palm fronds. Three fully developed fronds (ca 3-3.5 $\mathrm{m}$ in length) from each four to six randomly chosen palms per plot were collected ( 3 fronds per palms, 6 plots; 102 fronds in total). All studied fronds were selected at a middle position in the ring of fronds to ensure that all fronds belonged to the same developmental stage intermediate between the outermost oldest and innermost youngest fronds. After the initial proximal cut with a palm frond cutter, we immediately re-cut the frond's proximal end (cut segment ca $0.5-1 \mathrm{~m}$ long) under water to avoid artifacts from cutting under tension (Wheeler et al. 2013, Torres-Ruiz et al. 2015). We applied 1.3-fold maximum vessel length (MVL) to determine the frond section that could be used for conductance measurement. From the investigation with an adapted air injection method of 23 additional fronds from the same palms used for the hydraulic measurements, we determined a mean $( \pm \mathrm{SE}) \mathrm{MVL}$ of $1.76( \pm 0.10) \mathrm{m}$ for our frond development stage (Table 3.3), suggesting to choose a length of ca $2.20 \mathrm{~m}$ between petiole base and the rachis section used for conductance measurement, located ca $0.4 \mathrm{~m}$ distant to the frond tip. Briefly, air was injected with a syringe at low pressure $(0.10 \mathrm{MPa})$ into the cut, open xylem crosssection at the distal frond end, while the proximal end was submerged in water. At the proximal end, successive cuts were then conducted until bubbles became visible. We assumed that the remaining length of the frond rachis roughly equaled MVL. According to the estimated MVL, basal ends of the fronds were cut under water at $220 \mathrm{~cm}$ distance from the segments targeted for conductance measurements. This cut end was immediately covered with Parafilm (Bemis NA, Neenah, WI, USA) to avoid dehydration. 


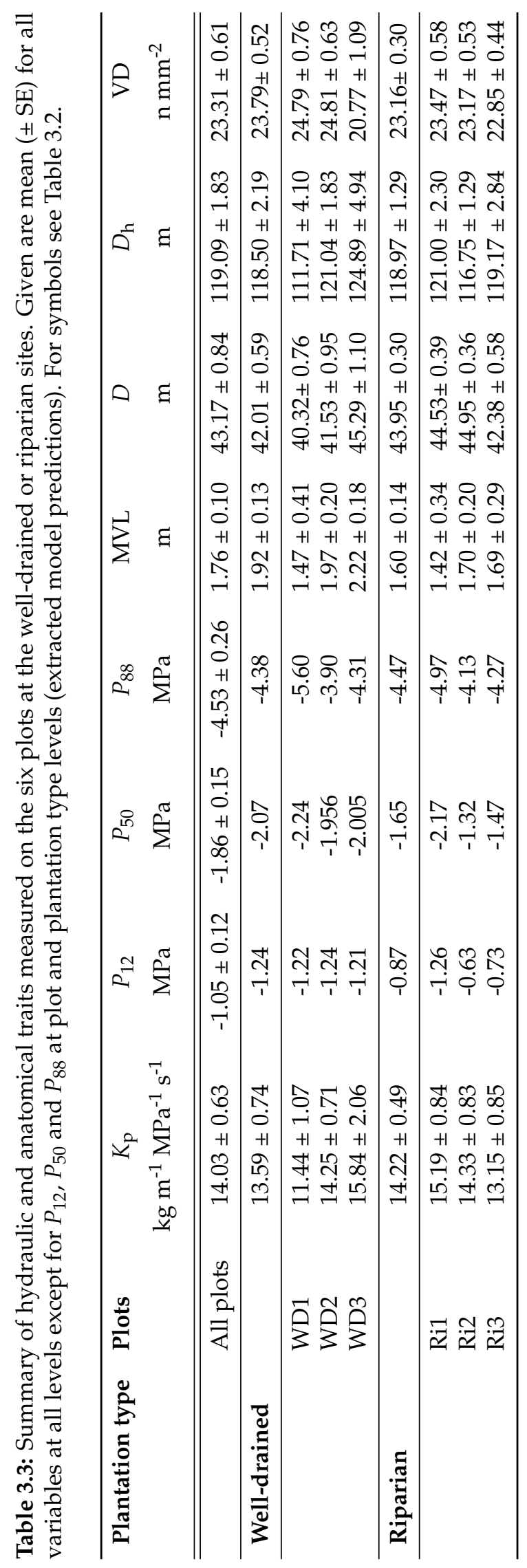


The frond segment (2.5-2.7 $\mathrm{m}$ total length; the frond tip remained uncut) was stored in a large moist plastic bag during transfer to the laboratory at Jambi University. Transportation by car took between 1 and $3 \mathrm{~h}$. In the laboratory, we placed the cut frond ends into water buckets and covered the fronds overnight with black plastic bags to allow full turgor recovery. Before starting frond drying on the bench, two opposite leaflets at the segment base were cut off and the scars immediately sealed with glue (Loctite 431; Henkel, Düsseldorf, Germany) in order to generate a leafless rachis segment of 50-60 mm length, which is needed for conductance measurement. This segment preparation was conducted on fully rehydrated frond sections in order to minimize cutting effects on the subsequent conductance measurement. Each frond was exposed to a variable and unique drying period between 1 and $24 \mathrm{~h}$. At the end of the drying procedure, two leaflets per frond distal to the segment for conductance measurement were used for water potential determination with a pressure chamber (PMS Instruments, Corvallis, OR, USA). The leaflets were covered with aluminium foils and placed for $1 \mathrm{~h}$ in a black, moistened plastic bag to reduce water potential gradients across the sample. After cutting the dried frond several times under water to release tension, we carefully extracted the segment used for conductance measurement with a sharp razorblade (avoiding parenchyma shrinking) and connected it to a XYL'EM embolism meter apparatus (Bronkhorst, Montigny-lès-Cormeilles, France) This is the second column. to measure flow rate at a defined pressure difference. We used a solution of deionized water to which $10 \mathrm{mM} \mathrm{KCl}$ and $1 \mathrm{mM} \mathrm{CaCl} 2$ was added in order to simulate the ion concentration of natural xylem sap (Zwieniecki et al. 2001, Nardini et al. 2007). We degassed the solution for at least $6 \mathrm{~h}$ using a vacuum pump that created a vacuum of $10 \mathrm{kPa}$ (ME1 diaphragm pump; Vacuubrand GMBH + CO KG, Wertheim, Germany). Due to the triangular cross-section of the palm rachis, custom-made tubing and hose clamps were used for tightly connecting the frond segment to the embolism meter. The initial conductance value $\left(K_{\mathrm{i}}\right)$ that is obtained before flushing reflects the state of the xylem with emboli generated through the dehydration treatment. The emboli were then eliminated by flushing the segment with pressurized solution (ca $0.20 \mathrm{MPa}$ ) for $5 \mathrm{~min}$, and conductance was measured again to obtain $K_{1}$. We repeated the flushing and conductance measurement cycle until conductance reached a plateau $\left(K_{\max }\right)$ and remained fairly constant. Vulnerability curves were generated by plotting the leaflet water potential against the corresponding percent loss of conductivity (PLC $\mathrm{PL}_{\mathrm{i}}$ according to Eq. (3.1):

$$
\mathrm{PLC}_{\mathbf{i}}=100 *\left(\left(1-K_{\mathbf{i}}\right) / K_{\max }\right)
$$




\section{Anatomical and hydraulic properties of the frond xylem}

Transversal cuts were done with a sliding microtome (G.S.L.1; Schenkung Dapples, Zurich, Switzerland) on one rachis per palm using the samples that were collected for conductance measurement (6 plots with 6 palms investigated, in total 36 samples). We dyed the transversal section with Alcian blue and safranin and took pictures of xylem anatomy at $\times 100$ magnification using a stereomicroscope equipped with a digital camera (SteREOV20; Carl Zeiss MicroImaging GmbH, Göttingen, Germany). The digital pictures were processed with Adobe Photoshop CC (Adobe Systems Inc., San Jose, CA, USA) and ImageJ using the particle analysis function. For every cut (Fig. 3.1A), cross-sectional area $\left(A_{\text {tot }} \mathrm{m}^{2}\right)$, vessel density $\left(\mathrm{VD} ; \mathrm{n} \mathrm{mm}{ }^{-2}\right)$ and diameter of metaxylem vessels $(D ; \mathrm{m})$ were calculated (Fig. 3.1B, C), with $D$ obtained from the major and minor vessel radii according to the equation of Lewis and Boose (1995). From $D$, hydraulically weighted diameter $\left(D_{\mathrm{h}} ; \mathrm{m}\right)$ was calculated according to Sperry et al. (1994) using Eq. (3.2):

$$
D_{\mathrm{h}}=\left(\sum D^{5}\right) /\left(\sum D^{4}\right)
$$

Potential conductivity $\left(K_{\mathrm{p}} ; \mathrm{kg} \mathrm{m}^{-1} \mathrm{MPa}^{-1} \mathrm{~s}^{-1}\right)$ was calculated with the Hagen-Poiseuille Eq. (3.3), where $\eta$ is the viscosity $\left(1.00210^{-9} \mathrm{MPa} \mathrm{s}^{-1}\right)$ and $\rho$ the density of water $\left(998.2 \mathrm{~kg} \mathrm{~m}^{-3}\right)$, both at $20^{\circ} \mathrm{C}$, and $A_{\text {tot }}\left(\mathrm{m}^{2}\right)$ the cross-sectional area of the xylem:

$$
K_{p}=\left(\left(\left(\pi * \sum D^{4}\right) / 128 \eta\right) * \rho\right) /\left(A_{t o t}\right)
$$

\section{Measurement of stomatal conductance}

During a measuring campaign in October 2016, we recorded diurnal courses of stomatal conductance in order to characterize the water loss regulation of oil palm at our site. Measurements were conducted with three porometers (AP4-UM-3; Delta-T Devices Ltd, Burwell, Cambridge, UK) that were used in parallel on nine fronds per palm and on three different individual palms (27 fronds in total). Measurements were conducted in a plantation owned by the company PT Humusindo, equipped with a microclimate measuring tower, located 5-10 km from the riparian and well-drained plots. Measurements were conducted on six sunny days between 9:30 and 17:00 h. All days had similar climatic conditions. Consecutive measurements were always conducted on the same marked leaflets of sun-exposed frond sections, which we accessed with $5 \mathrm{~m}$ high wooden platforms. $T_{\mathrm{a}}$ and $\mathrm{RH}$ were recorded by a meteorological station located in an open area of the plantation and equipped with a thermohygrometer (type 1.1025.55.000, Thies Clima, 
Göttingen, Germany) at $2 \mathrm{~m}$ height. Solar radiation was recorded by a global radiation sensor (CMP3 Pyranometer, Kipp and Zonen, Delft, The Netherlands) installed at a height of $3 \mathrm{~m}$. Measurements were taken every $15 \mathrm{~s}$ and averaged and stored on a DL16 Pro data logger (Thies Clima) every 10 min (see Meijide et al. 2018 for more details). Diurnal courses of stomatal conductance were plotted against local time every day by averaging over all 27 fronds investigated and additionally by averaging over all 6 days for deriving more general patterns of stomatal regulation in dependence on VPD and solar radiation.

\section{Statistical analyses}

Statistical analyses were conducted with R version 3.5.1 (R Development Core Team 2018). Investigated variables are summarized in Table 3.2. The design of the hydraulic study is nested with three fronds $i$ investigated per palm $j$ and six palms per plot $k$. Vulnerability curves were described with the cumulative distribution function of the Weibull distribution and fit to the dataset with non-linear hierarchical models using $R$ package nlme (Pinheiro et al. 2018) to account for plot- and palm-level variability in parameter estimates. The model equations were re-parameterized with $P_{50}$ and slope at $P_{50}$ (Ogle et al. 2009) to build Eq. (3.4), where $P_{50}$ is the xylem pressure $\left(\psi_{\mathrm{x}}\right)$ at which $50 \%$ of maximum conductivity (PLC) is lost:

$$
P L C_{i j k}=100 *\left(0.5\left(^{\left(\frac{\psi_{i j k}}{P_{50 j k}}\right)}\right)^{\left(\frac{-P_{50 j k} * \text { slope }_{j k}}{50 * \ln (0.5)}\right)}\right)
$$

In a second stage of the model, the estimated parameters $P_{50}$ and slope were described as linear functions of the type of oil palm plantation (well-drained vs riparian), palm height (stem length; centered around the average palm height of each plantation type) and their interaction, and allowed to vary randomly between palms nested in plots. Palm height, as a natural variable, was centered to avoid model output values for a non-existing palm height (typically a negative height). Model output values are thus corresponding to palms having the same height averaged for the region (all plots and plantation types) and are not necessarily equal to the predicted values for palms at different average height for each plantation type (see Fig. 3.5D). $P_{50}$ and also $P_{12}$ and $P_{88}$ values (12\% and $88 \%$ loss of conductivity) were derived from plot- or plantation type- based model predictions for plot- and plantation-type levels. Overall $P_{12}, P_{50}$ and $P_{88}$ means for the region (all plots) were computed from plot-level predictions. 
We used linear mixed effects models for analyzing the variation in anatomical traits $\left(D_{\mathrm{h}} ; \mathrm{VD}\right.$ and $K_{\mathrm{p}}$ ) with palm height and plantation type considered as fixed effects and plot as a random effect using the $\mathrm{R}$ package lme4 (Bates et al. 2015). In addition, we used a variance identity function applied on plantation type to take into account different variances between well-drained and riparian sites. Means and standard errors of the studied variables were calculated for plot, plantation type and region levels (all plots) using data averaged over palm individuals.

Although $r^{2}$ is not defined in nonlinear models, we calculated equivalent $r^{2}$ values as the ratio of residual and total variance of the model according to Nakagawa and Schielzeth (2013). Conditional (including fixed and random effects) and marginal (including only fixed effects) $r^{2}$ equivalents were calculated.

The genetic analyses were based on the binary matrix clone identification. Pairwise genetic distances as well as analyses of molecular variance, within and between sites (analysis of molecular variance, 999 permutations), were calculated using the Excel-Adding GenAlEx 6.501 (Peakall and Smouse 2006, 2012).

\section{Results}

\section{Diurnal course of stomatal conductance}

According to the porometer measuring campaign on sunny days in October 2016, the stomatal conductance of oil palm fronds typically peaks early in the day at local time 10:00 $\mathrm{h}$ and subsequently declines more or less continuously until 17:00 h (Fig. 3.3C), while radiation flux density often continues to increase until noon and VPD even until the early afternoon (Fig. 3.3A, B). This indicates partial stomatal closure over most of the day from $\sim 10: 00 \mathrm{~h}$ onwards.

\section{Genetic constitution of the investigated palm individuals}

Based on the AFLP markers, no palm clones could be identified. However, pairwise genetic distances did not reveal any pattern of genetic differentiation between riparian and well-drained sites. High and low genetic distances were found between individuals within one plot, but also between individuals growing in different plots and site types, i.e., riparian and well-drained (Table A3.3 in the Appendix). Accordingly, the main genetic variance (97\%) was found within plantation types. The differentiation between the two plantation types was low and not significant $(P$ $=0.083$ ), and only $3 \%$ of the genetic variance was found between the two types (Fig. A3.2 in the Appendix). 

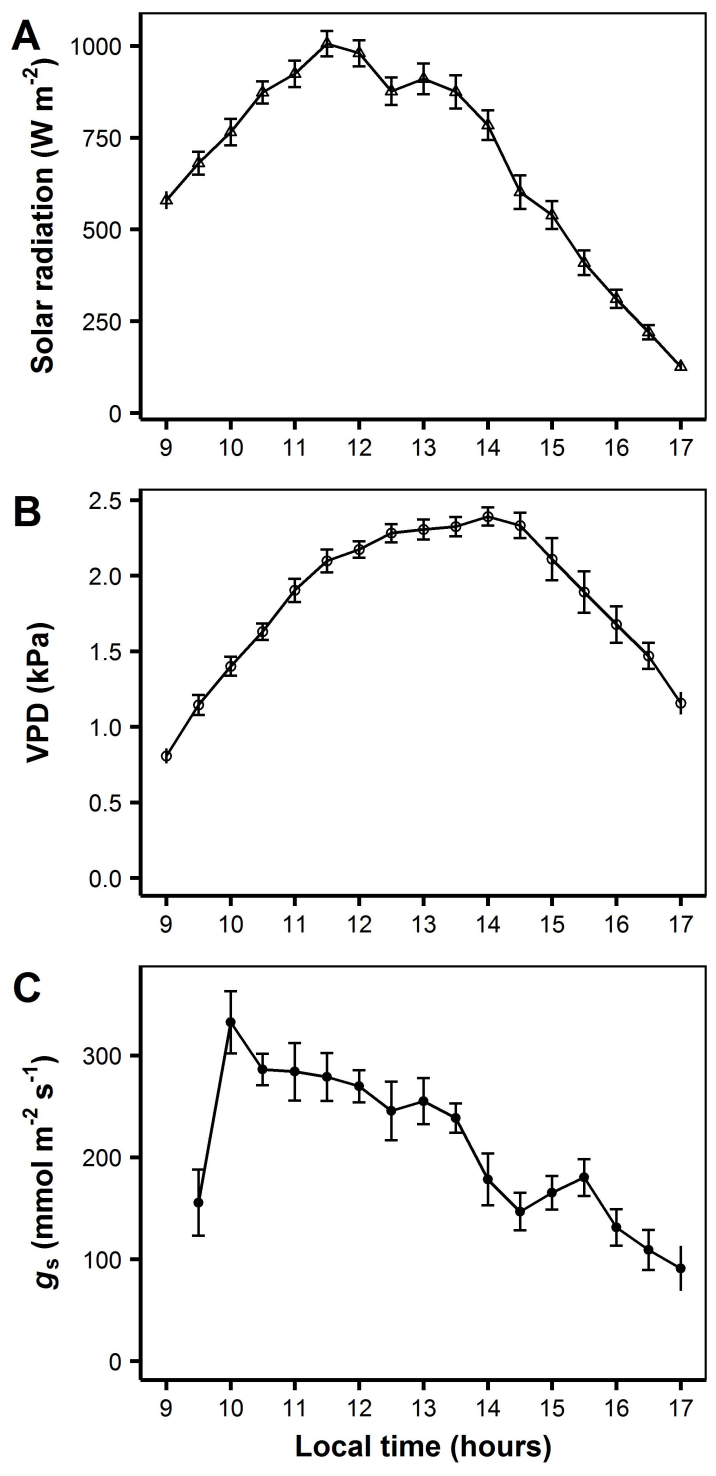

Fig. 3.3: Daily course of solar radiation (A), atmospheric VPD (B) and stomatal conductance (C) of palm fronds on sunny days in October 2016 at the PT Humusindo plantation site. Presented data are averages over 6 days and three palms each with nine fronds measured in a rotating measuring scheme (means $\pm \mathrm{SE})$.

\section{Embolism resistance}

When calculating the shape parameter $k$ of the Weibull distribution from our model estimates, all plot-level predictions achieved values well above 1, indicating a sigmoidal shape for the bulk of VCs. Across the six plots at the riparian and well-drained sites, we found mean $( \pm \mathrm{SE}) P_{12}$, $P_{50}$ and $P_{88}$ values of $1.05 \mathrm{MPa}( \pm 0.12), 1.86 \mathrm{MPa}( \pm 0.15)$ and $4.53 \mathrm{MPa}( \pm 0.26)$, respectively, for fully developed oil palm fronds (Table 3.3). The VCs differed between the three plots of a plantation type (Fig. A3.3 in the Appendix; Table 3.3). Despite this variation, the mixed effects 
model with a conditional $r^{2}$ of 0.63 and a marginal $r^{2}$ of 0.58 predicted a significantly lower $P_{50}$ in the well-drained plots compared with the riparian plots (Fig. 3.4). The $P_{50}$ of palms of equal size in well-drained plots was predicted to be 1.29 MPa lower than in riparian plots (Table 3.4). This difference corresponds to the effect of plantation type for palms centered at a similar height and averaged for the region (regional mean: $6.93 \mathrm{~m}$ ). As palms in well-drained and riparian plots have different heights (means: 7.55 vs $6.37 \mathrm{~m}$ ), predicted $P_{50}$ increased by $0.42 \mathrm{MPa}$ in riparian plots, when height difference was not accounted for (Fig. 3.4; Table 3.3).

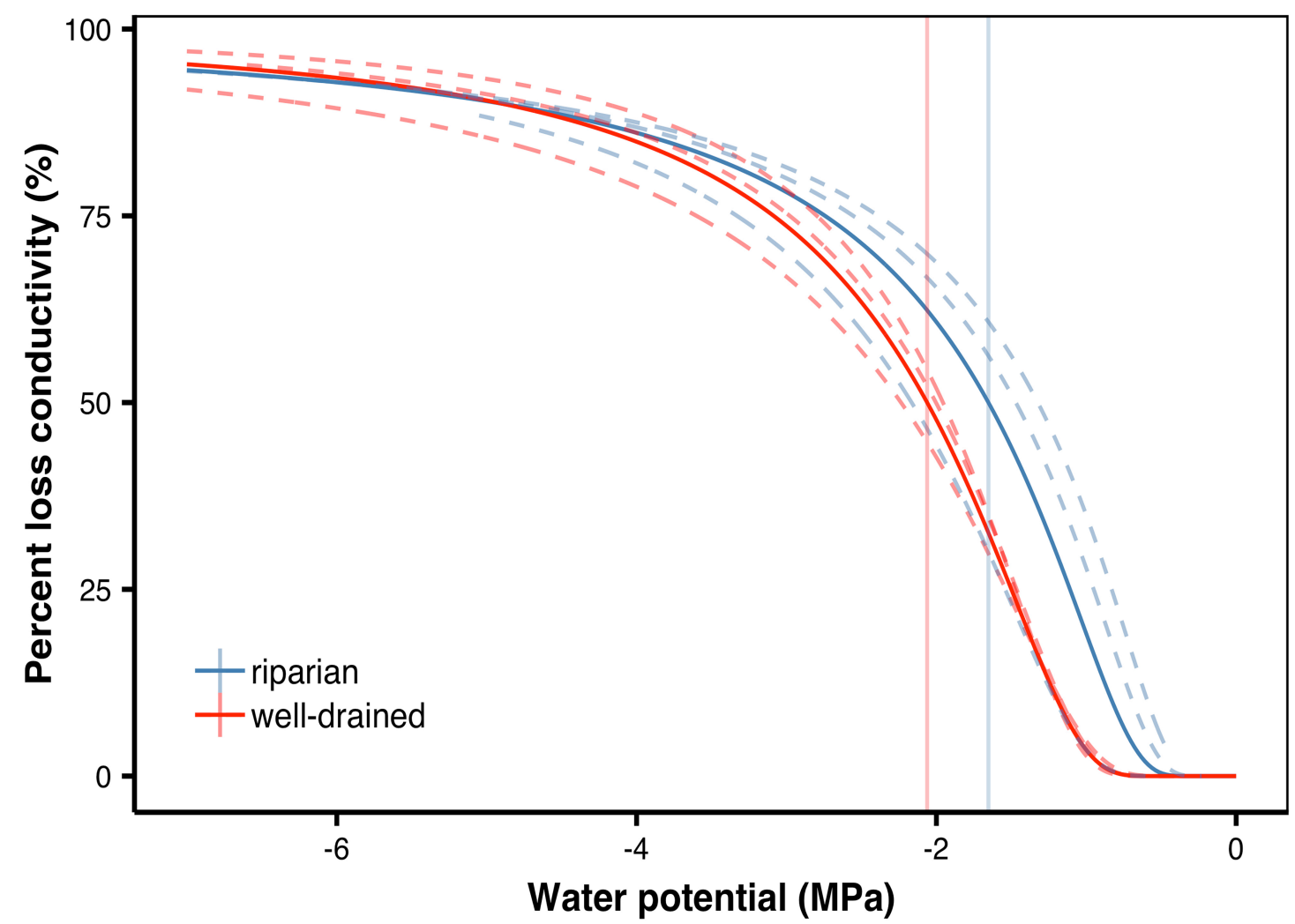

Fig. 3.4: Site- and plot-averaged VCs for the three well-drained and three riparian plots and corresponding $P_{50}$ values, indicated by vertical lines ( $n=6$ palms per plot, 3 plots per plantation type). Blue-colored lines stand for riparian sites and red-colored lines for well-drained sites. Dashed lines stand for plot-level predictions and full lines for plantation type level predictions. 
This difference between general model output and predictions for the plantation types is caused by the fact that $P_{50}$ is also strongly dependent on palm height. We found an increase in $P_{50}$ by $1.02 \mathrm{MPa}$ per m palm height in the riparian sites (Fig. 3.5D; Table 3.4), indicating that taller palms tend to be more vulnerable to embolism (higher $P_{50}$ ) than smaller ones. Although predicted values indicate a weaker height effect in the well-drained sites (Fig. 3.5D), we found no significant interaction effect between height and plantation type on $P_{50}$. Regarding the slope of the VCs, neither palm height nor plantation type had a significant effect on this parameter. Nonetheless, our model shows a significant interaction of height and plantation type, with tall palms in well-drained plots having a slope 36\% lower than tall palms in riparian plots (Table 3.4), indicating that the palm height effect on embolism resistance is more important at the riparian sites. In accordance with the $P_{50}$ difference between sites, the $P_{12}$ value in the riparian plots was 0.37 MPa higher than in the well-drained plots, which was not the case for $P_{88}$ (Table 3.3).

Table 3.4: Results of a hierarchical mixed effects model on the influence of site (riparian vs welldrained) and plant height and their interactions on $P_{50}$ and the slope of the VCs (slope $+P_{50}$ $\sim$ plantation type height). Given are PLC values (numbers in parentheses give SE of the estimates) and t-values (from Wald z-test) for the fixed effects and standard deviation (SD) for random effects. Degrees of freedom of the model were equal to 61. Fixed effects were plantation type and plant height, random effects plot and palm nested in plot. Asterisks indicate the level of significance: ${ }^{*} P<0.05$; ${ }^{* *} P<0.01$.

\begin{tabular}{|c|c|c|c|}
\hline Parameters & Coefficients & & \\
\hline \multirow{5}{*}{ Slope } & & PLC & $t$-value \\
\hline & intercept (riparian) & $\begin{array}{c}41.29^{* *} \\
(1.00)\end{array}$ & 4.08 \\
\hline & well-drained & $\begin{array}{l}12.81 \\
(1.55)\end{array}$ & 0.82 \\
\hline & height (riparian) & $\begin{array}{c}8.83 \\
(1.30)\end{array}$ & 0.67 \\
\hline & well-drained $x$ height & $\begin{array}{c}-36.85^{*} \\
(1.59)\end{array}$ & -2.2 \\
\hline \multirow{4}{*}{$P_{50}$} & intercept (riparian) & $\begin{array}{c}-1.09^{* *} \\
(0.03)\end{array}$ & -3.6 \\
\hline & well-drained & $\begin{array}{c}-1.29^{* *} \\
(0.04)\end{array}$ & -3.5 \\
\hline & height (riparian) & $\begin{array}{l}1.02^{* *} \\
(0.03)\end{array}$ & 3.03 \\
\hline & well-drained $x$ height & $\begin{array}{l}-0.50 \\
(0.05)\end{array}$ & -1.07 \\
\hline Random effects & & palms nested in plots & \\
\hline SD residuals & & 19.83 & \\
\hline Number of plots & & 6 & \\
\hline SD plot (slope) & & 0.05 & \\
\hline SD plot $\left(P_{50}\right)$ & & 0.23 & \\
\hline Number of palms & & 34 & \\
\hline SD palm (slope) & & 3.40E-06 & \\
\hline SD palm $\left(P_{50}\right)$ & & 3.23E-08 & \\
\hline Observations & & 102 & \\
\hline
\end{tabular}




\section{Xylem anatomical traits}

In contrast to $P_{12}$ and $P_{50}$, we found no differences in xylem anatomical traits between riparian and well-drained plots (Fig. 3.5; Table 3.5). The mixed models had low conditional $r^{2}$ values for all variables $\left(r^{2}=0.18,0.18\right.$ and 0.15 for $K_{\mathrm{p}}, \mathrm{VD}$ and $\left.D_{\mathrm{h}}\right)$, indicating no influence of plantation type. Yet, palm height had a significant effect on $K_{\mathrm{p}}$ and $D_{\mathrm{h}}$. According to our model, a palm height increase of $1 \mathrm{~m}$ is associated with a $D_{\mathrm{h}}$ decrease of $9.27 \mathrm{~m}$ (Fig. 3.5B; Table 3.5) and a $K_{\mathrm{p}}$ decrease of $3.79 \mathrm{~kg} \mathrm{~m}^{-1} \mathrm{MPa}^{-1} \mathrm{~s}^{-1}$ (Fig. 3.5C; Table 3.5) in the riparian sites. There was no significant height effect on VD (Fig. 3.5A; Table 3.5), and for none of the three variables was a significant interaction between height and plantation type found. The variability in anatomical traits among the plants was generally larger in the well-drained than in the riparian plots (Fig. 3.5).

Table 3.5: Results of mixed effects models on the influence of site (riparian vs. well-drained) and plant height and their interactions on hydraulically weighted mean vessel diameter $\left(D_{\mathrm{h}}\right)$, potential conductivity $\left(K_{\mathrm{p}}\right)$ and VD of the palm frond rachis. Given are values (numbers in parentheses give SE of the estimates) and $t$-values for the fixed effects and SD for the random effects. SD weight for riparian sites are also given (SD weight of well-drained sites equal 1). Fixed effects were plantation type and plant height; random effect was plot. Asterisks indicate the level of significance: ${ }^{* *} P<0.01$.

\begin{tabular}{lcccccc}
\hline Coefficients & $D_{\mathrm{h}}$ & $t$-value & $K_{\mathrm{p}}$ & $t$-value & VD & $t$-value \\
\hline intercept (riparian) & $113.84^{* *}$ & 59.00 & $12.12^{* *}$ & 13.53 & $22.93^{* *}$ & 25.66 \\
& $(1.93)$ & & $(0.90)$ & & $(0.89)$ & \\
well-drained & 7.56 & 1.91 & 2.67 & 1.72 & 0.44 & 0.31 \\
& $(3.95)$ & & $(1.55)$ & & $(1.39)$ & \\
height (riparian) & $-9.27^{* *}$ & -3.88 & $-3.79^{* *}$ & -3.97 & -0.43 & -0.60 \\
& $(2.39)$ & & $(0.95)$ & & $(0.71)$ & \\
well-drained x height & 4.74 & 1.00 & 2.00 & 1.19 & 0.76 & 0.64 \\
& $(4.76)$ & & $(1.69)$ & & $(1.19)$ & \\
\hline Random effect & & & & & & \\
\hline Number of plots & 6 & & 6 & & 6 & \\
SD residuals & 14.96 & & 4.92 & & 1.26 & \\
SD plot & 1.42 & & 1.02 & & 0.68 & \\
SD weight (riparian) & 0.56 & & 0.63 & & 102 & \\
Observations & 102 & & 102 & & & \\
\hline
\end{tabular}



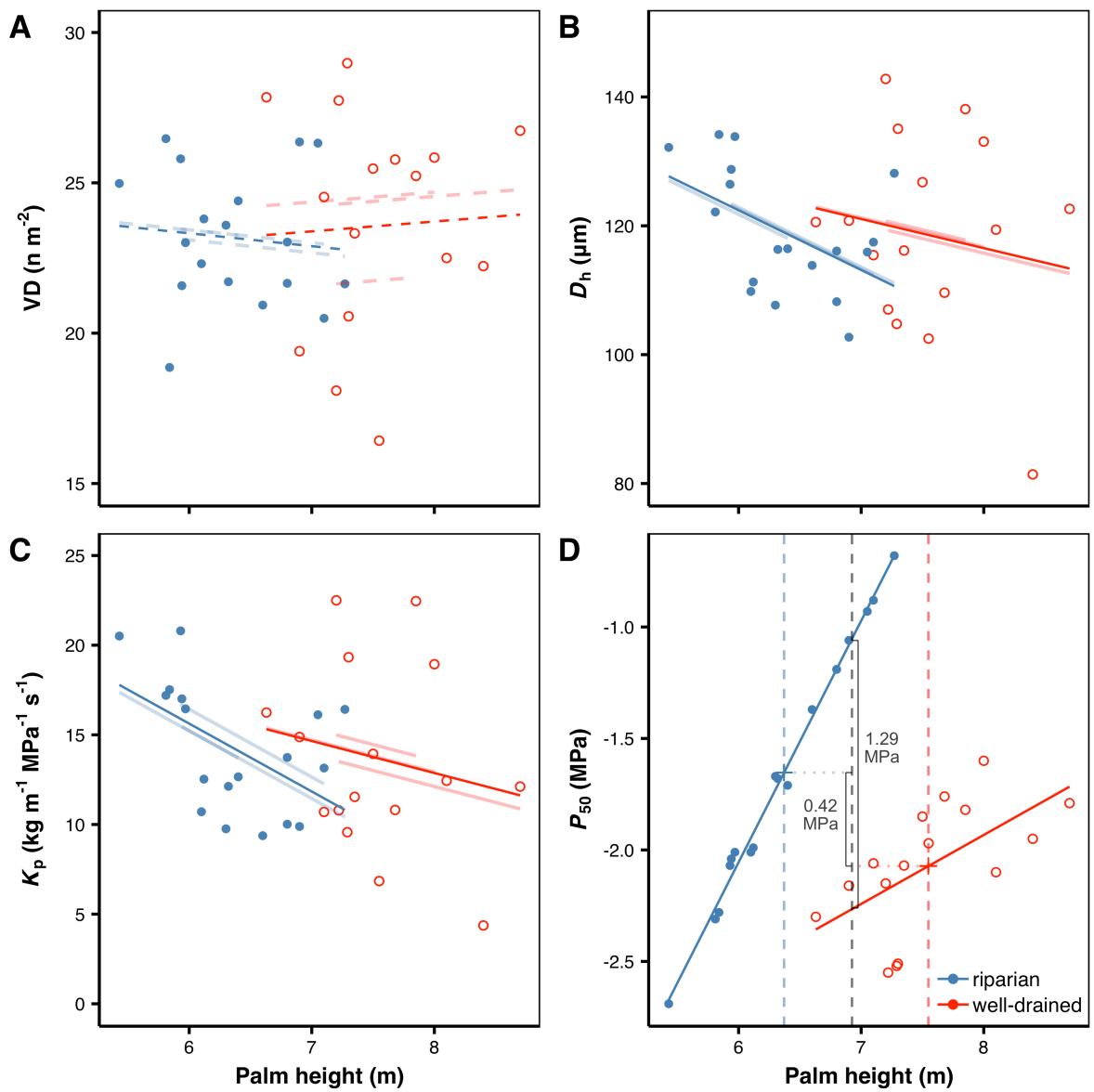

Fig. 3.5: Dependence of (A) vessel density (VD), (B) hydraulically weighted vessel diameter $\left(D_{\mathrm{h}}\right)$, (C) potential conductivity $\left(K_{\mathrm{p}}\right)$ and $(\mathrm{D})$ water potential at $P_{50}$ on palm height for all investigated palms. Each point represents one frond. Given are regression lines for each plantation type (blue line, filled circles: riparian; red line, open circles: well-drained). Solid lines depict significant trends $(P<0.05)$, dashed lines non-significant trends. Crosses given in (D) stand for predicted $P_{50}$ for each plantation type; further given are differences in $P_{50}$ between plantation types when comparing palms of a similar regionally averaged height (long brackets, $1.29 \mathrm{MPa}$ ) and palms of different plantation-type-averaged heights (short brackets, $0.42 \mathrm{MPa}$ ) are also indicated.

\section{Discussion}

\section{Stomatal regulation and drought sensitivity of oil palm}

Our porometer measurements on oil palm fronds evidence sensitive stomatal regulation during a sunny period with relatively high soil moisture content. Stomatal conductance decreased with increasing VPD between 10:00 and 14:00 $\mathrm{h}$ in most individuals, which matches the diurnal course of sap flux density measured in palms of the same study region (Hardanto et al. 2017). Our results confirm earlier reports of rapid stomatal closure with increasing VPD in oil palm (Smith 1989, Dufrêne and Saugier 1993). Whether this response is triggered by stomatal sensitiv- 
ity to VPD or mediated by chemical or pressure signals, must remain open. Since we investigated fronds at an intermediate developmental stage, we assume that our results are representative of the majority of palm fronds in the stands and do not reflect a senescence effect of old foliage.

A sensitive stomatal regulation of oil palm seems to conflict with the high productivity of this C3 species (Apichatmeta et al. 2017). However, oil palm has a high photosynthetic efficiency (Dufrêne et al. 1990, Squire 1990) reaching photosynthetic rates $>14 \mathrm{~mol} \mathrm{CO} 2 \mathrm{~m}^{2} \mathrm{~s}^{-1}$ (Apichatmeta et al. 2017). According to those studies, it seems that partial stomatal closure during most of the day does not lead to a relevant reduction in assimilation rate. However, extended drought periods can result in substantial yield reductions, as was observed during El Niño drought episodes in south-east Asia (Henson 1999). Thus, oil palm must be considered as a fairly drought-sensitive species in terms of productivity (Carr 2011). One reason is that drought seems to trigger physiological processes such as the development of a higher proportion of male flowers and the abortion of young inflorescences (Corley and Tinker 2016) that reduce fruit set and thus cause yield reductions under water deficits (Nouy et al. 1999). Legros et al. (2009) observed that oil palm can store quite large amounts of carbohydrates in the stem, which can be mobilized during periods of water shortage and might buffer the effects of reduced photosynthetic carbon gain to a certain extent.

\section{Embolism resistance in oil palm}

With a regional $P_{50}$ average of $-1.86 \mathrm{MPa}(-1.65$ in the riparian plots, $-2.07 \mathrm{MPa}$ in the welldrained plots), the oil palms of our study region exhibited relatively high xylem water potential thresholds. In combination with the porometer measurements, this indicates that E. guineensis follows an isohydric stomatal control strategy. The relatively high $P_{50}$ values match well with the results of other studies on tropical tree and palm species, which suggest that many tree or tree-like species from the moist tropics seem to be quite vulnerable to water deficits (Rowland et al. 2015, Santiago et al. 2018, Oliveira et al. 2018). For rubber trees (Hevea brasiliensis Müll. Arg.), another economically important tropical woody crop species, an average $P_{50}$ of -1.86 to $-1.89 \mathrm{MPa}$ was reported (Jinagool et al. 2016). Even less negative $P_{50}$ values were recorded for some other tree species of the tropical moist forest biome (e.g. Schefflera morotoni Aubl.: -1.5 MPa; Tyree et al. 1991). The only few existing $P_{50}$ data for tropical palms compare quite well with our results (e.g., in Iriartea deltoidea, $P_{50}=-1.4 \mathrm{MPa}$; Renninger and Phillips 2011). Concluding on the scarce information available, it appears that $P_{50}$ varies largely among tree and tree-like plant species from the moist tropics (Oliveira et al. 2018), with palms mostly being fairly vulnerable. 
A relatively high $P_{50}$ and thus putatively greater vulnerability to embolism could be part of a strategy of oil palm to protect more durable organs from hydraulic failure. The frond, as a 'replaceable' and expendable organ, could act as a 'safety valve' to avoid runaway embolism in the connected palm stem (Chen et al. 2010, McCulloh et al. 2014, Pivovaroff et al. 2014). Further, palms have a higher proportion of living cells in their stem, which means that stored stem water plays a larger role in daily and seasonal water relations than in many angiosperm trees (Renninger and Phillips 2016). In date palms, for example, $25 \%$ of daily water use was derived from stored stem water (Sperling et al. 2015), but corresponding data for oil palm are lacking. Thus, xylem vulnerability should be assessed in relation to stem capacitance. Finally, although few studies are available, it is important to highlight the fact that oil palm may possess mechanisms of embolism reversal to maintain its stem hydraulic integrity. Such mechanisms may imply positive root pressure as found in other monocot species (e.g., in some bamboo species; Cochard et al. 1994, Yang et al. 2012) or the accumulation of organic solutes (e.g., in Cocos nucifera; Bai and Rajagopal 2000).

\section{Plasticity in hydraulic traits}

Oil palms of the well-drained plots had -1.29 MPa lower $P_{50}$ values when comparing palms of similar averaged height and presumably a higher embolism resistance than the palms in the riparian plots, indicating substantial plasticity of the foliar xylem in its vulnerability to cavitation in dependence on water availability. We assume that this pattern was not caused by genetic differentiation between populations as the genetic distance between the individuals was low and the main genetic variance was found within the plantation types and not between well-drained and riparian populations. Thus, xylem vulnerability to embolism in oil palm seems to be subject to quite high phenotypic plasticity as a consequence of environmental control, a pattern that was found in other studies as well (Corcuera et al. 2011, Schuldt et al. 2016, Cardoso et al. 2018). In contrast to embolism resistance, the xylem anatomical properties of the palm fronds, namely $D_{\mathrm{h}}$, VD and $K_{\mathrm{p}}$, did not differ between oil palms in well-drained and riparian plots. This suggests that other conduit properties may be more important for hydraulic safety, notably the structure of pit membranes and pit cavities (Wheeler et al. 2005, Li et al. 2016). Our study is, to our knowledge, apparently the first to investigate embolism resistance in oil palm and the plasticity of embolism resistance in palms. To achieve a more general understanding of the variability of hydraulic properties and xylem vulnerability in this species, further studies comparingdifferent oil palm genotypes and covering a broader range of habitats are needed.

The slope of the VCs at $P_{50}$ was similar for palms in well-drained and riparian plots, and $P_{88}$ 
values did not differ between the two sites. This suggests that, despite considerable variability in embolism resistance in early stages of multiple cavitation events, oil palm fronds reach the threshold of major hydraulic failure at a similar water potential. This could mean that the observed plasticity in frond vulnerability to embolism is a strategy primarily serving to protect the plant against short- or low-intensity drought events that do not reduce xylem water potential drastically. In case of more severe drought events, oil palms growing at the drier sites would experience major hydraulic failure at a similar water potential as palms from the moister riparian sites.

With this study we present evidence for considerable intraspecific variability in the embolism resistance of palm fronds. This may suggest that oil palm, and perhaps other tree-like monocots with a rather simple hydraulic architecture, produces a relatively plastic xylem in their replaceable organs as part of an acclimation and adaptation strategy to water deficits. Angiosperm and gymnosperm trees with secondary growth, in contrast, have to build a more durable hydraulic architecture in their canopies, which has to accommodate many subsequent leaf generations and must withstand changing climatic conditions over time, which could limit the extent of realized phenotypic plasticity.

\section{Effect of plant height and soil conditions on xylem embolism resistance and anatomy}

An unexpected result of our study is that palm height appears to be one of the main drivers of embolism resistance. The height effect was found to be independent of plantation type and site (Table 3.4). A plausible explanation for this observation could be that taller palms are more vulnerable to cavitation than smaller ones due to frictions that increase with growing hydraulic path length and gravity force, lowering hydraulic efficiency with increasing height (hydraulic limitation hypothesis; Ryan and Yoder 1997). However, the height gradient across our plant sample is far too small to explain a $P_{50}$ increase of $1 \mathrm{MPa} \mathrm{m}^{-1}$, as the gravity effect can account only for a potential reduction of $0.01 \mathrm{MPa} \mathrm{m}^{-1}$ (Koch et al. 2004). We propose that, across all sites, the general effect of palm height on embolism resistance must be indirect. The effect could be due to a set of developmental modifications associated with palm height such as deeper rooting and higher stem water capacitance that affect oil palm frond vulnerability to embolism and hydraulic traits. This is suggested by the observed negative height effect on $D_{\mathrm{h}}$ and $K_{\mathrm{p}}$ (Fig. 3.5B, C). Although palm height influences embolism resistance in both plantation types, this effect is stronger at the riparian sites. We indeed found a much larger variability of palm-level $P_{50}$ values with changing palm height (Fig. 3.5D) and a steeper slope in the riparian plots compared with the well-drained 
plots (Table 3.4). This could reflect differences in soil texture or soil chemistry between the two sites. Several studies confirmed that water availability directly affects embolism resistance (e.g., Schuldt et al. 2016, Lübbe et al. 2017). Because soil pore size is a major determinant of the water holding capacity and thus the water potential of soils, a direct relationship between soil texture and embolism resistance is most likely. We suppose that plants growing on coarse-grained soils are more frequently exposed to water limitation, which should translate into the development of a safer xylem within a given species compared with plants growing on sites with better soil water availability. In contrast to this assumption, the limited number of available studies on the influence of soil texture on embolism resistance showed the opposite, namely that shrubs or trees growing on coarser-grained soils tend to be more vulnerable to embolism formation than plants growing on finer-grained soils (Hacke et al. 2000, Sperry and Hacke 2002). However, the authors likewise assumed that the former would more frequently experience greater drought limitation. This should, according to our findings, cause the development of a more resistant xylem as observed by the present study, where oil palms from the riparian sites with more fine-grained soils developed a more vulnerable xylem compared with plants from the well-drained sites with coarser-grained soils. Since average VPD was higher at the riparian sites, it is unlikely that the atmospheric moisture status has caused the sites differences in $P_{50}$ values.

\section{Conclusion}

Our $P_{50}$ data suggest that oil palm is vulnerable to embolism when exposed to water deficits, which matches observations of yield decreases during severe dry spells. The relatively high $P_{50}$ values suggest that the species maintains milder operating pressures in its frond xylem than observed in the canopy of many other tree species; this requires stringent stomatal control. Our porometer measurements in conjunction with literature data qualify oil palm as a mostly isohydric species, which maintains the integrity of its water transport system through sensitive stomatal control of water loss even in moist periods. High stem capacitance could be another element in a conservative water status regulation strategy.

An important finding is the considerable variation in $P_{50}$ values that exists among individuals, size classes and sites. This may represent an adaptive strategy of oil palm to respond to mild seasonal water deficits with anatomical and physiological plasticity in the xylem of its relatively short-lived fronds, thereby securing the hydraulic integrity of the longer-lived stem and coarse root system. However, despite this remarkable plasticity in early stages of multiple cavitation 
events, all palms in our study had relatively similar $P_{88}$ values. This indicates that catastrophic hydraulic failure happens at all sites at the same water potential threshold, and oil palm may be unable to withstand long and severe droughts on well-drained and also groundwater-influenced sites. There is a need to study stem water storage, root hydraulics and osmotic processes in embolism reversal to fully understand the mechanisms protecting oil palm stem hydraulic integrity.

Our findings further suggest that tropical lowland riparian regions with flooded soil may be less suitable for planting oil palm. Given that riparian woodlands fulfill important ecological functions as a buffer zone between upland oil palm plantations and streams (Chellaiah and Yule 2018a, 2018b, Mitchell et al. 2018), land-use managers should consider other options than replacing natural riparian vegetation by oil palm plantations.

\section{Acknowledgement and fundings}

This study is part of the Collaborative Research Centre CRC 990 - EFForTS (Ecological and Socioeconomic Functions of Tropical Lowland Rainforest Transformation Systems) conducted by the University of Göttingen, Germany, Bogor Agricultural University, the University of Jambi and Tadulako University of Palu, Indonesia. We thank the University of Jambi and all our counterparts for providing space to conduct laboratory work, the plot owners for allowing us to sample palm fronds, Syahbarudin and Kairul Anwar for their valuable help in sampling fronds and measuring water potential, Vira Addriyati Achmad and Pratiwi Hamson for their excellent anatomical work, Mathilde Millan for her support in the course of her internship, Christian Stiegler for providing the climatic data and Aiyen Tjoa for the provision of plot data and information on oil palm seed origins. The genetic analyses (AFLPs) were performed in the Department of Forest Genetics and Forest Tree Breeding of the University of Göttingen under the supervision of Oliver Gailing. We thank Christine Radler and Alexandra Dolynska for their help with the AFLP analyses, as well as Oliver Gailing for reviewing and commenting on the manuscript.

The study was funded by the Deutsche Forschungsgemeinschaft (German Research Foundation)—project number 192626868 — subproject B04 and the Ministry of Research, Technology and Higher Education (Ristekdikti) in the framework of the collaborative German-Indonesian research project CRC990. We thank subproject B14 (Oliver Gailing) for covering the costs for the DNA extractions and AFLP analyses and subproject A04 for providing soil texture data for the riparian sites. 


\section{Appendix}

Table A3.1: Coordinates and elevations ( $\mathrm{m}$ above sea level) of the studied plots.

\begin{tabular}{|c|c|c|c|c|}
\hline Plantation type & Plot & Coordinates S & Coordinates E & Elevation \\
\hline \multirow{3}{*}{ well-drained } & WD1 & 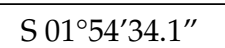 & E $103^{\circ} 15^{\prime} 57.6^{\prime \prime}$ & 64 \\
\hline & WD2 & S 015'01.4" & E $103^{\circ} 18^{\prime} 27.5^{\prime \prime}$ & 65 \\
\hline & WD3 & S $01^{\circ} 47^{\prime} 13.8^{\prime \prime}$ & E $103^{\circ} 16^{\prime} 14.7^{\prime \prime}$ & 46 \\
\hline \multirow{3}{*}{ riparian } & Ri1 & S 01⒌ $54^{\prime} 07.6^{\prime \prime}$ & E $103^{\circ} 22^{\prime} 53.6^{\prime \prime}$ & 9 \\
\hline & Ri2 & S $01^{\circ} 52^{\prime} 41.8^{\prime \prime}$ & E $103^{\circ} 21^{\prime} 21.6^{\prime \prime}$ & 21 \\
\hline & Ri3 & S $01^{\circ} 51^{\prime} 39.4^{\prime \prime}$ & E $103^{\circ} 18^{\prime} 19.0^{\prime \prime}$ & 42 \\
\hline
\end{tabular}

Table A3.2: depth-related soil texture of five of the investigated plots. Given are the percent of sand, silt and clay depending of soil depth (m).

\begin{tabular}{|c|c|c|c|c|c|}
\hline Plantation type & Plot & Depth & Sand (\%) & Silt (\%) & Clay (\%) \\
\hline \multirow{6}{*}{ well-drained } & \multirow{3}{*}{ WD2 } & 5.00 & 66.25 & 16.88 & 16.87 \\
\hline & & 20.00 & 52.00 & 12.00 & 36.00 \\
\hline & & 40.00 & 49.00 & 12.62 & 37.88 \\
\hline & \multirow{3}{*}{ WD3 } & 5.00 & 44.45 & 32.40 & 23.15 \\
\hline & & 20.00 & 45.00 & 25.38 & 29.62 \\
\hline & & 40.00 & 44.55 & 22.18 & 33.27 \\
\hline \multirow{9}{*}{ riparian } & \multirow{3}{*}{ Ri1 } & 5.00 & 4.22 & 38.40 & 57.38 \\
\hline & & 20.00 & 3.38 & 35.92 & 60.71 \\
\hline & & 40.00 & 22.36 & 43.71 & 33.94 \\
\hline & \multirow{3}{*}{ Ri2 } & 5.00 & 6.70 & 41.48 & 51.83 \\
\hline & & 20.00 & 17.45 & 43.85 & 38.71 \\
\hline & & 40.00 & 22.23 & 43.76 & 34.00 \\
\hline & \multirow{3}{*}{ Ri3 } & 5.00 & 23.35 & 48.18 & 28.48 \\
\hline & & 20.00 & 22.02 & 48.59 & 29.40 \\
\hline & & 40.00 & 21.11 & 46.77 & 32.12 \\
\hline
\end{tabular}


Table A3.3: Pairwise genetic dissimilarity between 36 investigated individuals. Gradient colors indicate the level of dissimilarity, light green colors low distance, dark green colors high distance. Zero is shown for the comparison of the same individual.

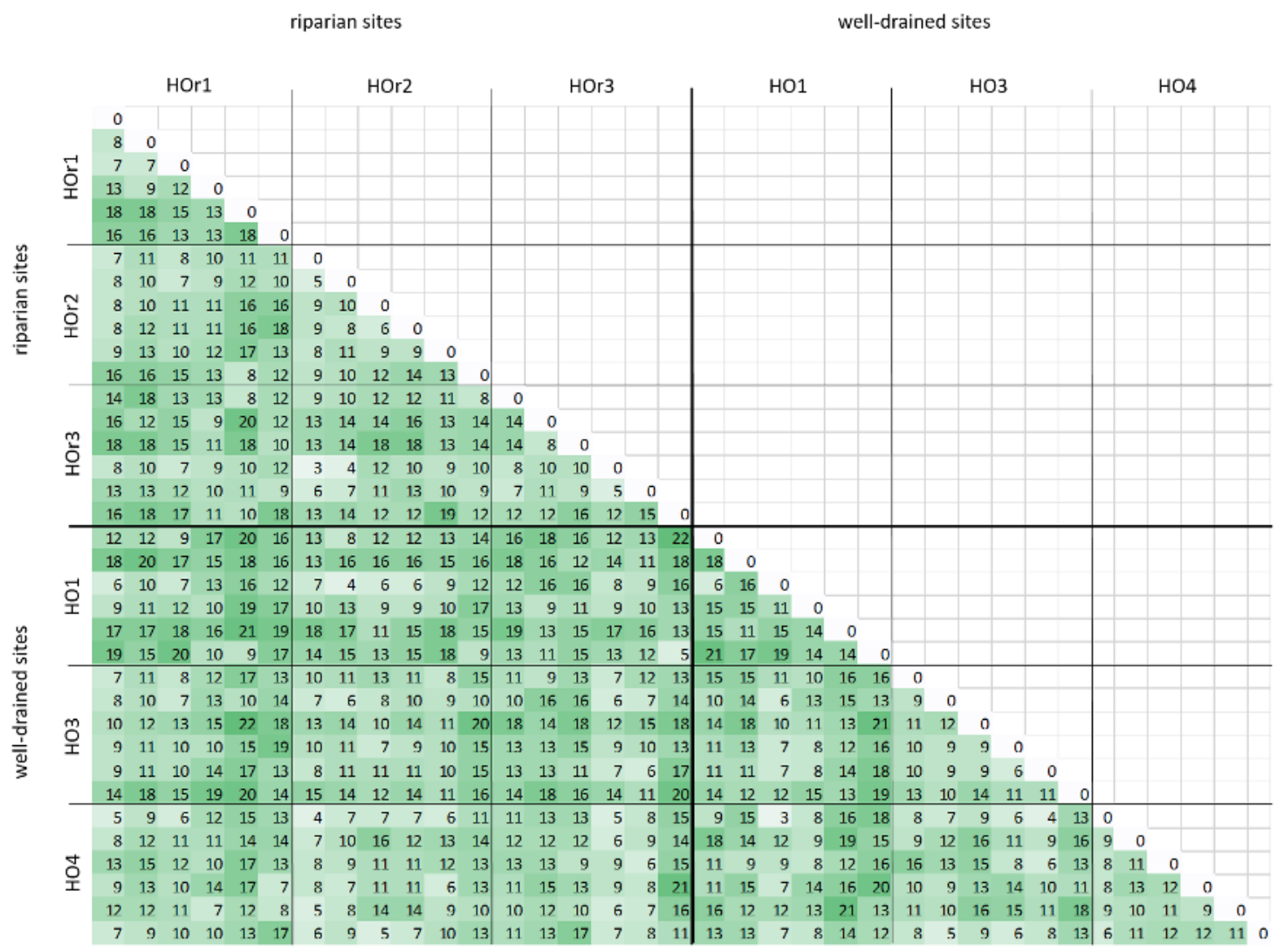


Fig. A3.1: Daily course of vapor pressure deficit (VPD) of the investigated plots including (A) every days from June 2017 to August 2018, (B) the 25\% driest days from the same period. Thick lines are the averages $( \pm \mathrm{SE}$ ) of riparian (blue lines; filled circles) and well-drained (red lines; open circles) plantation types, dashed lines stand for the individual plots.
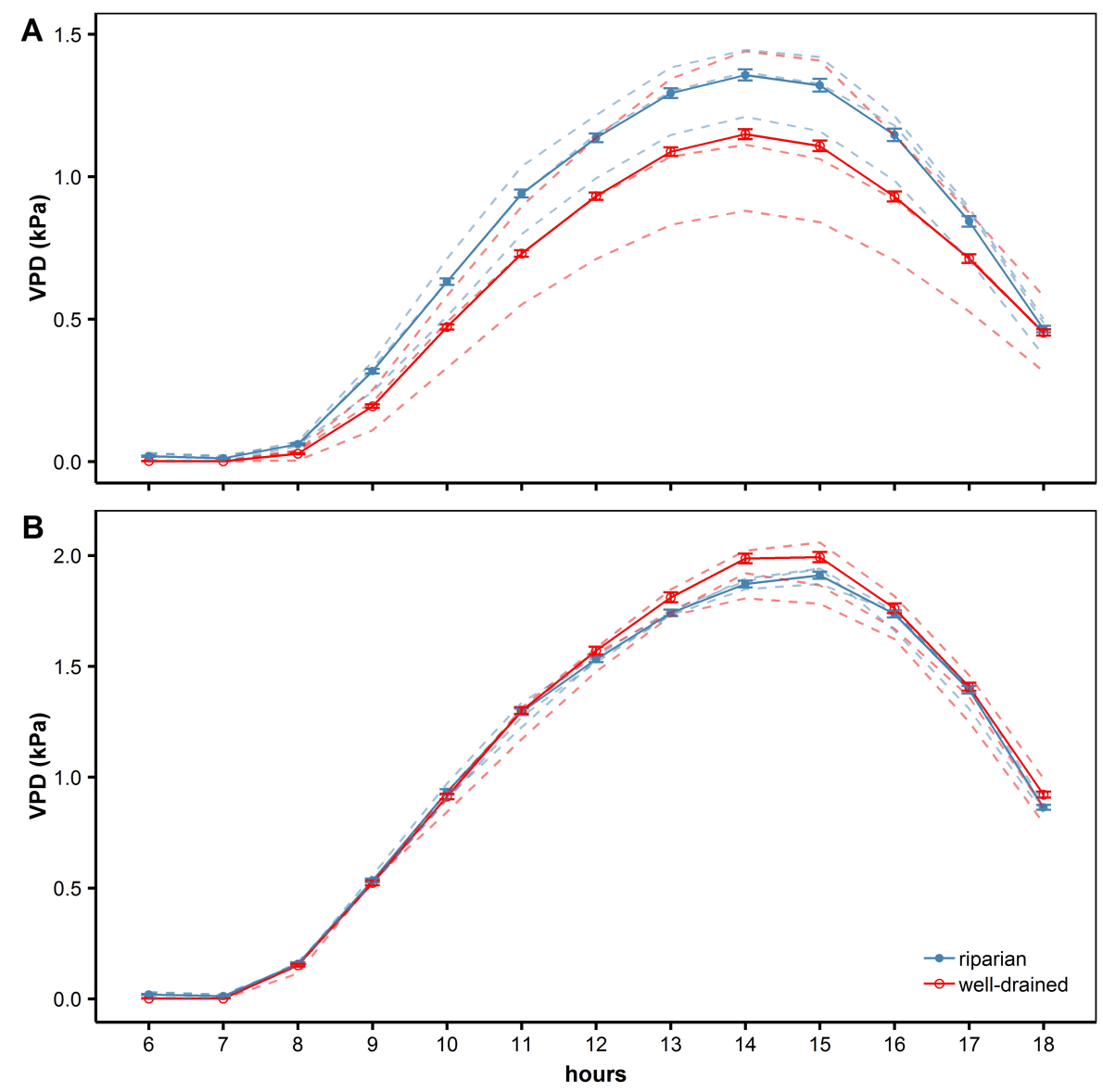

Fig. A3.2: AMOVA results between well-drained and riparian site types, based on 999 permutations. Dark grey indicates the genetic variance among the two types and light grey within the well-drained and riparian sites.

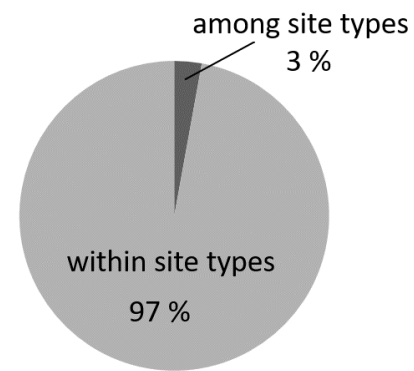


Fig. A3.3: Predicted vulnerability curves (VCs; percent loss of conductivity vs. xylem water potential) of oil palm fronds given for all palms measured in the six plots on the well-drained (upper row) and riparian sites (lower row). Color: palm identity; colored lines - palm level predictions; dashed black lines - plot level predictions; solid black lines - plantation type level predictions.

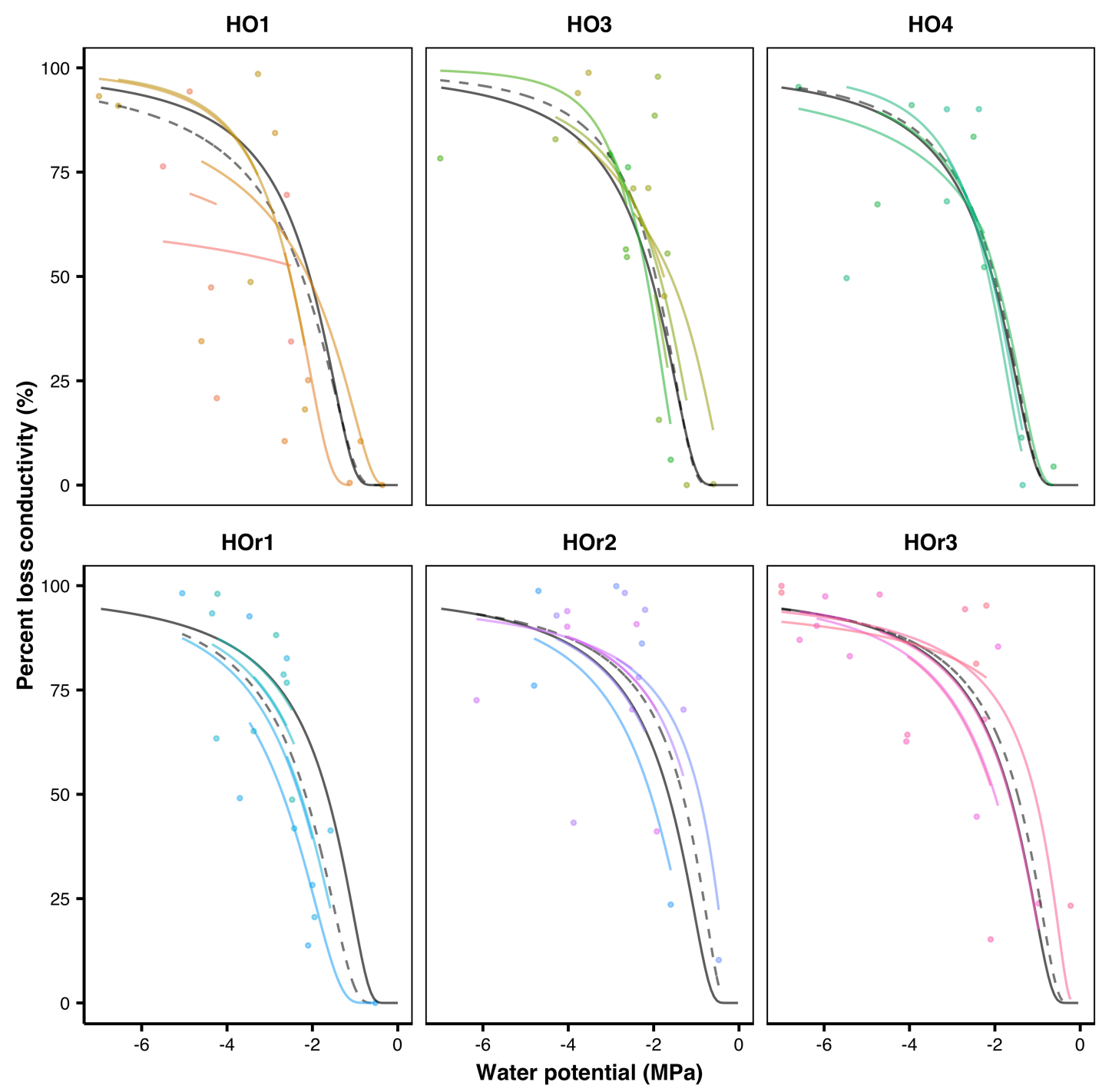




\section{References}

Adam, H., Collin, M., Richaud, F., Beulé, T., Cros, D., Omoré, A., NodichaO, L., NouY, B., AND TREgEAR, J. W. 2011. Environmental regulation of sex determination in oil palm: current knowledge and insights from other species. Annals of botany 108:1529-1537.

Aholoukpè, H., Dubos, B., Flori, A., Deleporte, P., Amadji, G., Chotte, J. L., AND BLAVET, D. 2013. Estimating aboveground biomass of oil palm: Allometric equations for estimating frond biomass. Forest Ecology and Management 292:122-129.

Aitken, S. N., Yeaman, S., Holliday, J. A., WAng, T., And Curtis-Mclane, S. 2008. Adaptation, migration or extirpation: climate change outcomes for tree populations. Evolutionary applications 1:95-111.

Allen, C. D., Breshears, D. D., AND MCDowell, N. G. 2015. On underestimation of global vulnerability to tree mortality and forest die-off from hotter drought in the anthropocene. Ecosphere 6:1-55.

Allen, C. D., Macalady, A. K., Chenchouni, H., Bachelet, D., McDowell, N. G., VenNetier, M., Kitzberger, T., Rigling, A., Breshears, D. D., Hogg, E. H., Gonzalez, P., Fensham, R., Zhang, Z., Castro, J., Demidova, N., Lim, J.-H., Allard, G., Running, S. W., SEmerci, A., AND COBB, N. 2010. A global overview of drought and heat-induced tree mortality reveals emerging climate change risks for forests. Forest Ecology and Management 259:660-684.

Allen, K., Corre, M. D., Kurniawan, S., Utami, S. R., And VeldKamp, E. 2016. Spatial variability surpasses land-use change effects on soil biochemical properties of converted lowland landscapes in sumatra, indonesia. Geoderma 284:42-50.

Apichatmeta, K., Sudsiri, C. J., And Ritchie, R. J. 2017. Photosynthesis of oil palm (elaeis guineensis). Scientia Horticulturae 214:34-40.

Aranda, I., Cano, F. J., Gascó, A., Cochard, H., Nardini, A., Mancha, J. A., López, R., AND SÁNCHEZ-GÓMEZ, D. 2015. Variation in photosynthetic performance and hydraulic architecture across european beech (fagus sylvatica 1.) populations supports the case for local adaptation to water stress. Tree physiology 35:34-46.

BAI, K. AND RAJAGOPAL, V. 2000. Osmotic adjustment as a mechanism for drought tolerance in coconut (cocos nucifera 1.). Indian Journal of Plant Physiology 5:320-323. 
BATES, D., MÄChleR, M., BOlKer, B., AND WALKeR, S. 2015. Fitting linear mixed-effects models using lme4. Journal of Statistical Software 67.

Bjorholm, S., Svenning, J.-C., SKOv, F., AND BALslev, H. 2005. Environmental and spatial controls of palm (arecaceae) species richness across the americas. Global Ecology and Biogeography 14:423-429.

Breidenbach, N., Rahayu, S., Siregar, I. Z., Siregar, U. J., Hamzah, and Finkeldey, R. 2018. Genetic diversity of dominant plant species in tropical land-use systems in sumatra, indonesia. Tropical Conservation Science 11:1-14.

Cardoso, A. A., Brodribb, T. J., Lucani, C. J., DaMatta, F. M., And McAdam, S. A. M. 2018. Coordinated plasticity maintains hydraulic safety in sunflower leaves. Plant, cell $\mathcal{E}$ environment 41:2567-2576.

CARR, M. K. 2011. The water relations and irrigation requirements of oil palm (elaeis guineensis): A review. Experimental Agriculture 47:629-652.

Chellaiah, D. And Yule, C. M. 2018a. Riparian buffers mitigate impacts of oil palm plantations on aquatic macroinvertebrate community structure in tropical streams of borneo. Ecological Indicators 95:53-62.

Chellaiah, D. AND YUle, C. M. 2018b. Effect of riparian management on stream morphometry and water quality in oil palm plantations in borneo. Limnologica 69:72-80.

Chen, J.-W., Zhang, Q., LI, X.-S., AND CAO, K.-F. 2010. Gas exchange and hydraulics in seedlings of hevea brasiliensis during water stress and recovery. Tree physiology 30:876-885.

Cheng Xu, S., Hong XING, C., Hong Bo, S., XIN TaO, L., And YOnG, X. 2011. Growth and physiological responses to water and nutrient stress in oil palm. African Journal of Biotechnology 10:10465-10471.

Chota, B., Brodribb, T. J., Brodersen, C. R., Duursma, R. A., López, R., And Medlyn, B. E. 2018. Triggers of tree mortality under drought. Nature 558:531-539.

Cochard, H., Badel, E., Herbette, S., Delzon, S., Choat, B., And Jansen, S. 2013. Methods for measuring plant vulnerability to cavitation: a critical review. Journal of experimental botany 64:4779-4791.

Cochard, H., EWERs, F. W., AND TyReE, M. T. 1994. Water relations of a tropical vine-like bamboo (rhipidocladum racemiflorum): root pressures, vulnerability to cavitation and seasonal changes in embolism. Journal of Experimental Botany 45:1085-1089. 
Corcuera, L., Cochard, H., Gil-Pelegrin, E., And Notivol, E. 2011. Phenotypic plasticity in mesic populations of pinus pinaster improves resistance to xylem embolism ( $\mathrm{p} 50$ ) under severe drought. Trees 25:1033-1042.

Corley, R. H. V. AND TinkeR, P. B. 2016. The oil palm. John Wiley \& Sons, Hoboken, NJ, fifth edition edition.

Cornaire, B., Daniel, C., Zuily-Fodil, Y., And Lamade, E. 1994. Oil palm performance under water stress. background to the problem, first results and research approaches. Oléagineux, 49:1-12.

DIN ISO 11277: 2002-08 2002. Bodenbeschaffenheit - Bestimmung der Partikelgröenverteilung in Mineralböden - Verfahren mittels Siebung und Sedimentation. Iso 11277: 1998/cor.1:2002, Beuth Verlag, Berlin, Germany.

Drescher, J., Rembold, K., Allen, K., Beckschäfer, P., Buchori, D., ClOugh, Y., FAust, H., Fauzi, A. M., Gunawan, D., Hertel, D., Irawan, B., Jaya, I. N. S., Klarner, B., Kleinn, C., KnOHL, A., Kotowska, M. M., Krashevska, V., Krishna, V., Leuschner, C., Lorenz, W., Meijide, A., Melati, D., Nomura, M., Pérez-Cruzado, C., Qaim, M., Siregar, I. Z., Steinebach, S., TJoA, A., Tscharntke, T., Wick, B., Wiegand, K., Kreft, H., AND SCHEU, S. 2016. Ecological and socio-economic functions across tropical land use systems after rainforest conversion. Philosophical transactions of the Royal Society of London. Series B, Biological sciences 371 .

DufrêNe, E., OCHS, R., AND SAUgier, B. 1990. Oil palm photosynthesis and productivity linked to climatic factors. Oléagineux, 45:346-355.

DUfRÊNE, E. AND SAUGIER, B. 1993. Gas exchange of oil palm in relation to light, vapour pressure deficit, temperature and leaf age. Functional Ecology 7:97-104.

FAOSTAT 2017. Statistics database: Un food and agricultural oganisation statistic database.

Hacke, U. G., Sperry, J. S., Ewers, B. E., Ellsworth, D. S., Schäfer, K. V., AND Oren, R. 2000. Influence of soil porosity on water use in pinus taeda. Oecologia 124:495-505.

HajeK, P., KuRJAK, D., VON WÜHlisch, G., Delzon, S., AND SCHUldt, B. 2016. Intraspecific variation in wood anatomical, hydraulic, and foliar traits in ten european beech provenances differing in growth yield. Frontiers in Plant Science 7:791.

Hardanto, A., RÖll, A., Niu, F., Meijide, A., Hendrayanto, And Hölscher, D. 2017. Oil palm and rubber tree water use patterns: Effects of topography and flooding. Frontiers in plant science 8:1-12. 
HENSON, I. E. 1999. Notes on oil palm productivity. v. evaluation of alternative mechanisms for supporting seasonal variation in dry matter production. Journal of Oil Palm Research 2:41-52.

HochberG, U., Rockwell, F. E., Holbrook, N. M., AND Cochard, H. 2018. Iso/anisohydry: A plant-environment interaction rather than a simple hydraulic trait. Trends in plant science 23:112-120.

IPCC 2014. Intergovernmental Panel on Climate Change 2013 - The Physical Science Basis. Cambridge University Press, Cambridge.

Jinagool, W., Rattanawong, R., Sangsing, K., Barigah, T. S., Gay, F., Cochard, H., Kasemsap, P., AND Herbette, S. 2016. Clonal variability for vulnerability to cavitation and other drought-related traits hevea brasiliensis müll. arg. Journal of Plant Hydraulics 2:1-12.

Kallarackal, J., JeYaKumar, P., AND GeOrge, S. 2004. Water use of irrigated oil palm at three different arid locations in peninsular india. Journal of Oil Palm Research 16:45-53.

KLEIN, T. 2014. The variability of stomatal sensitivity to leaf water potential across tree species indicates a continuum between isohydric and anisohydric behaviours. Functional Ecology 28:1313-1320.

Koch, G. W., Sillett, S. C., Jennings, G. M., And Davis, S. D. 2004. The limits to tree height. Nature 428:851-854.

Lamy, J.-B., Delzon, S., Bouche, P. S., Alia, R., Vendramin, G. G., Cochard, H., AND PLOMION, C. 2014. Limited genetic variability and phenotypic plasticity detected for cavitation resistance in a mediterranean pine. The New phytologist 201:874-886.

Legros, S., Mialet-Serra, I., Caliman, J.-P., Siregar, F. A., Clément-Vidal, A., And DingKuHn, M. 2009. Phenology and growth adjustments of oil palm (elaeis guineensis) to photoperiod and climate variability. Annals of botany 104:1171-1182.

Lewis, A. M. AND Boose, E. R. 1995. Estimating volume flow rates through xylem conduits. American journal of botany 82:1112-1116.

Li, S., Klepsch, M., JAnsen, S., Schmitt, M., Lens, F., Karimi, Z., Schuldt, B., Espino, S., AND SCHENK, H. J. 2016. Intervessel pit membrane thickness as a key determinant of embolism resistance in angiosperm xylem. IAWA Journal 37:152-171.

Lobo, A., Torres-Ruiz, J. M., Burlett, R., Lemaire, C., Parise, C., Francioni, C., Truffaut, L., TomášKovÁ, I., Hansen, J. K., KJÆR, E. D., Kremer, A., And Delzon, S. 2018. Assessing inter- and intraspecific variability of xylem vulnerability to embolism in oaks. Forest Ecology and Management 424:53-61. 
LÜBbe, T., Schuldt, B., AND Leuschner, C. 2017. Acclimation of leaf water status and stem hydraulics to drought and tree neighbourhood: alternative strategies among the saplings of five temperate deciduous tree species. Tree physiology 37:456-468.

Maillard, G., Daniel, C., AND Ochs, R. 1974. Analyse des effets de la sécheresse sur le palmier a huile. Oléagineux 8:397-404.

Martínez-Vilalta, J., Cochard, H., Mencuccini, M., Sterck, F., Herrero, A., KorhoNen, J. F. J., Llorens, P., NikinmaA, E., Nolè, A., Poyatos, R., Ripullone, F., SassKLAASSEN, U., AND ZWEIFEL, R. 2009. Hydraulic adjustment of scots pine across europe. The New phytologist 184:353-364.

MartíneZ-Vilalta, J. AND PiÑOL, J. 2002. Drought-induced mortality and hydraulic architecture in pine populations of the ne iberian peninsula. Forest Ecology and Management 161:247-256.

MartíneZ-Vilalta, J., SAlA, A., AND PiÑOL, J. 2004. The hydraulic architecture of pinaceae a review. Plant Ecology 171:3-13.

McCulloh, K. A., Johnson, D. M., Meinzer, F. C., AND WoodrufF, D. R. 2014. The dynamic pipeline: hydraulic capacitance and xylem hydraulic safety in four tall conifer species. Plant, cell E environment 37:1171-1183.

McDowell, N. G., Pockman, W. T., Allen, C. D., Breshears, D. D., Cobb, N., Kolb, T., Plaut, J., Sperry, J. S., West, A., Williams, D. G., And Yepez, E. A. 2008. Mechanisms of plant survival and mortality during drought: why do some plants survive while others succumb to drought? The New phytologist 178:719-739.

Meijide, A., Badu, C. S., Moyano, F., Tiralla, N., Gunawan, D., and Knohl, A. 2018. Impact of forest conversion to oil palm and rubber plantations on microclimate and the role of the 2015 enso event. Agricultural and Forest Meteorology 252:208-219.

Mitchell, S. L., Edwards, D. P., Bernard, H., Coomes, D., Jucker, T., Davies, Z. G., AND STRUEBIG, M. J. 2018. Riparian reserves help protect forest bird communities in oil palm dominated landscapes. Journal of Applied Ecology 55:2744-2755.

NAKAGAWA, S. AND SChielzeth, H. 2013. A general and simple method for obtaining $r 2$ from generalized linear mixed-effects models. Methods in Ecology and Evolution 4:133-142.

NArdini, A., Gascò, A., Trifilò, P., Lo Gullo, M. A., AND SAlleo, S. 2007. Ion-mediated enhancement of xylem hydraulic conductivity is not always suppressed by the presence of ca2+ in the sap. Journal of experimental botany 58:2609-2615. 
NouY, B., Baudouin, L., DJÉGui, N., AND Omoré, A. 1999. Oil palm under limiting water supply conditions. Plantations, Recherche, Développement 6:31-45.

Ogle, K., BArber, J. J., Willson, C., And Thompson, B. 2009. Hierarchical statistical modeling of xylem vulnerability to cavitation. The New phytologist 182:541-554.

Oliveira, R. S., Costa, F. R. C., van BaAlen, E., De Jonge, A., Bittencourt, P. R., Almanza, Y., Barros, F. D. V., Cordoba, E. C., Fagundes, M. V., Garcia, S., Guimaraes, Z. T. M., Hertel, M., Schietti, J., Rodrigues-Souza, J., AND Poorter, L. 2018. Embolism resistance drives the distribution of amazonian rainforest tree species along hydro-topographic gradients. The New phytologist .

Peakall, R. AND Smouse, P. E. 2012. Genalex 6.5: genetic analysis in excel. population genetic software for teaching and research—an update. Bioinformatics 28:2537-2539.

PeAKall, R. O. And SMOUSE, P. E. 2006. genalex 6: genetic analysis in excel. population genetic software for teaching and research. Molecular Ecology Notes 6:288-295.

Pinheiro, J., Bates, D., DebRoy, S., SARKar, D., AND R Core Team 2018. nlme: Linear and nonlinear mixed effects models.

Pivovaroff, A. L., Sack, L., And Santiago, L. S. 2014. Coordination of stem and leaf hydraulic conductance in southern california shrubs: a test of the hydraulic segmentation hypothesis. The New phytologist 203:842-850.

R CORE TEAm 2018. R: A language and environment for statistical computing.

REES, A. R. 1961. Midday closure of stomata in the oil palm elaeis guineensis. jacq. Journal of experimental botany 12:129-146.

RenNinger, H. J. AND Phillips, N. G. 2011. Hydraulic properties of fronds from palms of varying height and habitat. Oecologia 167:925-935.

Renninger, H. J. And Phillips, N. G. 2016. Palm physiology and distribution in response to global environmental change, pp. 67-101. In G. Goldstein and L. S. Santiago (eds.), Tropical Tree Physiology, volume 6 of Tree Physiology. Springer International Publishing, Cham.

Rowland, L., DA Costa, A. C. L., Galbraith, D. R., Oliveira, R. S., BinKs, O. J., Oliveira, A. A. R., Pullen, A. M., Doughty, C., Metcalfe, D., Vasconcelos, S. S., Ferreira, L. V., Malhi, Y., Grace, J., Mencuccini, M., And Meir, P. 2015. Death from drought in tropical forests is triggered by hydraulics not carbon starvation. Nature 528:119-122.

RYAN, M. G. AND YODER, B. J. 1997. Hydraulic limits to tree height and tree growth: What keeps trees from growing beyond a certain height? BioScience 47:235-242. 
Santiago, L. S., de Guzman, M. E., Baraloto, C., VogenberG, J. E., Brodie, M., Hérault, B., Fortunel, C., AND BOnAL, D. 2018. Coordination and trade-offs among hydraulic safety, efficiency and drought avoidance traits in amazonian rainforest canopy tree species. The New phytologist 218:1015-1024.

Schuldt, B., Knutzen, F., Delzon, S., Jansen, S., Müller-Haubold, H., Burlett, R., CLOUGH, Y., AND LeusCHNER, C. 2016. How adaptable is the hydraulic system of european beech in the face of climate change-related precipitation reduction? The New phytologist 210:443458.

SMITH, B. G. 1989. The effects of soil water and atmospheric vapour pressure deficit on stomatal behaviour and photosynthesis in the oil palm. Journal of experimental botany 40:647-651.

Sperling, O., Shapira, O., Schwartz, A., AND LaZarovitch, N. 2015. Direct in vivo evidence of immense stem water exploitation in irrigated date palms. Journal of experimental botany 66:333-338.

SPERry, J. S., DonNelly, J. R., AND TYReE, M. T. 1988. A method for measuring hydraulic conductivity and embolism in xylem. Plant, cell \& environment 11:35-40.

SPERRY, J. S. AND HACKE, U. G. 2002. Desert shrub water relations with respect to soil characteristics and plant functional type. Functional Ecology 16:367-378.

Sperry, J. S., Nichols, K. L., Sullivan, J. E. M., And Eastlack, S. E. 1994. Xylem embolism in ring-porous, diffuse-porous, and coniferous trees of northern utah and interior alaska. Ecology 75:1736-1752.

SPERRY, J. S. AND TYREE, M. T. 1988. Mechanism of water stress-induced xylem embolism. Plant physiology 88:581-587.

SQUIRE, G. R. 1990. The physiology of tropical crop production. C.A.B. International, Oxon, UK.

Statistics InDONeSia 2016. Production of palm oil in indonesia from 2012 to 2017 (in million tons).

Stout, D. L. AND SAlA, A. 2003. Xylem vulnerability to cavitation in pseudotsuga menziesii and pinus ponderosa from contrasting habitats. Tree physiology 23:43-50.

TARDiEU, F. AND SimONNEAU, T. 1998. Variability among species of stomatal control under fluctuating soil water status and evaporative demand: modelling isohydric and anisohydric behaviours. Journal of experimental botany 49:419-432.

TOMlinson, P. B. AND Huggett, B. A. 2012. Cell longevity and sustained primary growth in palm stems. American journal of botany 99:1891-1902. 
Torres-Ruiz, J. M., Jansen, S., ChoAt, B., McElrone, A. J., Cochard, H., Brodribb, T. J., Badel, E., Burlett, R., Bouche, P. S., Brodersen, C. R., Li, S., Morris, H., And Delzon, S. 2015. Direct x-ray microtomography observation confirms the induction of embolism upon xylem cutting under tension. Plant physiology 167:40-43.

Tyree, M. T., Snyderman, D. A., Wilmot, T. R., And Machado, J.-L. 1991. Water relations and hydraulic architecture of a tropical tree (schefflera morototoni) 1: Data, models, and a comparison with two temperate species (acer saccharum and thuja occidentalis). Plant physiology 96:1105-1113.

Venturas, M. D., Sperry, J. S., And Hacke, U. G. 2017. Plant xylem hydraulics: What we understand, current research, and future challenges. Journal of integrative plant biology 59:356389.

Vos, P., Hogers, R., Bleeker, M., Reijans, M., van De Lee, T., Hornes, M., Friters, A., Pot, J., Paleman, J., Kuiper, M., And Zabeau, M. 1995. Aflp: a new technique for dna fingerprinting. Nucleic Acids Research 23:4407-4414.

Wheeler, J. K., Huggett, B. A., Tofte, A. N., Rockwell, F. E., AND Holbrook, N. M. 2013. Cutting xylem under tension or supersaturated with gas can generate plc and the appearance of rapid recovery from embolism. Plant, cell E environment 36:1938-1949.

Wheeler, J. K., Sperry, J. S., HACKe, U. G., AND HoAnG, N. 2005. Inter-vessel pitting and cavitation in woody rosaceae and other vesselled plants: a basis for a safety versus efficiency trade-off in xylem transport. Plant, cell \& environment 28:800-812.

YANG, S.-J., ZHANG, Y.-J., SUN, M., GOLDSTEIN, G., AND CAO, K.-F. 2012. Recovery of diurnal depression of leaf hydraulic conductance in a subtropical woody bamboo species: embolism refilling by nocturnal root pressure. Tree physiology 32:414-422.

ZimmermanN, M. H. 1973. Transport problems in arborescent monocotyledons. The Quarterly Review of Biology 48:314-321.

ZimmermanN, M. H. AND SPERRY, J. S. 1983. Anatomy of the palm rhapis excelsa, ix. xylem structure of the leaf insertion. Journal of the Arnold Arboretum 64:599-609.

ZimmermanN, M. H. AND TOMLinson, P. B. 1972. The vascular system of monocotyledonous stems. Botanical Gazette 133:141-155.

Zwieniecki, M. A., Melcher, P. J., AND Michele HolbrooK, N. 2001. Hydrogel control of xylem hydraulic resistance in plants. Science 291:1059-1062. 


\section{Chapter 4}

Plasticity of wood and leaf traits related to hydraulic efficiency and safety is linked to the evaporative demand and not soil moisture in rubber (Hevea brasiliensis)

Pierre-André WAITE, Christoph LEUSCHNER, Sylvain DELZON, Triadiati TRIADIATI, Asmadi SAAD, Bernhard SCHULDT 


\begin{abstract}
The predicted increase of drought intensity in Southeast Asia has raised concern about the sustainability of rubber (Hevea brasiliensis) cultivation. In order to quantify the degree of phenotypic plasticity in this important tree crop species, we analysed a set of wood and leaf traits related to drought resistance that might respond sensitively to the local environment in PB260 clones. Averaged across the four plots per soil type (riparian v. well-drained soil types), only two out of the 16 traits differed in response to the soil moisture regime, namely stem wood density and leaf turgor loss point $\left(\pi_{\text {tlp }}\right)$. Surprisingly, the lowest $\pi_{\text {tlp }}$ was observed at riparian, and not well-drained sites. Across all eight plots representing an environmental gradient due to a given variability in local microclimatic and edaphic conditions within soil types, branch embolism resistance $\left(P_{50}\right)$ ranged from -2.14 to -2.58 $\mathrm{MPa}$, with again no dependence on soil moisture levels. Instead, both the $P_{50}$ and $P_{88}$ value declined, and the hydraulic safety margin $\left(\pi_{\text {tlp }}-P_{50}\right)$ increased with an increase in vapour pressure deficit (VPD) at the plot level. While we could not confirm a trade-off between hydraulic safety and efficiency, vessel density (VD) emerged as a major trait associated with both safety and efficiency. VD, and not vessel diameter $(D)$, was closely related to $P_{50}$ and $P_{88}$, as well as to specific hydraulic conductivity, the lumen-to-sapwood area ratio and the vessel grouping index. In conclusion, our results demonstrate a high degree of phenotypic plasticity in wood traits related to hydraulic safety in this tropical tree species, but only in response to local changes in evaporative demand and not soil moisture. Given that VPD may increasingly limit plant growth in a warmer world, our results provide first evidence from trees for acclimation in hydraulic traits to a rising evaporative demand.
\end{abstract}

Keywords: embolism resistance, leaf turgor loss point, phenotypic plasticity, vapour pressure deficit, vulnerability curve, wood anatomy. 


\section{Introduction}

In Southeast Asia, rubber (Hevea brasiliensis Müll. Arg.) plantations are one of the economically most important cash crops. Indonesia, the second largest latex producer worldwide, produced in 20173.6 million tons of latex on an area of 3.7 million hectares (FAO 2017). Rubber, a tree species originally introduced from the Amazon basin, is traditionally cultivated under ample water supply on well-drained soils in the equatorial belt under humid tropical and monsoon climates (Raj et al. 2005, Priyadarshan 2017). The increasing intensity of El Niño-Southern Oscillation (ENSO) events during the last decades, however, might threaten the growth and yield potential of this important crop in part of its current distribution range (Wichichonchai and Manmeun 1992, Chandrashekar et al. 1998, Irawan 2003). To explore the likely agronomic consequences of increasing drought exposure in Indonesia (Susilo et al. 2013), evaluating the plasticity of functional traits related to growth and drought resistance of rubber is of high interest.

As a consequence of global climate warming, the drought response of tropical trees has been intensively studied during the past decades (Moser et al. 2014, Rowland et al. 2015, Santiago et al. 2016, McDowell et al. 2018). As the involved drought response mechanisms are complex (Aroca 2012), there is a need to understand and identify key factors or traits linked to the mechanisms of drought avoidance and resistance (Rungwattana et al. 2018, Pritzkow et al. 2020). Because plant hydraulic strategies are multidimensional, several interdependent and coordinated functional traits associated with drought-induced mortality have been identified in the recent past (Adams et al. 2017, Choat et al. 2018). At the wood level, xylem hydraulic safety as a direct measure of the functionality of the water transport system has emerged as a major trait related to drought resistance (Rowland et al. 2015, Anderegg et al. 2016, Adams et al. 2017, Laginha Pinto Correia et al. 2019). Hydraulic efficiency, on the other hand, is closely related to growth (Kotowska et al. 2015, Hajek et al. 2014, Schumann et al. 2019), while wood density as integrative trait has been associated with both growth (Hoeber et al. 2014, Finegan et al. 2015) and drought survival (Phillips et al. 2010, Poorter et al. 2019, Janssen et al. 2020). At the leaf level, leaf turgor loss point $\left(\pi_{\mathrm{tlp}}\right)$ emerged as a good predictor of drought tolerance (Oppenheimer 1963, Bartlett et al. 2012a).

In angiosperms, most current research has examined inter-specific variability of hydraulicrelated functional traits, while much less is known about trait variation at the intra-specific level (Anderegg and Meinzer 2015). However, understanding intra-specific variability is mandatory in order to understand the adaptive capacity of a given species. Such variability can result from 
genetic differences between individuals or be an expression of phenotypic plasticity (Aitken $e t$ al. 2008). In temperate forests, for example, branch hydraulic safety increased in Fagus sylvatica with climatic aridity (Schuldt et al. 2016, Stojnic et al. 2018). A similar dependence on aridity was observed in this species for the turgor loss point and the sapwood-to-leaf area ratio (Rosas et al. 2019), while this study could not detect a relation between embolism resistance and climatic aridity. Likewise, no effect of water availability on embolism resistance was observed in Quercus ilex (Martin StPaul et al. 2012, Rosas et al. 2019). In fact, several factors other than precipitation rates may influence embolism resistance across climatic gradients, which could lead to contradicting results. These include soil physical properties related to water-holding capacity (Hultine et al. 2006, Waite et al. 2019) and sampling height in the tree (Burgess et al. 2006, Rowland et al. 2015). Sapling studies with variable soil water availability have shown that hydraulic safety generally increases with decreasing water availability (Plavcova and Hacke 2012, Lübbe et al. 2017, Knipfer et al. 2018) due to vascular adjustment. When grown in drier soil, tree saplings typically form narrower vessels, while vessel density increases (Fonti et al. 2013, Lübbe et al. 2017).

Other than in temperate forests, intra-specific variation in hydraulic traits has rarely been studied in tropical tree species along environmental gradients. The only study we are aware of has been carried out on oil palm (Elaeis guineensis Jacq.), a tropical monocot that responded sensitively in its hydraulic architecture to changes in soil moisture (Waite et al. 2019). It therefore remains an open question, whether embolism resistance in rubber is a more conservative or a plastic trait that responds sensitively to local environmental conditions. This tree crop has been widely distributed across the tropics and is currently grown under a broad range of climates outside its native range. In some regions, it is tolerating a certain level of drought at the cost of reduced yield (Rao et al. 1998, Cahyo et al. 2016). Because the photosynthetic activity, growth and yield of rubber are sensitive to the atmospheric evaporative demand and soil water availability (Devakumar et al. 1998, Clermont-Dauphin et al. 2013, Falqueto et al. 2017), at least some degree of phenotypic variability as a result of either genetic variation and/or phenotypic plasticity is to be expected (Valladares et al. 2007). In fact, Rungwattana et al. (2018) observed for some drought-related wood and leaf traits a high degree of intra-specific genetic variability in a rubber provenance trial. Because leaf traits were more closely related to the climate at the place of origin than wood traits, the latter seem to me more plastic, while the former may contain a stronger phylogenetic signal. 
The main objective of the present study was to investigate the phenotypic plasticity of several morphological, anatomical and physiological leaf and wood traits associated with drought resistance in rubber (H. brasiliensis) that might respond sensitively to the local environment (see Table 1). We compared clonal trees of similar height from plantations on well-drained or riparian soils differing in soil water availability. Although site selection enabled a clear separation between both soil types, we additionally analysed trait variation across the eight plots due to a given variability in local microclimatic and edaphic conditions. As all trees belonged to the same clone, we could attribute all trait variation to phenotypic plasticity. From the existing knowledge about acclimation of hydraulic-related traits to water deficits, we hypothesized that (i) hydraulic safety is higher and hydraulic efficiency lower at well-drained versus riparian sites, and (ii) wood traits are more plastic than leaf traits.

\section{Materials and methods}

\section{Study site, plot and soil characteristics}

The study was carried out in eight smallholder rubber (Hevea brasiliensis) plantations in the province of Jambi, Sumatra (Indonesia), at elevations of 39-79 $\mathrm{m}$ a.s.l. The region has a moist equatorial climate with a mean annual precipitation (MAP) of 2,235 mm, a mean annual temperature of $26.7^{\circ} \mathrm{C}$ (Drescher et al. 2016) and a distinct dry season between May and September. The plantations were located in level terrain in a landscape, which is best defined by its dominant soil type and texture, i.e. clayey Acrisol (Allen et al. 2016). In every plantation, a $50 \mathrm{~m} \times 50$ $\mathrm{m}$ plot was demarcated. Four plantations were selected on well-drained soil, another four plots on riparian soils in vicinity to streams (P1-P4: well-drained soil; P5-P8: riparian soil; Table 4.2). The latter sites are periodically flooded causing hydromorphic features in the soil profiles due to changes between aerobic and anaerobic conditions. Soil texture was determined in all plots except P1 in 0-30 cm soil depth by means of the pipette method of Köhn (DIN ISO 11277:2002-08). The clay and sand content varied considerably among the plots (Table 4.2). All eight plots were situated in close proximity to each other (maximum distance: $10 \mathrm{~km}$; see Table A4.1 for plot details). Plantations were on average $9-29$ years old with stems planted at densities of $300-732$ stems per hectare (Table 4.2), which is within the optimal range for latex production (Carr et al. 2012). Well-drained and riparian plots differed significantly with respect to tree age (22.5 vs. 19.4 yr), stem density (422.0 vs. $564.7 \mathrm{n} \mathrm{ha}^{-1}$ ) and diameter at breast height (23.24 vs. $16.07 \mathrm{~cm}$; Table 4.2). Despite these stand structural differences between the two soil types that were addressed in 
the statistical analyses, all investigated trees belonged to a similar development stage and had a similar average height of $14.5 \mathrm{~m}$.

Table 4.1: List of studied variables with abbreviations, units and definitions.

\begin{tabular}{|c|c|c|}
\hline Abbreviation & Unit & Definition \\
\hline \multicolumn{3}{|c|}{ Environmental characteristics } \\
\hline VWC & vol. \% & Volumentric soil water content at $0.3 \mathrm{~m}$ depth \\
\hline VPD & $\mathrm{kPa}$ & $\begin{array}{l}\text { Annual average vapor pressure deficit calculated from } \\
\text { relative humidity and temperature for } 2018\end{array}$ \\
\hline $\mathrm{VPD}_{\mathrm{dry}}$ & $\mathrm{kPa}$ & $\begin{array}{l}\text { Annual average vapor pressure deficit calculated from } \\
\text { relative humidity and temperature for the } 20 \% \text { driest days of } 2018\end{array}$ \\
\hline \multicolumn{3}{|c|}{ Plot parameters } \\
\hline Density & $\mathrm{n} \mathrm{ha}^{-1}$ & Stem density per hectare \\
\hline$A$ & year & Plantation age \\
\hline$\%$ sand & $\%$ & Percentage of sand in the soil top $30 \mathrm{~cm}$ \\
\hline$\%$ clay & $\%$ & Percentage of clay in the soil top $30 \mathrm{~cm}$ \\
\hline
\end{tabular}

\begin{tabular}{lll}
\hline \multicolumn{2}{l}{ Stand structural parameters } & \\
\hline $\mathrm{DBH}$ & $\mathrm{cm}$ & Tree diameter at $1.7 \mathrm{~m}$ height \\
$\mathrm{H}$ & $\mathrm{m}$ & Tree height \\
$\mathrm{WD}$ & $\mathrm{g} \mathrm{cm}^{-3}$ & Stem wood density
\end{tabular}

\begin{tabular}{|c|c|c|}
\hline \multicolumn{3}{|l|}{ Hydraulic traits } \\
\hline$K_{\mathrm{p}}$ & $\mathrm{kg} \mathrm{m}^{-1} \mathrm{MPa}^{-1} \mathrm{~s}^{-1}$ & Potential hydraulic conductivity \\
\hline$K_{\mathrm{s}}$ & $\mathrm{kg} \mathrm{m}^{-1} \mathrm{MPa}^{-1} \mathrm{~s}^{-1}$ & Branch xylem-specific hydraulic conductivity \\
\hline$K_{1}$ & $\mathrm{~kg} \mathrm{~m}^{-1} \mathrm{MPa}^{-1} \mathrm{~s}^{-1}$ & Leaf-specific hydraulic conductivity \\
\hline$P_{12}$ & $\mathrm{MPa}$ & Xylem pressure at $12 \%$ loss of hydraulic conductance \\
\hline$P_{50}$ & $\mathrm{MPa}$ & Xylem pressure at $50 \%$ loss of hydraulic conductance \\
\hline$P_{88}$ & $\mathrm{MPa}$ & Xylem pressure at $88 \%$ loss of hydraulic conductance \\
\hline HSM & $\mathrm{MPa}$ & Hydraulic safety margin calculated as $\pi_{\mathrm{tlp}}-P_{50}$ \\
\hline \multicolumn{3}{|c|}{ Anatomical traits } \\
\hline$A_{\text {lumen }}: A_{\text {xylem }}$ & $\%$ & Lumen-to-sapwood area ratio \\
\hline$D$ & $\mathrm{~m}$ & Vessel diameter \\
\hline VD & $\mathrm{n} \mathrm{mm} \mathrm{m}^{-2}$ & Vessel density \\
\hline$V_{\mathrm{g}}$ & - & Vessel grouping index: mean number of cells per group \\
\hline \multicolumn{3}{|l|}{ Leaf traits } \\
\hline SLA & $\mathrm{cm}^{2} \mathrm{~g}^{-1}$ & Specific leaf area \\
\hline$\pi_{\mathrm{tlp}}$ & Mpa & Leaf turgor loss point \\
\hline HV & $\mathrm{m}^{2} \mathrm{~m}^{-2}$ & $\begin{array}{l}\text { Huber value as the ratio of branch xylem area and total leaf area } \\
\text { distal to the branch }\end{array}$ \\
\hline$\delta^{13} \mathrm{C}$ & $\%$ & Carbon isotope signature \\
\hline
\end{tabular}




\section{Microclimatic and hydrologic conditions}

On every plot, a climate station was installed in the centre below the canopy and operated throughout the year 2018, which was a representative year for the area in terms of climatic conditions. Volumetric soil water content at $30 \mathrm{~cm}$ soil depth (VWC, vol. \%) was measured with a Trime-Pico 32 sensor (IMKO, Ettlingen, Germany), and air temperature $\left(T,{ }^{\circ} \mathrm{C}\right)$ and relative air humidity ( $\mathrm{RH}, \%$ ) at $2 \mathrm{~m}$ height were recorded with a thermohygrometer (Galltec Mela, Bondorf, Germany). Data were logged every hour using a UIT LogTrans 16-GPRS data logger (UIT, Dresden, Germany). Atmospheric vapour pressure deficit (VPD) was calculated from $T$ and RH according to Allen et al. (1998). Air and soil humidity in the stands were high throughout the year with a monthly mean daytime VPD (6am to $6 \mathrm{pm}$ ) of 0.5-0.8 $\mathrm{kPa}$ and a monthly mean VWC varying between $30 \%$ and $60 \%$ (Fig. 4.1). According to the VWC data in the topsoil, well-drained and riparian plots were clearly distinguished from each other (means of 36.62 vs. $43.34 \%$, respectively), although VWC varied considerably across plots (from 30.4 to $56.6 \%$; Table 4.2). Likewise, annual mean VPD in 2018 ranged from 0.49 to $0.87 \mathrm{kPa}$ across plots (Table 4.2). In 2018, a distinct dry season between July and September was observed, which we used to calculate VPD for the $20 \%$ driest days of the year $\left(\mathrm{VPD}_{\text {dry }}\right.$; Table 4.2$)$.

\section{Tree selection and plant material}

In each plot, 15 mature rubber trees of similar height and canopy position were selected. According to the plot owners, all sampled rubber trees are PB260 clones, a widely planted clone in Indonesia and Malaysia, from where it originates (Hoong 1997, Pereira et al. 2018). The PB260 clone is supposed to be suitable for areas with low MAP (Cahyo et al. 2017) and is one of the best studied clones of the Sumbawa Research Centre in South Sumatra (Ardika et al. 2017; Cahyo et al. 2017). Per tree, wood cores of $c .7 \mathrm{~cm}$ length were taken with an increment corer (Haglöf, Långsele, Sweden) at $1.7 \mathrm{~m}$ stem height. Sun-exposed branches with a length of $c .60 \mathrm{~cm}$ collected between September and November 2017 from the uppermost sun-lit canopy with a long-reaching branch cutter for measurements of leaf morphology and hydraulic efficiency $(n=120)$, and in March 2018 for determining xylem safety $(n=70)$. In the field, all leaves distal to the branch segments to be used for measuring hydraulic efficiency were collected, and branches immediately transferred to polyethylene tubes filled with deionized water containing a sodium-silver-chloride complex (16 $\mathrm{\mu g} \mathrm{l}^{-1} \mathrm{Ag}$ and $8 \mathrm{mg} \mathrm{l}^{-1} \mathrm{NaCl}$; Micropur katadyn, Wallisellen, Switzerland) to prevent microbial growth. In addition, small adjacent leafy branch segments with a length of $c .20 \mathrm{~cm}$ were collected and immediately stored in humidified bags for subsequent analyses of leaf turgor 
loss point. After harvest, all samples were transported to the University of Jambi (UNJA) and stored at $4{ }^{\circ} \mathrm{C}$ until being possessed at UNJA, except for the branch samples collected in March 2018 that were shipped to the University of Bordeaux, France.
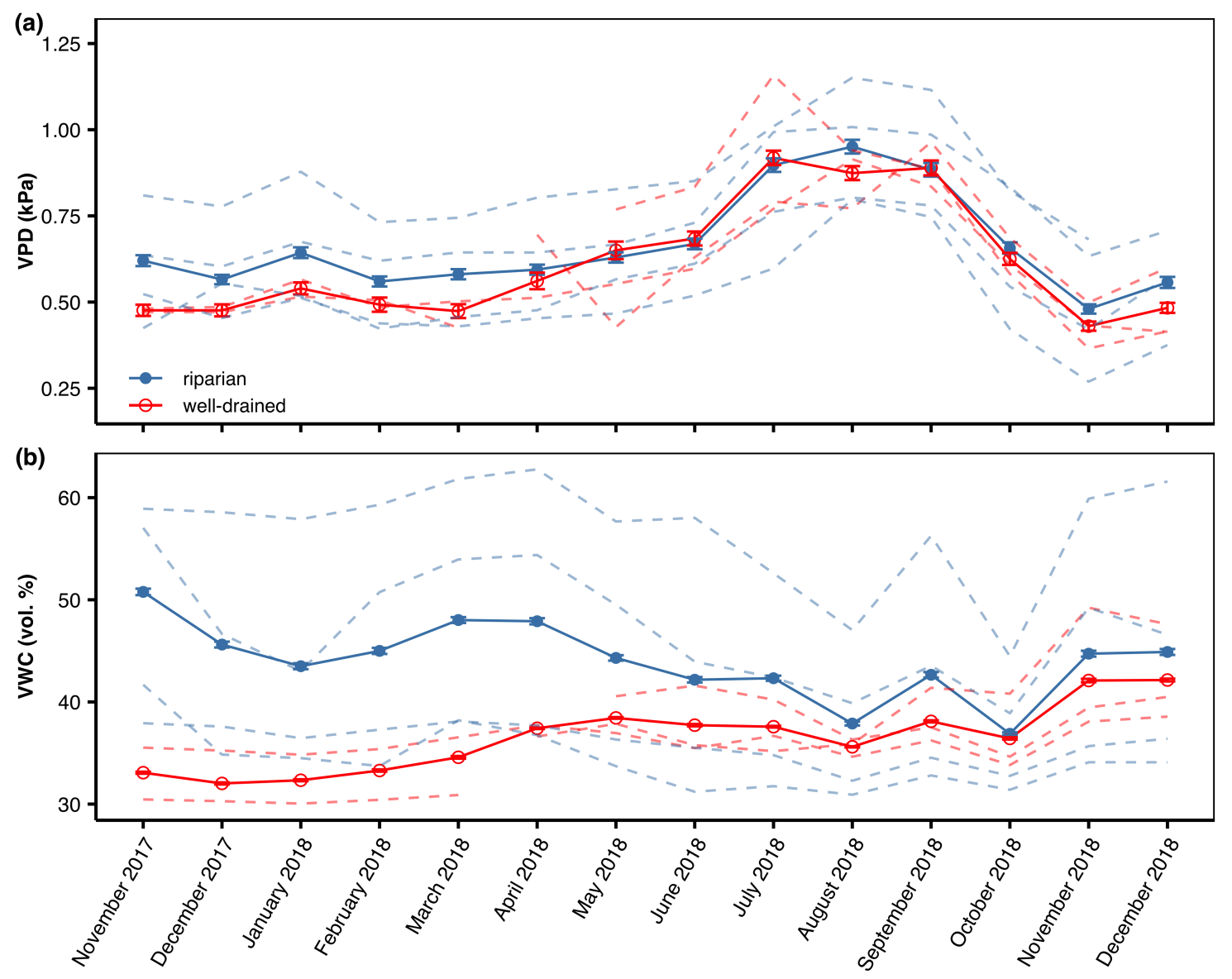

Fig. 4.1: Seasonal course of (a) atmospheric vapour pressure deficit (VPD, daily averages) and (b) volumetric soil moisture (daily averages) from November 2017 to December 2018 in the eight studied H. brasiliensis plots at the riparian and well-drained soil types in Jambi province, Sumatra, Indonesia. Solid lines are the monthly averages at riparian (blue solid lines; filled circles) and well-drained (red solid lines; open circles) sites, dashed lines stand for individual plots.

\section{Stand structure and wood density}

Tree height $(H)$ was measured with a Vertex III height meter in 2016 (Haglöf, Långsele, Sweden). Stem wood density ( $\mathrm{WD}, \mathrm{g} \mathrm{cm}^{-3}$ ), defined as oven-dry mass over wet volume, was measured for 119 trees after removing the bark. The fresh volume of each core was calculated based on means of two length and ten diameter measurements using a digital caliper ( $c f$. Schüller $e t$ al. 2013). Subsequently, cores were oven-dried at $105^{\circ} \mathrm{C}$ for $72 \mathrm{~h}$ to obtain dry mass. 


\section{Leaf morphology}

All leaves distal to the twig segments used for hydraulic conductivity measurements were scanned in order to determine single-leaf and cumulative leaf areas (WinFolia 2005; Régent Instruments, Quebec, Canada). Per branch segment, five to 52 leaves were scanned, yielding 2,313 leaves in total. We calculated the Huber value as the ratio of branch sapwood area to total leaf area ( $A_{\text {xylem }}: A_{\text {leaf }} ; 10^{-4} \mathrm{~m}^{2} \mathrm{~m}^{-2}$ ). Subsequently, leaves were oven-dried at $70^{\circ} \mathrm{C}$ for $48 \mathrm{~h}$ and specific leaf area (SLA $\left.; \mathrm{cm}^{2} \mathrm{~g}^{-1}\right)$ calculated. Dried and grinded leaf samples were shipped to the University of Göttingen, Germany, and analyzed for the carbon isotope signature $\left(\delta^{13} \mathrm{C}\right)$ by mass ratio spectroscopy (Deltaplus; ThermoFinnigan, Bremen, Germany) at the Center for Stable Isotope Research and Analysis (KOSI).

\section{Turgor loss point}

A vapour pressure osmometer (VAPRO 5600, Wescor, Logan, US) was used to measure leaf osmotic potential $\left(\pi_{\mathrm{osm}} ; \mathrm{MPa}\right)$, from which the turgor loss point $\left(\pi_{\mathrm{tlp}} ; \mathrm{MPa}\right)$ was derived according to the equation given by Bartlett et al. (2012b). We used fully hydrated leaves from branches re-cut under water, stored at $4^{\circ} \mathrm{C}$ with their basipetal end submerged in water and covered with an opaque plastic bag. Prior to measurement, two leaves per branch segment were stored in humidified, air-blown and refrigerated plastic bags in order to avoid dehydration. For each leaf, one 8-mm-diameter disc was stamped out between the midrib and the margin of one of the leaflets, thereby avoiding minor veins. Following the method described in Bartlett et al. (2012b), we wrapped each disc in an aluminium foil and submerged it into liquid nitrogen $\left(\mathrm{LN}_{2}\right)$ for $2 \mathrm{~min}$. After the $\mathrm{LN}_{2}$ treatment, the disc was punctured with sharp pliers in order to facilitate evaporation and placed in the osmometer chamber within $30 \mathrm{sec}$. The apparatus subsequently measured $\pi_{\text {osm }}$ until equilibrium was reached, i.e. two following readings differed by less than $0.01 \mathrm{MPa}$ from each other. Subsequently, leaf $\pi_{\text {tlp }}$ was calculated according to Bartlett $e t$ al. (2012b) as:

$$
\pi_{t l p}=0.832 * \pi_{o s m}-0.631
$$




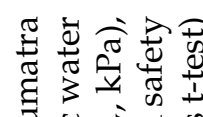

की

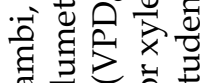

등 궁

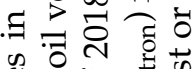

o

$\sum^{2} \infty^{\infty}=$

नี

o

它司责

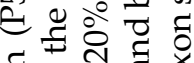

व

可 है

تृ

द्व 융

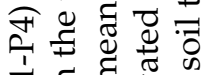

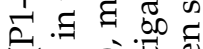

0 类

$\widetilde{\sigma} \frac{\sigma}{0}$

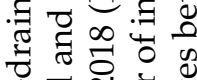

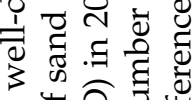

制全言.

央

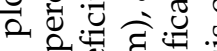

=

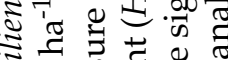

क्षे $=$ के

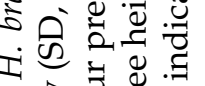

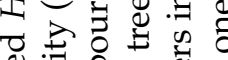

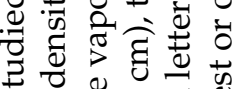

to

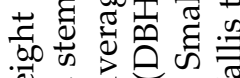

ब

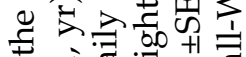

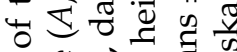

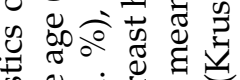

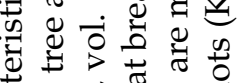

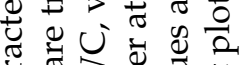

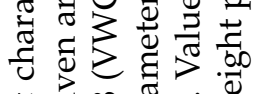

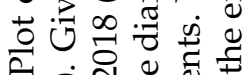

ज

구 .95

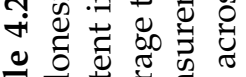

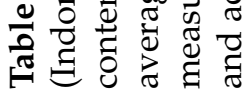

\begin{tabular}{|c|c|c|}
\hline & $\begin{array}{cccc}\infty & \infty & 1 & 0\end{array}$ & lom \\
\hline & 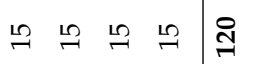 & 록 \\
\hline & 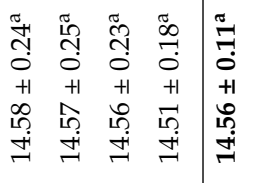 & 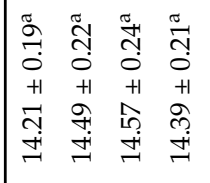 \\
\hline & 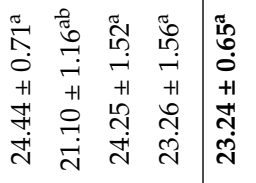 & 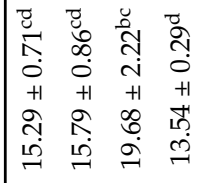 \\
\hline & 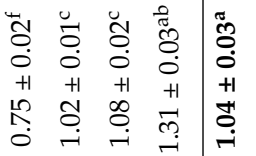 & 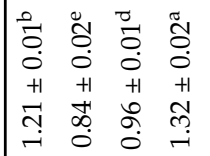 \\
\hline & 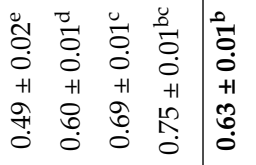 & 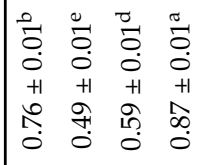 \\
\hline & 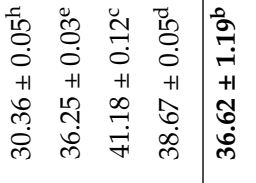 & 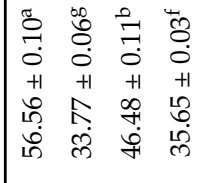 \\
\hline & 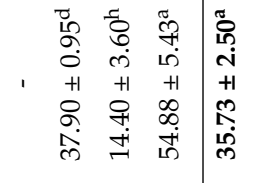 & 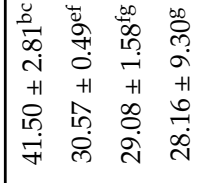 \\
\hline & 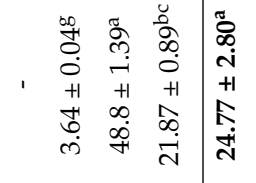 & 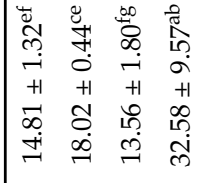 \\
\hline & 足 \& & 总采䒺 \\
\hline & 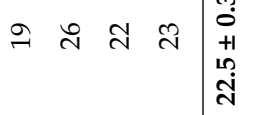 & নি $\vec{N} \stackrel{\infty}{\sim} \sigma$ \\
\hline & $\Xi \approx \cong \vec{\Xi}$ & $\stackrel{2}{2} \approx \stackrel{\infty}{\alpha}$ \\
\hline & 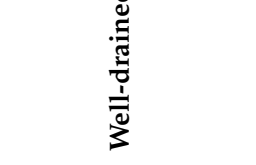 & 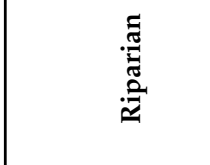 \\
\hline
\end{tabular}




\section{Hydraulic efficiency and safety}

Axial hydraulic conductivity was measured on branch segments (mean diameter \pm SE: 7.81 $\pm 0.09 \mathrm{~mm}$ ) from 14-15 trees per plot, yielding 115 samples in total. After harvest, each branch was processed in the laboratory within a week. Before measurements, branch segments were shortened (mean length \pm SE: $39.73 \pm 4.16 \mathrm{~cm}$ ), branch diameter measured twice at basal and distal ends and at four positions along the segment, lateral branches cut-off and scars sealed with a quick-drying glue (Loctite 431, Henkel, Düsseldorf, Germany). Subsequently, segments were connected to the Xyl'em apparatus (Bronkhorst, Montigny les Cormeilles, France), flushed three times for $10 \mathrm{~min}$ at a pressure of $120-180 \mathrm{kPa}$ and hydraulic conductivity $\left(K_{\mathrm{h}}, \mathrm{kg} \mathrm{m} \mathrm{MPa}^{-1} \mathrm{~s}^{-1}\right)$ measured at $25^{\circ} \mathrm{C}$ at a pressure head of $5 \mathrm{kPa}$. For the conductivity measurements, a degassed and filtered $(0.22 \mu \mathrm{m}) 10 \mathrm{mM} \mathrm{KCl}$ and $1 \mathrm{mM} \mathrm{CaCl}_{2}$ solution was used. Sapwood-specific hydraulic conductivity $\left(K_{\mathrm{s}}, \mathrm{kg} \mathrm{m}^{-1} \mathrm{MPa}^{-1} \mathrm{~s}^{-1}\right)$ was calculated by dividing $K_{\mathrm{h}}$ by the average xylem crosssectional area (cf. Schuldt et al. 2016). We used anatomical images taken at the base of the same branches to quantify the proportion of xylem tissue $\left(A_{\text {xylem }}, \mathrm{mm}^{2}\right)$ per cross-section area $\left(A_{\text {cross }}\right.$, $\mathrm{mm}^{2}$ ) for each branch. The following regression coefficients were used to calculate sapwood area without pith and bark for a given segment diameter: $A_{\text {xylem }}=-6.02+0.54 A_{\text {cross }}\left(r^{2}=0.81, P\right.$ $<0.001, n=90)$. Leaf-specific hydraulic conductivity $\left(K_{1}, \mathrm{~kg} \mathrm{~m}^{-1} \mathrm{MPa}^{-1} \mathrm{~s}^{-1}\right)$ was calculated by dividing $K_{\mathrm{h}}$ by the total supported leaf area distal to the branch segment.

Branch xylem vulnerability curves (VCs) were measured according to standard protocols (Delzon et al. 2010) at the Phenobois platform of the University of Bordeaux (France) using a modified centrifuge flow technique (Cochard et al. 2005) and the Cavisoft software (Cavisoft v1.5, University of Bordeaux, Bordeaux, France). Per plot, branch samples from 3-6 trees were processed, yielding 35 constructed VCs in total (well-drained sites: $n=17$; riparian sites: $n=18$ ). Prior to measurements, additional branch material was used to determine whether open-cut vessels were present at a segment length of $30 \mathrm{~cm}$ using the air-injection method; the result was negative. Branches were shortened to $27 \mathrm{~cm}$ length and the bark removed at both ends. Segments were subsequently placed in a custom-made honeycomb rotor mounted on a commercially available centrifuge (HS18; MSE Scientific, London, UK). Conductivity measurements with a degassed and filtered $(0.22 \mu \mathrm{m}) 10 \mathrm{mM} \mathrm{KCl}$ and $1 \mathrm{mM} \mathrm{CaCl}_{2}$ solution started at $-0.8 \mathrm{MPa}$ and were repeated stepwise at intervals of $0.2-0.3 \mathrm{MPa}$ until c. $85 \%$ loss of hydraulic conductance was recorded. The xylem pressures at $12 \%, 50 \%$ and $88 \%$ loss of hydraulic conductance $\left(P_{12}, P_{50}\right.$, and $\left.P_{88}\right)$ were calculated according to a Weibull function (see section statistical analyses). We further calculated 
the hydraulic safety margin (HSM) as the difference between $\pi_{\mathrm{tlp}}$ and $P_{50}$ (Martin-StPaul et al. 2017, Berry et al. 2019, Ziegler et al. 2019).

\section{Wood anatomy and potential conductivity}

Semi-thin branch transversal sections were cut with a sliding microtome (G.S.L.1; Schenkung Dapples, Zurich, Switzerland) on 120 branches. Transversal sections were dyed with alcian blue and safranin, embedded in Euparal (Carl Roth, Karlsruhe, Germany) and the complete crosssection digitalized at $\times 100$ magnification using a stereomicroscope equipped with a digital camera (SteREOV20; Carl Zeiss MicroImaging GmbH, Göttingen, Germany). Image processing was done with the add-on ROXAS (von Arx and Carrer 2014) for the software Image-Pro Plus v7.0 (Media Cybernetics, Rockville, USA). For every section, total cross-sectional $\left(A_{\text {cross }}, \mathrm{m}^{2}\right)$, xylem $\left(A_{\text {xylem }}\right.$, $\mathrm{m}^{2}$ ) and lumen area, average vessel lumen area $\left(A_{\text {lumen }} \mu \mathrm{m}^{2}\right)$, relative vessel lumen area, i.e. the lumen-to-sapwood area ratio $\left(A_{\text {lumen }}: A_{\text {xylem }} \%\right)$, vessel density $\left(\mathrm{VD} ; \mathrm{n} \mathrm{mm}{ }^{-2}\right)$, vessel group index $\left(V_{\mathrm{g}}\right)$, i.e. mean number of cells per group (Carlquist 2001), and radial and tangential vessel diameters were estimated. The latter were used to calculate the average vessel diameter $(D, \mu \mathrm{m})$ according to Lewis and Boose (1995). Potential conductivity $\left(K_{\mathrm{p}} ; \mathrm{kg} \mathrm{m}^{-1} \mathrm{MPa}^{-1} \mathrm{~s}^{-1}\right)$ was calculated according to the Hagen-Poiseuille equation as:

$$
K_{p}=\left(\left(\left(\pi * \sum D^{4}\right) / 128 \eta\right) * \rho\right) /\left(A_{x y l e m}\right)
$$

where $\eta$ is the viscosity $\left(1.00210^{-9} \mathrm{MPa} \mathrm{s}^{-1}\right)$ and $\rho$ the density of water $\left(998.2 \mathrm{~kg} \mathrm{~m}^{-3}\right)$, both at 20 ${ }^{\circ} \mathrm{C}$.

\section{Statistical analysis}

Statistical analyses were conducted with R version 3.5.3 (R Development Core Team 2019). All investigated variables are summarized in Table 4.1. Vulnerability curves were described with the cumulative function of the Weibull distribution and fit to the data with non-linear hierarchical models using R package "nlme" (Pinheiro et al. 2018) to account for plot effects in parameter estimates. We used a nested study design and investigated one branch $i$ per tree $j$ and 3-6 trees per plot $k$. Model equations were re-parameterized with $P_{50}$ and slope at $P_{50}$ (Ogle et al. 2009) to build equation (4.3):

$$
P L C_{i j k}=100 *\left(0.5\left(^{\left(\frac{\psi_{x_{i j k}}}{P_{50 j k}}\right)}{ }^{\left(\frac{-P_{50 j k} * \operatorname{slope~}_{j k}}{50 * \ln (0.5)}\right)}\right)\right.
$$


To investigate differences between soil types (well-drained vs riparian soils), we described the parameters $P_{50}$ and slope as linear functions of soil type and allowed them to vary randomly between trees nested in plots (Table A4.3, model 1). For a better fit, we also chose to describe $P_{50}$ and slope as linear functions of plot-aggregated VPD (Table A4.3, model 2) with trees and plots as random effects. As a natural variable, VPD was centred around the mean before implementation in the model in order to avoid results for VPD values that are not possible (typically negative values). We estimated $P_{12}, P_{50}, P_{88}$ values (water potential at 12,50 and $88 \%$ loss of hydraulic conductivity) at the soil type level using the predictions of model 1, and for each plot and tree from the predictions of model 2 at the plot and tree level (Table A4.2). Due to some differences in stand structure between the two soil types (see Table 4.2), we considered stem diameter, plot age and density as either fixed or random effects, but none of them improved the different models, allowing us to keep the initial hierarchical structure of trees nested in plots. Comparative tests were carried out between soil types for stand, edaphic, climatic data and functional traits. We also realized tests across plots for stand, edaphic and climatic data. We did unpaired Student's t-tests (between soil types) and one-way analysis of variance (ANOVA across plots) for variables that were following a normal distribution according to a Shapiro-Wilk test of normality. For variables that were not following a normal distribution, we carried out Wilcoxon signed rank tests (between soil types) and Kruskal-Wallis rank tests (across plots). To explore interrelationships among xylem and leaf traits and relationships to local environmental factors, a pair-wise Pearson correlation table was constructed using the R package "corrmorant" (https://github.com/r-link/corrmorant/) at the tree level. To complement the correlation analyses, we employed linear mixed effects models (R package "lme4"; Bates et al. 2015) to take into account plot, tree diameter, plantation age and density as random effects, selecting the best model based on Akaike information criterion (AIC). We thoroughly investigated the relation of hydraulic conductivity $\left(K_{\mathrm{s}}, K_{1}\right)$, branch embolism resistance $\left(P_{12}, P_{50}\right.$ and $\left.P_{88}\right)$, anatomical traits (i.e. WD, $\left.A_{\text {lumen }}: A_{\mathrm{xylem}}, \mathrm{VD}, D, V_{\mathrm{g}}\right)$, leaf traits (i.e. SLA, $\pi_{\text {tlp }}, \delta^{13} \mathrm{C}$ and HV), and hydraulic safety margin (HSM) with VPD, VPD dry and VWC. Further models were developed to describe the variation of $P_{88}$ as a function of VD and $V_{\mathrm{g}}$, and $P_{50}$ as a function of VD, SLA, their interaction, the mean $D$ per cut, and $V_{\mathrm{g}}$. We always introduced tree and plot as random effects. To estimate goodness-of-fit of nonlinear VC models, we calculated equivalent $r^{2}$ values as the ratio of residual and total variance of the model, following Nakagawa and Schielzeth (2013). For linear mixed effects models, we calculated generalized $r^{2}$ values after Jaeger et al. (2016), using the standardized generalized variance approach, and marginal $r^{2}$ values after Nakagawa and Schielzeth (2013). 

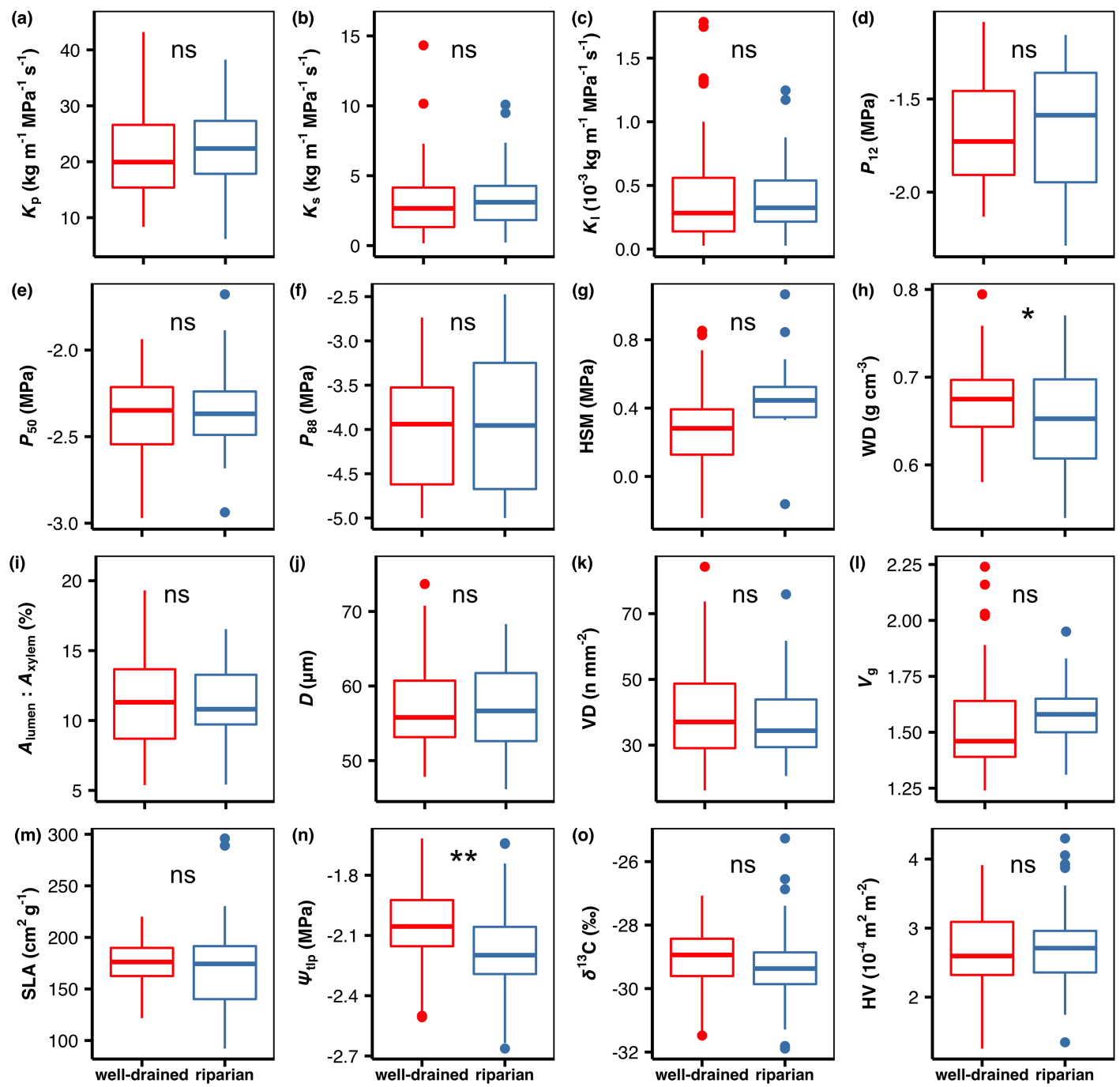

Fig. 4.2: Boxplots of all functional wood and leaf traits in H. brasiliensis from well-drained (red colour, left) and riparian (blue colour, right) sites. Given are (a) potential conductivity $\left(K_{\mathrm{p}}\right),(\mathrm{b})$ specific conductivity $\left(K_{\mathrm{s}}\right)$, (c) leaf-specific conductivity $\left(K_{1}\right)$, (d) xylem pressures at $12 \%\left(P_{12}\right)$, at (e) $50 \%\left(P_{50}\right)$, and at $(\mathrm{f}) 88 \%$ loss of hydraulic conductance $\left(P_{88}\right),(\mathrm{g})$ hydraulic safety margin (HSM; $\left.\pi_{\text {tlp }}-P_{50}\right)$, (h) wood density (WD), (i) lumen-to-sapwood area ratio $\left(A_{\text {lumen }}: A_{\text {xylem }}\right)$, (j) vessel diameter $(D),(\mathrm{k})$ vessel density $(\mathrm{VD}),(\mathrm{l})$ vessel grouping index $\left(V_{\mathrm{g}}\right),(\mathrm{m})$ specific leaf area (SLA), (n) leaf water potential at turgor loss point $\left(\pi_{\text {tlp }}\right)$, (o) carbon isotope signature $\left(\delta^{13} C\right)$, and the $(p)$ Huber value (HV). The significance of differences (Wilcoxon signed-rank test and Student's t-test) between well-drained and riparian soils are indicated for each trait with $\mathrm{ns}(P>0.05),{ }^{*}(P<0.05)$ or ** $(P<0.01)$. 


\section{Results}

\section{Soil moisture status and microclimatic conditions}

The selected sites allowed a clear distinction between well-drained and riparian soil types with respect to atmospheric evaporative demand and soil moisture levels (Fig. 4.1, Table 4.2). In 2018, volumetric soil water content (VWC) averaged at $36.62 \pm 1.19 \%$ and $43.34 \pm 0.52 \%$ in well-drained and riparian sites, respectively. Likewise, vapour pressure deficit (VPD) differed significantly between the two soil types, but the difference was less pronounced $(0.63 \pm 0.01 \mathrm{kPa}$ vs. $0.68 \pm 0.02 \mathrm{kPa}$, respectively). In contrast, the vapour pressure deficit of the $20 \%$ driest days of the year $\left(\mathrm{VPD}_{\mathrm{dry}}\right)$ did not differ significantly between the two systems. Despite significant differences in soil moisture and evaporative demand between well-drained and riparian sites (Fig. 4.1), a considerable variability across plots within a given system was observed in soil texture and environmental conditions (Table 4.2). For example, VWC varied between 57\% in P5 and 34\% in P6, two plots classified as riparian (Table 4.2). Similarly, VPD varied between $0.49 \mathrm{kPa}$ and 0.75 $\mathrm{kPa}$ in well-drained sites, and between $0.49 \mathrm{kPa}$ and $0.87 \mathrm{kPa}$ in riparian sites. Even larger were the differences between sites in $\mathrm{VPD}_{\text {dry }}$ within a system.

\section{Variation in embolism resistance between well-drained and riparian soil types}

All tree-level predictions of the xylem vulnerability curves (VCs) showed sigmoidal shapes as indicated by the shape parameter $k$ of the Weibull distribution, which achieved values well above 1 (Fig. A4.1). We found no significant differences in the xylem pressures causing $12 \%, 50 \%$ or $88 \%$ loss of conductivity $\left(P_{12}, P_{50}\right.$ or $P_{88}$ value, respectively) between trees growing on well-drained and riparian soils (Fig. 4.2; Table A4.2, A4.3, model 1). Our model predicted similar $P_{12}$ values (-1.77 MPa versus -1.76 MPa), $P_{50}$ values (-2.34 MPa versus $\left.-2.39 \mathrm{MPa}\right)$ as well as $P_{88}$ values (3.59 MPa versus -3.79 MPa) for well-drained and riparian sites, respectively (Table A4.2, A4.3). We also found similar results for the slope parameter (Table A4.3, model 1). However, there was a large variation of embolism resistance thresholds across the plots of a soil type, with e.g. $P_{50}$ ranging from -2.14 MPa to -2.58 $\mathrm{MPa}$ (Fig. 4.2, Table A4.2). 

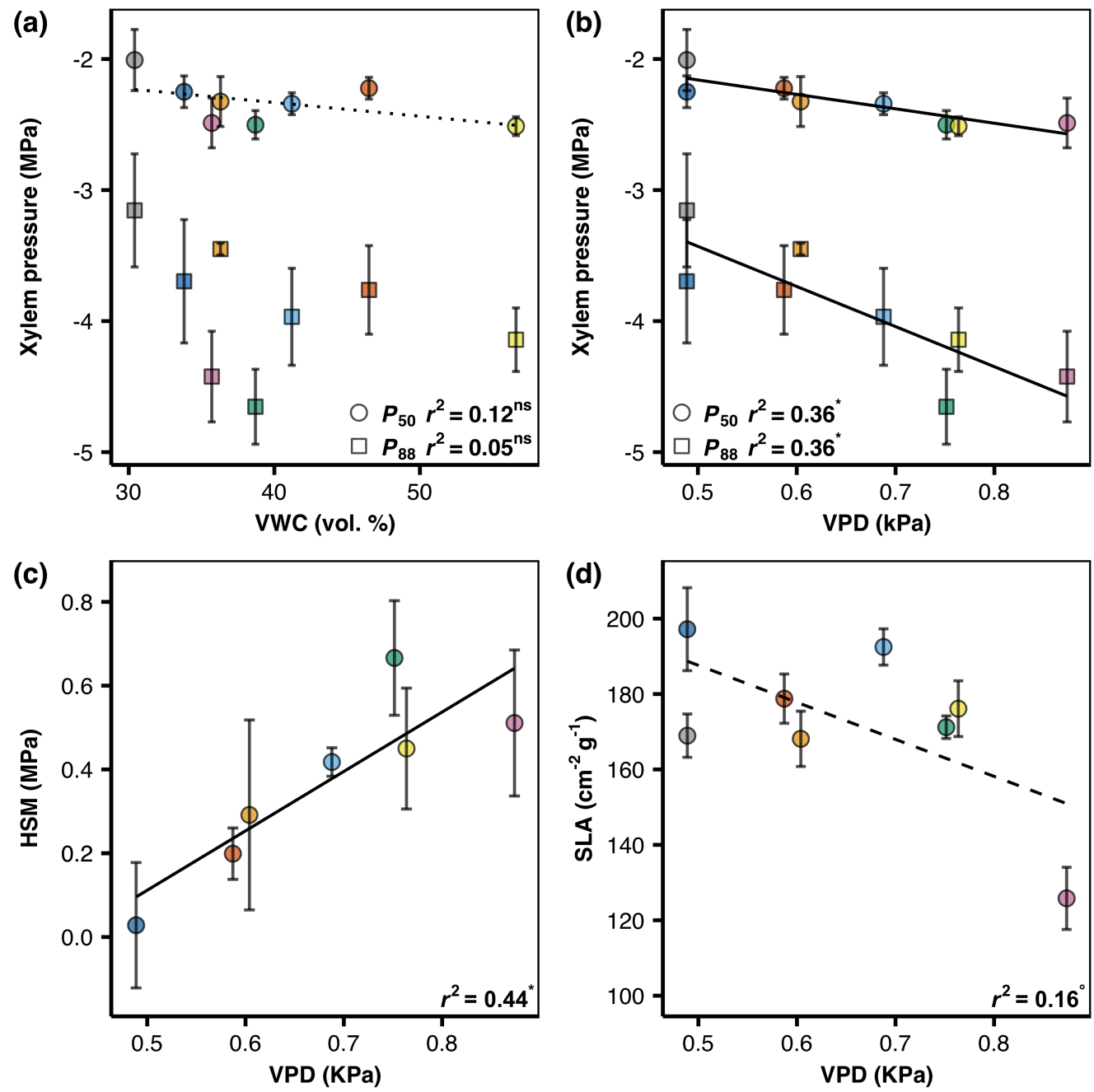

Fig. 4.3: Xylem pressures inducing $50 \%$ or $88 \%$ loss of hydraulic conductance (circle $=P_{50}$; square $\left.=P_{88}\right)$ of $H$. brasiliensis branches in relation to (a) volumetric soil water content (VWC) and (b) vapour pressure deficit (VPD). Further shown are (c) hydraulic safety margin (HSM), and (d) specific leaf area (SLA) in dependence on VPD. Values are mean \pm SE per plot. Given are the conditional $r^{2}$ of the LME models, asterisks indicate the level of significance (ns, $P>0.05 ;{ }^{*}, P<$ 0.05). Each plot is represented by one colour.

\section{Differences in functional traits between well-drained and riparian soil types}

Of all 16 morphological, anatomical and physiological leaf and wood traits studied, only two differed significantly between well-drained and riparian plantation types (Fig. 4.2, Table A4.2). These were stem wood density (WD; 0.674 vs. $0.652 \mathrm{~g} \mathrm{~cm}^{-3}, P<0.05$ ) and leaf turgor loss point $\left(\pi_{\text {tlp }} ;-2.17 \mathrm{MPa}\right.$ vs. $\left.-2.07 \mathrm{MPa}, P<0.01\right)$. In contrast, none of the branch wood anatomical or efficiency-related hydraulic traits differed significantly between the two soil types. The branch xylem of trees on well-drained and riparian soils was composed of vessel diameters of similar size $(D ; 57.26 \pm 0.81$ vs. $56.96 \pm 0.74 \mu \mathrm{m})$ and density $\left(\mathrm{VD} ; 39.17 \pm 1.95 \mathrm{n} \mathrm{mm}^{-2}\right.$ vs. $37.48 \pm 1.41$ 
$\left.\mathrm{n} \mathrm{mm} \mathrm{m}^{-2}\right)$. Consequently, neither empirically measured specific conductivity $\left(K_{\mathrm{p}}\right)$ nor theoretically calculated potential conductivity $\left(K_{\mathrm{p}} ; 21.99 \mathrm{~kg} \mathrm{~m}^{-1} \mathrm{MPa}^{-1} \mathrm{~s}^{-1} \mathrm{vs} .22 .48 \mathrm{~kg} \mathrm{~m}^{-1} \mathrm{MPa}^{-1} \mathrm{~s}^{-1}\right)$ differed between soil types. Similarly, specific leaf area (SLA), the Huber value, i.e. sapwood-to-leaf area ration, and carbon isotopic signature $\left(\delta^{13} \mathrm{C}\right)$ were comparable between well-drained and riparian sites (Fig. 4.2, Table A4.2).

Table 4.3: Summary of mixed effects models on the influence of volumetric soil water content (VWC), mean annual vapour pressure deficit (VPD) and mean VPD of the $20 \%$ driest days $\left(\mathrm{VPD}_{\mathrm{dry}}\right)$ on the 16 wood and leaf traits related to hydraulic efficiency and safety. For abbreviations, see Table 2.1. Given are the marginal $r^{2}$, conditional $r^{2}$ and $P$ values of the models, details are shown in Table A4.4. Significant relationships $(P<0.05)$ are marked in bold, marginally significant relationships $(P<0.10)$ in bold and italics.

\begin{tabular}{|c|c|c|c|c|c|c|c|c|c|}
\hline \multirow{2}{*}{ Variable } & \multicolumn{3}{|c|}{ VWC } & \multicolumn{3}{|c|}{ VPD } & \multicolumn{3}{|c|}{ VPD $_{\text {dry }}$} \\
\hline & $\begin{array}{c}\text { marg. } \\
r^{2}\end{array}$ & $\begin{array}{c}\text { cond. } \\
r^{2}\end{array}$ & $P$ & $\underset{r^{2}}{\operatorname{marg} .}$ & $\begin{array}{c}\text { cond. } \\
r^{2}\end{array}$ & $P$ & $\underset{r^{2}}{\operatorname{marg}}$ & $\begin{array}{c}\text { cond. } \\
r^{2}\end{array}$ & $P$ \\
\hline$K_{\mathrm{p}}$ & 0.01 & 0.01 & 0.56 & 0.01 & 0.02 & 0.51 & 0.01 & 0.01 & 0.53 \\
\hline$K_{\mathrm{s}}$ & 0.01 & 0.02 & 0.55 & 0.00 & 0.00 & 0.82 & 0.00 & 0.00 & 0.81 \\
\hline$K_{1}$ & 0.02 & 0.02 & 0.48 & 0.00 & 0.00 & 0.65 & 0.00 & 0.00 & 0.96 \\
\hline$P_{12}$ & 0.02 & 0.03 & 0.46 & 0.00 & 0.00 & 0.70 & 0.00 & 0.00 & 0.70 \\
\hline$P_{50}$ & 0.07 & 0.12 & 0.20 & 0.24 & 0.36 & 0.02 & 0.28 & 0.40 & $>0.001$ \\
\hline$P_{88}$ & 0.03 & 0.05 & 0.45 & 0.25 & 0.36 & 0.02 & 0.31 & 0.43 & $>0.001$ \\
\hline HSM & 0.01 & 0.02 & 0.73 & 0.30 & 0.44 & 0.02 & 0.38 & 0.52 & 0.01 \\
\hline WD & 0.01 & 0.02 & 0.72 & 0.18 & 0.24 & 0.11 & 0.13 & 0.18 & 0.17 \\
\hline$A_{\text {lumen }}: A_{\text {xylem }}$ & 0.03 & 0.03 & 0.45 & 0.10 & 0.11 & 0.11 & 0.15 & 0.16 & 0.04 \\
\hline$D$ & 0.00 & 0.00 & 0.79 & 0.01 & 0.01 & 0.53 & 0.03 & 0.04 & 0.30 \\
\hline VD & 0.03 & 0.04 & 0.52 & 0.11 & 0.14 & 0.19 & 0.19 & 0.23 & 0.07 \\
\hline$V_{\mathrm{g}}$ & 0.07 & 0.07 & 0.19 & 0.08 & 0.08 & 0.15 & 0.11 & 0.12 & 0.07 \\
\hline SLA & 0.01 & 0.02 & 0.63 & 0.15 & 0.22 & 0.07 & 0.1 & 0.16 & 0.14 \\
\hline$\pi_{\mathrm{tlp}}$ & 0.00 & 0.00 & 0.74 & 0.02 & 0.02 & 0.45 & 0.04 & 0.04 & 0.30 \\
\hline$\delta^{13} \mathrm{C}$ & 0.03 & 0.03 & 0.20 & 0.01 & 0.01 & 0.74 & 0.01 & 0.01 & 0.55 \\
\hline HV & 0.00 & 0.00 & 0.89 & 0.01 & 0.01 & 0.54 & 0.01 & 0.01 & 0.50 \\
\hline
\end{tabular}

\section{Traits variation in response to the local site-specific environment}

Although embolism resistance did not differ significantly between well-drained and riparian sites, we observed a strong relationship between the local microclimatic conditions and branch xylem safety (Fig. 4.3, Table 4.3). Plot-level VPD was a good predictor for $P_{50}\left(r^{2}=0.36, P<0.05\right.$, $\left.b=1.14 \mathrm{MPa} \mathrm{kPa}^{-1}\right), P_{88}\left(r^{2}=0.36, P<0.01, b=3.13 \mathrm{MPa} \mathrm{kPa}^{-1}\right)$ and the hydraulic safety margin (HSM; $r^{2}=0.44, P<0.05$ ) (Fig. 4.3, Table 4.3). In contrast, local volumetric soil water content (VWC) had no influence on branch embolism resistance. Surprisingly, local VWC was likewise 
unrelated to $\pi_{\mathrm{tlp}}$ in contrast to the comparison of systems. Including VPD as a predictor improved model estimates for the tree-level vulnerability curves (VCs). The nonlinear model for the VCs had a marginal $r^{2}$ of 0.83 (Table A4.3, model 2) and a conditional $r^{2}$ of 0.94 (including plot and tree effects). In contrast to xylem safety, no effect of local evaporative demand on hydraulic efficiency was observed (Table 4.3). Likewise, changes in VPD did not affect vessel diameter (Table 4.3). However, lumen-to-sapwood area ratio $\left(A_{\text {lumen }}: A_{\text {xylem }}\right)$ increased significantly with an increase in $\operatorname{VPD}_{\text {dry }}(P<0.04$; Table 4.3$)$. $\mathrm{VPD}_{\text {dry }}$ also tended to explain the variation of $\mathrm{VD}(P<0.07)$ and vessel group index $\left(V_{\mathrm{g}} ; P<0.07\right)$, although at marginal significance only (Table 4.3). At the leaf level, specific leaf area (SLA) tended to decline with an increase in VPD $\left(r^{2}=0.16, P<0.07\right.$; Fig. 4.3, Table 4.3), indicating that leaves become smaller and thicker with an increase in atmospheric evaporative demand.

\section{Interrelationships between functional leaf and wood traits}

The interrelationships among traits as revealed by the tree-level Pearson correlation analyses (Fig. 4.4) were in good agreement with the output of our linear mixed effects models for which plot, tree diameter, plantation age and density added as random effects (Table A4.4). According to the Pearson correlation analyses, VD $(r=-0.57, P<0.001), A_{\text {lumen }}: A_{\text {xylem }}(r=-0.55, P=0.002)$ and $V_{\mathrm{g}}(r=-0.38, P<0.01)$ were closely related to $P_{88}$. VD was also related to $P_{50}$, but only at marginal significance (VD: $r=-0.35, P=0.054$; Fig. 4.4). When accounting for random plot effects, however, the relationship between VD and $P_{50}$ became significant according to the LME output (effect $r^{2}=$ 0.33; Fig. 4.5, Table A4.4). In contrast, vessel diameter $(D)$ and the three measures of hydraulic efficiency $\left(K_{\mathrm{p}}, K_{\mathrm{s}}, K_{\mathrm{l}}\right)$ were all unrelated to embolism resistance (Fig. 4.4, Table A4.4). In addition to the three anatomical measures related to the number of vessel, i.e. VD, $V_{\mathrm{g}}$ and $A_{\text {lumen }}: A_{\mathrm{xylem}}$, also specific leaf area (SLA) was associated with the $P_{50}$-value according to the LME (Table A4.4, Fig. A4.2). Accordingly, a relationship with the two measures of embolism resistance, i.e. $P_{50}$ and $P_{88}$, was observed at both the wood and leaf level. At the wood level, VD emerged as a major trait responding sensitively to changes in VPD and being positively associated with hydraulic efficiency $\left(K_{\mathrm{s}} ; r=0.31, P=0.003\right)$ and negatively with hydraulic safety $\left(P_{50}\right.$ and $\left.P_{88}\right)$ (Fig. 4.4, Table A4.4). Additionally, VD was closely related to $V_{\mathrm{g}}(r=0.59, P<0.001)$ and $A_{\text {lumen }}: A_{\mathrm{xylem}}(r$ $=0.77, P<0.001$ ), while $D$ was not (Fig. 4.4). At the leaf level, VD was closely negatively related to the Huber value, i.e. the sapwood-to-leaf area ratio (HV; $r=-0.44, P<0.001)$. However, no relationship between VD and the turgor loss point $\left(\pi_{\mathrm{tlp}} ; r=0.11, P=\right.$ n.s. $)$ was observed, and $\pi_{\mathrm{tlp}}$ was also unrelated to $P_{50}(r=0.04, P=$ n.s. $)$ or $P_{88}(r=-0.01, P=$ n.s. $)$ (Fig. 4.4). Overall, SLA 
emerged as one of the most influential traits at the leaf level. This widely studied functional leaf trait did not only tend to respond to changes in VPD $(P<0.07)$, it was also positively related to wood density (WD; $r=0.39, P<0.001)$ and to $P_{50}$ at marginal significance $(r=0.32, P=0.088)$ (Fig. 4.4). Similarly to the relationship between VD and $P_{50}$, however, random plot effects had to be accounted for in order to observe a significant relationship between SLA and $P_{\text {tlp }}\left(\right.$ effect $r^{2}=$ 0.14; Table A4.4; Fig. A4.2).

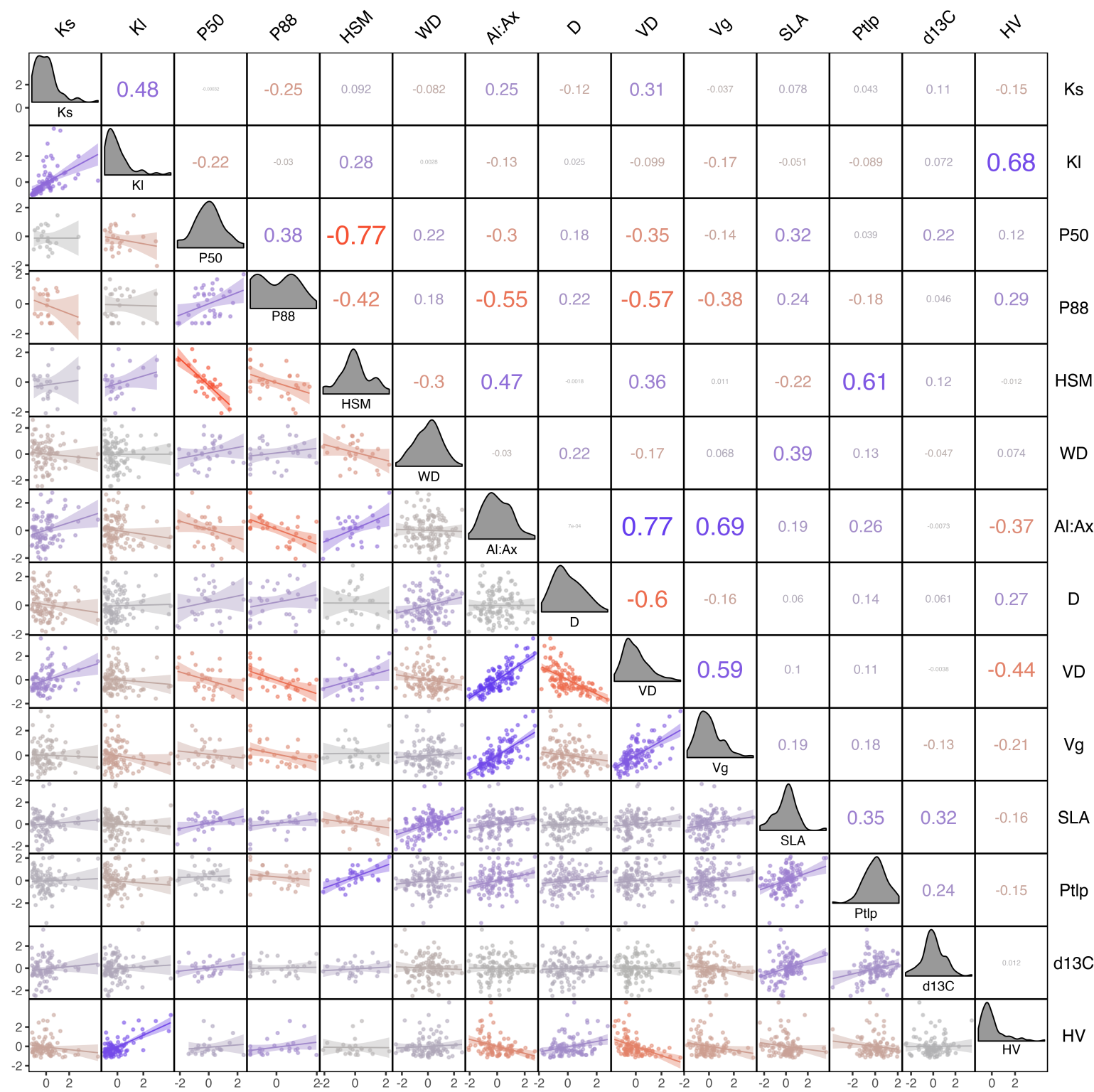

Fig. 4.4: Pair-wise Pearson correlation table (upper triangle), scatter plot (lower triangle) and density plot (diagonal panels) for the relationships between 14 functional traits of $H$. brasiliensis. Shown are the data on tree level $(n=125)$, including trend lines from linear regressions with $95 \%$ confidence intervals. Please note that embolism resistance was only quantified for a subset of tree individuals $(n=35)$. Color and size indicate the strength of the correlation. 

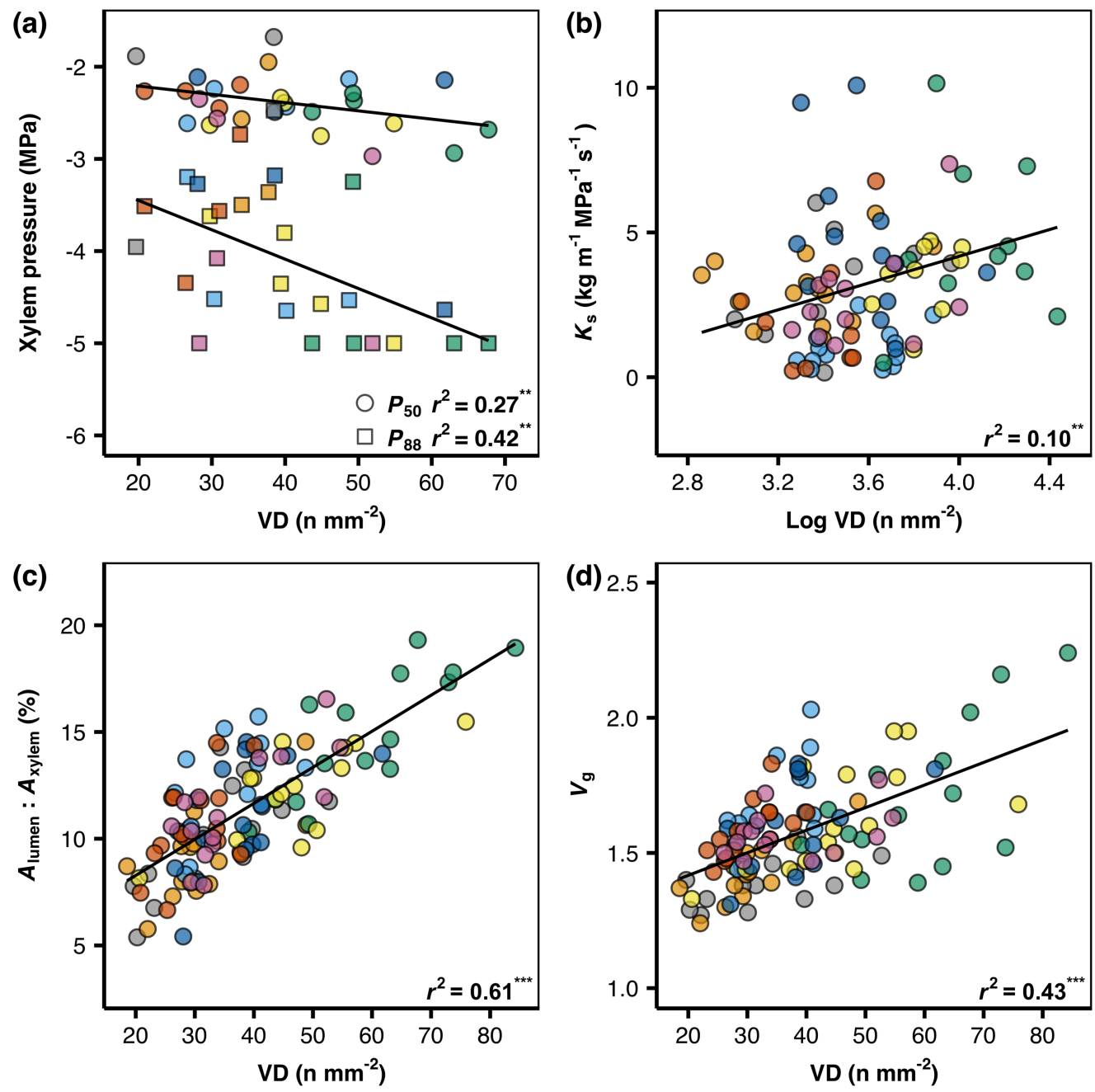

Fig. 4.5: Relationships between vessel density (VD) and (a) tree-level xylem pressures inducing $50 \%$ or $88 \%$ loss of hydraulic conductance (circle $=P_{50}$; square $\left.=P_{88}\right)$ of $H$. brasiliensis branches; $(\mathrm{b})$ sapwood-specific hydraulic conductance $\left(K_{\mathrm{s}}\right)$; (c) lumen-to-sapwood-area ratio $\left(A_{\text {lumen }}: A_{\mathrm{xylem}}\right)$; and $(\mathrm{d})$ vessel grouping index $\left(V_{\mathrm{g}}\right)$. Given are the conditional $r^{2}$ based on the LME models, asterisks indicate the level of significance $(* *, P<0.01 ; * * *, P<0.01)$. Different colours indicate different plots.

\section{Discussion}

\section{Hydraulic strategy of Hevea brasiliensis}

As a consequence of an increasing global demand for latex, rubber plantations are expanding into drought-prone and thus climatically suboptimal areas. This indicates that this economically important tree crop species must tolerate a certain extent of drought intensity, even though it originates from a humid tropical environment. Our data on the xylem pressure at 50\% loss of hydraulic conductance are the lowest $P_{50}$ values documented for H. brasiliensis so far (-2.33 MPa; 
clone PB260). Jinagool et al. (2016) reported $P_{50}$ values for PB260 clones of $-1.96 \mathrm{MPa}$ using the same methodology as we did, while Chen and Cao (2015) found less negative values using the bench dehydration method ( $-1.06 \mathrm{MPa})$. However, these values indicate that rubber is fairly vulnerable to drought-induced embolism, even though the sensitivity may vary according to environmental conditions. This suggests that rubber trees require a rather stringent stomatal control of transpiration in order to avoid hydraulic failure. In agreement hereon, several studies have reported a tight stomatal control of transpiration in rubber in order to avoid hydraulic failure (Isarangkool Na Ayuttaya et al. 2011, Kumagai et al. 2015, Sopharat et al. 2015). These results confirm the drought-avoiding strategy of rubber, which may explain why this species can be cultivated in drought-prone areas, even though it has a high water demand (Tan et al. 2011). If water deficits become critical, it sheds its leaves for weeks to months in order to avoid hydraulic failure, even though the species is not deciduous under optimal climatic conditions (Chen and Cao 2015). Thus, the length of the growing season is reduced at climatically suboptimal sites at the cost of carbon gain and yield. Flexibility in leaf phenology seems to match a certain extent of intra-specific plasticity in hydraulic traits, because this species thrives in climatically quite variable habitats.

\section{Variability of wood and leaf traits between well-drained and riparian sites}

We observed a very limited impact of soil water availability on wood and leaf traits related to hydraulic efficiency or safety, when comparing well-drained and riparian sites, in contradiction to our first hypothesis. Because all studied trees belong to the same clone (PB260), we were able to quantify the degree of phenotypic plasticity in response to water availability. In a provenance trial with 15 rubber provenances located in Northern Thailand, Rungwattana et al. (2018) observed a strong correlation between leaf traits and the climate at the place of origin, while wood-related traits were only weakly related. We therefore assumed that wood-related traits might respond more plastically to the local environment, while leaf traits are under stronger genetic control. In contrast to this assumption, however, all traits related to xylem safety and efficiency were comparable between the two systems differing in soil water availability. Instead, we found leaf turgor loss point $\left(\pi_{\mathrm{tlp}}\right)$ to differ significantly between well-drained and riparian sites. Pritzkow et al. (2020) postulated that leaf vulnerability is generally more plastic in trees than sapwood vulnerability. Our results across soil types seem to support the assumption that leaves as shorter-lived organs than branches are better suited to respond to variable environmental conditions in a plastic way, at least at first glance. Unexpected is the finding that leaves from well-drained sites had higher, and not lower, $\pi_{\text {tlp }}$ values than leaves from riparian sites (-2.02 MPa versus -2.17 MPa, 
respectively), since leaves with higher $\pi_{\mathrm{tlp}}$ values generally lose their turgor at smaller tissue water losses and therefore seem to be less drought-resistant. Such cell water relations could be an adaptation to increase the hydraulic safety margin, i.e. the difference between $\pi_{\mathrm{tlp}}$ and $P_{50}$ value. In any case, our data confirm that stomates are closed relatively early at high leaf water potentials in rubber in support of the sensitive stomatal regulation of this species ( $c f$. Rodriguez-Dominguez et al. 2016, Berry et al. 2019). It is reasonable to speculate that the drought-induced modification of a tree's anatomy, morphology and physiology is related to the leaf habit, i.e. drought-deciduous or evergreen. The xylem of tropical evergreen tree species must withstand greater xylem pressure gradients during the dry season than that of drought-deciduous species (Choat et al. 2005, Fu et al. 2012). As a consequence, evergreen tree species should require greater adjustments in xylem properties in response to altered water availability in order to maintain water transport to the canopy, than would be necessary in drought-avoiding deciduous tree species. This could explain why soil water availability did not affect the hydraulic safety of rubber in our study. Yet, even if embolism resistance requires no or only minor adjustment in response to declining water availability, we had expected modifications in xylem anatomy, notably a decrease in conduit diameters and increases in conduit numbers (Fonti et al. 2013, Schuldt et al. 2016, Lübbe et al. 2017). Although we indeed observed a higher wood density at well-drained sites in agreement with our second hypothesis, this was not associated with modifications in any of the wood anatomical parameters. This finding is less surprising, when taking into account that wood density is not closely linked to vessel traits related to hydraulic efficiency, but instead is largely determined by the fibre wall and lumen fractions (Ziemińska et al. 2013). Furthermore, water availability likely does not affect vascular differentiation directly, but rather indirectly through reduced growth and thus tree size (Olson et al. 2014, Dòria et al. 2019, Lechthaler et al. 2019). Because all rubber trees in our study had a similar height and the branches were of comparable diameter, we do not expect any differences in flow path length or cambial age between plots (cf. Li et al. 2019).

\section{Trait plasticity in response to the local environment}

Although site selection enabled a clear separation between well-drained and riparian sites, the given variability in volumetric soil water content (VWC) across plots within a soil type demanded to investigate trait plasticity in response to the local environmental variability in more detail. As was found in the comparison of well-drained and riparian plots, all wood and leaf traits related to xylem safety were unrelated to variation in VWC, when the analysis was conducted at the plot level $(n=8)$. Instead, a strong influence of the local evaporative demand on xylem safety was 
observed. With an increase in vapour pressure deficit (VPD), the xylem pressures at $50 \%$ and $88 \%$ loss of hydraulic conductance ( $P_{50}$ and $P_{88}$, respectively) both declined, while the hydraulic safety margin increased. In contrast to the wood-related traits, $\pi_{\text {tlp }}$ was unaffected by changes in VPD at the leaf level. The increase in xylem safety was accompanied by an increase in vessel density but not vessel diameter. Traditionally, the atmospheric water status has been viewed as the factor driving long-distance water transport and influencing stomatal aperture, but its role as a factor influencing tree water status, growth and vitality has only rarely been considered (Köcher et al. 2012, Brodribb et al. 2017, Amitrano et al. 2019). However, rising global temperatures have resulted in an increase in the frequency and intensity of "hotter droughts" (Allen et al. 2015), which has increased awareness to consider VPD as a driving factor of drought-induced tree mortality (Eamus et al. 2013, Grossiord et al. 2020a). While Blackmann et al. (2017) related VPD to leaf embolism resistance in Corymbia calophylla, a direct link between the VPD level at a site and branch xylem $P_{50}$ has, to our knowledge, not yet been shown. Because annual mean VPD has strongly increased since the late 1990s, both regionally and globally (Barkhordarian et al. 2019, Yuan et al. 2019, Schuldt et al. 2020), our finding of an apparent adaptive response of xylem safety in rubber to a VPD increase is of high interest. Rubber trees growing in an environment with higher mean VPD had lower $P_{50}$ and especially $P_{88}$ values and a higher safety margin than trees exposed to lower VPD. The hydraulic safety margin, calculated here as the difference between $\pi_{\text {tlp }}$ and $P_{50}$, increased from plots with lower to higher evaporative demand due to the decrease in $P_{50} / P_{88}$, while $\pi_{\text {tlp }}$ remained constant. With respect to climate warming, this is a promising result, as it may indicate that certain species are able to counteract increases in the evaporative demand to a certain extent by increasing xylem hydraulic safety. In the absence of electron microscopic data, we can only speculate that higher VPD may have triggered the development of more embolism-resistant pit membranes in the xylem.

At the leaf level, we observed a tendency of a decline in specific leaf area (SLA) with increasing VPD level. A decrease in leaf area per dry mass is caused by anatomical changes in the lamina and has been linked to a reduced drought-induced mortality of trees (Greenwood et al. 2017). Both adjustments, the increase in xylem safety and the development of smaller and/or thicker leaves, have frequently been observed with inter-specific trait variation along climatic gradients, but were rarely confirmed for intra-specific trait variation within a species (e.g. Schuldt et al. 2016, Rosas et al. 2019). As the leaf carbon isotope signature $\left(\delta^{13} C\right)$ did not differ between plots in our study, this suggests that the vascular modifications resulting in higher xylem safety in 
combination with the development of leaves capable of tolerating more negative tissue water potentials were sufficient to avoid reductions in stomatal conductance in the face of a higher VPD. Our results show that this deciduous tropical tree species has a sufficiently high phenotypic plasticity to adjust its xylem structure in response to a higher evaporative demand, in agreement with our first hypothesis. A high degree of phenotypic plasticity in traits related to hydraulic safety might be more advantageous for coping with the anticipated increase in drought intensity than genetic adaptation (Grossiord et al. 2020b). The tight relationship between $P_{50}$ and VPD clearly demonstrates the magnitude of phenotypic plasticity in rubber.

\section{Relationships among traits}

In agreement with a growing body of intra-specific studies, we could not confirm any tradeoff between hydraulic safety and efficiency (e.g. Schuldt et al. 2016, Hajek et al. 2016, Pritzkow et al. 2020). Our results support the assumption that this trade-off is generally weak, and that safety and efficiency might largely be decoupled (Gleason et al. 2016). In intra-specific data sets, the variation in either hydraulic safety or efficiency might simply be too small to observe this tradeoff, as speculated by Schuldt et al. (2016). In fact, most recent studies confirming this classic plant hydraulic paradigm (cf. Tyree et al. 1994) were inter-specific studies (e.g. Maherali et al. 2006, Fan et al. 2011, Markesteijn et al. 2011, Schumann et al. 2019, van der Sande et al. 2019). In contrast to vessel diameter $(D)$ and hydraulic efficiency, a close relationship between vessel density (VD) and embolism resistance was observed. While the often observed relationship between $D$ and $P_{50}$ (e.g. Wheeler et al. 2005, Domec et al. 2010, Hajek et al. 2014) is most likely related to changes in pit properties ( $\mathrm{Li}$ et al. 2016), the observed relationship between VD and embolism resistance has been attributed to pathway redundancy (Schuldt et al. 2016). In rubber, VD is further associated with the lumen-to-sapwood area ratio $\left(A_{\text {lumen }}: A_{\text {xylem }}\right)$ and consequently hydraulic efficiency, while $D$ is not. According to Hagen-Poiseuille's law, one would expect $D$ to be the principal determinant of hydraulic conductivity. One explanation for this surprising finding could be that the branch xylem of rubber is composed of very large vessels of c. $60 \mu \mathrm{m}$ in diameter, resulting in a high specific conductivity $\left(K_{\mathrm{s}}\right.$; mean $\pm \mathrm{SE}$ : $\left.3.22 \pm 0.40 \mathrm{~kg} \mathrm{~m}^{-1} \mathrm{MPa}^{-1} \mathrm{~s}^{-1}\right)$. Because hydraulic efficiency is already high, it might be favourable to increase vessel numbers and not vessel diameter. In rubber, the high degree of trait plasticity of VD and $A_{\text {lumen }}: A_{\text {xylem }}$ in relation to other functional wood traits has also been observed by Rungwattana et al. (2018). In their provenance trial, both traits were related to the climate at the place of origin, even though a much closer relationship was observed for SLA. In our study, we likewise observed that VD and SLA were not only react- 
ing sensitively to changes in evaporative demand, but both were also related to the $P_{50}$. At the leaf level, significant relationships between xylem safety and leaf scleromorphy have mainly been observed across species (Willson et al. 2008, Fan et al. 2011, but see Schumann et al. 2019), but not within species. While $H$. brasiliensis seems to increase its xylem safety mostly through vascular adjustments, leaf morphological modifications seem also to contribute.

\section{Conclusion}

A main motivation of the present study in Indonesian rubber plantations was to analyse the effect of soil type and thus soil moisture regime (well-drained vs. riparian) on 16 wood and leaf traits related to hydraulic safety and efficiency. Because all trees belonged to the same clone (PB260), we were able to quantify the degree of phenotypic plasticity in response to variation in edaphic and atmospheric water status between soil types and across an environmental gradient. Surprisingly, volumetric soil water content had no effect on branch xylem safety and efficiency, and leaf morphological traits across the two soil types and along the gradient. The only exception was turgor loss point, which was significantly lower, and not higher, at the moister riparian sites, but this surprising finding could not be confirmed in the plot-level analysis. In contrast, we observed a close dependency of xylem embolism resistance on the local evaporative demand. With increasing VPD level, both $P_{50}$ and $P_{88}$ declined, while the hydraulic safety margin increased. The increase in xylem safety was accompanied by an increase in vessel density and a decline in specific leaf area, but not in vessel diameter or hydraulic efficiency. In the light of the general VPD increase with global warming during the past 30 years, our results are first evidence that trees may be able to modify their woody and foliar tissue to acclimatize to an increasing evaporative demand. Due to its drought-avoiding strategy in conjunction with a high degree of phenotypic plasticity, rubber might be able to acclimatize successfully to more intensive droughts at the cost of reduced yield. Future experimental studies have to show which atmospheric and soil moisture conditions will drive rubber beyond its drought limit. 


\section{Acknowledgements}

This study is part of the Collaborative Research Centre CRC 990 - EFForTS (Ecological and Socioeconomic Functions of Tropical Lowland Rainforest Transformation Systems) funded by the German Research Foundation (Deutsche Forschungsgemeinschaft, project number 192626868, subproject B04) and the Ministry of Research, Technology and Higher Education (Ristekdikti, research permit number: 251/SIP/FRP/E5/Dit.KI/VII/2016). We thank the University of Jambi for providing space to conduct the laboratory work, the plot owners for allowing us to collect rubber branches, Syahbarudin and Kairul Anwar for support in the field and in the laboratory, Vira Addriyati Achmad and Pratiwi Hamson for the anatomical sectioning, Christian Stiegler from subproject A03 for provision of climatic data, Nina Hennings from subproject A04 for providing soil texture data for the riparian sites, Aiyen Tjoa for the provision of plot data and information on rubber clones origins, and Gaelle Capdeville and Regis Burlett from the University of Bordeaux for their help with the Cavitron measurements. 


\section{Appendix}

Table A4.1: Coordinates and elevation ( $\mathrm{m}$ above sea level) of all eight investigated rubber plantation plots.

\begin{tabular}{|c|c|c|c|}
\hline Plot & Coordinates S & Coordinates E & Elevation \\
\hline P1 & S $01^{\circ} 91^{\prime} 09.9^{\prime \prime}$ & Е $103^{\circ} 26^{\prime} 66.4^{\prime \prime}$ & 76 \\
\hline P2 & S $01^{\circ} 87^{\prime} 95.0^{\prime \prime}$ & E $103^{\circ} 27^{\prime} 45.9^{\prime \prime}$ & 79 \\
\hline P3 & 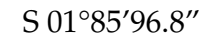 & E $103^{\circ} 30^{\prime} 05.5^{\prime \prime}$ & 56 \\
\hline P4 & S $01^{\circ} 48^{\prime} 20.2^{\prime \prime}$ & E $103^{\circ} 15^{\prime} 53.7^{\prime \prime}$ & 62 \\
\hline P5 & $\mathrm{S} 01^{\circ} 42^{\prime} 39.5^{\prime \prime}$ & E $103^{\circ} 18^{\prime} 50.0^{\prime \prime}$ & 39 \\
\hline P6 & S 01 ${ }^{\circ} 53^{\prime} 14.3^{\prime \prime}$ & E $103^{\circ} 17^{\prime} 29.2^{\prime \prime}$ & 61 \\
\hline P7 & S 01 $51^{\prime} 42.3^{\prime \prime}$ & E $103^{\circ} 18^{\prime} 20.4^{\prime \prime}$ & 58 \\
\hline P8 & S $01^{\circ} 42^{\prime} 39.5^{\prime \prime}$ & E $103^{\circ} 17^{\prime} 31.1^{\prime \prime}$ & 39 \\
\hline
\end{tabular}

Table A4.2: Summary of wood and leaf functional traits of $H$. brasiliensis for the four well-drained (P1-P4) and four riparian (P5-P8) sites. Given are means $\pm \mathrm{SE}$ except for $P_{12}, P_{50}$ and $P_{88}$ that were extracted from model predictions. For symbols and units, see Table 4.1. Letters indicate significant differences between soil types (Wilcoxon signed rank test or Student's t-test).

\begin{tabular}{|c|c|c|c|c|c|c|c|c|c|}
\hline $\begin{array}{l}\text { Soil } \\
\text { type }\end{array}$ & Plot & WD & $K_{\mathrm{p}}$ & $K_{\mathrm{s}}$ & $K_{1}$ & $P_{12}$ & $P_{50}$ & $P_{88}$ & HSM \\
\hline \multirow{5}{*}{$\begin{array}{l}\text { Well- } \\
\text { drained }\end{array}$} & P1 & $0.65 \pm 0.01$ & $17.92 \pm 1.95$ & $3.25 \pm 0.63$ & $2.82 \mathrm{E}-04 \pm 4.47 \mathrm{E}-05$ & -1.68 & -2.14 & -3.10 & - \\
\hline & P2 & $0.67 \pm 0.01$ & $17.75 \pm 1.54$ & $3.13 \pm 0.36$ & $7.35 \mathrm{E}-04 \pm 1.21 \mathrm{E}-04$ & -1.74 & -2.28 & -3.42 & $0.29 \pm 0.23$ \\
\hline & P3 & $0.71 \pm 0.01$ & $29.49 \pm 2.59$ & $1.01 \pm 0.19$ & $1.27 \mathrm{E}-04 \pm 3.41 \mathrm{E}-05$ & -1.76 & -2.37 & -3.71 & $0.42 \pm 0.03$ \\
\hline & $\mathrm{P} 4$ & $0.66 \pm 0.01$ & $22.81 \pm 1.61$ & $5.55 \pm 1.19$ & $5.55 \mathrm{E}-04 \pm 1.29 \mathrm{E}-04$ & -1.77 & -2.44 & -3.99 & $0.67 \pm 0.14$ \\
\hline & & $0.67 \pm 0.01^{b}$ & $21.99 \pm 1.14^{a}$ & $3.13 \pm 0.33^{a}$ & $4.38 \mathrm{E}-04 \pm 5.71 \mathrm{E}-05^{\mathrm{a}}$ & $-1.77^{a}$ & $-2.32^{\mathrm{a}}$ & $-3.59^{a}$ & $0.31 \pm 0.08^{a}$ \\
\hline \multirow{5}{*}{ Riparian } & P5 & $0.61 \pm 0.01$ & $19.37 \pm 1.13$ & $3.34 \pm 0.38$ & $4.33 \mathrm{E}-04 \pm 8.31 \mathrm{E}-05$ & -1.77 & -2.46 & -4.05 & $0.45 \pm 0.14$ \\
\hline & P6 & $0.68 \pm 0.01$ & $21.02 \pm 2.15$ & $4.70 \pm 0.74$ & $7.87 \mathrm{E}-04 \pm 1.91 \mathrm{E}-04$ & -1.68 & -2.14 & -3.10 & $0.03 \pm 0.15$ \\
\hline & P7 & $0.71 \pm 0.01$ & $26.65 \pm 2.18$ & $2.02 \pm 0.70$ & $1.87 \mathrm{E}-04 \pm 5.91 \mathrm{E}-05$ & -1.73 & -2.26 & -3.47 & $0.20 \pm 0.06$ \\
\hline & P8 & $0.61 \pm 0.01$ & $22.87 \pm 1.61$ & $2.74 \pm 0.50$ & $4.04 \mathrm{E}-04 \pm 5.91 \mathrm{e}-05$ & -1.72 & -2.58 & -4.76 & $0.50 \pm 0.17$ \\
\hline & & $0.65 \pm 0.01^{\mathrm{a}}$ & $22.48 \pm 0.96^{a}$ & $3.31 \pm 0.40^{\mathrm{a}}$ & $4.74 \mathrm{E}-04 \pm 6.54 \mathrm{E}-05^{\mathrm{a}}$ & $-1.76^{a}$ & $-2.38^{a}$ & $-3.79^{a}$ & $0.31 \pm 0.08^{\mathrm{a}}$ \\
\hline
\end{tabular}




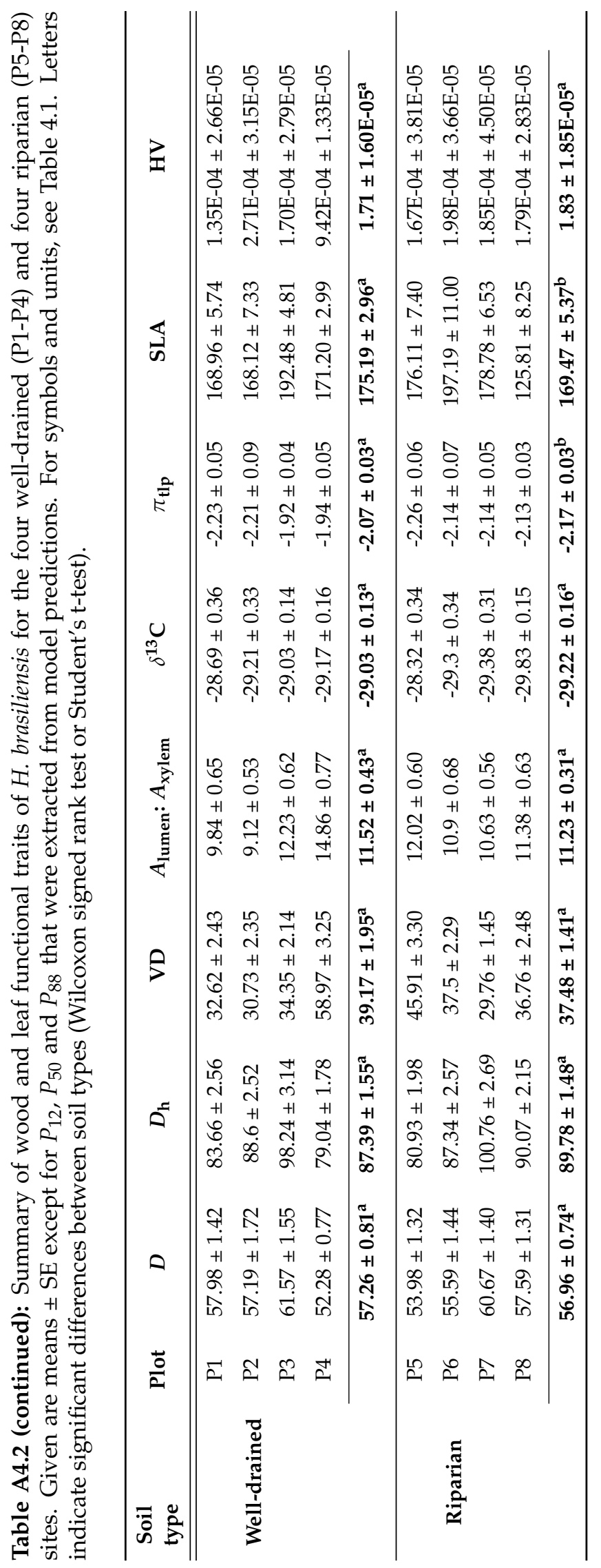


Table A4.3: Results of hierarchical mixed effects models on the influence of (M1) site (riparian vs. well-drained) and (M2) plot vapour pressure deficit in 2018 (VPD) on $P_{50}$ and slope of the vulnerability curves of $H$. brasiliensis branches. Given are PLC values (numbers in parentheses indicate the standard error) for the fixed effects, standard deviation (SD) for random effects (trees nested in plots) and residuals, and marginal (only with fixed effects) as well as conditional (including random effects) pseudo $r^{2}$. Level of significance is indicated with ${ }^{* *}(P<0.01)$ and ${ }^{* * *}(P$ $<0.001)$.

\begin{tabular}{|c|c|c|c|c|}
\hline \multirow{2}{*}{ Parameters } & \multicolumn{2}{|c|}{ M1: slope $+P_{50} \sim$ soil type } & \multicolumn{2}{|c|}{ M2: slope $+P_{50} \sim$ VPD centered } \\
\hline & Coefficients & PLC (SE) & Coefficients & PLC (SE) \\
\hline slope & intercept (riparian) & $53.93(8.32)^{* * *}$ & intercept & $55.86(4.44)^{* * *}$ \\
\hline slope & well-drained & $7.90(11.95)$ & VPD & $-97.07(37.37)^{* *}$ \\
\hline$P_{50}$ & intercept (riparian) & $-2.38(0.09)^{* * *}$ & intercept & $-2.36(0.04)^{* * *}$ \\
\hline$P_{50}$ & well-drained & $0.07(0.12)$ & VPD & $-1.14(0.36)^{* *}$ \\
\hline \multicolumn{5}{|c|}{ Random effects : trees nested in plots } \\
\hline SD residuals & & 7.94 & & 7.96 \\
\hline Number of plots & & 8 & & 8 \\
\hline SD plot (slope) & & 10.75 & & 2.97E-03 \\
\hline SD plot $\left(P_{50}\right)$ & & 0.12 & & 4.72E-05 \\
\hline Number of tree & & 35 & & 35 \\
\hline SD tree (slope) & & 25.62 & & 25.09 \\
\hline SD tree $\left(P_{50}\right)$ & & 0.25 & & 0.25 \\
\hline Observations & \multicolumn{4}{|c|}{781} \\
\hline Marginal $r^{2}$ & & 0.81 & & 0.83 \\
\hline Conditional $r^{2}$ & & 0.94 & & 0.94 \\
\hline
\end{tabular}


Table A4.4: Model summary of the influence of (a) VPD and (b) VPD dry on key functional traits (Table 4.1). Given are intercept (SE), coefficient values (coef.) (SE), standard deviation (SD) for random effects (plot) and residuals as well as number of observations ( $n$ ). For all models, tree diameter, plantation age and density were tested as random effect in addition to plot. Only plantation age improved the models with SLA and 13C. Significance is indicated by values in bold and with ${ }^{\circ}(P<0.10){ }^{*}(P<0.05),{ }^{* *}(P<0.01)$.

\begin{tabular}{|c|c|c|c|c|c|c|}
\hline \multicolumn{7}{|c|}{ (a) Traits $\sim$ VPD } \\
\hline Parameter & $\begin{array}{l}\text { Intercept } \\
\quad \text { (SE) }\end{array}$ & Coef. & $\begin{array}{l}\text { Value } \\
\text { (SE) }\end{array}$ & $\begin{array}{l}\text { SD } \\
\text { plot }\end{array}$ & $\begin{array}{c}\mathrm{SD} \\
\text { residual }\end{array}$ & $n$ \\
\hline$K_{\mathrm{s}}$ & $3.80(2.50)$ & VPD & $-0.89(3.73)$ & 1.18 & 2.14 & 90 \\
\hline$K_{1}$ & 6.37E-04 (4.12E-04) & VPD & $-2.95 \mathrm{E}-04(6.15 \mathrm{E}-04)$ & $1.94 \mathrm{E}-04$ & $3.86 \mathrm{E}-04$ & 103 \\
\hline$P_{12}$ & $-1.55(0.32)$ & VPD & $-0.19(0.46)$ & 4.73E-06 & 0.32 & 35 \\
\hline$P_{50}$ & $-1.59(0.24)$ & VPD & $-1.14(0.35)^{*}$ & 2.77E-06 & 0.24 & 35 \\
\hline$P_{88}$ & $-1.88(0.66)$ & VPD & $-3.13(0.96)^{*}$ & $1.88 \mathrm{E}-05$ & 0.66 & 35 \\
\hline HSM & $-0.63(0.31)$ & VPD & $1.49(0.45)^{*}$ & $3.86 \mathrm{E}-06$ & 0.25 & 28 \\
\hline WD & $0.77(0.06)$ & VPD & $-0.16(0.08)$ & 0.03 & 0.03 & 119 \\
\hline$A_{\text {lumen }}: A_{\text {xylem }}$ & $6.74(2.53)$ & VPD & $7.06(3.78)$ & 1.21 & 2.46 & 120 \\
\hline$D$ & $60.53(5.29)$ & VPD & $-5.22(7.92)$ & 2.50 & 5.38 & 120 \\
\hline VD & $16.56(14.93)$ & VPD & $33.20(22.34)$ & 7.66 & 9.77 & 120 \\
\hline$V_{\mathrm{g}}$ & $1.31(0.16)$ & VPD & $0.40(0.24)$ & 0.08 & 0.16 & 115 \\
\hline SLA & $24.67(2.93)$ & VPD & $-9.81(4.38)^{\circ}$ & 1.41 & 2.76 & 120 \\
\hline$\pi_{\mathrm{tlp}}$ & $-2.29(0.21)$ & VPD & $0.26(0.32)$ & 0.10 & 0.21 & 117 \\
\hline$\delta^{13} \mathrm{C}$ & $-28.65(0.77)$ & VPD & $-0.71(1.15)$ & 0.31 & 1.06 & 116 \\
\hline $\mathrm{HV}$ & 2.30E-04 (8.36E-05) & VPD & $-8.22 \mathrm{E}-05(1.25 \mathrm{E}-04)$ & 3.03E-05 & $1.18 \mathrm{E}-04$ & 102 \\
\hline \multicolumn{7}{|c|}{ (b) Traits $\sim V P D_{\text {dry }}$} \\
\hline Parameter & $\begin{array}{l}\text { Intercept } \\
\text { (SE) }\end{array}$ & Coef. & $\begin{array}{l}\text { Value } \\
\text { (SE) }\end{array}$ & $\begin{array}{l}\text { SD } \\
\text { plot }\end{array}$ & $\begin{array}{c}\mathrm{SD} \\
\text { residual }\end{array}$ & $n$ \\
\hline$K_{\mathrm{s}}$ & $2.55(2.68)$ & $\mathrm{VPD}_{\text {dry }}$ & $0.62(2.48)$ & 1.18 & 2.14 & 90 \\
\hline$K_{1}$ & 4.69E-04 (4.46E-04) & $\mathrm{VPD}_{\text {dry }}$ & $-2.41 \mathrm{E}-04(4.13 \mathrm{E}-04)$ & $1.98 \mathrm{E}-04$ & $3.86 \mathrm{E}-04$ & 103 \\
\hline$P_{12}$ & $-1.54(0.33)$ & $\mathrm{VPD}_{\text {dry }}$ & $-0.12(0.30)$ & $4.78 \mathrm{E}-06$ & 0.32 & 35 \\
\hline$P_{50}$ & $-1.50(0.25)$ & $\mathrm{VPD}_{\text {dry }}$ & $-0.78(0.22)^{* *}$ & 2.43E-06 & 0.24 & 35 \\
\hline$P_{88}$ & $-1.53(0.67)$ & $\mathrm{VPD}_{\mathrm{dry}}$ & $-2.25(0.60)^{* * *}$ & $1.35 \mathrm{E}-05$ & 0.64 & 35 \\
\hline HSM & $-0.89(0.33)$ & $\mathrm{VPD}_{\text {dry }}$ & $1.15(0.29)^{*}$ & $1.59 \mathrm{E}-06$ & 0.24 & 28 \\
\hline WD & $0.76(0.06)$ & $\mathrm{VPD}_{\text {dry }}$ & $-0.09(0.06)$ & 0.03 & 0.03 & 119 \\
\hline$A_{\text {lumen }}: A_{\text {xylem }}$ & $5.36(2.40)$ & $\mathrm{VPD}_{\text {dry }}$ & $5.67(2.23)^{*}$ & 1.03 & 2.46 & 120 \\
\hline$D$ & $63.08(5.38)$ & $\mathrm{VPD}_{\text {dry }}$ & $-5.63(4.99)$ & 2.34 & 5.38 & 120 \\
\hline VD & 7.53 (14.17) & $\mathrm{VPD}_{\text {dry }}$ & $29.04(13.15)^{\circ}$ & 6.71 & 9.77 & 120 \\
\hline$V_{\mathrm{g}}$ & $1.23(0.16)$ & $\mathrm{VPD}_{\text {dry }}$ & $0.32(0.15)^{\circ}$ & 0.07 & 0.16 & 115 \\
\hline SLA & $22.90(3.43)$ & $\mathrm{VPD}_{\text {dry }}$ & $-5.35(3.18)$ & 1.58 & 2.76 & 120 \\
\hline$\pi_{\mathrm{tlp}}$ & $-2.37(0.22)$ & $\mathrm{VPD}_{\text {dry }}$ & $0.23(0.20)$ & 0.10 & 0.21 & 117 \\
\hline$\delta^{13} \mathrm{C}$ & $-28.61(0.82)$ & $\mathrm{VPD}_{\text {dry }}$ & $-0.48(0.76)$ & 0.31 & 1.06 & 116 \\
\hline $\mathrm{HV}$ & 2.40E-04 (8.98E-05) & $\mathrm{VPD}_{\text {dry }}$ & $-6.02 \mathrm{E}-05(8.36 \mathrm{E}-04)$ & $3.00 \mathrm{E}-05$ & $1.18 \mathrm{E}-04$ & 102 \\
\hline
\end{tabular}


Table A4.4 (continued): Model summary of the influence of (c) VWC and (b) anatomy and leaf traits on key functional traits (Table 4.1). Given are intercept (SE), coefficient values (coef.) (SE), standard deviation (SD) for random effects (plot) and residuals as well as number of observations (n). For all models, tree diameter, plantation age and density were tested as random effect in addition to plot. Only plantation age improved the models with SLA and 13C. Significance is indicated by values in bold and with ${ }^{\circ}(P<0.10),{ }^{*}(P<0.05),{ }^{* *}(P<0.01)$.

\begin{tabular}{|c|c|c|c|c|c|c|}
\hline \multicolumn{7}{|c|}{ (c) Traits $\sim$ VWC } \\
\hline Parameter & $\begin{array}{l}\text { Intercept } \\
\text { (SE) }\end{array}$ & Coef. & $\begin{array}{l}\text { Value } \\
\text { (SE) }\end{array}$ & $\begin{array}{l}\text { SD } \\
\text { plot }\end{array}$ & $\begin{array}{c}\text { SD } \\
\text { residual }\end{array}$ & $n$ \\
\hline$K_{\mathrm{s}}$ & $4.76(2.48)$ & VWC & $0.04(0.06)$ & 1.15 & 2.14 & 90 \\
\hline$K_{1}$ & 4.69E-04 (4.46E-04) & VWC & $-2.41 \mathrm{E}-04(4.13 \mathrm{E}-04)$ & 1.98E-04 & 3.86E-04 & 103 \\
\hline$P_{12}$ & $-1.45(0.29)$ & VWC & $-0.01(0.01)$ & 4.42E-06 & 0.31 & 35 \\
\hline$P_{50}$ & $-1.99(0.26)$ & VWC & $-0.01(0.01)$ & 5.93E-02 & 0.26 & 35 \\
\hline$P_{88}$ & $-3.30(0.84)$ & VWC & $-0.02(0.02)$ & 0.28 & 0.69 & 35 \\
\hline HSM & $0.22(0.43)$ & VWC & 3.69E-03 (1.00E-02) & 0.14 & 0.26 & 28 \\
\hline WD & $0.69(0.07)$ & VWC & $-6.28 \mathrm{E}-04(1.68 \mathrm{E}-03)$ & 0.04 & 0.03 & 119 \\
\hline$A_{\text {lumen }}: A_{\text {xylem }}$ & $9.05(2.94)$ & VWC & $0.06(0.07)$ & 1.44 & 2.46 & 120 \\
\hline$D$ & $58.63(5.44)$ & VWC & $-0.04(0.13)$ & 2.57 & 5.38 & 120 \\
\hline VD & $27.32(16.54)$ & VWC & $0.28(0.41)$ & 8.5 & 9.77 & 120 \\
\hline$V_{\mathrm{g}}$ & $1.33(0.17)$ & VWC & 6.06E-03 (4.09E-03) & 0.08 & 0.16 & 115 \\
\hline SLA & $15.38(3.71)$ & VWC & $0.05(0.09)$ & 1.86 & 2.76 & 120 \\
\hline$\pi_{\mathrm{tlp}}$ & $-2.05(0.22)$ & VWC & $-1.84 \mathrm{E}-03(5.41 \mathrm{E}-03)$ & 0.10 & 0.21 & 117 \\
\hline$\delta^{13} \mathrm{C}$ & $-30.13(0.71)$ & VWC & $0.03(0.02)$ & 0.25 & 1.06 & 116 \\
\hline $\mathrm{HV}$ & $1.88 \mathrm{E}-04(8.82 \mathrm{E}-05)$ & VWC & $-3.12 \mathrm{E}-07(2.17 \mathrm{E}-06)$ & 3.21E-05 & $1.18 \mathrm{E}-04$ & 102 \\
\hline \multicolumn{7}{|c|}{ (d) Embolism resistance traits $\sim$ anatomy and leaf traits } \\
\hline Parameter & $\begin{array}{c}\text { Intercept } \\
\text { (SE) } \\
\end{array}$ & Coef. & $\begin{array}{c}\text { Value } \\
\text { (SE) }\end{array}$ & $\begin{array}{l}\text { SD } \\
\text { plot }\end{array}$ & $\begin{array}{c}\mathrm{SD} \\
\text { residual }\end{array}$ & $n$ \\
\hline & & VD & $-0.08(40.02)^{* *}$ & & & \\
\hline$P_{50}$ & $0.87(1.15)$ & $\begin{array}{c}\text { SLA } \\
D \\
\text { VD:SLA }\end{array}$ & $\begin{array}{c}-0.11(0.05)^{*} \\
-0.01(0.01) \\
0.004(0.001 * *\end{array}$ & 0.18 & 0.19 & 30 \\
\hline$P_{88}$ & $-2.54(0.48)$ & VD & $-0.04(0.012)^{* *}$ & 0.19 & 0.82 & 30 \\
\hline$K_{\mathrm{s}}$ & $-5.06(2.79)$ & Log VD & $2.31(0.78)^{* *}$ & 2.22 & 0.83 & 90 \\
\hline$A_{\text {lumen }}: A_{\text {xylem }}$ & $4.71(0.65)$ & VD & $0.17(0.01)^{* * *}$ & 1.75 & 0.65 & 120 \\
\hline$V_{\mathrm{g}}$ & $1.21(0.06)$ & VD & $0.009(0.001)^{* * *}$ & 0.07 & 0.13 & 115 \\
\hline$P_{50}^{8}$ & $-2.12(0.47)$ & $V_{\mathrm{g}}$ & $0.15(0.29)$ & 0.18 & 0.23 & 28 \\
\hline$P_{88}$ & $-1.16(1.38)$ & $V_{\mathrm{g}}^{\circ}$ & $-1.80(0.86)^{*}$ & 0.68 & 0.26 & 28 \\
\hline
\end{tabular}




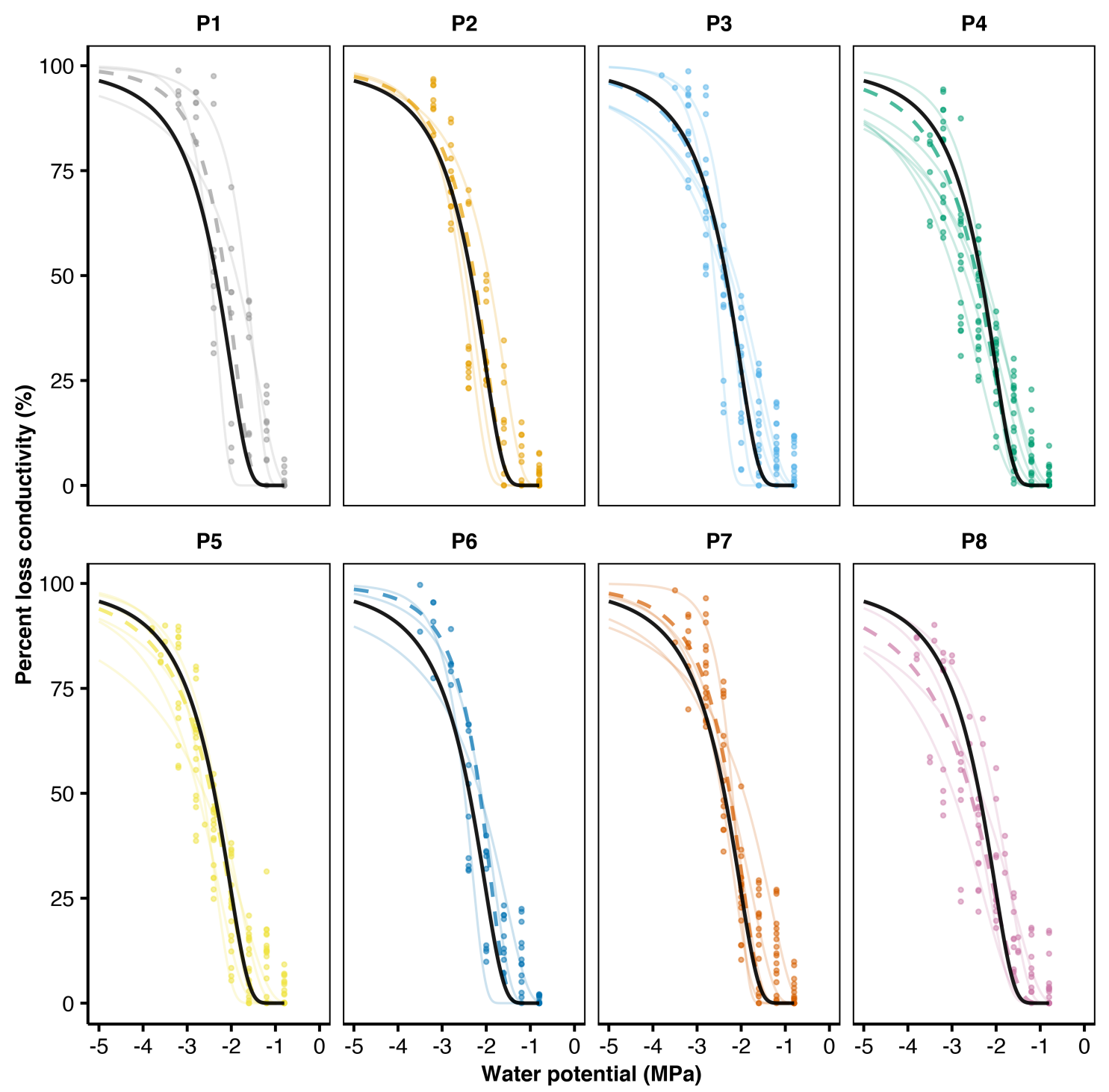

Fig. A4.1: Predicted vulnerability curves (VCs; percent loss of conductivity vs. xylem water potential) of Hevea brasiliensis branches for all trees sampled in the eight plots on well-drained (upper row) and riparian soil type (lower row). Color: tree identity; colored lines - tree level predictions; dashed black lines - plot level predictions; solid black lines - soil type-level predictions. 


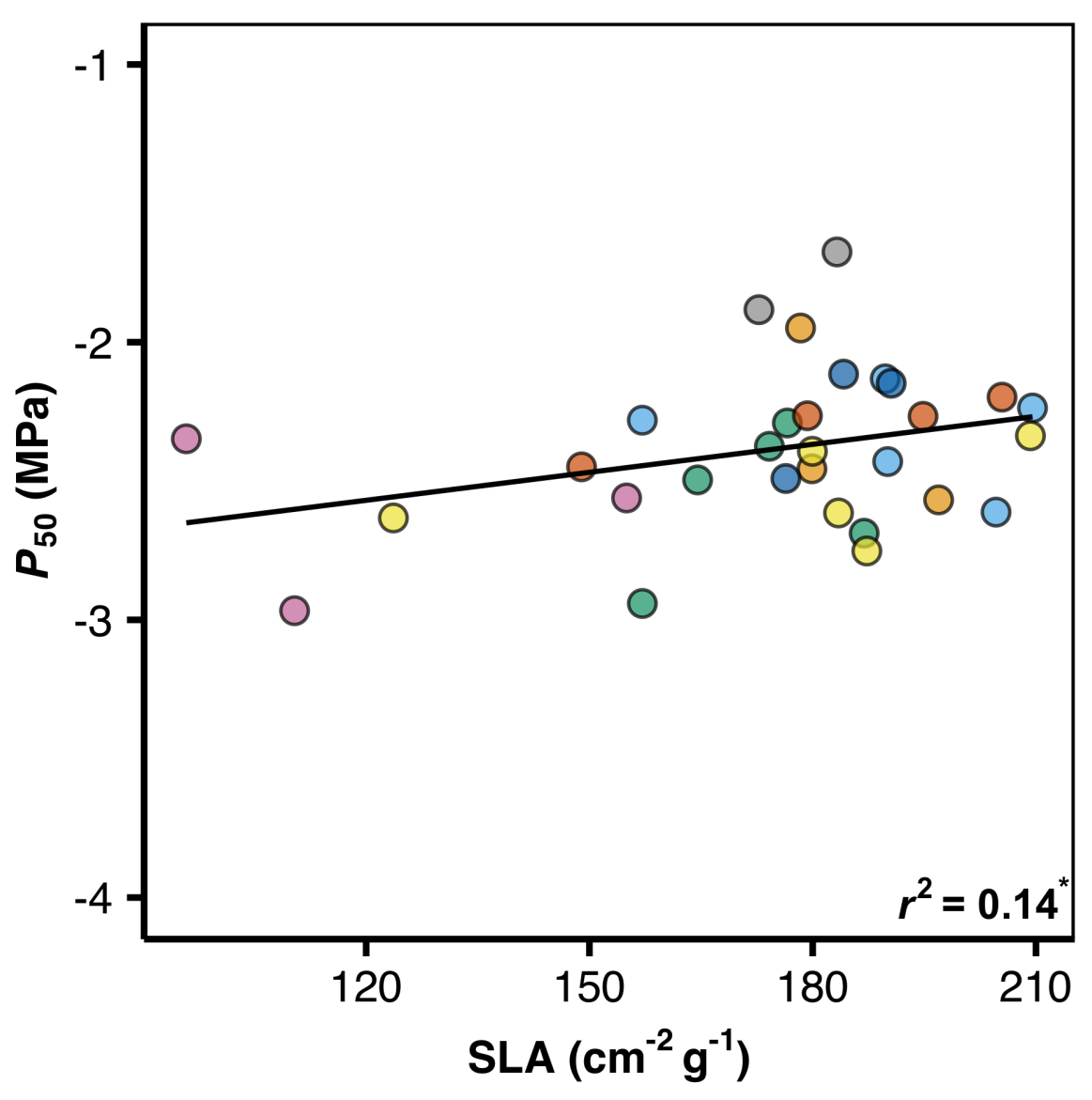

Fig. A4.2: Relationship between tree-level specific leaf area (SLA) and the xylem pressure at $50 \%$ loss of hydraulic conductance $\left(P_{50}\right)$. Given is the conditional $r^{2}$ of the linear mixed effect model, and the level of significance $(P<0.05)$. Each plot is represented by one symbol colour. 


\section{References}

Adams, H. D., Zeppel, M. J. B., ANDeregG, W. R. L., HARTMAnN, H., LANdhäUsser, S. M., Tissue, D. T., Huxman, T. E., Hudson, P. J., Franz, T. E., Allen, C. D., AnderegG, L. D. L., BARron-Gafford, G. A., BeErling, D. J., Breshears, D. D., BrodribB, T. J., Bugmann, H., Cobb, R. C., Collins, A. D., Dickman, L. T., Duan, H., Ewers, B. E., Galiano, L., Galvez, D. A., Garcia-Forner, N., Gaylord, M. L., Germino, M. J., Gessler, A., Hacke, U. G., Hakamada, R., Hector, A., Jenkins, M. W., Kane, J. M., Kolb, T. E., LaW, D. J., Lewis, J. D., Limousin, J.-M., Love, D. M., Macalady, A. K., Martínez-Vilalta, J., Mencuccini, M., Mitchell, P. J., Muss, J. D., O’Brien, M. J., O'Grady, A. P., Pangle, R. E., Pinkard, E. A., Piper, F. I., Plaut, J. A., Pockman, W. T., Quirk, J., Reinhardt, K., Ripullone, F., Ryan, M. G., Sala, A., Sevanto, S., Sperry, J. S., Vargas, R., Vennetier, M., Way, D. A., Xu, C., Yepez, E. A., And McDowell, N. G. 2017. A multi-species synthesis of physiological mechanisms in drought-induced tree mortality. Nature ecology \& evolution 1:1285-1291.

Aitken, S. N., Yeaman, S., Holliday, J. A., WAng, T., And Curtis-Mclane, S. 2008. Adaptation, migration or extirpation: climate change outcomes for tree populations. Evolutionary applications 1:95-111.

Allen, C. D., Breshears, D. D., AND McDowell, N. G. 2015. On underestimation of global vulnerability to tree mortality and forest die-off from hotter drought in the anthropocene. Ecosphere 6:art129.

Allen, K., Corre, M. D., Kurniawan, S., Utami, S. R., and VeldKamp, E. 2016. Spatial variability surpasses land-use change effects on soil biochemical properties of converted lowland landscapes in sumatra, indonesia. Geoderma 284:42-50.

Allen, R. G., Pereira, L. S., Raes, D., AND Smith, M. 1998. FAO Irrigation and Drainage Paper No. 56: Crop Evapotranspiration: guidelines for computing crop water requirements.

Amitrano, C., Arena, C., Rouphael, Y., De Pascale, S., And de Micco, V. 2019. Vapour pressure deficit: The hidden driver behind plant morphofunctional traits in controlled environments. Annals of Applied Biology 152:688.

AnderegG, W. R. L., Klein, T., Bartlett, M. K., Sack, L., Pellegrini, A. F. A., Choat, B., AND JANSEN, S. 2016. Meta-analysis reveals that hydraulic traits explain cross-species patterns of drought-induced tree mortality across the globe. Proceedings of the National Academy of Sciences 
of the United States of America 113:5024-5029.

ANDEREgG, W. R. L. AND MeinZer, F. C. 2015. Wood anatomy and plant hydraulics in a changing climate, pp. 235-253. In U. G. Hacke (ed.), Functional and Ecological Xylem Anatomy. Springer International Publishing, Cham.

ARdikA, R., SANChEZ, P. B., BADAyos, R. B., AND CRUZ, P. C. S. 2017. Growth of pb 260 clone (hevea brasiliensis (willd. ex a. juss.) muell-arg.) in different potting media and fertilization scheme. AGRIVITA Journal of Agricultural Science 39.

AROCA, R. 2012. Plant Responses to Drought Stress: From Morphological to Molecular Features. Springer, Berlin and Heidelberg.

Barkhordarian, A., SaAtchi, S. S., Behrangi, A., Loikith, P. C., AND Mechoso, C. R. 2019. A recent systematic increase in vapor pressure deficit over tropical south america. Scientific reports 9:15331.

Bartlett, M. K., Scoffoni, C., Ardy, R., Zhang, Y., Sun, S., CaO, K.-F., And Sack, L. 2012b. Rapid determination of comparative drought tolerance traits: using an osmometer to predict turgor loss point. Methods in Ecology and Evolution 3:880-888.

BARTLETT, M. K., SCOFFONI, C., AND SACK, L. 2012a. The determinants of leaf turgor loss point and prediction of drought tolerance of species and biomes: a global meta-analysis. Ecology letters 15:393-405.

BATES, D., MÄCHLER, M., BOLKeR, B., AND WALKER, S. 2015. Fitting linear mixed-effects models using lme4. Journal of Statistical Software 67.

Berry, Z. C., Espejel, X., Williams-Linera, G., And Asbjornsen, H. 2019. Linking coordinated hydraulic traits to drought and recovery responses in a tropical montane cloud forest. American journal of botany .

Blackman, C. J., Aspinwall, M. J., Tissue, D. T., And Rymer, P. D. 2017. Genetic adaptation and phenotypic plasticity contribute to greater leaf hydraulic tolerance in response to drought in warmer climates. Tree physiology 37:583-592.

Brodribb, T. J., Am McAdam, S., And Carins Murphy, M. R. 2017. Xylem and stomata, coordinated through time and space. Plant, cell \& environment 40:872-880.

Burgess, Stephen, O., Pittermann, J., And Dawson, T. E. 2006. Hydraulic efficiency and safety of branch xylem increases with height in Sequoia sempervirens (d. don) crowns. Plant, Cell and Environment 29:229-239. 
Cahyo, A. N., Babel, M. S., Datta, A., Prasad, K. C., And Clemente, R. 2016. Evaluation of land and water management options to enhance productivity of rubber plantation using wanulcas model. 2016 38:11.

A. N. Cahyo, Sahuri, C. T. Stevanus, and M. Aji (eds.) 2017. Production of PB 260 rubber clone in relation with field water balance.

CARlquist, S. 2001. Comparative Wood Anatomy: Systematic, Ecological, and Evolutionary Aspects of Dicotyledon Wood. Springer Series in Wood Science. Springer Berlin Heidelberg.

CARR, M. K. V. 2012. The water relations of rubber ( hevea brasiliensis ): A review. Experimental Agriculture 48:176-193.

Chandrashekar, T. R., Nazeer, M. A., Marattukalam, J. G., Prakash, G. P., AnnaMALAINATHAN, K., AND THOMAS, J. 1998. An analysis of growth and drought tolerance in rubber during the immature phase in a dry subhumid climate. Experimental Agriculture 34:287300.

CHEN, J.-W. AND CAO, K.-F. 2015. A possible link between hydraulic properties and leaf habits in hevea brasiliensis. Functional Plant Biology 42:718.

Choat, B., Ball, M. C., Luly, J. G., And Holtum, J. A. M. 2005. Hydraulic architecture of deciduous and evergreen dry rainforest tree species from north-eastern australia. Trees 19:305311.

ChoAt, B., Brodribb, T. J., Brodersen, C. R., DuUrsma, R. A., López, R., And Medlyn, B. E. 2018. Triggers of tree mortality under drought. Nature 558:531-539.

Clermont-Dauphin, C., Suvannang, N., Hammecker, C., Cheylan, V., Pongwichian, P., AND DO, F. C. 2013. Unexpected absence of control of rubber tree growth by soil water shortage in dry subhumid climate. Agronomy for Sustainable Development 33:531-538.

Cochard, H., Damour, G., Bodet, C., Tharwat, I., Poirier, M., And Glio, T. 2005. Evaluation of a new centrifuge technique for rapid generation of xylem vulnerability curves. Physiologia Plantarum - PHYSIOL PLANT 124.

Devakumar, A. S., Mohamed Sathik, M. B., Jacob, J., AnNamalainathan, K., Gawai Prakash, P., AND ViJayAKUmar, K. R. 1998. Effects of atmospheric and soil drought on growth and development of hevea brasiliensis. Journal of Rubber Research (Malaysia) 1:190-198.

DIN IsO 11277:2002-08 2002. Bodenbeschaffenheit - bestimmung der partikelgröbenverteilung in mineralböden - verfahren mittels siebung und sedimentation, iso 11277: 1998/cor.1:2002. beuth verlag, berlin, germany. 
Domec, J.-C., Schäfer, K., Oren, R., Kim, H. S., And MCCARthy, H. R. 2010. Variable conductivity and embolism in roots and branches of four contrasting tree species and their impacts on whole-plant hydraulic performance under future atmospheric $\mathrm{CO}_{2}$ concentration. Tree physiology 30:1001-1015.

Dória, L. C., Podadera, D. S., Lima, R. S., Lens, F., AND Marcati, C. R. 2019. Axial sampling height outperforms site as predictor of wood trait variation. IAWA Journal 40:191-S3.

Drescher, J., Rembold, K., Allen, K., Beckschäfer, P., Buchori, D., Clough, Y., Faust, H., Fauzi, A. M., Gunawan, D., Hertel, D., Irawan, B., Jaya, I. N. S., Klarner, B., Kleinn, C., KnOHL, A., Kotowska, M. M., Krashevska, V., Krishna, V., Leuschner, C., Lorenz, W., Meijide, A., Melati, D., Nomura, M., Pérez-Cruzado, C., Qaim, M., Siregar, I. Z., Steinebach, S., TJoA, A., Tscharntke, T., Wick, B., Wiegand, K., Kreft, H., AND SCHEU, S. 2016. Ecological and socio-economic functions across tropical land use systems after rainforest conversion. Philosophical transactions of the Royal Society of London. Series B, Biological sciences 371 .

Eamus, D., Boulain, N., Cleverly, J., And Breshears, D. D. 2013. Global change-type drought-induced tree mortality: vapor pressure deficit is more important than temperature per se in causing decline in tree health. Ecology and evolution 3:2711-2729.

Falqueto, A. R., Da Silva Júnior, R. A., Gomes, M. T. G., Martins, J. P. R., Silva, D. M., AND PARTELLI, F. L. 2017. Effects of drought stress on chlorophyll a fluorescence in two rubber tree clones. Scientia Horticulturae 224:238-243.

FAN, D.-Y., JIE, S.-L., LIU, C.-C., ZHANG, X.-Y., XU, X.-W., ZHANG, S.-R., AND XIE, Z.-Q. 2011. The trade-off between safety and efficiency in hydraulic architecture in 31 woody species in a karst area. Tree physiology 31:865-877.

FAO 2017. Un food and agricultural oganisation statistic database.

Finegan, B., Peña-Claros, M., De Oliveira, A., Ascarrunz, N., Bret-Harte, M. S., Carreño-Rocabado, G., Casanoves, F., Díaz, S., Eguiguren Velepucha, P., FernanDez, F., Licona, J. C., Lorenzo, L., Salgado Negret, B., Vaz, M., and Poorter, L. 2015. Does functional trait diversity predict above-ground biomass and productivity of tropical forests? testing three alternative hypotheses. Journal of Ecology 103:191-201.

Fonti, P., Heller, O., Cherubini, P., Rigling, A., AND Arend, M. 2013. Wood anatomical responses of oak saplings exposed to air warming and soil drought. Plant biology (Stuttgart, Germany) 15 Suppl 1:210-219. 
Fu, P.-L., Jiang, Y.-J., WANG, A.-Y., Brodribb, T. J., Zhang, J.-L., ZhU, S.-D., AND CAO, K.-F. 2012. Stem hydraulic traits and leaf water-stress tolerance are co-ordinated with the leaf phenology of angiosperm trees in an asian tropical dry karst forest. Annals of botany 110:189199.

Gleason, S. M., Westoby, M., Jansen, S., Choat, B., Hacke, U. G., Pratt, R. B., Bhaskar, R., Brodribb, T. J., Bucci, S. J., CaO, K.-F., Cochard, H., Delzon, S., DOMEC, J.-C., FAN, Z.-X., Feild, T. S., Jacobsen, A. L., Johnson, D. M., Lens, F., MAherali, H., MartínezVilalta, J., Mayr, S., McCulloh, K. A., Mencuccini, M., Mitchell, P. J., Morris, H., Nardini, A., Pittermann, J., Plavcová, L., Schreiber, S. G., Sperry, J. S., Wright, I. J., AND ZANNE, A. E. 2016. Weak tradeoff between xylem safety and xylem-specific hydraulic efficiency across the world's woody plant species. The New phytologist 209:123-136.

Greenwood, S., Ruiz-Benito, P., Martínez-Vilalta, J., Lloret, F., Kitzberger, T., Allen, C. D., Fensham, R., Laughlin, D. C., Kattge, J., Bönisch, G., Kraft, N. J. B., AND JUMP, A. S. 2017. Tree mortality across biomes is promoted by drought intensity, lower wood density and higher specific leaf area. Ecology letters 20:539-553.

Grossiord, C., Buckley, T. N., Cernusak, L. A., Novick, K. A., Poulter, B., Siegwolf, R. T. W., SPERry, J. S., AND MCDOWELL, N. G. 2020a. Plant responses to rising vapor pressure deficit. The New phytologist .

Grossiord, C., Ulrich, D. E. M., AND Vilagrosa, A. 2020b. Controls of the hydraulic safetyefficiency trade-off. Tree physiology 40:573-576.

HajeK, P., KuRJaK, D., VON WÜhlisch, G., Delzon, S., AND Schuldt, B. 2016. Intraspecific variation in wood anatomical, hydraulic, and foliar traits in ten european beech provenances differing in growth yield. Frontiers in Plant Science 7:791.

Hajek, P., Leuschner, C., Hertel, D., Delzon, S., And Schuldt, B. 2014. Trade-offs between xylem hydraulic properties, wood anatomy and yield in populus. Tree physiology 34:744756.

Hoeber, S., Leuschner, C., KöHler, L., Arias-Aguilar, D., And Schuldt, B. 2014. The importance of hydraulic conductivity and wood density to growth performance in eight tree species from a tropical semi-dry climate. Forest Ecology and Management 330:126-136.

Hoong, C. W. 1997. Performance of clone pb260 in a large plantation group in peninsular malaysia. the planter, Kuala Lumpur 73:403-418.

Hultine, K. R., Koepke, D. F., Pockman, W. T., Fravolini, A., Sperry, J. S., And 
WiLliams, D. G. 2006. Influence of soil texture on hydraulic properties and water relations of a dominant warm-desert phreatophyte. Tree Physiology 26:313-323.

IRAWAN, B. Multilevel impact assessment and coping strategies against el nino: Case of food crops in indonesia: Multilevel impact assessment and coping strategies against el nino: Case of food crops in indonesia.

Isarangkool Na Ayutthaya, S., Do, F. C., Pannangpetch, K., Junjittakarn, J., Maeght, J.-L., Rocheteau, A., AND Cochard, H. 2011. Water loss regulation in mature hevea brasiliensis: effects of intermittent drought in the rainy season and hydraulic regulation. Tree physiology 31:751-762.

JAeger, B., Edwards, L., DAS, K., AND SEN, P. 2016. An r 2 statistic for fixed effects in the generalized linear mixed model. Journal of Applied Statistics pp. 1-20.

Janssen, T. A. J., Hölttä, T., Fleischer, K., Naudts, K., And Dolman, H. 2020. Wood allocation trade-offs between fiber wall, fiber lumen, and axial parenchyma drive drought resistance in neotropical trees. Plant, cell \& environment 43:965-980.

Jinagool, W., RATTANAWONG, R., SANGSing, K., BARigaH, T. S., GAY, F., COCHARD, H., Kasemsap, P., AND Herbette, S. 2016. Clonal variability for vulnerability to cavitation and other drought-related traits hevea brasiliensis müll. arg. Journal of Plant Hydraulics 2:1-12.

Knipfer, T., Barrios-Masias, F. H., Cuneo, I. F., Bouda, M., Albuquerque, C. P., Brodersen, C. R., Kluepfel, D. A., AND McElrone, A. J. 2018. Variations in xylem embolism susceptibility under drought between intact saplings of three walnut species. Tree physiology 38:1180-1192.

KÖCHER, P., HORNA, V., AND LEUSCHNER, C. 2012. Environmental control of daily stem growth patterns in five temperate broad-leaved tree species. Tree physiology 32:1021-1032.

Kotowska, M. M., Leuschner, C., Triadiati, T., Meriem, S., And Hertel, D. 2015. Quantifying above- and belowground biomass carbon loss with forest conversion in tropical lowlands of sumatra (indonesia). Global change biology 21:3620-3634.

Kumagai, T., Mudd, R. G., Giambelluca, T. W., Kobayashi, N., Miyazawa, Y., Lim, T. K., LiU, W., Huang, M., Fox, J. M., Ziegler, A. D., Yin, S., MaK, S. V., And Kasemsap, P. 2015. How do rubber ( hevea brasiliensis ) plantations behave under seasonal water stress in northeastern thailand and central cambodia? Agricultural and Forest Meteorology 213:10-22.

Laginha Pinto Correia, D., Bouchard, M., Filotas, É., And Raulier, F. 2019. Disen- 
tangling the effect of drought on stand mortality and productivity in northern temperate and boreal forests. Journal of Applied Ecology 56:758-768.

Lechthaler, S., Turnbull, T. L., Gelmini, Y., Pirotti, F., Anfodillo, T., Adams, M. A., AND PetiT, G. 2019. A standardization method to disentangle environmental information from axial trends of xylem anatomical traits. Tree physiology 39:495-502.

LeWIS, A. M. AND Boose, E. R. 1995. Estimating volume flow rates through xylem conduits. American journal of botany 82:1112-1116.

Li, S., Klepsch, M., Jansen, S., Schmitt, M., Lens, F., Karimi, Z., Schuldt, B., Espino, S., AND SCHENK, H. J. 2016. Intervessel pit membrane thickness as a key determinant of embolism resistance in angiosperm xylem. IAWA Journal 37:152-171.

LI, S., Li, X., Link, R., Li, R., Deng, L., Schuldt, B., JiAnG, X., ZhaO, R., Zheng, J., Li, S., AND YIN, Y. 2019. Influence of cambial age and axial height on the spatial patterns of xylem traits in catalpa bungei, a ring-porous tree species native to china. Forests 10:662.

LINK, R. M. 2020. R package corrmorant.

LÜBbe, T., Schuldt, B., AND Leuschner, C. 2017. Acclimation of leaf water status and stem hydraulics to drought and tree neighbourhood: alternative strategies among the saplings of five temperate deciduous tree species. Tree physiology 37:456-468.

Maherali, H., Moura, C. E., Caldeira, M. C., Willson, C. J., And Jackson, R. B. 2006. Functional coordination between leaf gas exchange and vulnerability to xylem cavitation in temperate forest trees. Plant, cell \& environment 29:571-583.

Markesteijn, L., Poorter, L., Paz, H., SACK, L., AND Bongers, F. 2011. Ecological differentiation in xylem cavitation resistance is associated with stem and leaf structural traits. Plant, cell E environment 34:137-148.

Martin-StPaul, N. K., Delzon, S., And Cochard, H. 2017. Plants resistance to drought relies on early stomata closure, volume 20 .

Martin-StPaul, N. K., Limousin, J.-M., Rodríguez-Calcerrada, J., Ruffault, J., RaMBAL, S., LetTS, M. G., AND Misson, L. 2012. Photosynthetic sensitivity to drought varies among populations of quercus ilex along a rainfall gradient. Functional Plant Biology 39:25.

McDowell, N. G., Allen, C. D., Anderson-Teixeira, K., Brando, P., Brienen, R. J. W., Chambers, J. Q., Christoffersen, B. O., Davies, S., Doughty, C., Duque, A., EspiritoSanto, F., Fisher, R. A., Fontes, C. G., Galbraith, D. R., Goodsman, D., Grossiord, C., Hartmann, H., Holm, J., Johnson, D. J., Kassim, A. R., Keller, M., Koven, C., 
Kueppers, L., Kumagai, T., Malhi, Y., McMahon, S. M., Mencuccini, M., Meir, P., Moorcroft, P. R., Muller-landau, H. C., Phillips, O. L., Powell, T. L., Sierra, C. A., SPERry, J. S., WARrEN, J., XU, C., AND XU, X. 2018. Drivers and mechanisms of tree mortality in moist tropical forests. The New phytologist 219:851-869.

Moser, G., Schuldt, B., Hertel, D., Horna, V., Coners, H., Barus, H., And Leuschner, C. 2014. Replicated throughfall exclusion experiment in an indonesian perhumid rainforest: wood production, litter fall and fine root growth under simulated drought. Global change biology 20:1481-1497.

NAKAGAWA, S. AND SChiElZETH, H. 2013. A general and simple method for obtaining r2 from generalized linear mixed-effects models. Methods in Ecology and Evolution 4:133-142.

OGle, K., BARBer, J. J., Willson, C., AND ThOmpson, B. 2009. Hierarchical statistical modeling of xylem vulnerability to cavitation. The New phytologist 182:541-554.

Olson, M. E., Anfodillo, T., Rosell, J. A., Petit, G., Crivellaro, A., Isnard, S., LeÓnGómez, C., Alvarado-CÁrdenas, L. O., And Castorena, M. 2014. Universal hydraulics of the flowering plants: vessel diameter scales with stem length across angiosperm lineages, habits and climates. Ecology letters 17:988-997.

OPPENHEIMER, H. R. 1963. Zur kenntnis kritischer wasser-sättigungsdefizite in blättern und ihrer bestimmung. Planta 60:51-69.

PereirA, J. D. P., LeAl, A. C., AND Ramos, A. L. M. 2018. Evaluation of rubber tree clones under different tapping systems in northwestern paraná state, brazil. Brazilian Archives of Biology and Technology 61:430.

Phillips, O. L., VAn der Heijden, G., Lewis, S. L., López-GonzÁlez, G., Aragão, L. E. O. C., Lloyd, J., Malhi, Y., Monteagudo, A., Almeida, S., Dávila, E. A., Amaral, I., Andelman, S., Andrade, A., Arroyo, L., Aymard, G., BAKer, T. R., Blanc, L., Bonal, D., de Oliveira, A. C. A., Chao, K.-J., Cardozo, N. D., DA Costa, A. C. L., FeldPAusch, T. R., Fisher, J. B., Fyllas, N. M., Freitas, M. A., Galbraith, D. R., Gloor, E., Higuchi, N., Honorio, E., Jiménez, E., Keeling, H., Killeen, T. J., Lovett, J. C., Meir, P., Mendoza, C., Morel, A., Vargas, P. N., Patiño, S., Peh, K. S.-H., Cruz, A. P., PriEto, A., Quesada, C. A., Ramírez, F., Ramírez, H., Rudas, A., SAlamão, R., SchWARz, M., Silva, J., Silveira, M., Slik, J. W. F., Sonké, B., Thomas, A. S., Stropp, J., Taplin, J. R. D., VÁsqueZ, R., AND VilanOVA, E. 2010. Drought-mortality relationships for tropical forests. The New phytologist 187:631-646. 
Pinheiro, J., Bates, D., DebRoy, S., Sarkar, D., And R Core Team 2018. nlme: Linear and nonlinear mixed effects models.

PlavcovÁ, L. And Hacke, U. G. 2012. Phenotypic and developmental plasticity of xylem in hybrid poplar saplings subjected to experimental drought, nitrogen fertilization, and shading. Journal of Experimental Botany 63:6481-6491.

Poorter, L., Rozendahl, D. M. A., Bongers, F., De Almeida-Cortez, J. S., Almeyda Zambrano, A. M., Álvarez, F. S., Andrade, J. L., Villa, L. F. A., Balvanera, P., BeckNell, J. M., Bentos, T. V., Bhaskar, R., Boukili, V., Brancalion, P. H. S., Broadbent, E. N., César, R. G., Chave, J., Chazdon, R. L., Colletta, G. D., Craven, D., De Jong, Ben H. J., Denslow, J. S., Dent, D. H., DeWalt, S. J., García, E. D., Dupuy, J. M., Durán, S. M., Espírito Santo, M. M., Fandiño, M. C., Fernandes, G. W., Finegan, B., Moser, V. G., Hall, J. S., Hernández-Stefanoni, J. L., JakovaC, C. C., Junqueira, A. B., Kennard, D., Lebrija-Trejos, E., Letcher, S. G., Lohbeck, M., Lopez, O. R., Marín-Spiotta, E., Martínez-Ramos, M., Martins, S. V., Massoca, P. E. S., Meave, J. A., Mesquita, R., Mora, F., De Souza Moreno, V., Müller, S. C., Muñoz, R., MusCarella, R., De Oliveira Neto, Silvio Nolasco, Nunes, Y. R. F., Ochoa-Gaona, S., Paz, H., Peña-Claros, M., Piotto, D., Ruíz, J., Sanaphre-Villanueva, L., SanchezAzofeifa, A., Schwartz, N. B., Steininger, M. K., Thomas, W. W., Toledo, M., Uriarte, M., Utrera, L. P., van Breugel, M., van der Sande, M. T., van der Wal, H., Veloso, M. D. M., Vester, H. F. M., Vieira, I. C. G., Villa, P. M., Williamson, G. B., Wright, S. J., Zanini, K. J., Zimmerman, J. K., And Westoby, M. 2019. Wet and dry tropical forests show opposite successional pathways in wood density but converge over time. Nature Ecology \& Evolution 3:928-934.

Pritzkow, C., Williamson, V., Szota, C., Trouvé, R., and Arndt, S. K. 2020. Phenotypic plasticity and genetic adaptation of functional traits influences intra-specific variation in hydraulic efficiency and safety. Tree physiology 40:215-229.

PRIYADARSHAN, P. M. 2017. Biology of Hevea Rubber. Springer International Publishing, Cham. R CORE TEAM 2019. R: A language and environment for statistical computing.

Raj, S., DAS, G., Pothen, J., AND Dey, S. K. 2005. Relationship between latex yield of hevea brasiliensis and antecedent environmental parameters. International journal of biometeorology 49:189-196.

RaO, P. S., Saraswathyamma, C. K., And Sethuraj, M. R. 1998. Studies on the relationship 
between yield and meteorological parameters of para rubber tree (hevea brasiliensis). Agricultural and Forest Meteorology 90:235-245.

Rodriguez-Dominguez, C. M., Buckley, T. N., EgeA, G., de Cires, A., HernandezSantana, V., Martorell, S., AND DiaZ-Espejo, A. 2016. Most stomatal closure in woody species under moderate drought can be explained by stomatal responses to leaf turgor. Plant, cell \& environment 39:2014-2026.

Rosas, T., Mencuccini, M., Barba, J., Cochard, H., Saura-Mas, S., And MartínezVilalta, J. 2019. Adjustments and coordination of hydraulic, leaf and stem traits along a water availability gradient. The New phytologist 223:632-646.

Rowland, L., Da Costa, A. C. L., Galbraith, D. R., Oliveira, R. S., Binks, O. J., Oliveira, A. A. R., Pullen, A. M., Doughty, C., Metcalfe, D., Vasconcelos, S. S., Ferreira, L. V., Malhi, Y., Grace, J., Mencuccini, M., And Meir, P. 2015. Death from drought in tropical forests is triggered by hydraulics not carbon starvation. Nature 528:119-122.

Rungwattana, K., Kasemsap, P., Phumichai, T., Kanpanon, N., Rattanawong, R., And Hietz, P. 2018. Trait evolution in tropical rubber ( Hevea brasiliensis) trees is related to dry season intensity. Functional Ecology 32:2638-2651.

Santiago, L. S., Bonal, D., De Guzman, M. E., And Ávila-Lovera, E. 2016. Drought survival strategies of tropical trees, pp. 243-258. In G. Goldstein and L. S. Santiago (eds.), Tropical Tree Physiology, volume 6 of Tree Physiology. Springer International Publishing, Cham.

Schuldt, B., Buras, A., Arend, M., Vitasse, Y., Beierkuhnlein, C., Damm, A., Gharun, M., Grams, T., Hauck, M., Hajek, P., Hartmann, H., Hilbrunner, E., Hoch, G., Holloway-Phillips, M., Körner, C., Larysch, E., Luebbe, T., Nelson, D., Rammig, A., AND KAHMEN, A. 2020. A first assessment of the impact of the extreme 2018 summer drought on central european forests. Basic and Applied Ecology .

Schuldt, B., Knutzen, F., Delzon, S., Jansen, S., Müller-Haubold, H., Burlett, R., CLOUgh, Y., AND Leuschner, C. 2016. How adaptable is the hydraulic system of european beech in the face of climate change-related precipitation reduction? The New phytologist 210:443458.

SchÜller, E., MARTínez-RAmOS, M., AND HietZ, P. 2013. Radial gradients in wood specific gravity, water and gas content in trees of a mexican tropical rain forest. Biotropica 45:280-287.

SChUMANn, K., LeUSChNer, C., AND SCHUlDT, B. 2019. Xylem hydraulic safety and efficiency 
in relation to leaf and wood traits in three temperate acer species differing in habitat preferences. Trees 33:1475-1490.

Sopharat, J., Gay, F., Thaler, P., Sdoodee, S., Isarangkool Na Ayutthaya, S., TANAVUd, C., HAMMECKer, C., AND DO, F. C. 2015. A simple framework to analyze water constraints on seasonal transpiration in rubber tree (hevea brasiliensis) plantations. Frontiers in plant science 5:753.

Stewart, G. R., Turnbull, M. H., Schmidt, S., AND ERSKine, P. D. 1995. < sup $>13</$ sup $>$ c natural abundance in plant communities along a rainfall gradient: a biological integrator of water availability. Functional Plant Biology 22:51-55.

Stojnic, S., Suchocka, M., Benito-Garzón, M., Torres-Ruiz, J. M., Cochard, H., Bolte, A., Cocozza, C., CvjetKovic, B., De Luis, M., Martinez-Vilalta, J., RÆbild, A., Tognetti, R., AND Delzon, S. 2018. Variation in xylem vulnerability to embolism in european beech from geographically marginal populations. Tree physiology 38:173-185.

Susilo, G. E., YAмАмото, K., AND IMAI, T. 2013. Modeling groundwater level fluctuation in the tropical peatland areas under the effect of el nino. Procedia Environmental Sciences 17:119128.

Tan, Z.-H., Zhang, Y.-P., SONG, Q.-H., LiU, W.-J., DenG, X.-B., TANG, J.-W., DenG, Y., ZHOU, W.-J., YANG, L.-Y., YU, G.-R., Sun, X.-M., AND LiANG, N.-S. 2011. Rubber plantations act as water pumps in tropical china. Geophysical Research Letters 38:n/a-n/a.

TYReE, M. T., Cochard, H., AND DAVIS, S. D. 1994. Biophysical perspectives of xylem evolution: is there a tradeoff of hydraulic efficiency for vulnerability to dysfunction? IAWA Journal 15:335-360.

Valladares, F., Gianoli, E., AND Gómez, J. M. 2007. Ecological limits to plant phenotypic plasticity. New Phytologist 176:749-763.

van der Sande, M. T., Poorter, L., Schnitzer, S. A., Engelbrecht, B. M. J., And MARKESTEIjN, L. 2019. The hydraulic efficiency-safety trade-off differs between lianas and trees. Ecology 100:e2666.

VON ARX, G. AND CARRER, M. 2014. Roxas - a new tool to build centuries-long tracheid-lumen chronologies in conifers. Dendrochronologia 32:290-293.

Waite, P.-A., Schuldt, B., Link, R., Breidenbach, N., Triadiati, T., Hennings, N., SAAD, A., AND LEUSCHNER, C. 2019. Soil moisture regime and palm height influence embolism resistance in oil palm. Tree physiology . 
Wheeler, J. K., Sperry, J. S., Hacke, U. G., And HoAnG, N. 2005. Inter-vessel pitting and cavitation in woody rosaceae and other vesselled plants: a basis for a safety versus efficiency trade-off in xylem transport. Plant, cell \& environment 28:800-812.

Wichichonchai, N. AND MANMEUn, S. 1992. Yield of rubber in the northeastern province. Para Rubber Bull Thailand 12:81:101.

Willson, C. J., MANOS, P. S., AND JACKSON, R. B. 2008. Hydraulic traits are influenced by phylogenetic history in the drought-resistant, invasive genus juniperus (cupressaceae). American journal of botany 95:299-314.

Yuan, W., Zheng, Y., PiaO, S., Ciais, P., Lombardozzi, D., Wang, Y., Ryu, Y., Chen, G., Dong, W., Hu, Z., Jain, A., Jiang, C., Kato, E., Li, S., Lienert, S., LiU, S., Nabel, J., QIN, Z., QUINE, T., AND YANG, S. 2019. Increased atmospheric vapor pressure deficit reduces global vegetation growth. Science Advances 5:eaax1396.

Ziegler, C., Coste, S., Stahl, C., Delzon, S., Levionnois, S., Cazal, J., Cochard, H., Esquivel-Muelbert, A., Goret, J.-Y., Heuret, P., Jaouen, G., Santiago, L. S., And BONAL, D. 2019. Large hydraulic safety margins protect neotropical canopy rainforest tree species against hydraulic failure during drought. Annals of Forest Science 76:1285.

ZiemińsKa, K., Butler, D. W., GleAson, S. M., Wright, I. J., AND WeStOBY, M. 2013. Fibre wall and lumen fractions drive wood density variation across 24 australian angiosperms. $A o B$ PLANTS 5:25. 

Chapter 5

Synthesis 
In this study we have investigated from different angles the ability of trees to resist drought events. Multiple systems from the understudied lowland areas of Indonesia have been considered, each with its own properties. In the forest, which is a pluri-specific system, we have investigated a diversity of hydraulic traits linked to tree structural properties since large trees are reported to be more prone to dieback due to drought. In plantations, we have investigated the role of soil water fluctuations and evaporative demand on oil palms and rubber trees. Wood and leaf functional traits from genetically similar plants were analyzed, highlighting trait plasticity as a component of species' response to drought. While both oil palm and rubber are intensively cultivated in the Jambi region, they are different organisms with different sets of properties. The former is an angiosperm monocot and the latter a dicot. Despite such differences of approach and characteristics, the study's overarching aim has been to compare these natural and highly transformed systems to advance our understanding of plant and system responses to heat-induced drought spells. Our first objectives were to study the diversity and variability of hydraulic traits, xylem resistance to drought-induced embolism in particular, as part of this response. Across all the systems, the influence of xylem anatomy on resistance to drought traits at the leaf and xylem levels constituted other core objectives. These assessments of interrelationships across traits were used to describe the hydraulic strategies of different species, illustrating the multiple ways plants cope with droughts linked to climate change. We seek to make use of these results as a basis for the development of cultivation advice on plantations and for a description of dynamic system changes in the forest.

\section{Comparison of hydraulic safety traits across species and systems}

\section{Xylem hydraulic safety}

Vulnerability to drought-induced emboli is a major trait for assessment of species' drought resistance since it is linked to major hydraulic failure (Brodribb and Cochard 2009, Brodribb et al. 2010). Indonesian lowlands systems have yet to be studied in this regard, despite their paramount importance for ecological functions and the country's economy. While rubber trees growing in Thailand have been the subject of hydraulic studies in the last decade, demonstrating their relative vulnerability to drought-induced embolism, xylem resistance to cavitation in Southeast Asian forest species was last described in 1998 (Tyree et al. 1998). Moreover, there were no studies on oil palm resistance to drought-induced embolism.

In this study we therefore sought to provide unique reliable data for xylem embolism re- 
sistance in multiple moist tropical species from Indonesia, including economically important species. As expected, we found that most of the investigated species in lowland Sumatra were vulnerable to drought-induced emboli, as is often the case in the moist tropics (Choat et al. 2012; Fig. 5.1a, c). S. ovalis and oil palm were for example fairly sensitive to embolism formation (species $P_{50}=-1.79 \mathrm{MPa}$ and $-1.84 \mathrm{MPa}$, respectively). Also, rubber had a more negative $P_{50}$ than previously reported (mean =-2.36 MPa v. $-1.96 \mathrm{MPa}$; Jinagool et al. 2016). However, some species still presented a reasonable level of resistance to cavitation (e.g. P. caerulescens and N. kingii, Fig. 5.1c). When including all investigated species, the average $P_{50}$ in the present study was more negative than the worldwide mean for tropical rainforests (-1.70 MPa; Choat et al. 2012), and somewhat nearer to the $P_{50}$ values found in tropical dry forest (mean $=-2.27$ v. -2.40 , respectively; Choat et al. 2012). This tends to support the hypothesis that species from the wet tropics are not as vulnerable to embolism as previously reported (cf. Ziegler et al. 2019), or at least that some species are able to tolerate prolonged droughts. This can be illustrated by the $P_{50}$ value for $S$. ovalis, which was much lower in the present study compared to the value previously reported (-1.79 MPa v. -0.39 MPa; Tyree et al. 1998).

Despite different methodologies, the hydraulic safety margin (HSM; Fig 5. 1b) across the investigated systems was always greater than the general average for moist tropical forest $(<1$ MPa; Choat et al. 2012), although wide variation across species can be observed (Fig 5.1b). When comparing the HSM across systems we observed that the average difference between the onset of emboli and major hydraulic failure in oil palm is similar to the average value for forest species (mean $\pm \mathrm{SE}=1.87 \pm 0.11 \mathrm{MPa}$ v. $1.71 \pm 0.05 \mathrm{MPa}$, respectively; $P=0.56$; Fig. 5.1b). In addition, the HSM of rubber trees was narrower than that of oil palms and forest trees (Fig 5.1b). Although hydraulic failure in oil palm fronds occurs at milder water potential than in rubber, embolism in the latter spreads faster once it has started to form in the xylem conduits.

As hypothesized, analysis of one of the highest levels of variability per system (inter-specific for the forest and intra-specific for the plantations) revealed that $P_{50}$ across forest species had the highest variability among the systems (Fig. $5.1 \mathrm{a}$ and c), although only seven species were investigated. Similar or even greater variability of $P_{50}$ across species is commonly found in the tropics (e.g. Trueba et al. 2017; Ziegler et al. 2019). A range of $P_{50}$ may be linked to multiple species' water use strategies and growth habits (Tardieu and Simonneau 1998, Volaire et al. 2018; King et al. 2005, Poorter et al. 2010, Maherali et al. 2006; Awad et al. 2010). 
(a)

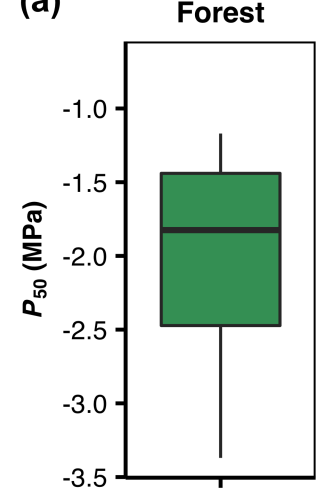

Oil palm

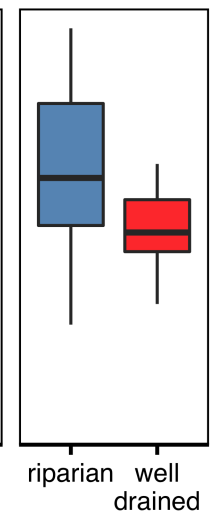

Rubber

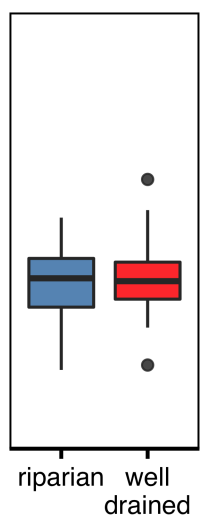

(b)
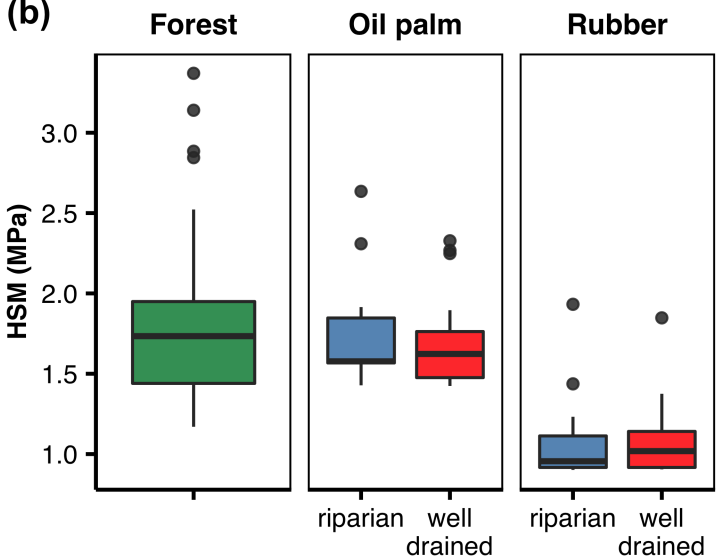
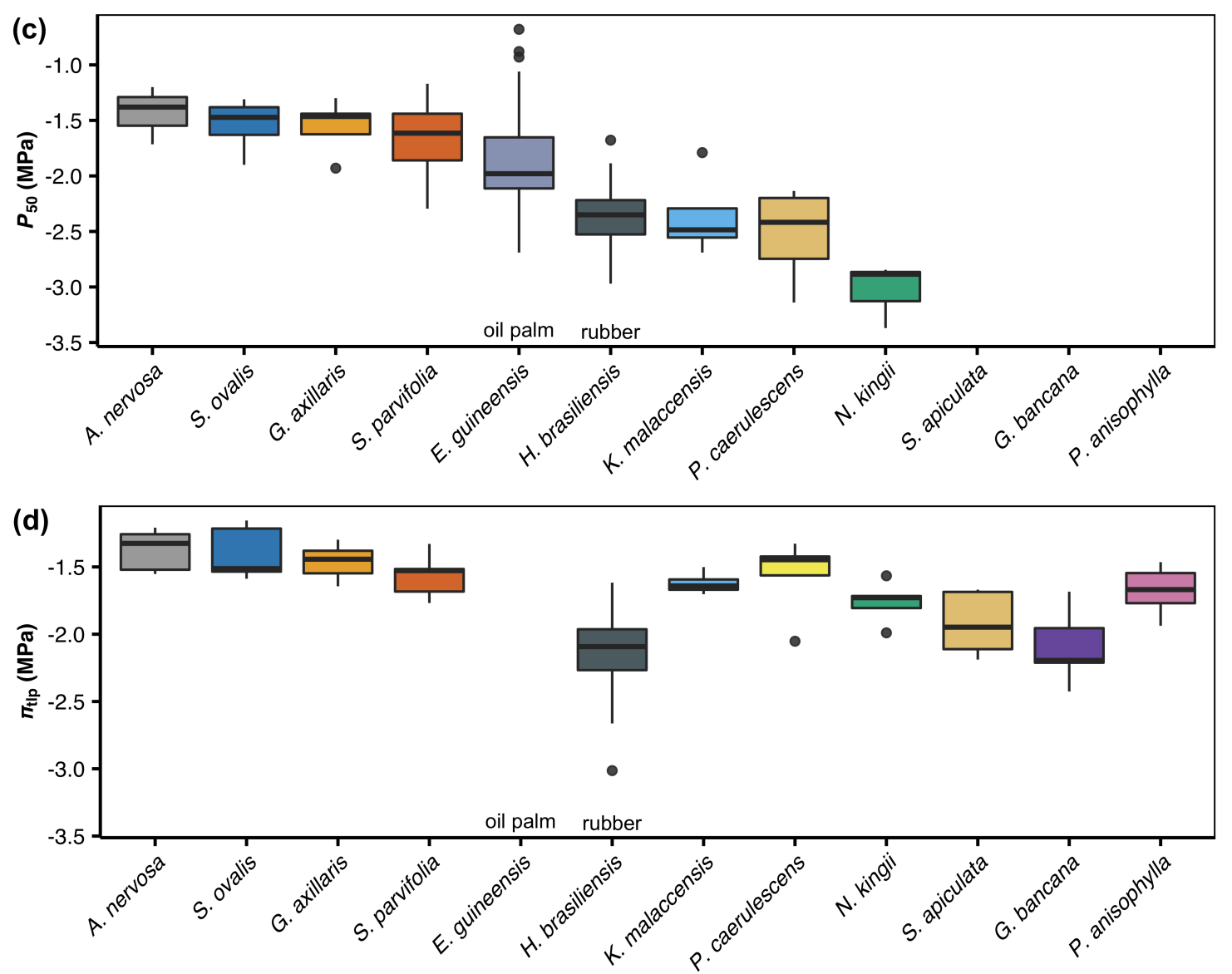

Fig. 5.1: (a) Boxplots of individual $P_{50}$ (water potential at $50 \%$ loss of hydraulic conductivity) per investigated system (Forest, Oil palm and Rubber plantations). Plantations are divided into riparian and well-drained sites. (b) Boxplots of individual hydraulic safety margins (HSM) per system calculated as $P_{\mathrm{e}}$ (water potential at the emergence of embolism as the intersection between the tangent at $P_{50}$ and the VC according to Meinzer et al. 2009) $-P_{50}$. Boxplots of (c) $P_{50}$ and (d) leaf turgor loss point $\left(\pi_{\text {tlp }}\right)$ per investigated species. $P_{50}$ of S. apiculata, G. bancana and $P$. anisophylla could not be compiled by the model (chapter 1 ). $\pi_{\text {tlp }}$ of E. guineensis (oil palm) has not been investigated. Panels (c) and (d) are organised by decreasing mean species $P_{50}$ values. 

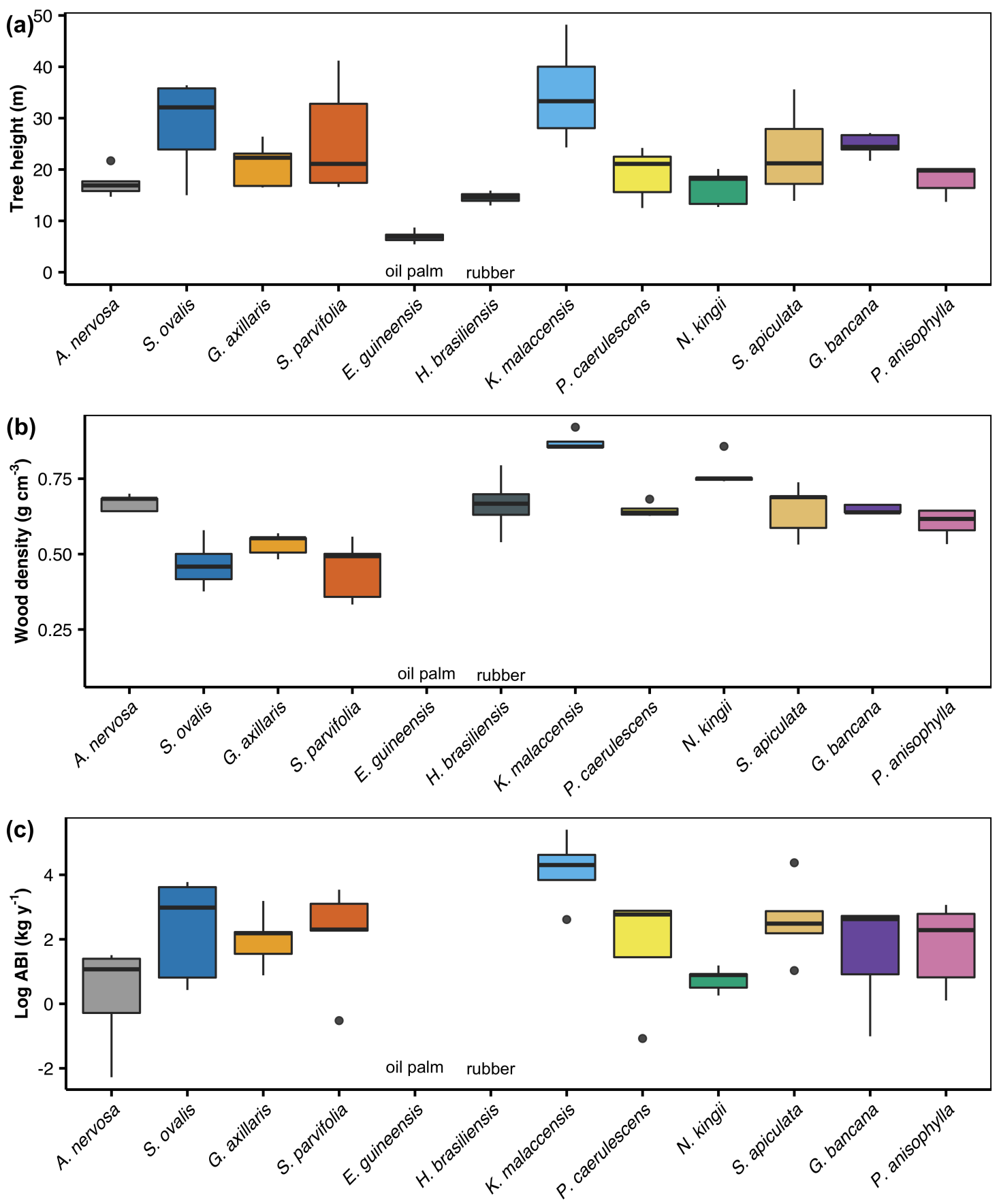

Fig. 5.2: Boxplots of (a) tree height, (b) wood density and (d) log aboveground biomass increment (ABI) per investigated species. Wood density of E. guineensis (oil palm) has not been investigated. ABI of $H$. brasiliensis (rubber) and E. guineensis (oil palm) have not been investigated. Boxplots are organised by decreasing mean species $P_{50}$ values. 


\section{Leaf functional traits}

Leaf hydraulic traits are of primary importance in species' response to drought since this organ is in direct contact with the dry atmosphere and solar radiation (e.g. Sack et al. 2015). Among other mechanisms, stomatal closure may prevent the spread of emboli in the xylem by limiting increases in water tension, at the cost of lower carbon intake (Mitchell et al. 2013). Oil palm have been described to have stringent stomatal control (Smith 1989, Dufrêne and Saugier 1993). This was confirmed by our experiment showing that on days with intense evaporative demands, oil palms close their stomata from 11am onwards (chapter 2). This probably prevents their frond xylem from reaching the vulnerable water potential responsible for major hydraulic failure (chapter 2 and Fig. 5.1c). In addition, oil palm fronds and leaflets are stiff, which may reduce water loss (Niinemets 2001, Aroca 2012). However, stomatal closure is effective as a rapid response but may not prevent major hydraulic failure during long, intense drought periods given that water can still evaporate for example through cuticular conductance (Duursma et al. 2019).

In the case of forest species, we did not directly measure stomatal closure but measured the leaf wilting point $\left(\pi_{\text {tlp }}\right)$, which is closely linked to stomatal closure (Brodribb et al. 2003). We found that most of the forest species had a high $\pi_{\text {tlp }}$ (Fig. 5.1d). Across forest species we found an average of $-1.64 \mathrm{MPa}$, a rather more negative value than has been reported for evergreen species from moist tropics (-1.48 MPa; Bartlett et al. 2012a). The average $\pi_{\text {tlp }}$ that we found was nonetheless much higher than for evergreen trees from tropical dry forest (-2.50 MPa; Bartlett et al. 2012a). This may indicate that growth limitation, along with reduced leaf hydraulic conductance and assimilation performance, occur at mild leaf water potential for most investigated species (Sack et al. 2003, Baltzer et al. 2008, Mitchell et al. 2008, Blackman et al. 2010, Bartlett et al. 2012a). In comparison, rubber had a much more negative $\pi_{\text {tlp }}$ (mean $=-2.12 \mathrm{MPa}$ ) than forest species. It is similar to the average $\pi_{\text {tlp }}$ measured in deciduous trees growing in dry tropical forest (-2.11 MPa; Bartlett et al. 2012a).

\section{Xylem hydraulic resistance plasticity as a mechanism of response to water stress}

Based only on the average results for $P_{50}$, HSM and $\pi_{\mathrm{tlp}}$, both plantation species appeared fairly vulnerable to heat-induced drought events, although with its more negative $P_{50}$ and $\pi_{\text {tlp }}$, rubber may withstand more intense falls in water potential than oil palm. However, as hypothesized, we found that the ability of plant populations to modify their functional traits in response to changes in the local environment is probably a key parameter for coping with increasing droughts. 
In the case of oil palm, we found that its frond $P_{50}$ changed significantly depending on soil water regime independently of palm stem height (chapter 2). Overall, oil palm $P_{50}$ showed very high plasticity for a single species, particularly in riparian areas (Fig. 5.1a). This was especially evident when compared to the variability of several forest species and the intra-specific variability of rubber. It could be suggested that fronds, as organs with a limited lifespan protecting the integrity of the stem hydraulic system, may have developed higher variability in their xylem properties in response to the environment. Xylem plasticity in oil palm fronds may be linked to the developmental properties of oil palm which, as a monocot, does not have a cambium producing secondary vessels in the stem. The integrity of the oil palm stem hydraulic system would thus be ensured by higher plasticity in the frond in response to water availability (chapter 2). Such plasticity can be part of the response of oil palm for coping with drier environments but may not be sufficient in case of exceptional drought events.

Despite a generally narrower variability of $P_{50}$ in rubber trees compared to other systems (i.e. mainly because we did not sample trees presenting a height gradient), they exhibited a xylem less vulnerable to drought-induced emboli and a greater hydraulic safety margin in plots with higher evaporative demand (chapter 3). Rubber has already been described as a species exhibiting phenotypic plasticity and genetic variability in its wood and leaf traits (Valladares et al. 2007, Rungwattana et al. 2018). However, such variability in response to evaporative demand is surprising because most described hydraulic trait adjustments are reported in response to a precipitation gradient (e.g. in Fagus sylvatica; Wortemann et al. 2011; Schuldt et al. 2016), soil properties (e.g. Hacke et al. 2000, Sperry and Hacke 2002) and soil water availability (e.g. in temperate species; Aranda et al. 2015, Lübbe et al. 2017). These results indicate a certain degree of xylem plasticity that may contribute to rubber's drought response strategy and improve its performance in areas at the edge of its natural distribution.

\section{Effects of plant height on hydraulic safety}

Plant height was one of the main factors influencing xylem resistance to drought-induced embolism in forest trees and oil palms (chapter 1 and 2). A general linear mixed effect model including every tree investigated in this study and accounting for plot differences showed that $P_{50}$ is related logarithmically to tree height $\left(r^{2}=0.30, P<0.05\right)$. Most of the relationship is however due to forest trees since the height gradient of sampled oil palms and rubber trees was relatively narrow (Fig. 5.2). However, these findings accord with former studies reporting that large trees 
are more vulnerable to drought and tend to have lower embolism resistance than smaller trees (e.g. Rowland et al. 2015, Olson et al. 2018, Liu et al. 2019), although opposite findings have led to an alternate hypothesis proposing that higher hydraulic constraints in tall plants would result to adaptations providing a higher hydraulic safety (cf. Domec et al., 2008, 2009).
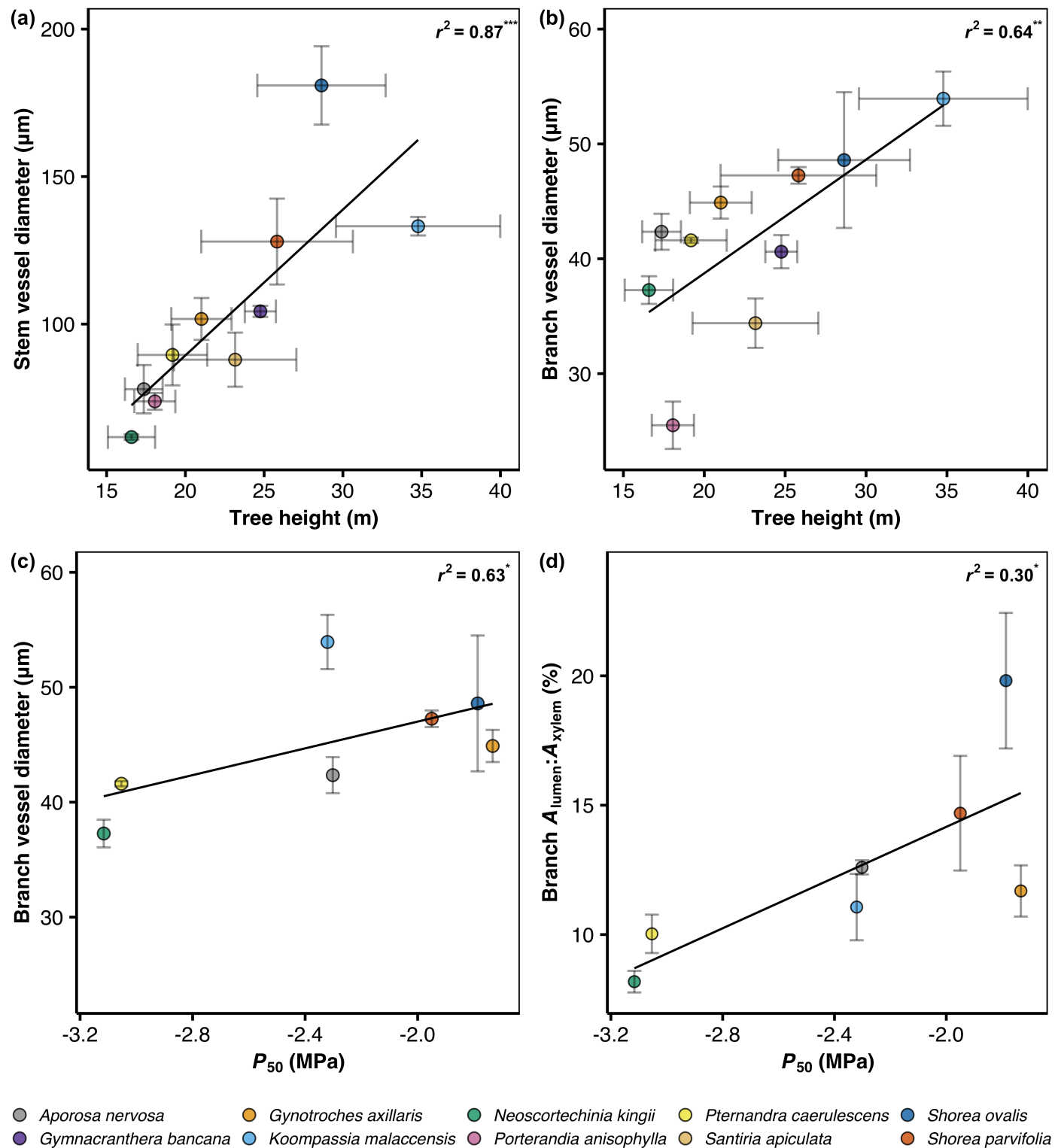

Fig. 5.3: Dependence of (a) branch and (b) stem vessel vessel diameter to species average height; and dependence of (c) branch vessel diameter and (d) branch lumen-to-sapwood area ratio to the water potential at $50 \%$ loss of hydraulic conductivity, $P_{50}$. Each point represents one species and error bars indicate standard errors of the measurements except for $P_{50}$ (modeled per species). Panels (c) and (d) present fewer species than panels (a) and (b) because the $P_{50}$ of 3 species could not be modelized (chapter 1). Regression lines and conditional $r$-squared from the models are shown. Level of significance is indicated as: ${ }^{*}(P<0.05),{ }^{* *}(P<0.01)$ and ${ }^{* * *}(P<0.001)$. 
Tree height does not influence embolism xylem resistance mechanistically; it is rather anatomical and physiological modifications co-occuring with height that may lead to a decrease in embolism resistance. There is for example a general basipetal pattern of conduit widening from the branches to the stem to compensate for hydraulic limitations linked to a longer hydraulic path (e.g. Weitz et al. 2006; Petit et al. 2008; Rosell et al. 2017). We can confirm this pattern in the investigated forest trees, which all had narrower vessels in their distant twig compared to the vessels in the trunk (chapter 1). Taking all trees together, tall individuals had on average wider vessels than smaller individuals. This was also verified at the species level since shorter-startured species had narrower vessels compared to tall-statured species (Fig. 5.3a, b). Large vessels in tall trees led indirectly to higher vulnerability to embolism, both at the tree level (chapter 1) and at the species level (Fig.5.3c).

Interestingly, we found that tall palms had narrower vessels in fronds at similar development stages when compared with smaller palms (chapter 2). Although axial patterns in xylem conduits in arborescent monocots are insufficiently studied, their basipetal vessel widening is reported to be similar to that of dicots (Petit et al. 2014). However, these studies focus mainly on vessel size pattern along the hydraulic paths of single individuals. The pattern that we found, although surprising, does not invalidate possible basipetal vessel widening from fronds to the stem within each individual. Smaller vessels in fronds of taller palms may also be linked to the developmental particularities of palms. Frond hydraulic system is largely disconnected from that of the stem (Zimmermann 1973). The only vascular connections are made through small vessels of protoxylem indicating a high degree of hydraulic segmentation between oil palm stem and its frond (Zimmermann 1973). It is therefore possible that no or an opposite pattern of vascular adjustments exist between the stem and the fronds. In addition, because oil palm does not exhibit radial cambial growth over its lifetime, its hydraulic system needs to be overbuilt during the establishment phase to allow the stem to reach several meters in height. Height, and by extension age given that both are highly correlated (Tan et al. 2013; Röll et al. 2015), can therefore strongly limit the hydraulic performance of oil palm (i.e. xylem function declines with age and height in some palms; Zimmerman 1973). Thus, it is also possible that leaf xylem is affected by the age/height of the palm, like fruit bunch production (Corley and Tinker 2016). Age-related alteration of frond xylem could also be one explanation for lower resistance to embolism in the fronds of tall oil palms. The exact effect of height and age on frond xylem must remain an open question but it emerged overall that tall palms may be particularly exposed during extreme heat-induced droughts. 
We did not investigate the effect of tree height on hydraulic safety in rubber trees since we focused on environmental effects. However, it is probable that the common basipetal vessel widening observed in dicot trees is also present in rubber and it may be associated with a higher vulnerability to drought-induced embolism.

\section{Relationships between hydraulic safety and xylem anatomy}

As hypothesized, we found that in some cases variability of $P_{50}$ was associated with anatomical adjustments. In oil palm, we did not find a link between $P_{50}$ and lumen-to-sapwood area ratio, frond conduit density and size, $(P=0.27, P=0.89$ and $P=0.38$, respectively; Table 5.1 , models 1 , 2 and 3), which accords with a recent report (Emilio et al. 2019). Even if both conduit size and $P_{50}$ decreased with oil palm height, their variability was too high for identification of any significant pattern. Again, that is potentially related to frond xylem anatomy that is inherently different to that of dicot tree branches (see transversal cut of oil palm rachis in chapter 2).

Table 5.1: Summary of models investigating effects of $(1-3)$ frond and $(4-13)$ stem and branch xylem anatomy of $(1-5)$ individuals and $(6-13)$ species on their resistance to drought-induced embolism, calculated as water potential at $50 \%$ loss of hydraulic conductivity $\left(P_{50}\right)$ and on their leaf turgor loss point, $\pi_{\mathrm{tlp}}$. Significant $P$ values $(P<0.05)$ are indicated in bold and marginally significant $P$ values $(P<0.10)$ are indicated in bold and in italics.

\begin{tabular}{|c|c|c|c|c|c|c|}
\hline ID & Level & Systems & Model & $\underset{r^{2}}{\text { Marg. }}$ & $\begin{array}{c}\text { Cond.. } \\
r^{2}\end{array}$ & $P$ \\
\hline 1 & \multirow{5}{*}{ Individuals } & \multirow{3}{*}{ oil palm } & $P_{50} \sim$ frond vessel diameter & 0.01 & 0.02 & 0.38 \\
\hline 2 & & & $P_{50} \sim$ frond vessel density & 0 & 0 & 0.89 \\
\hline 3 & & & $P_{50} \sim$ frond lumen-to-sapwood area ratio & 0.02 & 0.03 & 0.27 \\
\hline 4 & & \multirow{2}{*}{$\begin{array}{l}\text { rubber }+ \\
\text { forest }\end{array}$} & $\pi_{\mathrm{tlp}} \sim$ branch vessel diameter & 0.02 & 0.06 & 0.04 \\
\hline 5 & & & $\pi_{\mathrm{tlp}} \sim$ branch lumen-to-sapwood area ratio & 0.01 & 0.02 & 0.09 \\
\hline 6 & \multirow{8}{*}{ Species } & \multirow{2}{*}{$\begin{array}{l}\text { rubber }+ \\
\text { forest }\end{array}$} & $P_{50} \sim$ branch vessel diameter & 0.07 & 0.34 & 0.05 \\
\hline 7 & & & $P_{50} \sim$ branch lumen-to-sapwood area ratio & 0.13 & 0.31 & 0.02 \\
\hline 8 & & \multirow{4}{*}{ forest } & $P_{50} \sim$ stem vessel diameter & 0.46 & 0.46 & 0.07 \\
\hline 9 & & & $P_{50} \sim$ stem lumen-to-sapwood area ratio & 0.44 & 0.44 & 0.08 \\
\hline 10 & & & $P_{50} \sim$ branch vessel diameter & 0.55 & 0.63 & 0.02 \\
\hline 11 & & & $P_{50} \sim$ branch lumen-to-sapwood area ratio & 0.10 & 0.30 & 0.04 \\
\hline 12 & & \multirow{2}{*}{$\begin{array}{l}\text { rubber }+ \\
\text { forest }\end{array}$} & $\pi_{\text {tlp }} \sim$ branch vessel diameter & 0.01 & 0.01 & 0.76 \\
\hline 13 & & & $\pi_{\text {tlp }} \sim$ branch lumen-to-sapwood area ratio & 0.19 & 0.20 & 0.06 \\
\hline
\end{tabular}


The investigation of dicot trees produced different results. Forest trees more vulnerable to drought-induced embolism had larger vessels in both twigs and trunk (chapter 1). In rubber trees vessel density, and not conduit diameter, was found to be linked to embolism resistance (chapter 3). While vascular adjustments in forest and rubber trees are different, it emerged that they are both positively related to lumen-to-sapwood-area ratio. Rubber, which has very large vessels, achieves a low lumen-to-sapwood-area ratio by decreasing vessel density in its branches (chapter 3). In forest trees, low lumen-to-sapwood-area ratio was mainly associated with small-sized vessels. Consequently, in all forest and rubber trees, stem (in forest trees) and branch (in rubber and forest trees) lumen-to-sapwood-area ratio was related to embolism resistance (chapter 1 and 3).

While those vascular adjustments relate indirectly to embolism resistance ( $\mathrm{Li}$ et al. 2016), they may be closely related to the number of pits per vessel. A small number of wide or many narrow vessels will increase the amount of lumen per xylem area. This probably increases the number of pits and the corresponding risk of leaks which may enhance the risk of embolism formation, i.e. the "rare pit" (Wheeler et al. 2005, Pittermann et al. 2010) and "pit area" (Hacke et al. 2006) hypothesis.

Because it can be related to both vessel density and vessel diameter, lumen-to-sapwood-area ratio emerged in the present study as among the most important and easily accessible wood anatomy traits to be related to embolism resistance in dicot trees, together with vessel diameter. This is confirmed at the species level since the investigated species that had large vessels and high lumen-to-sapwood area ratio in the branch were the most vulnerable to drought-induced embolism $\left(r^{2}=0.34, P=0.05\right.$ and $r^{2}=0.31, P=0.02$, respectively; Table 5.1, models 6 and 7). Focusing on forest species alone, species that were more vulnerable to embolism had significantly wider vessels and more lumen-to-sapwood area ratio in their distant twigs $\left(r^{2}=0.63, P=0.02\right.$ and $r^{2}=0.30, P=0.04$, respectively; Table 5.1, models 10 and 11; Fig. 5.3 c, d). However, it seems that, unlike when investigated at the tree-level (chapter 1), vessel diameter and lumen-to-sapwood-area in the stem where only marginally related to $P_{50}$ in the forest species $\left(r^{2}=0.46, P=0.07\right.$ and $r^{2}=$ $0.44, P=0.08$, respectively; Table 5.1, models 8 and 9), This is probably because the relationships between stem anatomy and branch $P_{50}$ were mainly mediated by tree height. Because our models include trees of different size for each species, the relationships are less clear at the species level than at the tree level. 
Likewise, trees with a high turgor loss point had wide vessels $\left(r^{2}=0.06, P=0.04\right.$ Table 5.1, model 4) and tended to have high lumen-to-sapwood area ratio $\left(r^{2}=0.02, P=0.09\right.$; Table 5.1, model 5), although the goodness-of-fit was low. These results may indicate that trees with high hydraulic conductivity have leaves that close their stomates at mild water potential to limit transpiration. At the species level, only species that had high lumen-to-sapwood area ratio in their branches tended to have a high turgor loss point $\left(r^{2}=0.20, P=0.06\right.$; Table 5.1, model 13) since the pattern could not be confirmed for vessel diameter at the species level $\left(r^{2}=0.01, P=0.76\right.$; Table 5.1, model 12).

Overall, our results illustrate that drought resistance, in a tree and/or a species, may be approximated by wood anatomy traits such as lumen-to-sapwood area ratio and vessel diameter. Nonetheless we cannot exclude a species identity effect and further studies including a higher number of species should be made to confirm our results.

\section{Conclusion}

\section{Diversity of species' hydraulic strategies}

The present dissertation highlights the diversity of mechanisms involved in drought tolerance and allows us to identify some typical species strategies for water use.

Based on the result of the present dissertation, we can see that some species such as S. ovalis and S. parvifolia have very large vessels (Fig. 5.3) which may allow them to conduct large quantities of water to quickly reach great height (Fig. 5.2), thanks to their light wood requiring minimal carbon investments (Fig. 5.2). Such species do however have very low embolism resistance and are probably running greater risks in order to achieve this growth performance. Nonetheless, although this was not investigated, they may also rely heavily on their stem water capacitance to buffer water stress periods as indicated by their low wood density (Scholz et al. 2008, McCulloh et al. 2014). Shorea spp are dominant in Southeast Asian humid forests and can grow to impressive heights ( $>50$ meters) but with the intensification of drought spells combined with their apparent vulnerability, they may face major challenges.

Species such as N. kiingi seem to adopt strategies opposite to those of Shorea spp. Those species tend to be small-statured, to have high wood-density, narrow vessel diameter, low potential conductivity (directly related to their small vessels), higher embolism resistance and leaves that lose their turgor at lower water potential (Fig. 5.1, 5.2, 5.3). Those species may therefore rely on slow growth performance and greater water efficiency while being fairly resistant to water stress, at 
least when compared to other tropical species.

The present dissertation also illustrates that there are species that apparently follow more intermediate strategies. For example, K. malaccensis can grow extremely tall while having a very dense wood (Fig. 5.2). Its dense wood nevertheless had large vessels in the stem and in distal branches (Fig. 5.3). This is possible because wood density is not always linked to vessel lumen but tends to relate to the properties of the fibers (Ziemińska et al. 2013). K. malaccensis also present one of the most negative $P_{50}$ among the investigated species while probably still having relatively high hydraulic conductivity (based on its high potential conductivity and vessel diameter).

In the plantations, the results demonstrated that oil palm may be vulnerable to drought. This is notably so for tall palms given that their determinist hydraulic architecture may prevent them from achieving height above 10-15 meters without incurring strong negative effects such as very low embolism resistance in the fronds, associated with small vessels and low potential conductivity. Fronds may however protect the integrity of the stem hydraulic system and play a role as "safety valve". Their low resistance to cavitation, associated with stringent stomatal control may allow oil palm to mitigate the negative effects of mild droughts by rapidly closing its stomates to prevent steep water potential drops in its frond xylem. Moreover, given that the cells of oil palm parenchyma stay alive during the entire plant's life, oil palm may heavily rely on stem water capacitance to buffer drought spells (Renninger and Phillips 2016, Meijide et al. 2017).

Rubber trees presented some of the most negative turgor loss points and $P_{50}$ values of the investigated species, indicating that they may be able to better tolerate drought events than other tropical species. In addition, rubber trees exhibit a deciduous behavior when growing in areas with high evaporative demand (Chen and Cao 2015). Such observations, when added to a $P_{50}$ similar to the one that found in seasonally dry forest (-2.36 MPa v. -2.40 MPa; Choat et al. 2012), may indicate that rubber is following a water use strategy that is similar to typical deciduous trees growing in seasonally dry tropical forests. Those species tend to have very large vessels (like rubber) ensuring high water conductivity and growth performance during the favorable wet season. During the dry season, deciduous species shed their leaves, and all cambial activity is largely reduced, protecting them from the low water potential of the dry season.

\section{Implications of our results for system dynamics and plantation management.}

Compared to mono-specific systems, the higher diversity of water use strategy in the forest may lead to greater systemic resilience and resistance along with other benefits linked to species and functional diversity (Anderegg et al. 2018). Nonetheless, higher mortality in large 
trees during periods of exceptional drought associated with high temperatures and high evaporative demand may lead to changes in forest dynamic (McDowell et al. 2020). Notably, carbon cycling would be perturbated since large trees constitute large quantities of stored carbon (Lutz et al. 2018, Bradford and Murphy 2019). These drought-induced modifications would also result in tropical forests with on average younger and shorter stands as well as a shift toward a community of species with shorter stature (Johnson et al. 2018).

Our findings also showed that oil palm plantation sites at the end of their life cycle (i.e. 20-25 years) could face major damages, especially if they are located on soil with high moisture content. Since palms growing on riparian soils seem to be more vulnerable to drought, and that natural riparian woodlands have important ecological functions as a buffer zone between upland oil palm plantations and streams (Chellaiah and Yule 2018a, 2018b, Mitchell et al. 2018) it seems important to consider options other than replacing natural riparian vegetation with oil palm plantations.

Because rubber probable drought-avoiding strategy is similar to deciduous trees in dry forests, and given the plasticity of its wood, rubber may be able to cope with forthcoming intense drought spells. It is nonetheless likely that rubber productivity would be reduced in areas with high evaporative demand as already reported (Devakumar et al. 1998, Clermont-Dauphin et al. 2013, Falqueto et al. 2017).

\section{Future directions}

The present dissertation provides valuable insight into the resistance to drought of natural and intensively managed lowland systems in Indonesia. In order to confirm the results, several other traits should be investigated in future projects and experimentation. Notably, the minimum leaf water potential experienced by the trees and palms at midday allows calculation of hydraulic safety margin that is probably more accurate than leaf turgor loss point. Indeed, minimum leaf water potential represents what the plant is actually experiencing during periods of high evaporative demand and can accurately show how it is functioning at a point close to major hydraulic failure (Meinzer et al. 2009, Choat et al. 2012). Likewise, stem water capacitance shows how plants may buffer heat-induced drought events (Anderegg and Meinzer 2015). Studies of stem water capacitance in oil palm are scarce (e.g. Meijide et al. 2017) and provide interesting results given the developmental particularity of palms. Similarly, the interrelationships of stem water capacitance with wood density, height and $P_{50}$ in the forest would probably yield highly insightful knowledge on the buffering capacity of tall trees. 


\section{References}

AnderegG, W. R. L., Konings, A. G., Trugman, A. T., Yu, K., Bowling, D. R., Gabbitas, R., Karp, D. S., Pacala, S., Sperry, J. S., Sulman, B. N., AND Zenes, N. 2018. Hydraulic diversity of forests regulates ecosystem resilience during drought. Nature 561:538-541.

ANDeRegG, W. R. L. AND Meinzer, F. C. 2015. Wood anatomy and plant hydraulics in a changing climate, pp. 235-253. In U. G. Hacke (ed.), Functional and Ecological Xylem Anatomy. Springer International Publishing, Cham.

Aranda, I., Cano, F. J., Gascó, A., Cochard, H., Nardini, A., Mancha, J. A., López, R., AND SÁNCHEZ-GómEZ, D. 2015. Variation in photosynthetic performance and hydraulic architecture across european beech (fagus sylvatica 1.) populations supports the case for local adaptation to water stress. Tree physiology 35:34-46.

AROCA, R. 2012. Plant Responses to Drought Stress: From Morphological to Molecular Features. Springer, Berlin and Heidelberg.

Awad, H., Barigah, T., Badel, E., Cochard, H., and Herbette, S. 2010. Poplar vulnerability to xylem cavitation acclimates to drier soil conditions. Physiologia plantarum 139:280-288.

Baltzer, J. L., Davies, S. J., Bunyavejchewin, S., And Noor, N. S. M. 2008. The role of desiccation tolerance in determining tree species distributions along the malay-thai peninsula. Functional Ecology 22:221-231.

BARTLETT, M. K., SCOFFONI, C., AND SACK, L. 2012a. The determinants of leaf turgor loss point and prediction of drought tolerance of species and biomes: a global meta-analysis. Ecology letters 15:393-405.

BLACKMAN, C. J., BRODRIBb, T. J., AND JORDAN, G. J. 2010. Leaf hydraulic vulnerability is related to conduit dimensions and drought resistance across a diverse range of woody angiosperms. The New phytologist 188:1113-1123.

Bradford, M. AND Murphy, H. T. 2019. The importance of large-diameter trees in the wet tropical rainforests of australia. PloS one 14:e0208377.

BrodribB, T. J., Bowman, David J. M. S., Nichols, S., Delzon, S., AND Burlett, R. 2010. Xylem function and growth rate interact to determine recovery rates after exposure to extreme water deficit. New Phytologist 188:533-542.

BRODRIBB, T. J. AND COCHARD, H. 2009. Hydraulic failure defines the recovery and point of death in water-stressed conifers. Plant physiology 149:575-584. 
Brodribb, T. J., Holbrook, N. M., Edwards, E. J., And Gutiérrez, M. V. 2003. Relations between stomatal closure, leaf turgor and xylem vulnerability in eight tropical dry forest trees. Plant, Cell and Environment 26:443-450.

Chellaiah, D. AND Yule, C. M. 2018a. Riparian buffers mitigate impacts of oil palm plantations on aquatic macroinvertebrate community structure in tropical streams of borneo. Ecological Indicators 95:53-62.

Chellaiah, D. AND YUle, C. M. 2018b. Effect of riparian management on stream morphometry and water quality in oil palm plantations in borneo. Limnologica 69:72-80.

CHEN, J.-W. AND CAO, K.-F. 2015. A possible link between hydraulic properties and leaf habits in hevea brasiliensis. Functional Plant Biology 42:718.

Choat, B., Jansen, S., Brodribb, T. J., Cochard, H., Delzon, S., Bhaskar, R., Bucci, S. J., Feild, T. S., Gleason, S. M., Hacke, U. G., Jacobsen, A. L., Lens, F., Maherali, H., Martínez-Vilalta, J., Mayr, S., Mencuccini, M., Mitchell, P. J., Nardini, A., Pittermann, J., Pratt, R. B., Sperry, J. S., Westoby, M., Wright, I. J., And Zanne, A. E. 2012. Global convergence in the vulnerability of forests to drought. Nature 491:752-755.

Clermont-Dauphin, C., Suvannang, N., Hammecker, C., Cheylan, V., Pongwichian, P., AND DO, F. C. 2013. Unexpected absence of control of rubber tree growth by soil water shortage in dry subhumid climate. Agronomy for Sustainable Development 33:531-538.

Corley, R. H. V. And Tinker, P. B. 2016. The oil palm. John Wiley \& Sons, Hoboken, NJ, fifth edition edition.

Devakumar, A. S., Mohamed Sathik, M. B., Jacob, J., Annamalainathan, K., GaWai PRAKASH, P., AND VIJAYAKUMAR, K. R. 1998. Effects of atmospheric and soil drought on growth and development of hevea brasiliensis. Journal of Rubber Research (Malaysia) 1:190-198.

Domec, J.-C., Lachenbruch, B., Meinzer, F. C., Woodruff, D. R., Warren, J. M., And MCCUllOH, K. A. 2008. Maximum height in a conifer is associated with conflicting requirements for xylem design. Proceedings of the National Academy of Sciences of the United States of America 105:12069-12074.

Domec, J.-C., WARren, J. M., Meinzer, F. C., AND LACHENBruCh, B. 2009. Safety factors for xylem failure by implosion and air-seeding within roots, trunks and branches of young and old conifer trees. IAWA Journal 30:101-120.

Dufrêne, E. AND SAUGIER, B. 1993. Gas exchange of oil palm in relation to light, vapour pressure deficit, temperature and leaf age. Functional Ecology 7:97-104. 
Duursma, R. A., Blackman, C. J., Lopéz, R., Martin-StPaul, N. K., Cochard, H., AND MEDLYN, B. E. 2019. On the minimum leaf conductance: its role in models of plant water use, and ecological and environmental controls. The New phytologist 221:693-705.

Emilio, T., Lamarque, L., Torres-Ruiz, J. M., King, A., Charrier, G., Burlett, R., ConeJERO, M., RUdAll, P., BAKER, W., AND DELZON, S. 2019. Embolism resistance in petioles and leaflets of palms. Annals of Botany 124 .

Falqueto, A. R., da Silva Júnior, R. A., Gomes, M. T. G., Martins, J. P. R., Silva, D. M., AND PARTELLI, F. L. 2017. Effects of drought stress on chlorophyll a fluorescence in two rubber tree clones. Scientia Horticulturae 224:238-243.

Hacke, U. G., Sperry, J. S., Ewers, B. E., Ellsworth, D. S., Schäfer, K. V., And Oren, R. 2000. Influence of soil porosity on water use in pinus taeda. Oecologia 124:495-505.

Hacke, U. G., Sperry, J. S., Wheeler, J. K., AND CAstro, L. 2006. Scaling of angiosperm xylem structure with safety and efficiency. Tree Physiology 26:689-701.

Jinagool, W., Rattanawong, R., SAngsing, K., Barigah, T. S., GaY, F., Cochard, H., KASEMSAP, P., AND HerbetTe, S. 2016. Clonal variability for vulnerability to cavitation and other drought-related traits hevea brasiliensis müll. arg. Journal of Plant Hydraulics 2:1-12.

Johnson, D. J., Needham, J., Xu, C., Massoud, E. C., Davies, S. J., Anderson-Teixeira, K. J., Bunyavejchewin, S., Chambers, J. Q., Chang-Yang, C.-H., Chiang, J.-M., ChuYOng, G. B., Condit, R., Cordell, S., Fletcher, C., Giardina, C. P., Giambelluca, T. W., Gunatilleke, N., Gunatilleke, S., Hsieh, C.-F., Hubbell, S., Inman-Narahari, F., Kassim, A. R., Katabuchi, M., Kenfack, D., Litton, C. M., Lum, S., Mohamad, M., Nasardin, M., Ong, P. S., Ostertag, R., Sack, L., Swenson, N. G., Sun, I. F., Tan, S., Thomas, D. W., Thompson, J., Umaña, M. N., Uriarte, M., Valencia, R., Yap, S., Zimmerman, J., McDowell, N. G., AND McMahon, S. M. 2018. Climate sensitive sizedependent survival in tropical trees. Nature Ecology \& Evolution 2:1436-1442.

KinG, D. A., Davies, S. J., Supardi, M. N. N., AND TAN, S. 2005. Tree growth is related to light interception and wood density in two mixed dipterocarp forests of malaysia. Functional Ecology 19:445-453.

Li, S., Lens, F., Espino, S., KARIMI, Z., KLePSCH, M., SchenK, H. J., SchmitT, M., SCHuldT, B., AND JANSEN, S. 2016. Intervessel pit membrane thickness as a key determinant of embolism resistance in angiosperm xylem. IAWA Journal 37:152-171.

LiU, H., Gleason, S. M., HaO, G., HuA, L., He, P., Goldstein, G., And Ye, Q. 2019. Hy- 
draulic traits are coordinated with maximum plant height at the global scale. Science Advances 5:eaav1332.

LÜBbe, T., SChuldt, B., AND Leuschner, C. 2017. Acclimation of leaf water status and stem hydraulics to drought and tree neighbourhood: alternative strategies among the saplings of five temperate deciduous tree species. Tree physiology 37:456-468.

Lutz, J. A., Furniss, T. J., Johnson, D. J., Davies, S. J., Allen, D., Alonso, A., AndersonTeixeira, K. J., Andrade, A., BAltzer, J., Becker, K. M. L., Blomdahl, E. M., Bourg, N. A., Bunyavejchewin, S., Burslem, D. F. R. P., Cansler, C. A., CaO, K., CaO, M., CÁrdenas, D., Chang, L.-W., ChaO, K.-J., ChaO, W.-C., Chiang, J.-M., Chu, C., ChuYong, G. B., Clay, K., Condit, R., Cordell, S., Dattaraja, H. S., Duque, A., Ewango, C. E. N., Fischer, G. A., Fletcher, C., Freund, J. A., Giardina, C., Germain, S. J., Gilbert, G. S., HaO, Z., Hart, T., Hau, B. C. H., He, F., Hector, A., Howe, R. W., Hsieh, C.-F., Hu, Y.-H., Hubbell, S. P., InMan-Narahari, F. M., IToh, A., Janík, D., Kassim, A. R., Kenfack, D., Korte, L., KRÁl, K., Larson, A. J., Li, Y., Lin, Y., LiU, S., Lum, S., Ma, K., Makana, J.-R., Malhi, Y., McMahon, S. M., McShea, W. J., Memiaghe, H. R., Mi, X., Morecroft, M., Musili, P. M., Myers, J. A., Novotny, V., De Oliveira, A., OnG, P., Orwig, D. A., Ostertag, R., Parker, G. G., Patankar, R., Phillips, R. P., Reynolds, G., SACK, L., SONG, G.-Z. M., Su, S.-H., SuKumar, R., Sun, I.-F., SureSh, H. S., SWANSON, M. E., TAN, S., Thomas, D. W., Thompson, J., Uriarte, M., Valencia, R., Vicentini, A., VrŠKa, T., WANG, X., Weiblen, G. D., Wolf, A., Wu, S.-H., XU, H., YAMAKURA, T., YaP, S., AND ZimMERMAN, J. K. 2018. Global importance of large-diameter trees. Global Ecology and Biogeography 27:849-864.

Maherali, H., Moura, C. E., Caldeira, M. C., Willson, C. J., And Jackson, R. B. 2006. Functional coordination between leaf gas exchange and vulnerability to xylem cavitation in temperate forest trees. Plant, cell \& environment 29:571-583.

McCulloh, K. A., Johnson, D. M., Meinzer, F. C., And Woodruff, D. R. 2014. The dynamic pipeline: hydraulic capacitance and xylem hydraulic safety in four tall conifer species. Plant, cell \& environment 37:1171-1183.

McDowell, N. G., Allen, C. D., Anderson-Teixeira, K., Aukema, B. H., BondLamberty, B., Chini, L., Clark, J. S., Dietze, M., Grossiord, C., Hanbury-Brown, A., Hurtt, G. C., Jackson, R. B., Johnson, D. J., Kueppers, L., Lichstein, J. W., Ogle, K., Poulter, B., Pugh, T. A. M., Seidl, R., Turner, M. G., Uriarte, M., Walker, A. P., And 
XU, C. 2020. Pervasive shifts in forest dynamics in a changing world. Science (New York, N.Y.) 368.

Meijide, A., Röll, A., Fan, Y., Herbst, M., Niu, F., Tiedemann, F., June, T., Rauf, A., HÖLSCHER, D., AND KNOHL, A. 2017. Controls of water and energy fluxes in oil palm plantations: Environmental variables and oil palm age. Agricultural and Forest Meteorology 239:71 85.

Meinzer, F. C., Johnson, D. M., Lachenbruch, B., McCulloh, K. A., And Woodruff, D. R. 2009. Xylem hydraulic safety margins in woody plants: coordination of stomatal control of xylem tension with hydraulic capacitance. Functional Ecology 23:922-930.

Mitchell, P. J., O'Grady, A. P., Tissue, D. T., White, D. A., Ottenschlaeger, M. L., And PINKARD, E. A. 2013. Drought response strategies define the relative contributions of hydraulic dysfunction and carbohydrate depletion during tree mortality. The New phytologist 197:862-872.

Mitchell, P. J., VeneklaAs, E. J., Lambers, H., And Burgess, S. S. O. 2008. Leaf water relations during summer water deficit: differential responses in turgor maintenance and variation in leaf structure among different plant communities in south-western australia. Plant, cell $\mathcal{E}$ environment 31:1791-1802.

Mitchell, S. L., Edwards, D. P., Bernard, H., Coomes, D., Jucker, T., Davies, Z. G., AND STRUEBIG, M. J. 2018. Riparian reserves help protect forest bird communities in oil palm dominated landscapes. Journal of Applied Ecology 55:2744-2755.

NiINEMETS, Ü. 2001. Global-scale climatic controls of leaf dry mass per area, density, and thickness in trees and shrubs. Ecology 82:453-469.

Olson, M. E., Soriano, D., Rosell, J. A., Anfodillo, T., Donoghue, M. J., Edwards, E. J., León-Gómez, C., Dawson, T. E., Camarero Martínez, J. J., Castorena, M., EchevERría, A., ESPINOSA, C. I., FAJARDo, A., GAZOL, A., ISNARD, S., LiMA, R. S., MARCATI, C. R., AND MÉNDEZ-AlOnZO, R. 2018. Plant height and hydraulic vulnerability to drought and cold. Proceedings of the National Academy of Sciences of the United States of America 115:75517556.

Petit, G., Anfodillo, T., And Mencuccini, M. 2008. Tapering of xylem conduits and hydraulic limitations in sycamore (acer pseudoplatanus) trees. The New phytologist 177:653-664.

Petit, G., DeClerck, F. A. J., Carrer, M., And Anfodillo, T. 2014. Axial vessel widening in arborescent monocots. Tree physiology 34:137-145. 
Pittermann, J., Choat, B., Jansen, S., Stuart, S. A., LynN, L., And Dawson, T. E. 2010. The relationships between xylem safety and hydraulic efficiency in the cupressaceae: the evolution of pit membrane form and function. Plant physiology 153:1919-1931.

Poorter, L., McDonald, I., Alarcón, A., Fichtler, E., Licona, J.-C., Peña-Claros, M., SterCK, F., VillegAs, Z., AND SASS-KLAASSEN, U. 2010. The importance of wood traits and hydraulic conductance for the performance and life history strategies of 42 rainforest tree species. New Phytologist 185:481-492.

Renninger, H. J. And Phillips, N. G. 2016. Palm physiology and distribution in response to global environmental change, pp. 67-101. In G. Goldstein and L. S. Santiago (eds.), Tropical Tree Physiology, volume 6 of Tree Physiology. Springer International Publishing, Cham.

Röll, A., Niu, F., Meijide, A., Hardanto, A., KnOHL, A., And Hölscher, D. 2015. Transpiration in an oil palm landscape: effects of palm age. Biogeosciences 12:5619-5633.

Rosell, J. A., Olson, M. E., AND ANFOdillo, T. 2017. Scaling of xylem vessel diameter with plant size: Causes, predictions, and outstanding questions. Current Forestry Reports 3:46-59.

Rowland, L., DA Costa, A. C. L., Galbraith, D. R., Oliveira, R. S., BinKs, O. J., Oliveira, A. A. R., Pullen, A. M., Doughty, C., Metcalfe, D., Vasconcelos, S. S., Ferreira, L. V., Malhi, Y., Grace, J., Mencuccini, M., And Meir, P. 2015. Death from drought in tropical forests is triggered by hydraulics not carbon starvation. Nature 528:119-122.

Rungwattana, K., Kasemsap, P., Phumichai, T., Kanpanon, N., Rattanawong, R., And HieTZ, P. 2018. Trait evolution in tropical rubber ( hevea brasiliensis ) trees is related to dry season intensity. Functional Ecology 32:2638-2651.

SaCK, L., Cowan, P. D., Jaikumar, N., AND Holbrook, N. M. 2003. The 'hydrology' of leaves: co-ordination of structure and function in temperate woody species. Plant, Cell and Environment 26:1343-1356.

SACK, L., SCoffoni, C., Johnson, D. M., Buckley, T. N., AND BrodribB, T. J. 2015. The anatomical determinants of leaf hydraulic function, pp. 255-271. In U. Hacke (ed.), Functional and Ecological Xylem Anatomy. Springer International Publishing, Cham.

Scholz, F. G., Bucci, S. J., Goldstein, G., Moreira, M. Z., Meinzer, F. C., Domec, J.C., Villalobos-Vega, R., Franco, A. C., And Miralles-Wilhelm, F. 2008. Biophysical and life-history determinants of hydraulic lift in neotropical savanna trees. Functional Ecology 22:773-786. 
Schuldt, B., Knutzen, F., Delzon, S., Jansen, S., Müller-Haubold, H., Burlett, R., Clough, Y., AND Leuschner, C. 2016. How adaptable is the hydraulic system of european beech in the face of climate change-related precipitation reduction? The New phytologist 210:443458.

SMITH, B. G. 1989. The effects of soil water and atmospheric vapour pressure deficit on stomatal behaviour and photosynthesis in the oil palm. Journal of experimental botany 40:647-651.

SPERRY, J. S. AND HACKE, U. G. 2002. Desert shrub water relations with respect to soil characteristics and plant functional type. Functional Ecology 16:367-378.

TAN, K. P., Kanniah, K. D., And Cracknell, A. P. 2013. Use of uk-dmc 2 and alos palsar for studying the age of oil palm trees in southern peninsular malaysia. International Journal of Remote Sensing 34:7424-7446.

TARDiEU, F. AND SimONNEAU, T. 1998. Variability among species of stomatal control under fluctuating soil water status and evaporative demand: modelling isohydric and anisohydric behaviours. Journal of experimental botany 49:419-432.

Trueba, S., Delzon, S., ISNARD, S., AND Lens, F. 2019. Similar hydraulic efficiency and safety across vesselless angiosperms and vessel-bearing species with scalariform perforation plates. Journal of experimental botany 70:3227-3240.

TYReE, M. T., PATIÑO, S., AND BeCKeR, P. 1998. Vulnerability to drought-induced embolism of bornean heath and dipterocarp trees. Tree Physiology 18:583-588.

VAlladares, F., GianOli, E., AND GómeZ, J. M. 2007. Ecological limits to plant phenotypic plasticity. New Phytologist 176:749-763.

VOlAIRE, F. 2018. A unified framework of plant adaptive strategies to drought: Crossing scales and disciplines. Global change biology 24:2929-2938.

WeitZ, J. S., Ogle, K., AND Horn, H. S. 2006. Ontogenetically stable hydraulic design in woody plants. Functional Ecology 20:191-199.

Wheeler, J. K., SPERry, J. S., HACKe, U. G., AND HOANG, N. 2005. Inter-vessel pitting and cavitation in woody rosaceae and other vesselled plants: a basis for a safety versus efficiency trade-off in xylem transport. Plant, cell \& environment 28:800-812.

Wortemann, R., Herbette, S., Barigah, T. S., Fumanal, B., Alia, R., Ducousso, A., Gomory, D., Roeckel-Drevet, P., AND Cochard, H. 2011. Genotypic variability and phenotypic plasticity of cavitation resistance in fagus sylvatica 1. across europe. Tree physiology 31:1175-1182. 
Ziegler, C., Coste, S., Stahl, C., Delzon, S., Levionnois, S., Cazal, J., Cochard, H., Esquivel-Muelbert, A., Goret, J.-Y., Heuret, P., Jaouen, G., Santiago, L. S., And BONAL, D. 2019. Large hydraulic safety margins protect neotropical canopy rainforest tree species against hydraulic failure during drought. Annals of Forest Science 76:1285.

Ziemińska, K., Butler, D. W., Gleason, S. M., Wright, I. J., And Westoby, M. 2013. Fibre wall and lumen fractions drive wood density variation across 24 australian angiosperms. $A o B$ PLANTS 5:25.

ZimmermanN, M. H. 1973. Transport problems in arborescent monocotyledons. The Quarterly Review of Biology 48:314-321. 


\section{Index of figures}

1.1 Locations of substantial drought- and heat-induced tree mortality around the globe since 1970, documented by peer-reviewed studies. Global forest cover (dark green) and other wooded regions (light green) are based on FAO (2005). Red dots represent studies from 1970 to 2009. White dots (local studies) and shapes (studies focusing on broad areas) represent localities and measurement networks from post-2009 publications. Black dots represent post-2014 publications. A list of publications is available in Allen et al. 2010, IPCC 2014 and Allen et al. 2015. (Source: Allen et al. 2015)

1.2 Representation of the water transport pathways along the soil-plant-atmosphere continuum. Water moves from areas of high water potential (i.e. close to zero in the soil) to low water potential (i.e., air outside the leaves). Details of the CohesionTension mechanism are illustrated with the inset panels (1) where tension is generated by the evaporation of water molecules during leaf transpiration and is transmitted (2) down the continuous, cohesive water columns through the xylem and (3) out of the roots to the soil. (Source: McElrone et al. 2013) _ . . . . . . . . .

1.3 (A) Conduits in the xylem are interconnected through pits, which offer resistance to flow but provide safety to the system. (B) If air gets into these conduits, capillary forces are not strong enough to retain the water column because conduit diameters are too large, and $(\mathrm{C})$ water recedes into the adjacent tissue and the vessel becomes embolized and non-functional for water transport. (D) Pit "membranes" of modified primary cell wall material avoid the spread of air throughout the xylem network by generating the same capillary forces as the menisci of mesophyll cell walls, but (E) if the pressure differential between the air-filled and water-filled conduits is too large, air can seed in the water-filled conduit through stretched pit-pores or rupture of the membrane (in angiosperms). (Modified from Venturas et al. 2017: panel E was added $\ldots \ldots \ldots \ldots \ldots \ldots \ldots$ 
1.4 Location of EFForTS study sites in $(a, b)$ Sumatra and (c,d) Jambi Province. (d) Plot design is located in two landscapes near Bukit Duabelas National Park and Harapan Rainforest. (Source: Drescher et al. 2016) . . . . . . . . . . . . . . . . .

2.1 Pearson's correlation matrix of key functional traits. Tree height $(H)$, aboveground biomass increment $(\mathrm{ABI})$, stem and branch potential hydraulic conductivity $\left(K_{\mathrm{p} \text { stem }}\right.$ and $\left.K_{\mathrm{p} \text { branch }}\right)$, stem vessel diameter $\left(D_{\text {stem }}\right)$, stem and branch vessel density ( $\mathrm{VD}_{\text {stem }}$ and $\left.\mathrm{VD}_{\text {branch }}\right)$, stem and branch lumen-to-sapwood-area ratio $\left(F_{\text {stem }}\right.$ and $\left.F_{\text {branch }}\right)$, specific leaf area (SLA) and Huber value (HV) were logarithm transformed to achieve a normal distribution. Upper triangle indicates correlation strength. Lower triangle shows repartition of data points and linear interrelationships, data have been scaled by standard deviation and centred around zero. Colors indicate coefficient of correlation gradient from -1 (blue) to 1 (red). Diagonal line shows density curves of each variables. Abbreviations and definitions are available in Table 2.1. . . . . .

2.2 Relationships of the average $(a, b)$ branch and (c) stem vessel diameter and (d) stem wood density with $(a, c)$ tree height, and average $(b, d)$ stem vessel diameter. Points represent trees and colors, species (color codes available in Table 2.2). Displayed as black lines are predictions from linear mixed models (LME; Table A2.4) with bootstrap confidence intervals in light grey. Conditional pseudo $r^{2}$ and level of significance of LME are indicated with * as $P<0.05,{ }^{* *}$ as $P<0.01$ and ${ }^{* * *}$ as $P<$

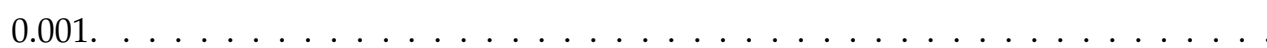

2.3 Relationships of $(a, b, c)$ tree-level water potential at 50\% loss of conductivity $\left(P_{50}\right)$ and $(\mathrm{d}, \mathrm{e}, \mathrm{f})$ leaf turgor loss point $\left(\pi_{\text {tlp }}\right)$ with $(\mathrm{a}, \mathrm{d})$ tree height, $(\mathrm{b}, \mathrm{e})$ stem wood density and (c, f) logarithm of aboveground biomass increment. Points represent trees and colors, species (color codes available in Table 2.2). Error bars in (d, e, f) represent standard errors based on two measurements of $\pi_{50}$ per tree. Displayed as black lines are predictions from linear mixed models (LME; Table A2.5) with bootstrap confidence intervals in light grey. Conditional pseudo $r^{2}$ and level of significance of LME are indicated with ns as $P>0.10,^{\circ}$ as $P<0.10,^{*}$ as $P<0.05$

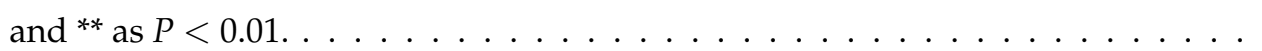


2.4 Dependence of tree-level water potential at $50 \%$ loss of conductivity $\left(P_{50}\right)$ with average (a) stem and (b) branch vessel diameter, (c) stem and (d) branch logarithm of lumen-to-sapwood area ratio $\left(F ; A_{\text {lumen }}: A_{\text {sapwood }}\right)$, and (e) stem and (f) branch logarithm of potential hydraulic conductivity $\left(K_{\mathrm{p}}\right)$. Points represent trees and colors, species (color code available in Table 2.2). Displayed as black lines are predictions from linear mixed models (LME; Table A2.4) with bootstrap confidence intervals in light grey. Conditional pseudo $r^{2}$ and level of significance of LME are indicated with ${ }^{*}$ as $P<0.05,{ }^{* *}$ as $P<0.01$ and ${ }^{* * *}$ as $P<0.001 . \ldots \ldots \ldots \ldots$

2.5 Relationships of tree-level water potential at $50 \%$ loss of conductivity $\left(P_{50}\right)$ on leaf turgor loss point $\left(\pi_{\mathrm{tlp}}\right)$. Points and colours stand for species average. Error bars indicate standard error of $P_{50}$ and $\pi_{\mathrm{tlp}}$, both predicted and measured at tree-level. Displayed as black lines are plot 1:1 line and predictions of linear mixed effect models (LME; Table A2.6) with bootstrap confidence intervals in light grey. Conditional pseudo $r^{2}$ and level of significance of LME are indicated next to the regression lines with ${ }^{*}$ as $P<0.05 \ldots \ldots \ldots \ldots \ldots \ldots \ldots \ldots$

A2.1 Vulnerability curves of seven lowland tropical forest species fit with a Weibull model. The water potential at $50 \%$ loss of conductivity $\left(P_{50}\right)$ is indicated by the

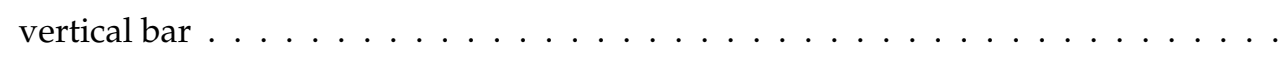

3.1 Example of (A) a cross-section of the rachis of an oil palm frond sampled in riparian plot Ri3 with focus on (B) a vascular bundle and (C) several peripheral vascular bundles. $\mathrm{Bu}$, vascular bundle; $\mathrm{Fb}$, fibers; $\mathrm{Mx}$, metaxylem vessels; $\mathrm{Pa}$, parenchyma cells; Ph, phloem cells; Px, protoxylem vessels. Picture scale bars are (A) $1000 \mathrm{~m}$ and (B) and (C) $100 \mathrm{~m}$.

3.2 Seasonal course of volumetric soil moisture (daily averages; A) and atmospheric VPD (daily averages; B) in the period from November 2017 to August 2018 on the six studied plots at the riparian and well-drained sites in Jambi province, Sumatra, Indonesia. Thick lines are the averages of riparian (blue lines; filled circles) and well-drained (red lines; open circles) sites; dashed lines stand for the individual plots. 
3.3 Daily course of solar radiation (A), atmospheric VPD (B) and stomatal conductance (C) of palm fronds on sunny days in October 2016 at the PT Humusindo plantation site. Presented data are averages over 6 days and three palms each with nine fronds measured in a rotating measuring scheme $($ means $\pm \mathrm{SE}) . \ldots \ldots \ldots$

3.4 Site- and plot-averaged VCs for the three well-drained and three riparian plots and corresponding $P_{50}$ values, indicated by vertical lines $(n=6$ palms per plot, 3 plots per plantation type). Blue-colored lines stand for riparian sites and red-colored lines for well-drained sites. Dashed lines stand for plot-level predictions and full lines for plantation type level predictions. . . . . . . . . . . . . . . .

3.5 Dependence of (A) vessel density (VD), (B) hydraulically weighted vessel diameter $\left(D_{\mathrm{h}}\right),(\mathrm{C})$ potential conductivity $\left(K_{\mathrm{p}}\right)$ and $(\mathrm{D})$ water potential at $P_{50}$ on palm height for all investigated palms. Each point represents one frond. Given are regression lines for each plantation type (blue line, filled circles: riparian; red line, open circles: well-drained). Solid lines depict significant trends $(P<0.05)$, dashed lines nonsignificant trends. Crosses given in (D) stand for predicted $P_{50}$ for each plantation type; further given are differences in $P_{50}$ between plantation types when comparing palms of a similar regionally averaged height (long brackets, $1.29 \mathrm{MPa}$ ) and palms of different plantation-type-averaged heights (short brackets, $0.42 \mathrm{MPa}$ ) are also indicated. . . . . . . . . . . . . . . . . . . . . 101

A3.1 Daily course of vapor pressure deficit (VPD) of the investigated plots including (A) every days from June 2017 to August 2018, (B) the 25\% driest days from the same period. Thick lines are the averages $( \pm \mathrm{SE})$ of riparian (blue lines; filled circles) and well-drained (red lines; open circles) plantation types, dashed lines stand for the individual plots. . . . . . . . . . . . . . .

A3.2 AMOVA results between well-drained and riparian site types, based on 999 permutations. Dark grey indicates the genetic variance among the two types and light grey within the well-drained and riparian sites. . . . . . . . . . . . . . . 109

A3.3 Predicted vulnerability curves (VCs; percent loss of conductivity vs. xylem water potential) of oil palm fronds given for all palms measured in the six plots on the well-drained (upper row) and riparian sites (lower row). Color: palm identity; colored lines - palm level predictions; dashed black lines - plot level predictions; solid black lines - plantation type level predictions. . . . . . . . . . . . . . 110 
4.1 Seasonal course of (a) atmospheric vapour pressure deficit (VPD, daily averages) and (b) volumetric soil moisture (daily averages) from November 2017 to December 2018 in the eight studied H. brasiliensis plots at the riparian and well-drained soil types in Jambi province, Sumatra, Indonesia. Solid lines are the monthly averages at riparian (blue solid lines; filled circles) and well-drained (red solid lines; open circles) sites, dashed lines stand for individual plots. . . . . . . . . . . . .

4.2 Boxplots of all functional wood and leaf traits in H. brasiliensis from well-drained (red colour, left) and riparian (blue colour, right) sites. Given are (a) potential conductivity $\left(K_{\mathrm{p}}\right)$, (b) specific conductivity $\left(K_{\mathrm{s}}\right)$, (c) leaf-specific conductivity $\left(K_{1}\right),(\mathrm{d})$ xylem pressures at $12 \%\left(P_{12}\right)$, at (e) 50\% (P $\left.P_{50}\right)$, and at (f) $88 \%$ loss of hydraulic conductance $\left(P_{88}\right)$, (g) hydraulic safety margin (HSM; $\left.\pi_{\text {tlp }}-P_{50}\right)$, (h) wood density (WD), (i) lumen-to-sapwood area ratio $\left(A_{\text {lumen }}: A_{\text {xylem }}\right)$, (j) vessel diameter $(D),(\mathrm{k})$ vessel density (VD), (l) vessel grouping index $\left(V_{\mathrm{g}}\right),(\mathrm{m})$ specific leaf area (SLA), (n) leaf water potential at turgor loss point $\left(\pi_{\mathrm{tlp}}\right),(\mathrm{o})$ carbon isotope signature $\left(\delta^{13} \mathrm{C}\right)$, and the (p) Huber value (HV). The significance of differences (Wilcoxon signedrank test and Student's t-test) between well-drained and riparian soils are indicated for each trait with $n s(P>0.05),{ }^{*}(P<0.05)$ or ${ }^{* *}(P<0.01) . \ldots \ldots \ldots$

4.3 Xylem pressures inducing $50 \%$ or $88 \%$ loss of hydraulic conductance (circle $=P_{50}$; square $\left.=P_{88}\right)$ of $H$. brasiliensis branches in relation to (a) volumetric soil water content (VWC) and (b) vapour pressure deficit (VPD). Further shown are (c) hydraulic safety margin (HSM), and (d) specific leaf area (SLA) in dependence on VPD. Values are mean \pm SE per plot. Given are the conditional $r^{2}$ of the LME models, asterisks indicate the level of significance (ns, $P>0.05 ;{ }^{*}, P<0.05$ ). Each plot is represented by one colour. . . . . . . . . . . . . . .

4.4 Pair-wise Pearson correlation table (upper triangle), scatter plot (lower triangle) and density plot (diagonal panels) for the relationships between 14 functional traits of $H$. brasiliensis. Shown are the data on tree level $(n=125)$, including trend lines from linear regressions with $95 \%$ confidence intervals. Please note that embolism resistance was only quantified for a subset of tree individuals $(n=35)$. Color and size indicate the strength of the correlation 
4.5 Relationships between vessel density (VD) and (a) tree-level xylem pressures inducing $50 \%$ or $88 \%$ loss of hydraulic conductance $\left(\right.$ circle $=P_{50}$; square $\left.=P_{88}\right)$ of $H$. brasiliensis branches; (b) sapwood-specific hydraulic conductance $\left(K_{\mathrm{s}}\right)$; (c) lumento-sapwood-area ratio $\left(A_{\text {lumen }}: A_{\text {xylem }}\right)$; and (d) vessel grouping index $\left(V_{\mathrm{g}}\right)$. Given are the conditional $r^{2}$ based on the LME models, asterisks indicate the level of significance $(* *, P<0.01 ; * * *, P<0.01)$. Different colours indicate different plots. . . 138

A4.1 Predicted vulnerability curves (VCs; percent loss of conductivity vs. xylem water potential) of Hevea brasiliensis branches for all trees sampled in the eight plots on well-drained (upper row) and riparian soil type (lower row). Color: tree identity; colored lines - tree level predictions; dashed black lines - plot level predictions; solid black lines - soil type-level predictions. . . . . . . . . . . . . . . . . . . . .

A4.2 Relationship between tree-level specific leaf area (SLA) and the xylem pressure at $50 \%$ loss of hydraulic conductance $\left(P_{50}\right)$. Given is the conditional $r^{2}$ of the linear mixed effect model, and the level of significance $(P<0.05)$. Each plot is represented by one symbol colour. $\ldots \ldots \ldots \ldots \ldots \ldots \ldots \ldots$

5.1 (a) Boxplots of individual $P_{50}$ (water potential at $50 \%$ loss of hydraulic conductivity) per investigated system (Forest, Oil palm and Rubber plantations). Plantations are divided into riparian and well-drained sites. (b) Boxplots of individual hydraulic safety margins (HSM) per system calculated as $P_{\mathrm{e}}$ (water potential at the emergence of embolism as the intersection between the tangent at $P_{50}$ and the VC according to Meinzer et al. 2009) $-P_{50}$. Boxplots of (c) $P_{50}$ and (d) leaf turgor loss point $\left(\pi_{\mathrm{tlp}}\right)$ per investigated species. $P_{50}$ of S. apiculata, G. bancana and P. anisophylla could not be compiled by the model (chapter 1). $\pi_{\text {tlp }}$ of E. guineensis (oil palm) has not been investigated. Panels (c) and (d) are organised by decreasing mean species

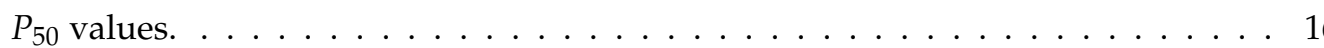

5.2 Boxplots of (a) tree height, (b) wood density and (d) log aboveground biomass increment (ABI) per investigated species. Wood density of E. guineensis (oil palm) has not been investigated. ABI of H. brasiliensis (rubber) and E. guineensis (oil palm) have not been investigated. Boxplots are organised by decreasing mean species $P_{50}$ values. . . . . . . . . . . . . . . . . . . . . . . . . . . . . . . . . 169 
5.3 Dependence of (a) branch and (b) stem vessel vessel diameter to species average height; and dependence of (c) branch vessel diameter and (d) branch lumen-tosapwood area ratio to the water potential at $50 \%$ loss of hydraulic conductivity, $P_{50}$. Each point represents one species and error bars indicate standard errors of the measurements except for $P_{50}$ (modeled per species). Panels (c) and (d) present fewer species than panels (a) and (b) because the $P_{50}$ of 3 species could not be modelized (chapter 1). Regression lines and conditional r-squared from the models are shown. Level of significance is indicated as: ${ }^{*}(P<0.05),{ }^{* *}(P<0.01)$ and ${ }^{* *}$

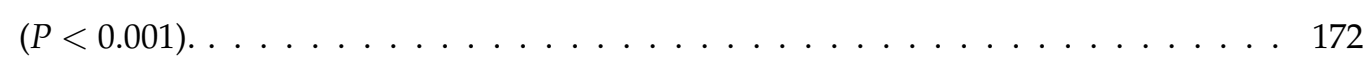





\section{Index of tables}

2.1 List of studied variables with abbreviations, units and definitions. . . . . . . . . . . 41

2.2 Summary of sample and stand characteristics for trees with $\mathrm{DBH}<10 \mathrm{~cm}$ from an inventory of 1 ha and belonging to the 10 investigated species. Given are species color codes throughout the study; diameter at breast height $(\mathrm{DBH})$ and height $(H)$ of trees sampled and in the stand; maximum tree height in the stand $\left(H_{\max }\right)$; wood density $(\mathrm{WD})$, aboveground biomass (AGB) as of January 2017 and aboveground biomass increment (ABI) of the sampled trees; and the stem density (SD) in the stand. All values correspond to mean ( \pm standard error) for all variables except for $n_{\text {sample }}, H_{\max }$ and SD. . . . . . . . . . . . .

2.3 Relationships summary of structural and growth variables with key functional traits. Given are marginal pseudo $r^{2}$ (mar. $\left.r^{2}\right)$, conditional pseudo $\left.r^{2}\right)$ (cond. $r^{2}$ ) and the effect $P$ value from linear mixed effect models (Table A2.5). Relationships with $P<0.05$ are given in bold, marginal relationships with $P<0.10$ are given in bold and italic. For abbreviations and units see Table $1 . \ldots$. . . . . . . . . . .

A2.1 Coordinates and elevations ( $\mathrm{m}$ above sea level), and stem diameter at breath height $(\mathrm{DBH})$, height $(H)$ and stem density $(\mathrm{SD})$ of trees in each plots. Given are mean \pm SE of $\mathrm{DBH}$ and $H$ of trees with $\mathrm{DBH}>10 \mathrm{~cm} \ldots \ldots \ldots$

A2.2 Summary of hydraulic safety and wood anatomy traits in the 10 investigated species (Table 2.2). Given are means \pm SE except for $P_{50}$ and $S_{50}$ that were extracted from

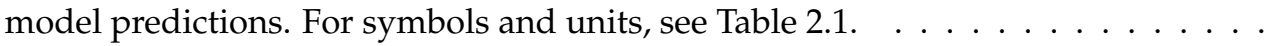

A2.3 Results of hierarchical mixed effects models to predict tree-level $P_{50}(\mathrm{M} 1)$ and to test the influence of plant height (H; M2), wood density (WD; M3) and aboveground biomass increment (ABI; M4) on $P_{50}$ and the slope at $P_{50}$. Given are PLC values (numbers in parentheses give SE of the estimates) for the fixed effects and standard deviation (SD) for random effects. Asterisks indicate the level of significance: ${ }^{\circ} P$ $<0.10{ }^{*} P<0.05 ;{ }^{* *} P<0.01 ;{ }^{* *} P<0.001$. For symbols and units, see Table 2.1 . 
A2.4 Results of linear mixed-effects models on the relationships between vascular architecture and structural and functional traits. All models accounted for trees nested in species as random effects. Given are model used, coefficient values $( \pm \mathrm{SE}), P$ values, weight function if used, degrees of freedom (DF), standard deviation (SD) of tree, species and residuals, number of observations $(n)$, the sense of the relationship (+ or -), marginal $r^{2}$ (Mar. $r^{2}$ ) and the conditional $r^{2}$ (Cond. $r^{2}$ ). For symbols and units, see Table 2.1. . . . . . . . . . . .

A2.5 Results of linear mixed-effects models on the mutual interrelationships between tree structure, growth and wood and leaf functional traits. All models accounted for trees nested in species as random effects. Given are model used, coefficient values $( \pm \mathrm{SE}), P$ values, weight function if used, degrees of freedom (DF), standard deviation (SD) of tree, species and residuals, number of observations $(n)$, the sense of the relationship (+ or -), marginal $r^{2}$ (Mar. $r^{2}$ ) and the conditional $r^{2}$ (Cond. $r^{2}$ ). For symbols and units, see Table 2.1. . . . . . . . . .

A2.6 Results of linear mixed-effects models on the mutual interrelationships across wood and leaf functional traits. All models accounted for trees nested in species as random effects. Given are model used, coefficient values $( \pm \mathrm{SE}), P$ values, weight function if used, degrees of freedom (DF), standard deviation (SD) of tree, species and residuals, number of observations $(n)$, the sense of the relationship (+ or -), marginal $r^{2}$ (Mar. $r^{2}$ ) and the conditional $r^{2}$ (Cond.

$r^{2}$ ). For symbols and units, see Table $2.1 \ldots \ldots \ldots \ldots$

A2.7 Results of hierarchical mixed effects models to test the influence of stem and branch vessel diameter $\left(D_{\text {stem }}\right.$ and $\left.D_{\text {branch }} ; \mathrm{M} 1, \mathrm{M} 4\right)$, stem and branch vessel density $\left(\mathrm{VD}_{\text {stem }}\right.$ and $\mathrm{VD}_{\text {branch }}$; M2, M5), and stem and branch lumen-to-sapwood area ratio ( $F_{\text {stem }}$ and $F_{\text {branch }} ;$ M3, M6) on $P_{50}$ and the slope at $P_{50}$. Given are PLC values (numbers in parentheses give SE of the estimates) for the fixed effects and standard deviation (SD) for the random effects. Asterisks indicate the level of significance: ${ }^{\circ} P<0.10 ;{ }^{*} P<0.05 ;{ }^{* *} P<0.01 ;{ }^{* * *} P<0.001$. For symbols and units, see Table $2.1 \ldots \ldots \ldots \ldots \ldots \ldots \ldots$

3.1 Stand structural characteristics and soil properties of the six studied oil palm plantation plots at the well-drained or riparian sites in Jambi, Sumatra, Indonesia. Given are palm age ( $A$, in years), palm density (PD, palms per hectare), the percent of sand and clay in the top $50 \mathrm{~cm}$ of the soil, the average weight of harvested fruit bunches in 2017 (mean \pm SE) yield per plot from February to December 2017; Mg), means $( \pm \mathrm{SE})$ of palm height $(H$, stem height to the apical meristem in $\mathrm{m})$ and the number of plants and fronds investigated per plot. . . . . . . . . . . . . . . . 
3.2 List of studied variables with abbreviations, units and definitions. . . . . . . . . . .

3.3 Summary of hydraulic and anatomical traits measured on the six plots at the welldrained or riparian sites. Given are mean $( \pm \mathrm{SE})$ for all variables at all levels except for $P_{12}, P_{50}$ and $P_{88}$ at plot and plantation type levels (extracted model predictions). For symbols see Table $3.2 . \ldots \ldots \ldots \ldots \ldots \ldots \ldots$

3.4 Results of a hierarchical mixed effects model on the influence of site (riparian vs well-drained) and plant height and their interactions on $P_{50}$ and the slope of the VCs (slope $+P_{50} \sim$ plantation type height). Given are PLC values (numbers in parentheses give SE of the estimates) and t-values (from Wald z-test) for the fixed effects and standard deviation (SD) for random effects. Degrees of freedom of the model were equal to 61. Fixed effects were plantation type and plant height, random effects plot and palm nested in plot. Asterisks indicate the level of significance: ${ }^{*} P<0.05 ;{ }^{* *} P<0.01 . \ldots \ldots \ldots \ldots \ldots \ldots$

3.5 Results of mixed effects models on the influence of site (riparian vs. well-drained) and plant height and their interactions on hydraulically weighted mean vessel diameter $\left(D_{\mathrm{h}}\right)$, potential conductivity $\left(K_{\mathrm{p}}\right)$ and VD of the palm frond rachis. Given are values (numbers in parentheses give $\mathrm{SE}$ of the estimates) and $t$-values for the fixed effects and SD for the random effects. SD weight for riparian sites are also given (SD weight of well-drained sites equal 1). Fixed effects were plantation type and plant height; random effect was plot. Asterisks indicate the level of significance: ${ }^{* *} P<0.01 \ldots \ldots \ldots$. . . . . . . . . . . . . . . . . . . . . 100

A3.1 Coordinates and elevations ( $m$ above sea level) of the studied plots. . . . . . . . . 107

A3.2 depth-related soil texture of five of the investigated plots. Given are the percent of sand, silt and clay depending of soil depth $(\mathrm{m}) \ldots \ldots$. . . . . . . . . . . . 107

A3.3 Pairwise genetic dissimilarity between 36 investigated individuals. Gradient colors indicate the level of dissimilarity, light green colors low distance, dark green colors high distance. Zero is shown for the comparison of the same individual. . . . . . . 108

4.1 List of studied variables with abbreviations, units and definitions. 
4.2 Plot characteristics of the eight studied H. brasiliensis plots on well-drained (P1-P4) and riparian (P5-P8) soil types in Jambi, Sumatra (Indonesia). Given are tree age ( $A$, $\mathrm{yr})$, stem density $\left(\mathrm{SD}, n \mathrm{ha}^{-1}\right)$, percent of sand and clay in the top $30 \mathrm{~cm}$ of the soil, average soil volumetric water content in 2018 (VWC, vol. \%), daily average vapour pressure deficit (VPD) in $2018(\mathrm{kPa})$, mean VPD of the 20\% driest days of 2018 $\left(\mathrm{VPD}_{\mathrm{dry}}, \mathrm{kPa}\right)$, average tree diameter at breast height $(\mathrm{DBH}, \mathrm{cm})$, tree height $(H$, $\mathrm{m})$, and number of investigated trees $\left(n_{\text {tree }}\right)$ and branches $\left(n_{\text {cavitron }}\right)$ for xylem safety measurements. Values are means \pm SE. Small letters indicate significant differences between soil types (Wilcoxon signed rank test or Student's t-test) and across the eight plots (Kruskall-Wallis test or one-way analysis of variance) . . . . . . . . .

4.3 Summary of mixed effects models on the influence of volumetric soil water content (VWC), mean annual vapour pressure deficit (VPD) and mean VPD of the $20 \%$ driest days $\left(\mathrm{VPD}_{\mathrm{dry}}\right)$ on the 16 wood and leaf traits related to hydraulic efficiency and safety. For abbreviations, see Table 2.1. Given are the marginal $r^{2}$, conditional $r^{2}$ and $P$ values of the models, details are shown in Table A4.4. Significant relationships $(P<0.05)$ are marked in bold, marginally significant relationships $(P<0.10)$ in bold and italics. . . . . . . . . . . . . . . . . . . . 135

A4.1 Coordinates and elevation ( $\mathrm{m}$ above sea level) of all eight investigated rubber plantation plots.

A4.2 Summary of wood and leaf functional traits of $H$. brasiliensis for the four welldrained (P1-P4) and four riparian (P5-P8) sites. Given are means \pm SE except for $P_{12}, P_{50}$ and $P_{88}$ that were extracted from model predictions. For symbols and units, see Table 4.1. Letters indicate significant differences between soil types (Wilcoxon signed rank test or Student's t-test). . . . . . . . . . . . . . . . . . . .

A4.3 Results of hierarchical mixed effects models on the influence of (M1) site (riparian vs. well-drained) and (M2) plot vapour pressure deficit in 2018 (VPD) on $P_{50}$ and slope of the vulnerability curves of $H$. brasiliensis branches. Given are PLC values (numbers in parentheses indicate the standard error) for the fixed effects, standard deviation (SD) for random effects (trees nested in plots) and residuals, and marginal (only with fixed effects) as well as conditional (including random effects) pseudo $r^{2}$. Level of significance is indicated with ${ }^{* *}(P<0.01)$ and ${ }^{* * *}(P<$ $0.001)$. 
A4.4 Model summary of the influence of (a) VPD and (b) VPD dry on key functional traits (Table 4.1). Given are intercept (SE), coefficient values (coef.) (SE), standard deviation (SD) for random effects (plot) and residuals as well as number of observations (n). For all models, tree diameter, plantation age and density were tested as random effect in addition to plot. Only plantation age improved the models with SLA and 13C. Significance is indicated by values in bold and with ${ }^{\circ}(P<0.10),{ }^{*}(P<$ 0.05), ${ }^{* *}(P<0.01) . \ldots \ldots \ldots \ldots \ldots$. . . . . . . . . . . . 148

5.1 Summary of models investigating effects of $(1-3)$ frond and $(4-13)$ stem and branch xylem anatomy of $(1-5)$ individuals and $(6-13)$ species on their resistance to drought-induced embolism, calculated as water potential at $50 \%$ loss of hydraulic conductivity $\left(P_{50}\right)$ and on their leaf turgor loss point, $\pi_{\text {tlp }}$. Significant $P$ values $(P<0.05)$ are indicated in bold and marginally significant $P$ values $(P<$ $0.10)$ are indicated in bold and in italics. . . . . . . . . . . . . . . 174 



\section{Acknowledgement}

First of all, I am grateful to the DFG for funding the EFForTS project. I would also like to thank Prof. Christoph Leuschner for trusting me in this challenging project. I am also especially thanking Prof. Bernhard Schuldt who supervised me with attention and, with curiosity and motivation, gave me new ideas and advices throughout my $\mathrm{PhD}$ journey.

I would like to thank Dr. Dietrich Hertel for helping me whenever I needed it. I thank Dr. Heinz Coners for helping with my soft- and hardware problems. In addition, I am particularly grateful to Astrid Röben who guided me through all the paperwork and offered her help whenever I had an administrative problem.

My thanks go to my working colleagues in the department of plant ecology and ecosystems research for the nice work atmosphere. Thanks to Sebastian Fuchs who first guided me when I arrived in Göttingen. I also particularly wish to thank Dr. Roman Link who helped me with methodological and statistical questions and with whom I had very productive discussions (and nice metal concerts!). I would also like to extend my gratitude to Dr. Martyna Kotowska who first guided me in Indonesia and who kindly helped me on any matter the whole time.

Thanks to the people in the office in Bogor and in Jambi for making the link between research and administration so efficient even when many obstacles were on the way. I would also like to express my deepest appreciation to my research assistants, Irul, Tiwi, Udin and Vira! You helped me so much! And also special thanks to Mathilde Millan and Kyra Zembold for the help in Jambi and for the many nice moments we spent together!

I am extremely grateful to all my colleagues from the CRC EFForTS for the good time spent together whereas it was in the field, in Jambi or in Göttingen! I heartfully thank my friends from the project and beyond: Britta, Carina, Clara, Dirk, Florian, Isabelle, Johannes, Joost, Joyson, Kristina, Rahmi and Tatiana! And of course, Greta who supported me the whole time!

Finally, I extend my sincere thanks to my family who also supported me even if I was not giving so much news. I especially thank my father who helped me proofreading the final dissertation. 



\section{Curiculum vitae}

WAITE PIERRE-ANDRE

Age: 28 (born 29/09/1991)

Sex: $M$

Nationality: French

Adress: Goethe-Allee 16,

37073 Göttingen, Germany

E-mail: waitepierreandre@gmail.com

PhD student in plant ecophysiology

\section{EDUCATION}

\section{6-2020}

PhD Student at the department of Ecology \& Ecosystem Research, University of Göttingen, Germany

\section{3-2015}

Master degree in Tropical Plant Biodiversity. University of Montpellier II, France.

2009-2013

B. Sc. in Organismal Biology and Ecology. University of Rouen, France.

\section{PUBLICATIONS}

Waite PA, Schuldt B, Link RM, Breidenbach N, Triadiati T, Hennings N, Saad A, Leuschner C (2019). Soil moisture regime and palm height influence embolism resistance in oil palm, Tree Physiology, Volume 39, Issue 10, October 2019, Pages 1696-1712, https://doi.org/10.1093/treephys/tpz061

Kotowska MM, Link RM, Röll A, Hertel D, Hölscher D, Waite PA, Moser G, Tjoa A, Leuschner C, Schuldt B (2020).

Effects of wood hydraulic properties on water use and productivity of tropical rainforest trees Tree Physiology, submitted

Waite PA, Leuschner C, Delzon S, Triadiati T, Saad A, Schuldt B (2020).

Plasticity of wood and leaf traits related to hydraulic efficiency and safety is linked to the evaporative demand and not soil moisture in rubber (Hevea brasiliensis)

Agricultural and Forest Meteorology, submitted

Ellsässer F, Röll A, Ahongshangbam J, Waite PA, Hendrayanto, Schuldt B, Hölscher D (2020). Predicting tree sap flux and stomatal conductance in a mixed agroforestry system from drone-recorded surface temperatures - a machine learning approach. Final draft

Waite PA, Leuschner C, Zembold K, Triadiati T, Saad A, Schuldt B (2020).

Tall tropical trees are more vulnerable to drought-induced hydraulic failure than individuals from the lower strata. Final draft 



\section{Presentations}

Waite PA, Leuschner C, Delzon S, Triadiati T, Saad A, Schuldt B (2019).

Xylem vulnerability to embolism in natural and transformed tropical systems in Sumatra, Indonesia. Xylem International Meeting, September 2019. Padua, Italy

Waite PA, Leuschner C, Delzon S, Triadiati T, Saad A, Schuldt B (2019).

Xylem vulnerability to embolism in natural and transformed tropical systems in Sumatra, Indonesia. GfÖ Annual Meeting 2019 September 2019. Münster, Germany

Waite PA, Schuldt B, Triadiati T, Saad A, Leuschner C (2018).

Xylem vulnerability to embolism in natural and intensively used tropical systems. Study of oil palm resistance to cavitation compared to other systems. EFForTS-Symposium, "Socio-ecological transformations of tropical lowland rainforests", October 2018. Bali, Indonesia 



\begin{abstract}
Affidavit
I hereby declare that the dissertation entitled "Variability of wood and leaf functional traits in response to structural and environmental changes in natural and transformed systems in Indonesia" is submitted in support of my application for the degree of Doctor in Philosophy to Georg-August-Universität Göttingen within the doctoral program Biology of the GeorgAugust University School of Science (GAUSS). This thesis has been written independently and with no other sources and aids other than quoted within texts, references and acknowledgments. This thesis has not been submitted in any previous application for any degree, elsewhere.
\end{abstract}

Göttingen, June 2020

Pierre-André Waite 